\title{
Water Control and Autonomy Peasant Irrigation Strategies in the Bolivian Andes
}

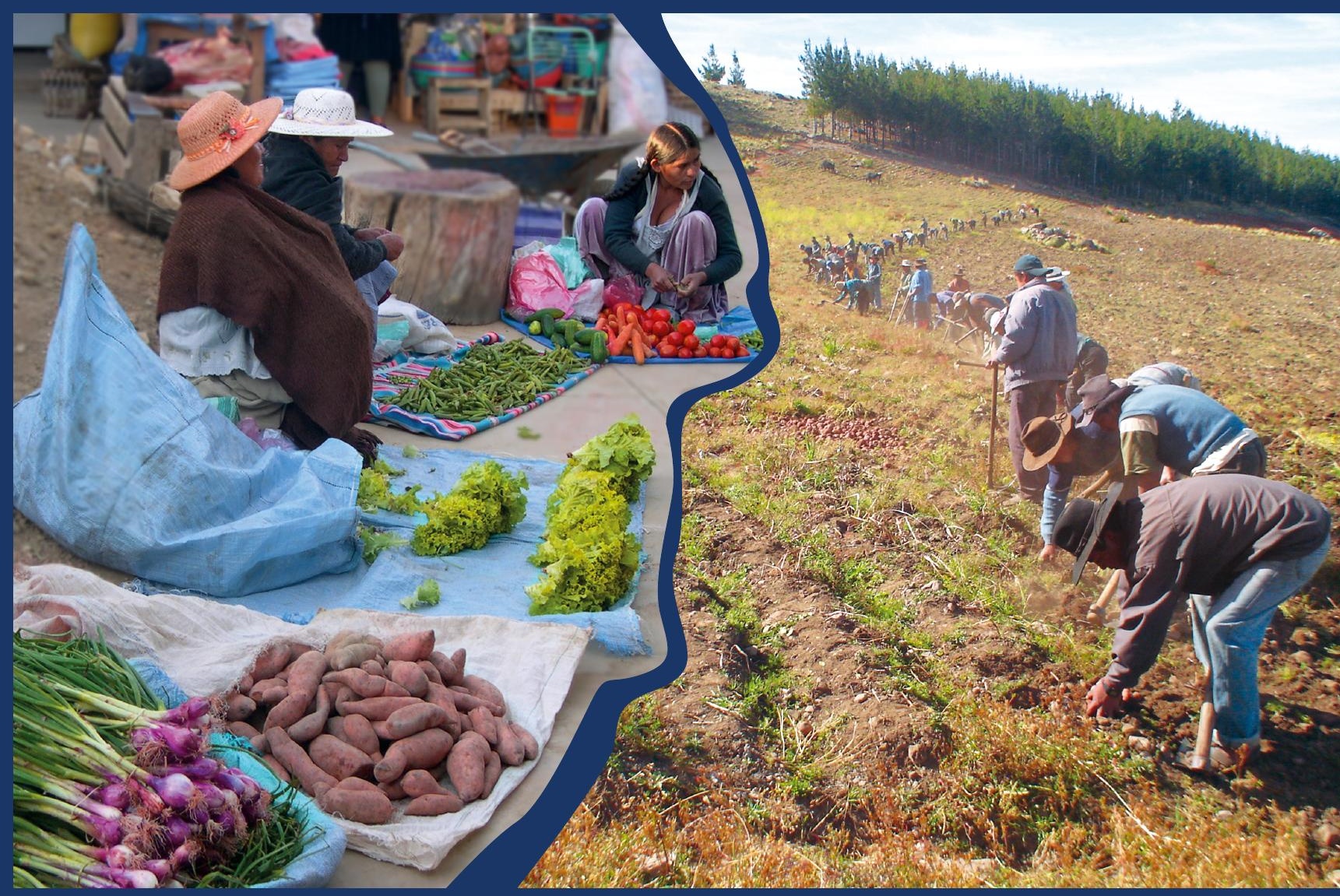

Ivan G. del Callejo Veracc 
Water Control and Autonomy

Peasant Irrigation Strategies in the Bolivian Andes

Ivan G. del Callejo-Veracc 


\section{Thesis committee}

\section{Promotors}

Prof. Dr R.A. Boelens

Professor of Water Governance and Social Justice

Wageningen University \& Research

Prof. Dr J.D. van der Ploeg

Emeritus Professor of Transition Processes in Europe

Wageningen University \& Research

\section{Co-promotor}

Dr Jaime D. Hoogesteger van Dijk

Assistant Professor, Water Resources Management

Wageningen University \& Research

\section{Other members}

Prof. Dr Bram E, Buscher, Wageningen University \& Research

Dr. Miriam Seemann, Gezellschaft fur Internationale Zusammenarbeit (GIZ), Bolivia

Dr Fábio de Castro, University of Amsterdam.

Dr. Dik Roth, Wageningen University \& Research

This research was conducted under the auspice of the Wageningen School of Social Sciences (WASS). 


\section{Water Control and Autonomy \\ Peasant Irrigation Strategies in the Bolivian Andes}

Ivan G. del Callejo-Veracc

\section{Thesis}

Submitted in fulfilment of the requirements for the degree of doctor at Wageningen University by the authority of the Rector Magnificus,

Prof. Dr A.P.J. Mol

in the presence of the

Thesis Committee appointed by the Academic Board

to be defended in public

on Tuesday 3 September 2019

at $13: 30$ in the Aula. 
Ivan G. del Callejo-Veracc

Water Control and Autonomy. Peasant Irrigation Strategies in the Bolivian Andes 197 pages.

$\mathrm{PhD}$ thesis, Wageningen University \& Research, Wageningen, the Netherlands (2019) With references, with summary in English and Spanish.

ISBN: 978-94-6395-023-7

DOI: https://doi.org/10.18174/495052 


\section{Acknowledgements}

This path has been long, but it has come to an end. On the way, I have had to share ideas, thoughts, experiences with many people. Those have contributed significantly to continue the path to the realization of this thesis.

First of all, I would like to acknowledge and thank the disinterested detachment of the people who shared their time during the field work: To the leaders, farmers, irrigators, men and women who agreed to be part of this research, sharing their experiences, their knowledge, in particular to the families of the communities of Chaupisuyo Grande, Tambillo Centro and Tambillo Linde in Punata, to those of Rumi Court in Aiquile and the families of the Chiyara Khochi irrigation system in Sacabamba. Among all of them a special thanks to Julián Espinoza, Froilán Ugarte and María Mercado who also gave me their friendship, welcoming me in their communities and in their home, sharing not only their food and a bit of chicha, but their knowledge and vision about "the art of irrigation".

Special thanks to the Dutch government through Nufficc and its Program for Co-operation for Higher Education (MHO); to the University of San Simón (UMSS) and to the University of Wageningen (WUR), that in the frame of this collaborative program gave me the opportunity to initiate the PhD research as part of the support in the consolidation of the "Centro AGUA" as one of the most important research centers in the subject of water at UMSS.

In the field work, Walter Cáceres, Sonia Vasquez and Germán Chila played a very important role, who, in their tasks as research assistants or students, supported significantly in the collection of field information and in its systematization. Thanks to their interest and vocation as field researchers, it was possible to get in touch very easily with the farmers who participated in the research and collect valuable information, especially about the high dynamics in which the peasant families are involved. It was very inspiring to work with them, as it also allowed me to remember and reflect on my own training process as a researcher.

At UMSS, several people also contributed directly or indirectly to the development of this research. Working conditions are often incompatible or at least can compete with the investigator's time and concentration. Fortunately, I was able to count on the support of a work team that in different periods and with different intensities, gave me their support (and sometimes enthusiasm), supporting me in my daily tasks while doing the field work or when I was absent in the activities of training or writing the thesis in Holland. Special thanks to my colleagues Alfredo Durán and the rest of Centro AGUA's team: to Vladimir Cossio, Oscar Delgadillo, Raul Ampuero, Rocio Bustamante, Rigel Rocha, Anibal Mayta and Silvia Encinas. Also to the administrative staff that supported in different moments during this process, that although not directly in the $\mathrm{PhD}$ research, but they did contribute in my daily tasks as researcher, to Karina Cardona, Claudia Rivera and Teresa Ledezma. These working conditions also helped me to clarify what a "Sandwich PhD" can mean under Bolivian conditions. This is: getting caught between two layers, or sometimes in more than two layers: the work and the PhD, just as a "sandwich" of completely different conditions and priorities that can generate a lot of stress... 
To friends I met in Holland or elsewhere on this path, some casual, and a few permanent ones. During the several moments I had to be in Wageningen, interaction and friendship with several people was important: Jean-Carlo Rodriguez, Yvan Lopez, Milagros Sosa, Eira Carvallo, Marisabel Pardo and Nico van Dixhorn, Edwar Menchaca, Jeroen Vos. A special recognition to Djura Prins and Juana Vera for their friendship, affection, support and inspiration and the pleasant and sometimes deep talks during dinners or walks in Wageningen and its surroundings. Also to Julie Wilk, for her support in the translation and revision of a first version of some of the thesis chapters, and above all for her friendship and inspiring philosophy of life.

In Wageningen, there were many people who supported me and offered their collaboration, starting from the formulation of the proposal upto the completion of the thesis: A special recognition to the Water Resources Management group (former IWE group): at the beginning to Linden Vincent and Gerben Gerbrandy who started to supervise my work. To Jeroen Vos, Jeroen Warner and Peter Mollinga with whom I had at the beginning of this process, inspiring talks that helped me give the initial orientation to my research work. To Gerrit van Vuren and Gerda de Fauw who helped me and provided the administrative support required to organize my trips and stay in the Netherlands. A special thanks to my promoters and co-promoter, to Rutgerd Boelens, Jan Dauwe van der Ploeg and Jaime Hoogesteger, for the time spent in the multiple revisions during the preparation of the document. With their help this thesis manuscript took its final form. Thanks for their encouragement, comments and suggestions and the time spent especially in the final stage of writing and final editing, so that the document reaches the required level. A special thanks to Rutgerd because in addition to supervising the work he gave me his friendship before and during the whole process.

Finally I want to thank and dedicate the work to my family: to Ximena, who at all times supported and encouraged me to continue, and conclude with the work. Thanks to her love and dedication to the family without leaving aside her own professional development (amazing dedication!), the work of concentrating and devoting a lot of time to work and the thesis (at the same time) and above all the stress that generates such combination, becomes more bearable. To Elias and Andres, who were my main source of inspiration and motivation and to my parents Donato and Olga (absents for several years now) and my brothers and sisters, for their unconditional love. 


\section{Content}

Chapter 1 Introduction: Peasant irrigation in the Bolivian Andes.....................................1

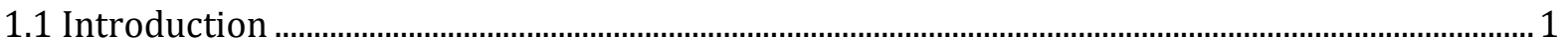

1.2 Context. Irrigated agriculture in the Bolivian Andes..................................................................... 2

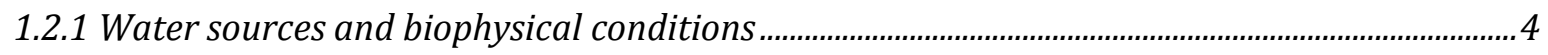

1.2.2 Collective management and irrigation practices in small-farming systems ................................ 6

1.2.3 Historical development of irrigation in Bolivia............................................................................

1.2.4 The institutional framework of irrigation. Two different starting-points that finally rejoin.

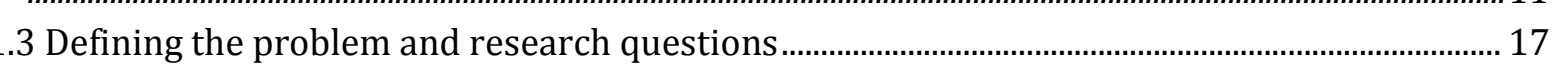

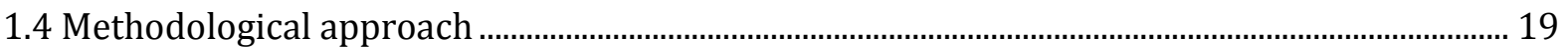

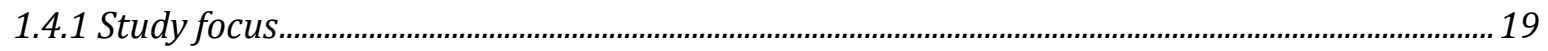

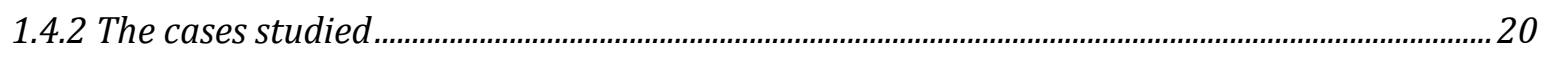

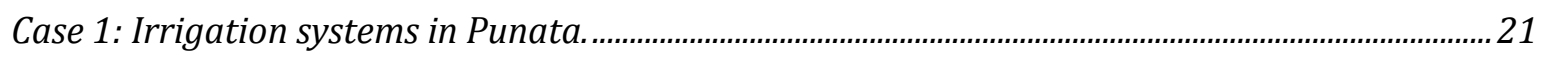

Case 2: The Chiyara Khochi irrigation system in Sacabamba .........................................................25

Case 3: Water harvesting systems. Atajados in the community of Rumi Cancha, Aiquile ................27

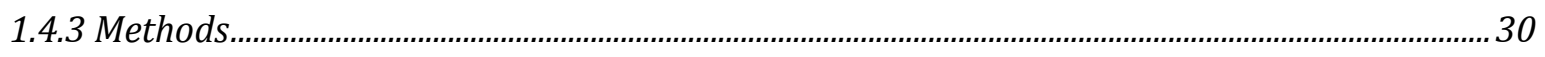

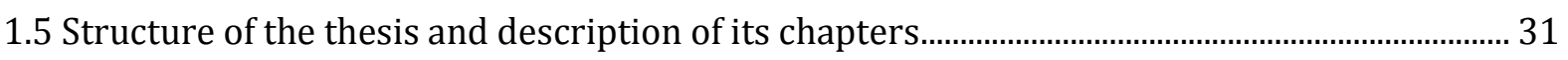

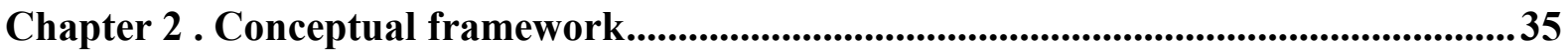

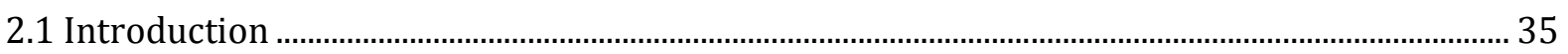

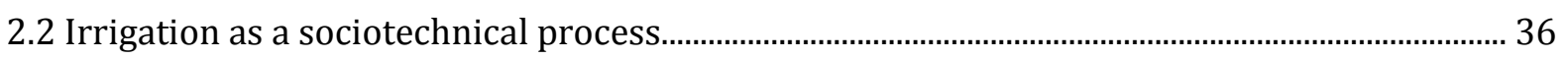

2.2.1 The "technical" as the privileged focal point of irrigation studies............................................36

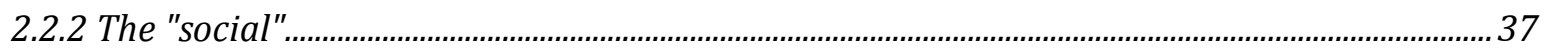

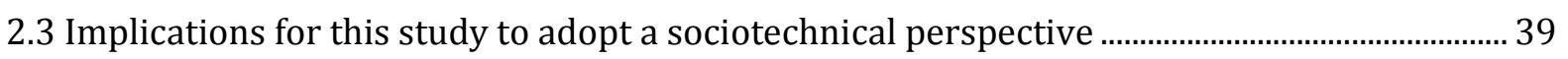

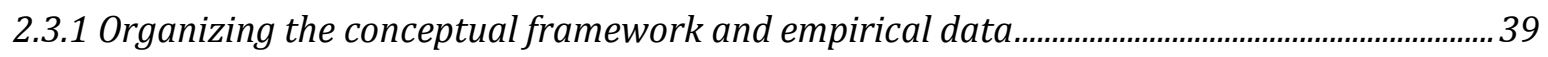

2.4 Collective action and social organization around water in peasant irrigation systems........... 40

2.4.1 The rationale for collective action and organization ................................................................... 40

2.4.2 Collective action, social cohesion and identity ................................................................................ 42

2.4.3 Collective action as strategies of social recognition and empowerment .................................... 43

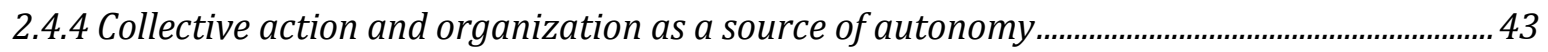

2.5 Water control in the collective domain in irrigation systems ....................................................... 44

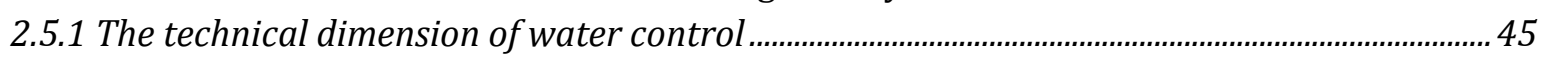

2.5.2 The organizational dimension of water control ..........................................................................46

2.5.3 Regulatory and political dimensions of water control............................................................... 48

2.6 Water institutions and institutional processes................................................................................ 50

2.6.1 Perspectives and approaches for institutional analysis ...........................................................51

2.7 The agro-productive domain in peasant irrigation systems ......................................................... 54

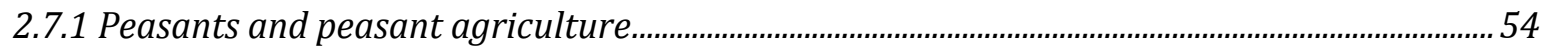

2.7.2 Multiple dimensions and key elements in the analysis of peasant agriculture .........................56

2.7.3 Peasant strategies and farming styles as analytical categories for understanding peasant

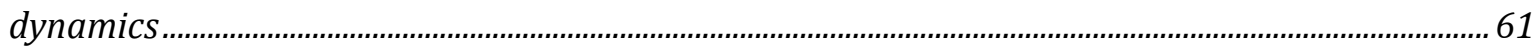




\section{Chapter 3 . Institutional development of the irrigation sector in Bolivia. From local}

practices to state restructuring.................................................................65

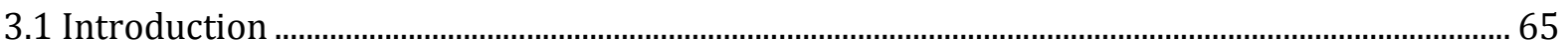

3.2 The new institutional framework for irrigation. Reconfiguring local institutions and

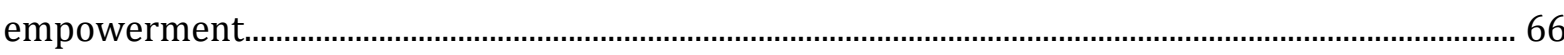

3.2.1 Configuration of the new formalized institutional setup ...........................................................66

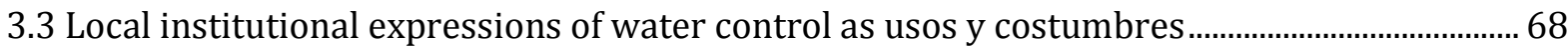

3.3.1 Usos y costumbres - more than only "traditional " water distribution systems.................... 68

3.3.2 "Usos y costumbres" -- physical and organizational dimensions............................................ 70

3.3.3 The territorial dimension of the "usos y costumbres" in Punata reservoirs.......................... 71

3.3.4 The multi-level character of usos y costumbres............................................................................. 74

3.3.5 "New" usos y costumbres in groundwater systems. Individual efforts, collective

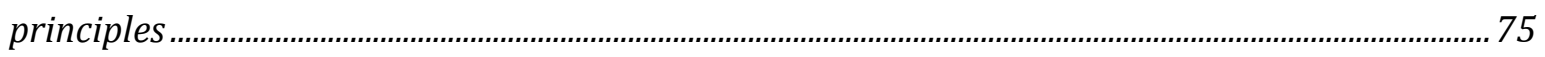

3.3.6 Uses and customs in atajados systems in the community of Rumi Cancha, Aiquile ................ 76

3.3.7 Technological artifacts that re-define usos y costumbres........................................................... 77

3.3.8 Summarizing the different expressions of usos y costumbres ...................................................... 78

3.4 Constructing normative frameworks from local practices................................................................. 79

3.4.1 Illustration1: The law on extracting aggregates.............................................................................. 80

3.4.2 Illustration 2: Groundwater regulations in Punata ..................................................................81

3.4.3 Reflection on regulating and formalizing local practices ............................................................. 83

3.5 Concluding remarks: Collective action and institutional development of the irrigation sector

Chapter 4 . Collective action for water control in peasant irrigation systems .................87

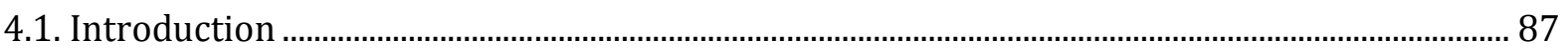

4.2 Changing demands and organizations: From freedom to access to land, to water control .... 88

4.2.1 From "haciendas" and "piquerías" to peasant unions and communities ........................8 88

4.2.2 From agrarian unions to "water communities" ........................................................................ 91

4.3 Organizational diversity and development: change and adaptation for water control........... 94

4.3.1 Atajados systems in Aiquile: Land management related to water control ...............................95

4.3.2 The Chiyara Khochi irrigation system, Sacabamba ................................................................96

4.3.3 The Punata Irrigation Systems …………...................................................................................... 100

4.3.4 Organizational requirements for operational/technical water control in reservoir systems

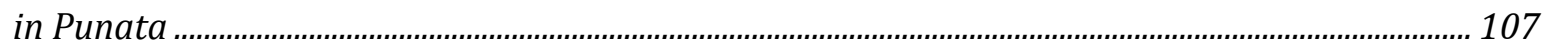

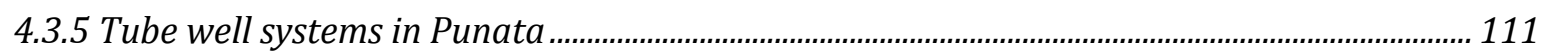

4.4 Creation of supra-organizations: Scaling-up collective action and empowerment..................111

4.5 Social mobilization ...............................................................................................................113

4.6 The co-evolution of endogenous water development processes ................................................114

Chapter 5 . Water control and spheres of production / reproduction on peasant

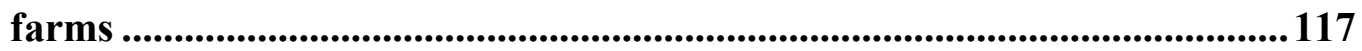

5. 1 The cases studied ....................................................................................................................117

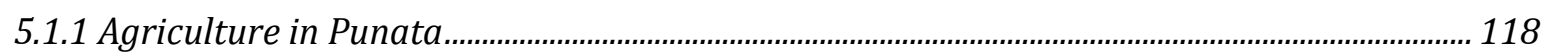

5.1.2 Agriculture in Rumi Cancha community, Aiquile ....................................................................... 122

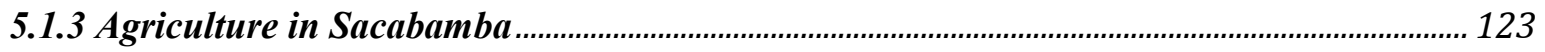

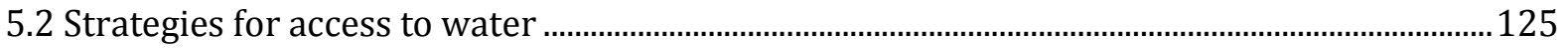

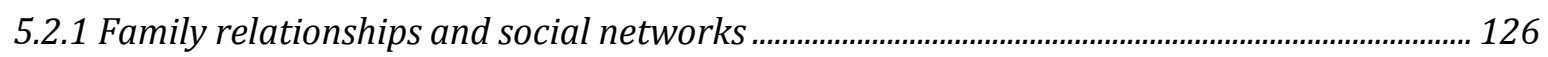


5.2.2 Family investments in irrigation: workforce, the role of migration and off-farm work..... 128

5.2.3 Involvement in water organizations: "knowing where water is " ......................................... 131

5.3 Range of agro productive strategies. From water control to farming security ..........................132

5.3.1 Water and soil management practices. Fallowing to cope with water shortage................... 132

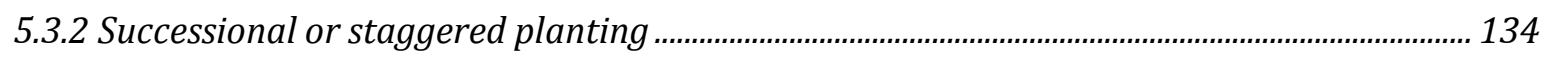

5.3.3 Strategies to optimize water use: combined use and prioritization of water sources......... 136

5.3.4 Combined use of different water sources and diversity in water uses.................................... 138

5.4 Organization of labor in peasant irrigation. Dynamics in institutions, technology and markets

139

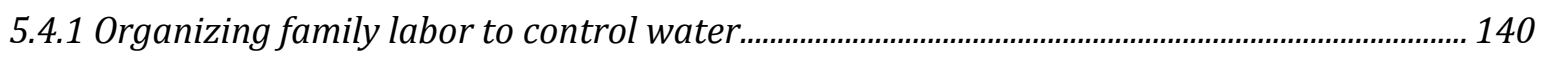

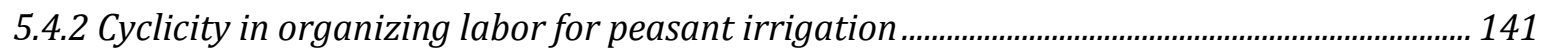

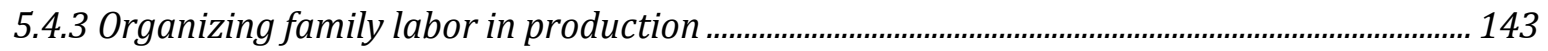

5.5 Heterogeneity in shaping different styles of farming ................................................................. 145

5.5.1 Intensification and "extensification ” ................................................................................... 146

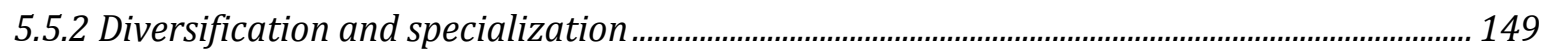

5.5.3 Interplay between commoditization and non-commoditization in production .................... 154

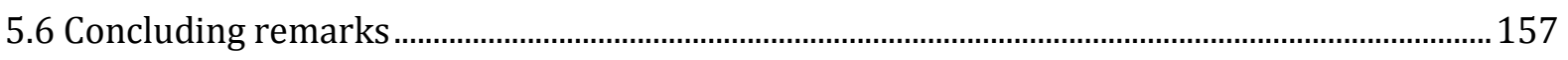

Chapter 6 . Conclusions: Local agrarian development patterns as a result of water and agroproductive control......................................................................................161

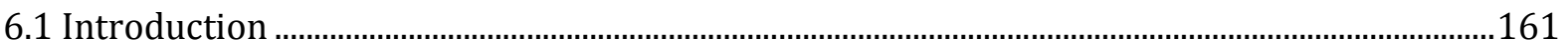

6.2 Uses and customs. Local institutional arrangements and practices and the quest for

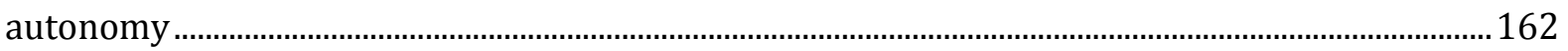

6.3 Seeking water control from collective action in water management..........................................165

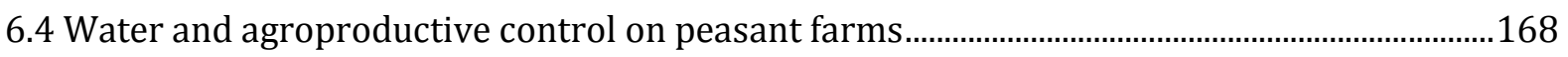

6.5 Conceptual contributions and considerations ...........................................................................171

6.6 Conclusion: Heterogeneity and endogenous development patterns: collective action, family

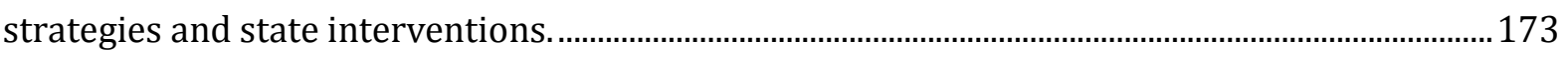

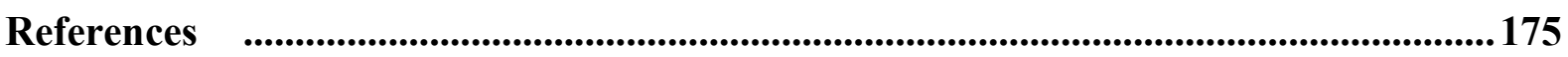

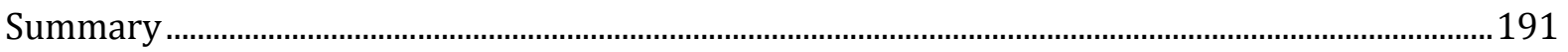

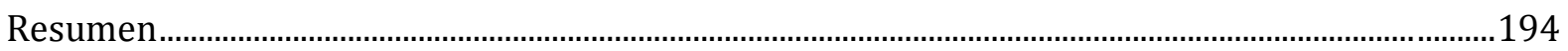




\section{List of Tables}

Table 4-1. Main irrigation interventions and organizational adaptations and strategies .................... 101

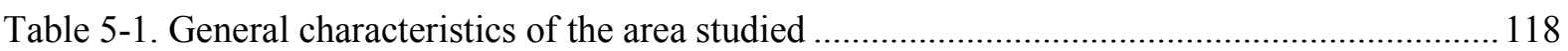

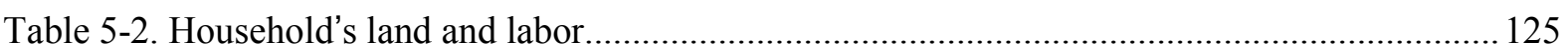

Table 5-3. Labour and monetary investments in creating water rights in the systems studied........... 129

Table 5-4. Main irrigated crops with different sources of water in Punata....................................... 137

\section{List of Figures}

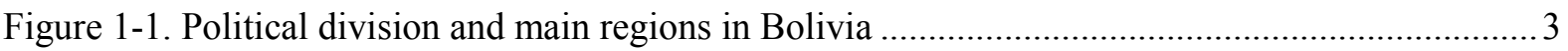

Figure 1-2. Percentage of irrigated areas served by different water sources ......................................... 4

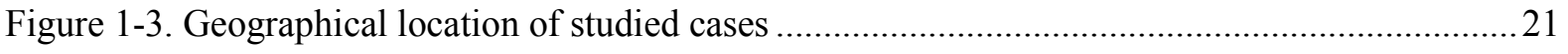

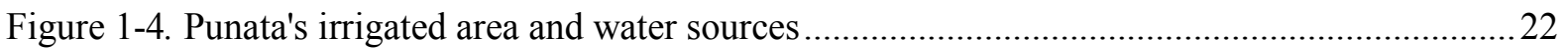

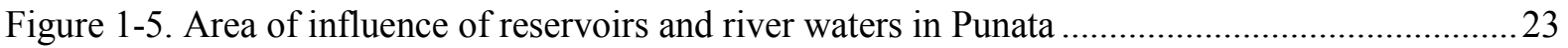

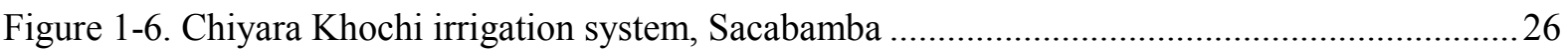

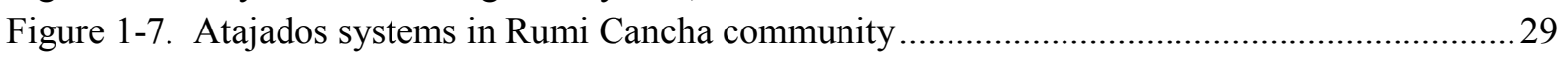

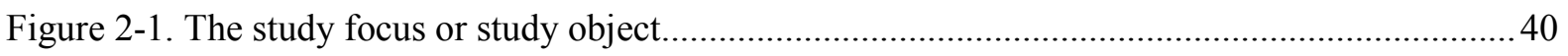

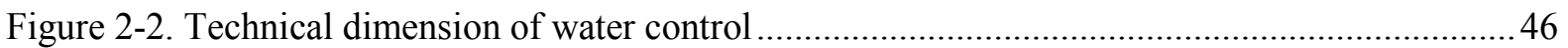

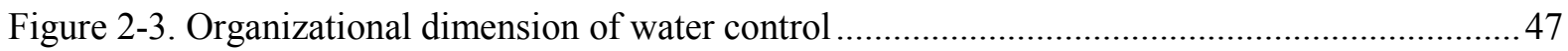

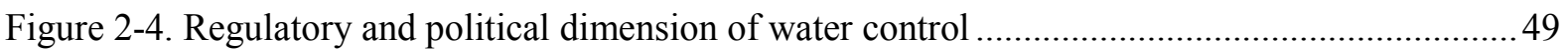

Figure 2-5. The multidimensional character of water control in irrigation systems ..............................50

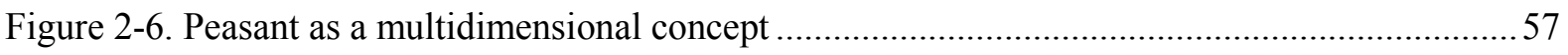

Figure 4-1. Organizational structure of agricultural unions in Bolivia .................................................. 90

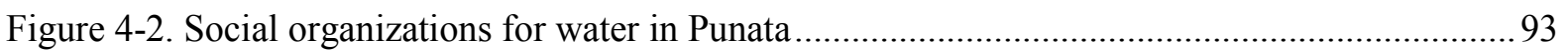

Figure 4-3. Operational and organizational water control in Rumi Cancha Atajados systems.............95

Figure 4-4. Operational and organizational water control levels in Chiyara Khochi system ...............98

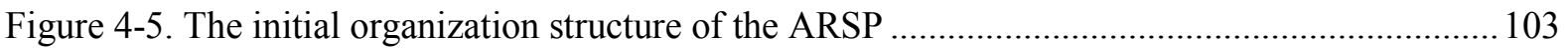

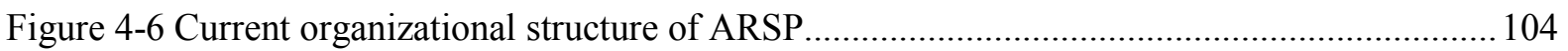

Figure 4-7. Punata's reservoir systems and inter-basin water transfers ............................................ 108

Figure 4-8. Variation of discharges between the dam and main intake for Laguna Robada and Llusk'

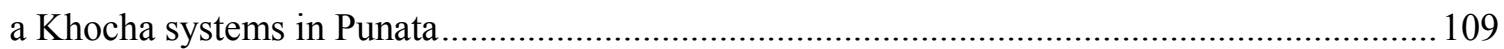

Figure 5-1. Spatial distribution of production zones and the studied cases in Punata ........................120

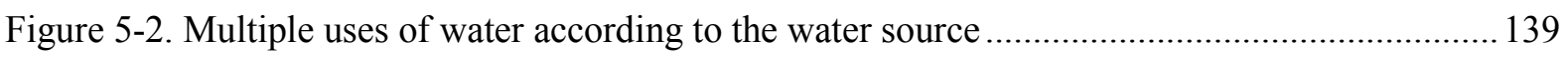

Figure 5-3. Example of labor organization, irrigation practices and water management practices

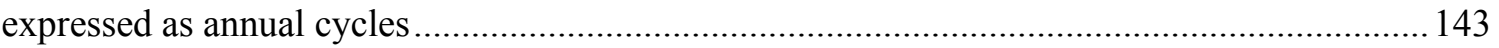

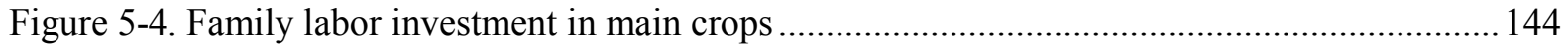

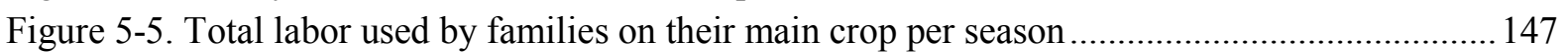

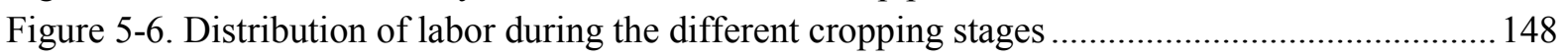

Figure 5-7. Cropping pattern and market orientation. Soto family strategy .................................... 150

Figure 5-8. Cropping pattern and market orientation. Ubaldo family strategy ................................. 151

Figure 5-9. Cropping pattern and market orientation. Lima family strategy (Rumi Cancha)..............152

Figure 5-10. Cropping pattern and market orientation. Roldán family strategy (Rumi Cancha)........153

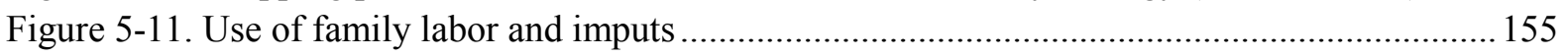

Figure 5-12. Organization of production process for main crops. Use of families' own resources. 156

Figure 5-13. Commodity and non-commodity circuits in reproducing peasant farms ........................ 158 


\section{List of Pictures}

Picture 1-1. Irrigation infrastructure: Atajados, lined canals, and combined technologies...................6

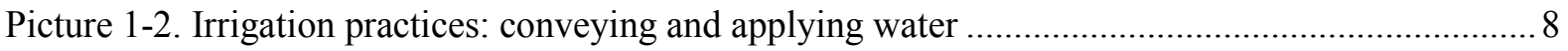

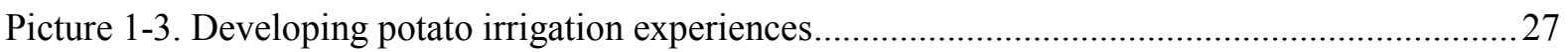

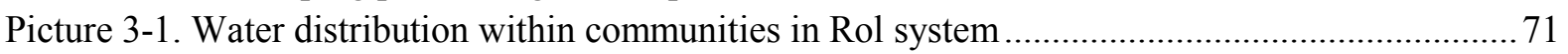

Picture 3-2 Sprinkler irrigation in Mishka Mayu community.......................................................... 78

Pictures 5-1. Contrasting landscapes in Rumi Cancha. The oasis effect of atajado systems ..............122 



\section{Chapter 1 Introduction: Peasant irrigation in the Bolivian Andes}

\subsection{Introduction}

In the Andean Region countries, high-altitude mountain zones are considered to be the territories where irrigation water is born. In Bolivia, however, this region is precisely where there are the greatest restrictions on agriculture, due to the adverse climatic conditions: frosts, droughts and a highly variable rainfall regime. Because of the agroecological conditions the inter-Andean valleys, which have less severe climatic restrictions, constitute the geographies with greater experience and tradition in water management; and they have a very marked dry period during which irrigation is indispensable (Cossio, 2011; Gerbrandy and Hoogendam, 2002; Gutiérrez and Gerbrandy, 1998a,b).

In these irrigation regions, inhabitants have based their historical development and cultures importantly on agriculture and water management. This management, in turn, is grounded in collective work, framed within the development of locally established practices and norms to control water sources and flows and distribute the resource all the way to their fields. Historically, different from neighbouring countries, in Bolivia, the Government has intervened very little in this development of irrigation systems and governance practices (Achi, 2010; Gutiérrez, 2010; Perreault, 2008; Seemann, 2014).

In Bolivian rural reality, agricultural practices to raise different types of crops and animals are based on the family unit. Households make decisions about what, when, how and how much to plant. However, these agricultural decisions are not isolated, but directly involved with collective water management, with the market, with government institutions and with local rules, regulations and customary institutions that have formed gradually on the basis of each locality's own practices and experiences (Gerbrandy \& Hoogendam, 1998; Saldias et al., 2012; Seemann, 2014, 2016). This thesis seeks to understand the interrelationship between these spheres, identifying collective actions expressed as strategies, and relating them with household practices and actions in terms of agricultural production strategies.

This introductory chapter, after describing in detail the biophysical and social context of irrigated agriculture in Bolivia, shows its small-farmer nature and its foundations in collective action. Then, I argue about the need to understand the interrelationship between collective water control and household-level production decisions and strategies, as an indispensable prerequisite to understand agrarian development and the diverse manifestations of irrigated agriculture.

In Bolivia's irrigation development, there have been major milestones marking key sociopolitical transformations, closely linked with water management and with the development of small farming and irrigation. These milestones are discussed, along with the irrigation sector's institutional development, in the third and fourth sections of this chapter, as a basis to identify 
the problem and research questions for this thesis. Answering this question will probe more deeply into interrelationships between the collective foundation of irrigation and individual (family) agricultural activities, both embedded in socio-political, cultural, economic and biophysical contexts shaping the direction that irrigated agriculture has ultimately taken in Bolivia.

The core question of this research is:

How do collective action and individual strategies entwine in peasant irrigation to foster diverse patterns of irrigation management and production organization in response to the quest for autonomous water control?

The chapter describes the research method applied to answer this question and the more specific sub-questions, and then describes the scope of each of the following chapters.

\subsection{Context. Irrigated agriculture in the Bolivian Andes}

Politically, Bolivia is divided into nine departments, six of which are located almost wholly in the Andean Region (altiplano highlands and inter-Andean valleys) and three in the Amazon lowlands. The Altiplano occupies 13.5\%, inter-Andean valleys and the eastern mountain range another $24.2 \%$ and the plains cover $62.3 \%$ (VRHyR, 2013).

A characteristic feature of Bolivia is that its population is distributed over the national territory in inverse proportion to the country's rainfall pattern and water availability zoning. That is, the altiplano and valley zones are the most populated, and have the greatest water deficit problems, whereas the moist lowlands have much lower demographic density. According to data from the National Statistics Institute (INE), for $2005,70 \%$ of the population was concentrated in the western zone (altiplano and inter-Andean valleys) and the remaining 30\% in the flatlands zone. Projections based on these statistics, and the last population census in 2012, show slight changes, but maintain higher population concentration in the west, with $68 \%$ of the population (VRHyR, 2013).

Up until approximately three decades ago, irrigation and therefore production of the main food crops was concentrated almost exclusively in the Andean Region highland zones, with much less agricultural production in the lowlands. Small-scale farms founded on household production systems have prevailed and persisted in the Andean zone. Although the cropland area under irrigation is only about $11 \%$ of the total land area under cultivation (Vice Ministry of Water Resources and Irrigation, 2012), this figure does not represent the high importance of small-farm agriculture and irrigation for food production (Guevara-Gil et al., 2010; Vos, 2010; Vos and Boelens, 2014; Zoomers, 1998, 2010, 2013). 


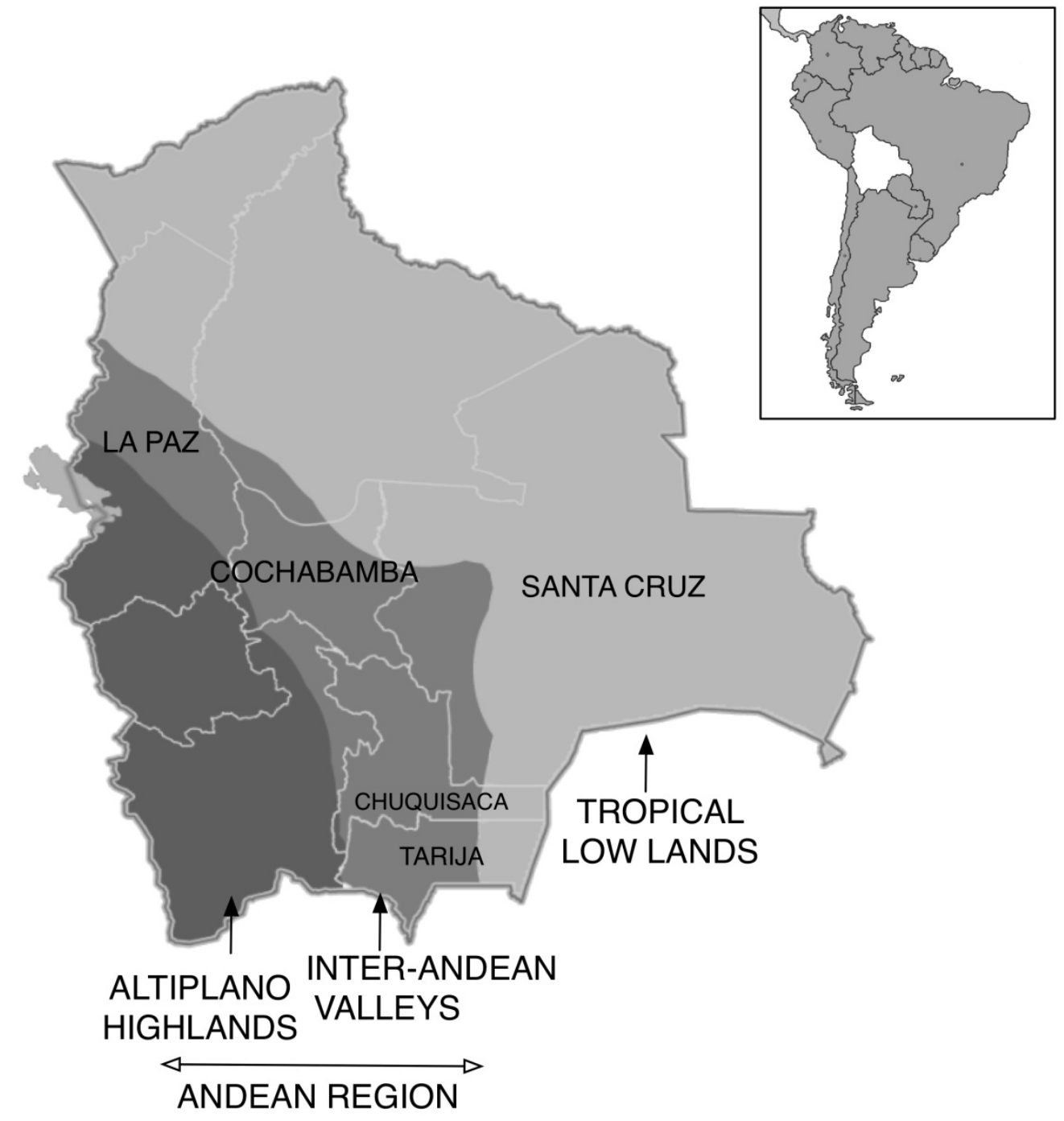

Figure 1-1. Political division and main regions in Bolivia

(Source: Prepared by the author)

Crops under irrigation for domestic consumption are grown in all three regions of the country, including tubers and vegetables such as potatoes, onions, carrots and garlic; legumes such as peas; cereal grains such as maize or forage that may also be irrigated, such as oats (VRHyR, 2013). Each zone also features its own crops. For example, the altiplano or high-altitude valleys and top ends of valleys have crops such as fava beans, oats and alfalfa. The inter-Andean valleys feature the greatest diversity of crops under irrigation: fruits, varied vegetables including tomatoes, lettuce, beets, cabbage and other crops such as flowers. The lowlands have other irrigated crops with high commercial value: watermelon, tobacco, peanuts, sunflowers and others grown extensively by medium and large producers engaged in agroindustry and agro-exports (Del Callejo, 2010; Vos, 2010).

Staple food crops include grains, tubers, legumes and vegetables, mainly grown in western and central Bolivia (in the highlands, the inter-Andean and the lower valleys), although in the past decade the areas planted with these crops have also increased considerably in the lowlands. 
Most of these crops are grown by small family farms. Small farmers account for an estimated $30 \%$ of cropland and $51 \%$ of production volumes for these crops (Del Callejo, 2010; Rocha et al., 2015; Vice Ministerio de Recursos Hídricos y Riego, 2012).

Diverse agroecological conditions, climatic risks, marked distribution of rainfall, and cultural diversity have yielded different water management experiences in different regions of the country, as well as a wide diversity in ways of doing agriculture and managing natural resources.

\subsubsection{Water sources and biophysical conditions}

Rainfall increases gradually from west to east and from south to north, from regions with under $100 \mathrm{~mm}$ a year at the southwestern end of Bolivia, up to 1200 to $1700 \mathrm{~mm} /$ year in the east and north (Montes de Oca, 1997). This spatial variability of rainfall does follow a pattern, concentrated in the summer months (December to March), above all in the west, which means that irrigation is indispensable in the dry season.

Water sources for irrigation are also season-limited, running dry in the dry season and with intermittent and often erratic flow during the rainy season, especially when drawn directly from rivers in the altiplano and inter-Andean valleys. These valleys have a wide diversity of water sources and greater possibilities to tap it than in other regions of the country (Gutiérrez and Gerbrandy, 1998a; Saldías et al., 2012).

The main source of water for irrigation is from rivers, which covers about $69 \%$ of irrigated area (see Figure 1.2). The total irrigated area is estimated at 303,000 hectares, approximately $26 \%$ of Bolivia's croplands according to data from the Instituto Nacional de Estadística (2014) and Vice-Ministerio de Recursos Hídricos y Riego (2012).

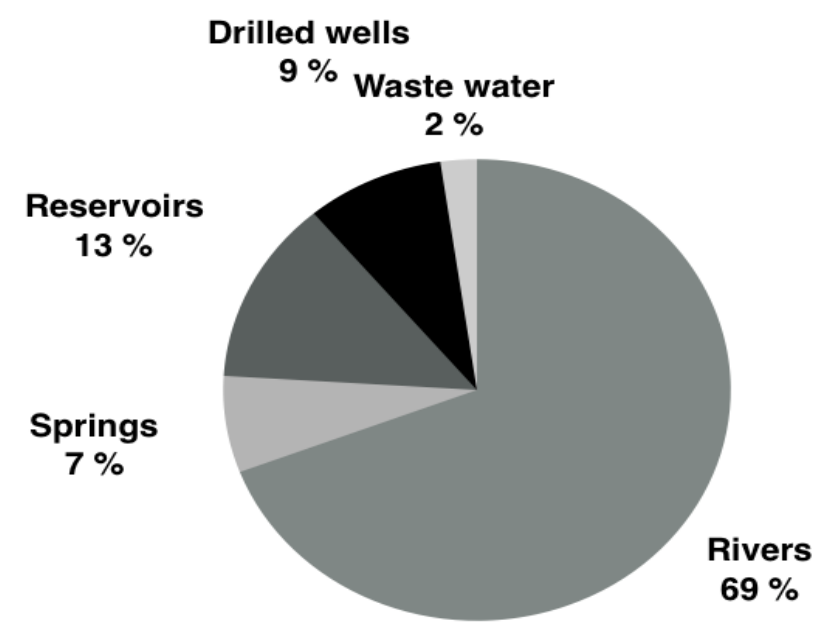

Figure 1-2. Percentage of irrigated areas served by different water sources

(Source: Vice-Ministry of Water Resources and Irrigation, 2012) 
The headwater zones of the inter-Andean valleys have great potential for dams to regulate water availability, accounting for $13 \%$ of the irrigated area (Vice Ministerio de Recursos Hídricos y riego, 2012). In high-altitude watersheds, natural lagoons and wetlands have been dammed to consolidate irrigation systems with good-quality water (clear and with very little sediment). For example, the higher parts of the inter-Andean valleys - crucial for irrigation coverage in Bolivia - have dam systems as in the Central and High ${ }^{1}$ valleys of Cochabamba. By contrast, the mid- and lower watersheds have steep slopes, semi-arid zones and little plant cover, flows with heavy sediment content, so these irrigation systems have problems operating and maintaining their infrastructure, shortening systems' useful lifetime. This type of utilization is typical in central valleys and southern Bolivia, from the so-called Southern Cone of Cochabamba, to the valleys of Santa Cruz, Chuquisaca and Tarija (see Figure 1.1) (Montes de Oca, 1992; Saldías et al., 2012; Vos, 2010).

In addition to these surface sources, the inter-Andean valleys, mainly in extensive valleys as in the north ("Central Valley" and "High Valley" in Cochabamba), have significant underground water resources, accounting for $56 \%$ of the area irrigated (Vice Ministerio de Recursos Hídricos y Riego, 2012). Systems with underground sources decrease in both quantity and quality going southward. The remaining $9 \%$ of irrigated areas is covered by systems with small springs or recently with sewage water in peri-urban agricultural zones (VRHyR, 2013).

The above shows that the main water source for irrigation is from rivers, the seasonality of which restricts agriculture to the rainy season. Irrigation plays a complementary role to rainfall. Only very few zones have year-round, "safer" water sources such as dams or underground water, for a full growing cycle during the dry season. These water sources are commonly tapped using rustic or sometimes concrete infrastructure, mainly direct intakes from rivers, with earthen or lined canals, dams, small reservoirs, ponds in the case of spring-based systems, or pumping from drilled wells (Saldías et al., 2012; Seemann, 2016; Vos, 2010; VRHyR, 2013. Cf. Zeitoun et al., 2016).

Existing irrigation systems vary in size. The classification done by the National Irrigation Program (Program National de Irrigation, 2000) updated by the Vice-Ministry of Water Resources and Irrigation (2012) shows mostly systems under 500 hectares, accounting for nearly $77 \%$ of irrigated area nationwide. The remaining $23 \%$ of the area is covered by systems considered large on a Bolivian scale (over 500 hectares).

\footnotetext{
${ }^{1}$ The region of Cochabamba's valleys is divided into three major areas: The "Central Valley" where the city of Cochabamba is located, the "Upper Valley" where the Tiraque and Punata reservoir systems are located and, finally, the Lower Valley, where mainly underground water is tapped.
} 

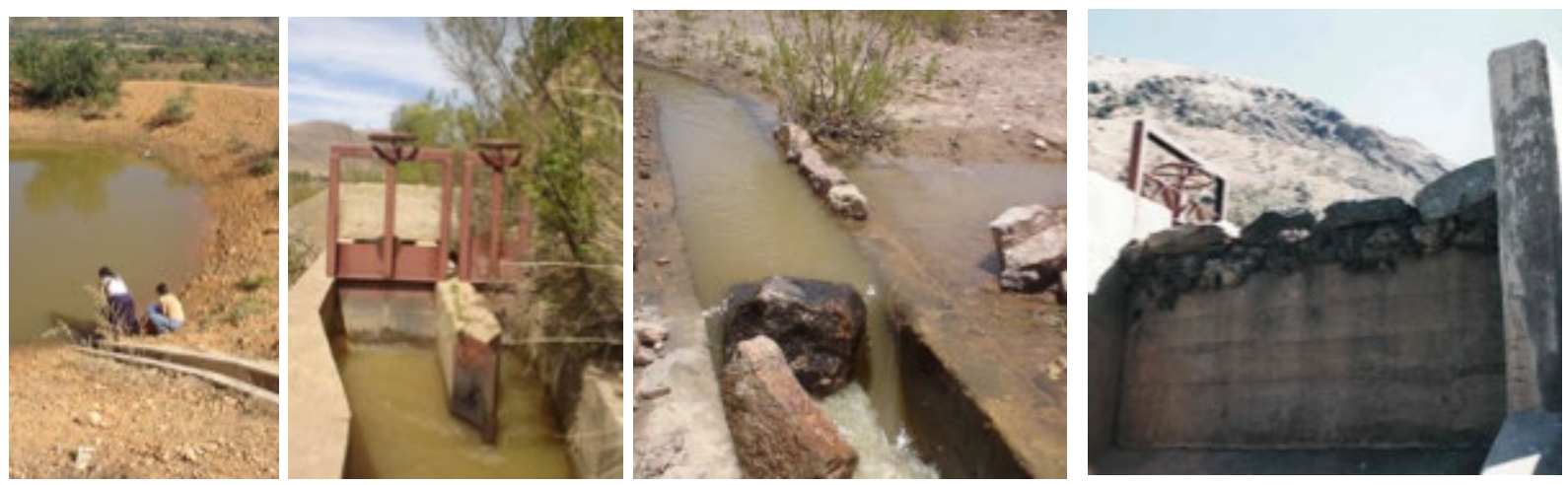

Picture 1-1. Irrigation infrastructure: Atajados, lined canals, and combined technologies

Photos: I. del Callejo

\subsubsection{Collective management and irrigation practices in small-farming systems}

The outstanding feature of irrigation by family farms in Bolivia's Andean Region is the impressive organizational and water management capacity that the people have developed (Cossio, 2011; Gerbrandy and Hoogendam, 1998; de Vos et al., 2006). This capacity is grounded in (or results from) collective action, based on practice, on day-to-day water management tasks, on the need to mobilize and work collectively to build, operationalize, rehabilitate or maintain infrastructure to catch and conduct water to their fields (e.g., Gerbrandy, 1998a,b; Gerbrandy and Hoogendam, 1998; Laruta and Bustamante, 2007. Cf. Guevara-Gil, et al., 2010; Mabry, 1996; Ostrom, 2009, 2010). These practices and above all water distribution entail agreements, negotiations, and norms that have been created and adapted locally, in what is currently recognized as their "uses and customs".

Another important feature of irrigation systems in Bolivia is that the Government does not intervene directly in setting or regulating water rights or ways of collectively managing water within irrigation systems - even though the current government attempts to register water rights at higher watershed levels (see e.g. Rocha et al., 2015; Seemann, 2014, 2016). Government intervention tends to be indirect, through irrigation projects. These projects are discussed with "beneficiary" rural communities or populations, regarding the form and amount of labor they must invest, as the main mechanism principal to create (or adjust) water rights in these intervened irrigation systems (Boelens and Vos, 2014. Cf. Gerbrandy and Hoogendam, 2002;). However, fundamental issues such as including or excluding (new) irrigation system users generally call for internal agreements within or among communities or user groups (Del Callejo, 2010).

A key element in forming water user organizations (particularly irrigator organizations) has been collective work invested in harnessing water sources and building the infrastructure needed to use the water (Boelens and Vos, 2014). This is a fundamental principle in creating water rights in family-farming irrigation systems in the Andes for collective and individual players. Collectively, this means differentiating between communities or groups of families who claim control over a certain territory and its natural resources, versus other groups or communities that have no such rights (Achi, 2010; Bustamante and Gutiérrez, 1999; Gerbrandy 
and Hoogendam, 1998; Gutiérrez, 2005). By contrast, individual rights are manifested as the possibilities of using water that a family acquires and exercises in an irrigation system as a function of the work or resources invested in operationalizing this irrigation system, according to collectively agreed rules (Boelens, 2015; Gerbrandy and Hoogendam 1998; Rocha et al., 2016).

Water rights are defined and water user organizations develop in their own unique contexts of time, space, social organization and institutions. Like the diversity of organizational arrangements regarding water, there is also great diversity in how water rights are expressed, in terms of time, water amounts or flow rates (see Boelens, 2011, 2015; Laruta and Bustamante, 2007; Saldías et al., 2012). Their temporary or permanent nature also varies. In some cases, rights may be permanent, year-round, whereas others may be only seasonal, or vary with the river's flow (Gerbrandy, 1998a, b; Gutiérrez, 2005, 2010; Rocha et al., 2016) The principles on which these rights are based also vary; as does their scope and the historical circumstances giving rise to them (Bustamante and Gutiérrez 1999; Gerbrandy and Hoogendam 1998; Gutiérrez 2005; Rocha et al., 2015). For example, there are collective and individual water rights that communities have claimed and practiced since prior to Spanish colonization, while in many other cases, they were created during the colonial period or derived from rights created by hacienda owners through efforts invested by their workers. Others are recent, resulting from government interventions through irrigation projects, or from rural families' own investments, organized to tap a water source (Achi, 2010; Bustamante, 2010; Guevara-Gil et al., 2010; Rocha et al. 2016).

In summary, water rights, organizational forms, water management agreements and practices for small-farm irrigation in Bolivia are not simply "ancestral indigenous rights", that is, they have no single form and come from no single time in history, nor are they all based on the same principles. At this time, irrigation systems are the outgrowth of a complex overlapping of processes, rules, and agreements intermingled in different physical settings, emerging from and blending through different historical processes and perfused with unique cultural and sociopolitical contexts (Andolina, 2012; von Benda-Beckmann et al., 1998; Boelens, 2014, 2015; Boelens et al., 2010; Roth et al., 2005, 2015). The Government has played a very limited role in the sector's institutional configuration and regulation, much less in managing irrigation systems.

From the individual family farm level, these systems arise within different organizational and institutional arrangements, in their communities and the market, to make their livelihoods viable (Boelens and Albó, 2007; Gerbrandy and Hoogendam, 1998; Urteaga and Boelens, 2006; Zoomers, 2013). Irrigation plays a fundamental role, directly expanding the possibilities of what, how much, what for and where they can produce. Irrigation practices, depending on water sources and infrastructure, on agreements to define collective and individual water rights or the different mechanisms granting rural families access to water, result in diversity of ways of managing water on each farm and using it to grow different crops (Del Callejo, 2010; Zoomers, 1998, 2010). 
Some commonly observed characteristics of these practices are (e.g., Boelens, 2015; Del Callejo, 2010; Delgadillo, 2003a,b; Gerbrandy and Hoogendam, 1998; Gutiérrez, 2005):

- Applying large flow volumes, if water is taken directly from rivers or dams, or relatively small flow rates from springs or wells.

- Irrigation intervals are fixed in some cases (for example, in permanent well or spring systems); in other cases, they are variable, but with the possibility of deciding when to irrigate (for example, dam systems); and in other cases (water sourced from nonpermanent rivers) intervals are random or uncertain.

- Water may be applied by furrows, by wider melga canals, by flooding, and recently sprinkling is expanding. The way these practices are done will depend on farmers' experience with and knowledge about water management, the availability of labor, the crops planted, and other factors of how their farm is organized.

- In practice, basic modes of irrigation norms, rules, rights and practices, become highly complex and diverse because of the variety of physical conditions, such as different soil types, variable slopes and often very rugged terrain, soil depth and field size.
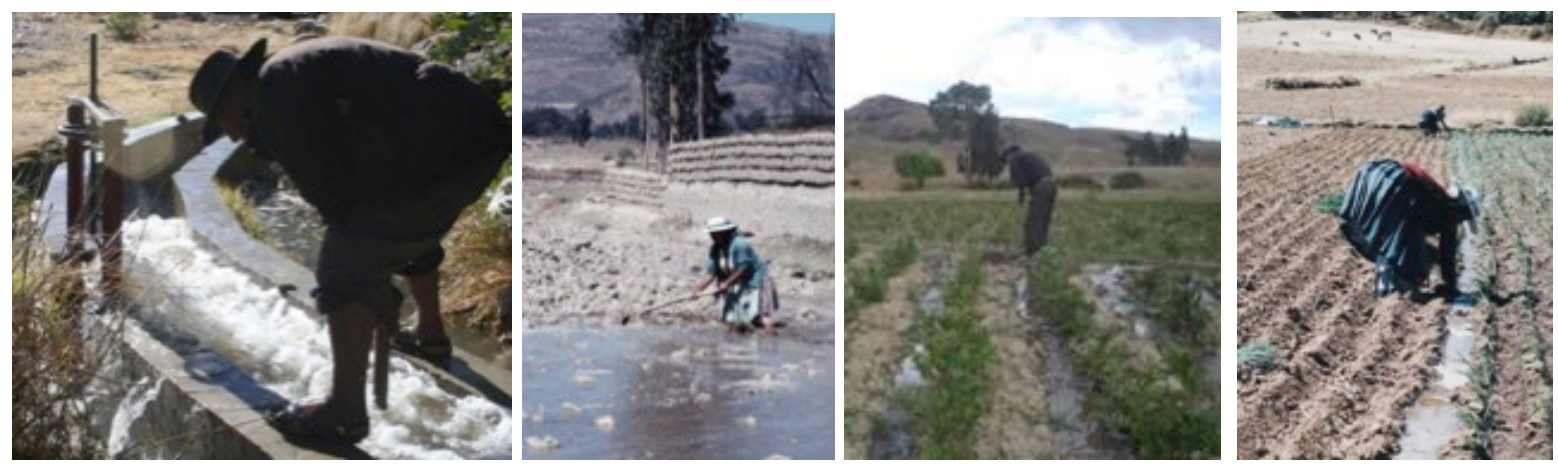

Picture 1-2. Irrigation practices: conveying and applying water

Photos: I. del Callejo

\subsubsection{Historical development of irrigation in Bolivia}

Irrigation development in Bolivia shows major changes in the role played by peasant societal organizations in organizing water control. The latter have grown progressively, passing through stages of empowerment to interact with the government, with development agencies and with different sectors of the population, thereby developing new water management experiences and practices under adverse conditions. Over time, the Government's role has also shifted, from almost total absence, to attempts to regulate the sector by formalizing customary water management practices in small-farm irrigation (Bustamante, 1995, 2010; Rocha et al., 2015, 2016; Seemann, 2014, 2016). These milestones marking major periods of changes, are outlined below, discussing their salient characteristics as a basis for understanding present-day irrigation governance in Bolivia. 
Several authors highlight the importance of irrigation and water management as one of the mainstays around which societies have formed since before Spanish colonization in the Andes (e.g., Boelens, 2015; Gelles 1986, 1994, 2000; Mitchell and Guillet 1994; Sherbondy 1994, 1998; Trawick 2001; Zuidema, 1986). These authors show the diverse ways of organizing and distributing water and the norms regulating water uses, whether under unified (community) organizational structures, or others with no set institutional structure, or yet others combining these options (Trawick 2001).

During Spanish colonization, one key aim of the colonial government was to organize and control resources exploitation, especially through labour control and taxation of the indigenous people. During this period, there was a direct relationship between people's control, population movement policies and agrarian and mining policies -- such as in one of Latin America's key mining regions, Potosí. This made the valleys, and particularly Cochabamba, the main food production zones for the country's mining centers, in addition to assuring ongoing labor provision for mining. To this end, the colonial government deployed different mechanisms: population movements to concentrate indigenous people around (or near) Spanish towns, using local institutions (practices and norms or rules) to wield power and control over indigenous people, and creating a power structure using local leaders (caciques) and their own practices (Larson 1988a).

During that time, water was defined as a privately allocated resource, linked to land ownership; in practice, the water was allocated largely to Spanish landlords. However, as Gerbrandy \& Hoogendam (1998) mention, partially, water management has maintained its collective/community nature. At the one hand, this happened in areas where the so-called "Pueblos de Indios" (Indian villages) were formed by the colonial powers. Indian villages were concentrations of indigenous population, organized by the colonial government supposedly to maintain and respect their existence. In practice, however, these population concentrations were the colonial government's most effective mechanism to collect indigenous tributes and control and coerce their inhabitants (Cf. Albó, 1987a; Baud, 2010; Boelens, 2015; Gelles, 2000; Larson, 1988a). At the other hand, in regions such as the Upper Valley of Cochabamba, large haciendas were established and managed under the "pongueaje" system. Here, peasant families were forced to work and produce for the landowner. Each family was also assigned a small plot ("pegujal") to grow their own family's food in their "free time", and collective water management practices partially continued if the landlord would allow for this - generally whenever it would mainly benefit the hacienda's productive interests (Larson, 2000; Mayer, 2002).

During the early republican period and up to 1952, this situation continued in practice, consolidating the haciendas' water and land control, though there were ongoing confrontations between hacienda owners and indigenous communities or with "free peasants" living around the haciendas. Another legal measure accentuated the private nature of water rights: the Law of "exvinculación", which granted land as private property to communities and to hacienda owners, recognizing also the individual allocation of water to residents (Bustamante, 1995). But with the 1953 agrarian reform, the hacienda system was dismantled in most of western 
Bolivia, and these large haciendas were parceled out among their workers, the pegujaleros. This meant that former workers from more densely populated haciendas received smaller plots than those from the larger or less densely populated ones (Dandler, 1984).

Since before the agrarian reform, as part of the buildup to the so-called "National Revolution" in 1952, pegujaleros from each hacienda formed agrarian unions, as rural partners (peasant unions) of the labor movement in cities (labor unions). These unions were designed for political support and social mobilization during the revolution. Agrarian unions, after the agrarian reform, gradually came to be known as rural communities (Dandler, 1984). Under this new scenario, water management changed hands, from the hacienda owners to the agrarian unions (rural or peasant communities). They commonly adjusted water distribution according to the (spatial) distribution used during the hacienda period (Gerbrandy and Hoogendam, 1998). This consolidated collective rights and individual rights to water, despite attempts by the State to regain control over both through constitutional amendments. For example, the 1978 constitutional amendment (re)establishes the "original right of the State" over land, water and other natural resources. In practice, this normative framework (starting with the Law of exvinculación mentioned above) facilitated inheritance and therefore land subdivision as well as land and associated water rights purchase/sale transactions (Bustamante, 1995).

Currently, although most irrigation systems in Bolivia have water rights linked to community land, each community assigns rights to persons, that is families. Often, water rights can therefore be redistributed (purchased, transferred or traded) separately. In some cases, an owner of land with water may transfer the water to someone else (via different mechanisms), and in others only the land without water, or both together. However, notwithstanding the individual nature of land tenure and water access in many parts of the country, communities regulate to some degree to whom land and water are sold or transferred to: preferably (but not exclusively) to community members, relatives or acquaintances from neighboring communities rather than to strangers. This is a mechanism that communities use to maintain certain (collective) control over water and land, although in the last few years this rule is becoming increasingly flexible (Bustamante and Gutiérrez, 1999; Gutierrez, 2010).

The basic organizational unit in rural zones are rural communities or agrarian unions ("sindicatos"). Similarly, or as a counterpart to state administration levels, these organizations aggregate at higher levels: unions are organized at the district level into "Peasant SubCentrales", then at the provincial levels as "Peasant Centrales", at the departmental level into Federations and nationally into the Single Union Confederation of Peasant Workers of Bolivia (CSUTCB, Confederación Sindical Única de Trabajadores Campesinos de Bolivia).

Since agrarian reform up to the present, the organizational situation regarding water has become increasingly complex. The formal rural organizational structure, described above, does not necessarily correspond to water-user organizations, of which there is a great diversity of organizational forms. In many cases, irrigators' organizations comprise only groups of families without belonging to any community; in others, they are part of one or more communities or sometimes the irrigators' organization is the same as the community organization. They group 
around a water source, forming autonomously managed irrigation systems with their own norms for operation. All this socio-organizational complexity and diversity regarding water may become even more complex, such as in the valleys of Cochabamba and in other regions of Bolivia, where several of these irrigation systems overlap in a single geographical space (e.g., Gutiérrez and Gerbrandy, 1998a; Hendriks, 2006; Saldías et al., 2012). This institutional development and current (irrigation) water-governance implications in Bolivia are discussed in greater detail below.

\subsubsection{The institutional framework of irrigation. Two different starting-points that finally rejoin.}

This section discusses the direction that the State has taken in its attempts to construct an irrigation-sector institutional structure, versus small farmers' organizational dynamics and current water-management practices under irrigators' organizations. It will also discuss where these two processes match up and where they clash, as they ultimately provide the form and contents of present-day irrigation-sector water governance.

The implications of this scenario provide the background and the subject of this research, in terms of the water control knowledge gaps that this research aims to fill: it concentrates on the inter-relationship between (the different dimensions of) collective water control and the strategies small farmers pursue as families / small farm systems.

In Bolivia, starting in the 1960s and more harshly during the following decade, the State, with direct support from international cooperation, turned its attention toward the Andean Region. This was because of the region's importance in food production for domestic food supply and also because it concentrates most of the country's population. Since then, it is possible to distinguish three periods of major institutional, political and state-policy changes regarding irrigation:

The first period began in the early 1960 s until the early $80 \mathrm{~s}$. In this period governed by military regimes, agricultural policies were strongly influenced by the so-called "Green Revolution" developed in Europe and North America and spread worldwide. This period created several experimental stations and research programs, promoting agricultural modernization by introducing technology packages including improved seeds, fertilizers, pesticides and irrigation as an important factor (Del Callejo, 2010).

The State made a major effort to develop irrigation, with international cooperation support to construct infrastructure (mainly dams and large-scale works) to modernize existing systems. Several of these systems have been operating since before agrarian reform under the hacienda system and then rural organizations took them over. Some of these interventions, implemented through irrigation programs and projects, worked with the country's experimental stations in different regions. The results reported during this period are discouraging because of the little or no "adoption" of the technologies proposed, with agricultural extension programs that would 
only focus on "technology transfer" without considering local needs, knowledge, context and history (Gandarillas et al., 1993).

In terms of water control, this period consolidated water rights and farmer management arrangements, governed by customary norms, locally established and supported by collective practice and action. However, this top-down and largely imported, a-historical modernist technology focus also meant progressive change toward individual land ownership and the individualization of water rights; particularly in Bolivia's valleys and some zones of the altiplano. Other regions of the Altiplano systems have preserved collective / community land and water management systems (Bustamante and Gutiérrez, 1999).

The second period runs from the early 1980s up to 2005 and featured many changes. It began with military governments, and ended with democratic governments. In this period the socalled "Structural Adjustment Plans", promoted globally by the World Bank and the International Monetary Fund, were gradually imposed. Part of these belt-tightening measures for public spending took the first steps toward liberalizing the economy, by reducing state intervention (and investment) in economic activities. This period closed down most experimental stations and agricultural extension and research programs, promoting privatesector involvement, through NGOs, foundations and consulting firms to support agricultural development, including irrigation project design and implementation. Toward the end of that period, the neoliberal measures increased, closing all state agencies providing direct assistance to agriculture, so the Ministry of Agriculture would play only the role of planning, regulating and engaging (private) services for technical assistance and research (Del Callejo, 2010).

Together with this general (neo-)liberalizing trend in public policies, this period also implemented norms and policies entailing major changes in interactions between the State and organized society, particularly in rural areas with peasant communities and with irrigators' organizations. These changes included: an array of norms re-structuring the State, such as the Law on Popular Participation and the Law on Administrative Decentralization of the State (in 1995), and implementing the National Irrigation Program (PRONAR) as of 1995, as a structured attempt by the State to regulate the irrigation sector and plan investment.

The first measures re-structured the central State toward decentralized local levels, implementing decentralization (allocation) of public funds to urban and rural municipalities on the basis of demographic population criteria. As part of their implementation, mechanisms for citizen participation were installed, in planning, decision-making and societal oversight of municipal (rural and urban) governments through legally recognized (formalized) local organizations, called "Territorial Grassroots Organizations" (OTBs) (Muñoz, 2000). In rural areas, these organizations became significant political and institutional resources for rural communities and agrarian unions, or even for water-users' organizations (mainly irrigators), to get them recognition and visibility vis-à-vis the Government (Ströbele-Gregor, 1999).

This was a transcendental step for municipalities and societal organizations in rural zones, to access state resources (public funds), enabling grassroots organizations to play a decisive, 
increasing role in defining their own priorities as part of implementing policies, plans and projects or their own "Development Plans"2 (Nijenhuis, 2002). For the irrigation sector, this also meant a crucial step toward identifying and responding to historical demands and complaints by remote communities where the State had no presence. These demands commonly were (and still are) strongly related to increased involvement by rural organizations in the irrigation project interventions.

This period also implemented the National Irrigation Program (PRONAR) ${ }^{3}$, as an attempt to structure Bolivia's irrigation policy. This promoted pre-investment (irrigation-system studies and designs), investment (building new systems or improving existing systems), training and the State's early attempts to organize the legal framework for water and particularly irrigation. Investments in irrigation concentrated mainly on improving infrastructure in micro-irrigation ${ }^{4}$ systems, improving canals, river intakes and some small dams.

The main characteristics of State administration and relations with rural organizations during this period were:

- Decentralizing public administration toward regional and municipal governments, although regulatory and financial norms and administrative and financial procedures, access to public funding and international cooperation remained under centralgovernment agency control;

- Interventions implemented by private agents (NGOs, consulting firms and construction companies) under contract with decentralized governments (especially municipalities);

- Strengthened participation, involvement and even control of municipal governments in rural areas by peasant leaders and organizations. Since then, it has been common for mayors and municipal authorities, council members and other key positions to come from these organizations.

Some implications of these institutional changes in the irrigation sector were (Del Callejo, 2010):

- Weakening the central Government's relations with rural areas;

- Decentralizing and therefore delegating central-government functions to municipal governments were not accompanied by other financial support or public governance assistance for municipalities' technical capacities. In general, this overloaded municipal governments' responsibilities, often exceeding their financial

\footnotetext{
${ }^{2}$ One of the instruments of state decentralization at the municipal level are the Municipal Development Plans (PDMs), prepared every five years in each municipality and implemented through annual operating plans (POAs).

${ }^{3}$ The National Irrigation Program (1996-2005) was implemented as a decentralized program of the Ministry of Agriculture. The program consisted of four components: Water resource management, institution-building, investments in infrastructure for (micro-) irrigation, and training. The first three components were financed by the Inter-American Development Bank (IDB) and the last by German cooperation (former GTZ).

${ }^{4}$ Micro-irrigation systems were considered by PRONAR and then by the whole public investment system, as those covering under 100 hectares.
} 
implementation capacity and leading to community complaints and conflicts over unmet demands;

- Empowering rural organizations and the emerging of new local leaders.

In this context, relations between government (municipal, regional and central) with irrigation organizations were limited to the former's funding to construct infrastructure in response to demands by the latter. This period had no direct State intervention in water or irrigation-system management. Even though the Law on Municipalities and the Law on Public Participation would grant municipalities the responsibilities to manage, maintain and improve irrigation systems within their jurisdiction, in practice this never happened ${ }^{5}$.

During this period, two major events resulted in important water-norm discussions and actions and a new scenario of water-sector power relationships: the so-called "Water War" in 2000 in Cochabamba, and next, the formulation of the "Irrigation Law" (Law 2878 of 2004). Discussion about water norms, particularly for irrigation water, had already begun in the late 1990s. This was partly motivated by conditions imposed by financing entities, to invest in the sectors of irrigation, water supply and sanitation. A condition to continue investing was to update the institutional and normative framework, particularly the Water Law, which dated back to 1906 (Gutiérrez, 2009).

The year 2000 conflict in Cochabamba consisted of a series of mobilizations nationwide, it established a multi-scale organization to defend their rights from other user sectors and against privatizing interests promoted by neoliberal policies. Cochabamba's evolving "Water War" showed water users' organizational power, the possibilities of establishing alliances among different sectors of society (urban and peri-urban residents, irrigators, rural communities, drinking-water users' organizations and others) around water and the social, political and cultural value of locally embedded water governance norms and practices. For several years, there had already been conflicts between the Cochabamba water-supply company (SEMAPA) and communities or collective water systems where SEMAPA extracted underground water to supply the city. These conflicts, as a preamble to the "water war", had already shown societal organizations' clear decision and mobilization capacity to defend "their rights to water", expressed increasingly as a defense of their "uses and customs" (Assies, 2003). The major mobilization and conflict in the year 2000 was triggered by the threat to raise water-supply service rates in Cochabamba city, based on a concession contract with a transnational company, Aguas del Tunari. A law was enacted (Water Supply and Basic Sanitation Law, no. 2029) ratifying the contract with the concessionaire, and directly threatening the autonomous management of collective (community) water systems in Cochabamba's urban and peri-urban zones. After several days of violent confrontations between police / army and the mobilized masses, the contract with Aguas del Tunari was rescinded and the Water Supply and Basic

\footnotetext{
${ }^{5}$ For example, the Public Participation Law states that: "Municipal governments are granted competent jurisdiction and increased resources and transferred infrastructure for education, health care, sports, rural roadways and micro irrigation, with the obligation to manage them, maintain them and renew them..." (Article 2, Chapter 2, Title I, paragraph b).
} 
Sanitation Law was amended (Boelens, Bustamante, \& Perreault, 2010; Perreault, 2005; Perreault, 2006).

A new Water Law was also discussed (Seemann, 2014). In view of the diverging interests of different user sectors, mainly irrigators, miners, industry and urban users, discussion of a general Law got watered down. This drove irrigators, led by the Cochabamba Federation of Irrigators (FEDECOR), to promote a sectoral Irrigation Law. It coincided with forming the National Association of Irrigators and Community Water-Supply and Sanitation Systems (ANARESCAPYS) in 2003 and enactment in October 2004, of Law No. 2878 to Promote and Support the Irrigation Sector (Seeman, 2014). Socio-political conditions were favorable for this Law, because a year before the country had been rocked by further social conflicts about natural resource management. This led to a profound crisis and conflicts that ended up getting President Sánchez de Lozada to resign and establish a transition government. This conflict significantly shifted Bolivia's power relationships. Different societal sectors who felt their basic rights and livelihoods were being trampled, called for greater management autonomy and political participation, reacting and demanding to be heard (Perreault, 2006).

The third period covers from 2006 to 2015, distinguished mainly by establishing a new institutional framework for irrigation and progressively implementing it, along with other public-policy actions. 2006 was a landmark year for Bolivia and particularly for the irrigation sector. Evo Morales, a leader of coca workers, became President of Bolivia, strongly supported by both the powerful coca and the irrigators federations.

The transition government prior to Evo Morales' election already set up a new water-sector institutional structure, strengthening it by creating a Ministry of Water and three Vice Ministries, one of which was for irrigation. During Evo Morales' administration, the Ministry has been reorganized several times, ending up as the Ministry of Environment and Water, with a Vice-Ministry for Drinking Water and Sanitation, a Vice-Ministry of Environment, Biodiversity, Climate Change and Forestry Management and Development, and the ViceMinistry of Water Resources and Irrigation (MMAyA, 2014). ${ }^{6}$

The Irrigation Law and its regulations formally recognized "uses and customs" as a foundation for organization, for water management and for water-use practices in small-farmer irrigation systems. In addition to this explicit, formal recognition, this granted decision-making rights to communities where water sources are located or used. This Law and its regulations also established the sector's institutional framework, based on participation by representatives of irrigators at the departmental and national level in Departmental Irrigation Services (SEDERI) and the National Irrigation Service (SENARI), respectively. Both entities are responsible for administering "registrations" for water sources actually being used by rural organizations (irrigators), and granting authorizations to other non-peasant users. Their functions also include providing support for training, establishing penalties, and helping conflict resolution, in addition to proposing plans, policies and programs to develop the sector (Seeman, 2014).

${ }^{6}$ Source: www. http://www.mmaya.gob.bo/ (Accessed 12/2015). 
Chapter 3 discusses the status of implementation and the challenges posed by this new irrigation-sector institutional structure.

As this institutional framework was implemented by the Ministry of Environment and Water, various other programs were created for public investment to support this sector. ${ }^{7}$ As in previous stages, these programs have inherited technocratic traditions and a focus on building infrastructure, with little or no action regarding irrigation-system water management, much less to support agricultural production or farm-level irrigation practices. Irrigation systems are completely managed by irrigators' organizations, and agricultural production and farm-level irrigation by rural families' own decisions and strategies. Although the programs propose support for management capacities and improved water-use efficiency, there is no direct State assistance.

In summary, where countries such as Peru and Ecuador have a longstanding background of state intervention in irrigation, with heavy state influence in setting norms, rules, and rights (Boelens, 2015; Vos, 2010), in Bolivia, attempts by the State to construct an institutional structure have failed repeatedly throughout history (Perreault, 2005, 2008; Seemann, 2014). What has had a meaningful impact has been recognizing customary practices, local institutions and organizations, and their higher federations, which have gradually mixed with public institutions to reach the top levels of State administration.

Implementing neoliberal policies has often weakened societal grassroots organizations (Colque, Urioste and Eyzaguirre, 2015; Muñoz, 2000;), and certainly this was the case for specific sectors of society, such as workers', miners' or even rural grassroots organizations (agrarian unions or their federations at higher levels). However, simultaneously, as examined in greater depth in Chapter 3, water control organizations, especially irrigators' organizations, are still active and have proven that they can coordinate other initiatives or societal movements, even challenging and - in some cases - reversing policies that have been implemented and jeopardize their water security. The model of decentralization and public participation implemented in Bolivia seems to have strengthened grassroots water control organizations' capacities, ironically taking them in the opposite direction from decentralization. This means that grassroots water-sector organizations (especially irrigators) began grouping and upscaling their capacities for mobilizing and accessing positions of power, from local to national levels. Perreault (2005) calls this the "institutionalization of local-level water governance". The opposite seems to have happened with State institutions, which have lost their possibilities of directly regulating irrigation at the local level.

\footnotetext{
7 This include PRONAREC since 2009 (National Irrigation Program with a Watershed Approach), SIRIC (Subprogram of Investments in Inter-community Irrigation, since 2005); "My Water" Programs I, II and III ("More investment for water" Program, since 2011); "My Irrigation" Program ("More investment for irrigation" since 2014) and others. In general, these programs are implemented by a centralized financial body, the Productive Social Investment Fund (FPS) through initiatives or demands resulting in commitments made by municipal and departmental governments.
} 
Irrigation policies have focused to date on resolving physical control of water by improving major infrastructure such as dams, river intakes or main canals. Such measures seem to be purely technical and neutral in irrigation-institution development, but their importance in recent years has proven crucial, since constructing irrigation infrastructure is one of the most important mechanisms to create water rights and "hydraulic property" (Boelens and Vos, 2014; Coward, 1986) in new systems, or when consolidating and expanding them in existing systems in the Andes (Boelens, 2015; Gerbrandy and Hoogendam, 1998; Gutiérrez, 2005). This means that, while State institutions tried and failed to intervene or regulate water rights through formal rules or institutional structures, irrigation infrastructure projects significantly impacted societal organizations, reorganizing and in many cases reinforcing local institutions, and consolidating water rights in small-farm irrigation systems. Irrigation interventions both created distortions and conflicts and at the same time they have contributed to rural organizations' mobilization capacity, empowerment and progressive involvement in decision-making at different levels of government. In other words, interventions in irrigation were the (tangible) vehicle, along with rural communities" own dynamics, recreating and reshaping old "uses and customs". This has created new socio-political scenarios in water governance.

\subsection{Defining the problem and research questions}

Both when implementing public policies or in professional practice regarding irrigation, water policy in Bolivia has given priority to focus on eminently technical or physical elements: infrastructure, as presumably the most important means to ensure water availability and develop irrigated agriculture. In Bolivia there is a major gap between what the State has attempted through irrigation infrastructure and legal regulation projects, and what rural families with local practices grounded in collective action and strategies have achieved.

In Bolivia's irrigation development, a recurring problem has been how irrigated agriculture is conceived of: It is assumed that interventions in irrigation, focused on designing and constructing infrastructure to catch and conduct more water to irrigation zones, will directly and unilaterally improve agriculture. This initial technician's assumption ignores or underestimates the importance of water management and all tasks and principles comprising and underpinning it. It underestimates the importance of collective action, and how local management is materialized concretely in water access and availability for rural families.

There is a huge knowledge gap, both in the implementation of public policies to support this sector, and in overall professional practice. The idea is that water will, by itself, generate substantial, direct, unwavering changes in agricultural practices. This problem is rooted in biased technocratic concepts about small-scale farming and its irrigation practices and technologies, comparing them with "modern agriculture" and therefore cataloging them as backward, static, inefficient or "poor in technology" (Boelens, 2015; Del Callejo, 2010; Gutiérrez, 2005; van der Ploeg, 2003, 2008; Sanchis-Ibor et al., 2017; Seemann, 2014. Cf. Long, 2001a,b). 
This ignoring or underestimating small-farm irrigation has focused State attention and prioritized State actions on modernizing irrigation by implementing irrigation technology. Although grounded in the argument of creating better conditions for production and thereby impacting rural families' income, productivity and livelihoods, this has often resulted in simplistic and de-contextualized infrastructure projects. These fail to meet their purpose of ensuring water availability, much less generating the expected changes in agriculture. Or, in production terms, projects disregard the logic, determining conditions and contexts of peasant agriculture and peasants' market relations, including their collective action that upholds their water control and access (Rocha et al., 2015; Saldías et al., 2012; Seemann, 2014, 2016; Vos, 2010).

This problem in Bolivia's rural reality has meant that the same kind of irrigation and agricultural development intervention projects have been planned and implemented for decades (Gerbrandy and Hoogendam, 1998, 2002; Roa-García, 2014; Rocha et al., 2015; de Vos et al., 2006). This continues the promotion of infrastructure with operational problems, social conflicts surrounding these interventions, increasing inequality in access to water, and difficulties in materializing technological changes that could improve rural families' production conditions (Guevara-Gil et al., 2010; Gutiérrez, 2009; Perrault, 2014; Salazar et al., 2010).

Rural communities' dynamics have proven to provide the foundation for operating and managing local irrigation systems, above all in view of the State's historical absence. For production systems, these dynamics unfold agroproductive diversity and ways of comprising rural livelihoods. The problems described above have led this research to pose the following question:

How do collective action and individual strategies entwine in peasant irrigation to foster diverse patterns of irrigation management and production organization in response to the quest for autonomous water control?

This question has been answered through three sub-questions helping to organize field research and analyze empirical evidence:

\section{Sub-questions:}

The first sub-question seeks to understand the institutional development of irrigation in Bolivia, which has been, in the State's absence, based strongly on local water-management practices and norms, the practices currently expressed as "uses and customs".

How have irrigation institutions developed from local practices, how do they conflict with official views and policies concerning irrigated agriculture; and how these mismatches in turn influence water control? 
The second sub-question focuses on collective action, to more deeply explore its implications or inter-relationships with water control:

How do the various forms of collective action in peasant irrigation systems become manifest and how do they inter-relate with the different dimensions of water control?

Finally, the third sub-question focuses on rural families' production strategies, to understand their inter-relations with collective water control and with control over their own production processes. This last aspect is addressed in this research in terms of the quest for self-reliance, as a characteristic feature of small-farmer agriculture and irrigation.

How do different peasant families' farming strategies relate to water control and control over production?

\subsection{Methodological approach}

\subsubsection{Study focus}

The thesis focuses on "peasant dynamics" in irrigation systems. Beccar et al. (2001:23) propose to understand an irrigation system as "... a complex water management system combining and inter-relating physical elements (water sources, water flows, the places where water is used, and the catchment, conduction, and distribution infrastructure); normative elements (water access rights and obligations); organizational elements (social organization and the array of rules to make the system work); and agroproductive elements (land, seeds, labor force, irrigation skills and practices, and capital)". These elements combine and interact, interwoven with specific institutional, political and cultural contexts.

On the basis of this definition, the "engine" making a peasant irrigation system work is human action, tasks, physical and organizational work, social and production relations, and their interaction with larger-scale socio-economic and political contexts. In this thesis, this is conceptualized as socio-environmentally grounded "peasant dynamics". ${ }^{8}$ Peasant dynamics, for this research's analytical purposes, has been differentiated in, on the one hand, the collective or organizational settings and arrangements and, on the other, the individual rural families' farm units' strategies and actions. Nevertheless, I acknowledge that these two levels are actually inseparable and mutually dependent in an irrigation system's operation.

Conceptually, speaking of "small farmers" or peasant agriculture and irrigation refers to the way they produce, the way they farm (small-farm agriculture), but also to a condition and lifestyle in the countryside, or what Van der Ploeg $(1990,1994,2008)$ describes as the "peasant

\footnotetext{
${ }^{8}$ To define the concept of "dynamics", this document begins with a basic definition regarding "forces and movement of a system", or in this case, to understand social changes or processes in time and space, identifying factors or forces generating those changes. This is expressed by Eggink and Ubels (1984) in terms of "social force".
} 
condition" (cf. Mayer, 2002). This differs from the conditions and ways in which agri-business or entrepreneurial agriculture are undertaken. For Bolivia, a strong, important cultural dimension, relating to social identity, must be added to this concept. Albó (1987a) mentions this as a key feature of social dynamics in Andean cultures, where notions of ethnicity, class and locality blend together, into the concept of "peasant" or "campesino" (see also Bebbington, 1999; Kearney, 1996; Mayer, 2002; van der Ploeg, 1985, 1998, 2006; Roseberry, 1995; Zoomers, 1998, 2013).

The contextual reason to discuss and concentrate on "peasant life", is that irrigation systems in Bolivia, unlike other Andean Region countries, are all managed by user organizations which are mostly peasant organizations. This means that irrigation in Bolivia's Andean Region is basically small-farm peasant irrigation.

In summary, this study focuses on the dynamics generated by collective action and rural families' actions and strategies to control water and other factors conditioning (enabling or restricting) reproduction of their production systems and livelihoods, which are ultimately manifested as localized expressions of campesino life in the countryside. This research has focused, therefore, on case studies in three irrigation systems in the Valleys of Cochabamba.

\subsubsection{The cases studied}

The cases studied were selected on the basis of contrasting characteristics regarding water availability, agroecological conditions and, above all, people's experience generated during history regarding water management. These cases help illustrate and analyze - not comparatively but complementarily with each other - the different elements of collective action and family strategies that explain different dimensions of water control. These systems are: irrigation systems in Punata, located in the Upper Valley of Cochabamba Department; the Chiyara Khochi irrigation system in the locality of Sacabamba; and the systems of "atajados" (individual reservoirs) in the community of Rumi Cancha, in the Department's southwestern area. The three cases are at different altitudes and also differ in their connection with towns and major markets in the region. 


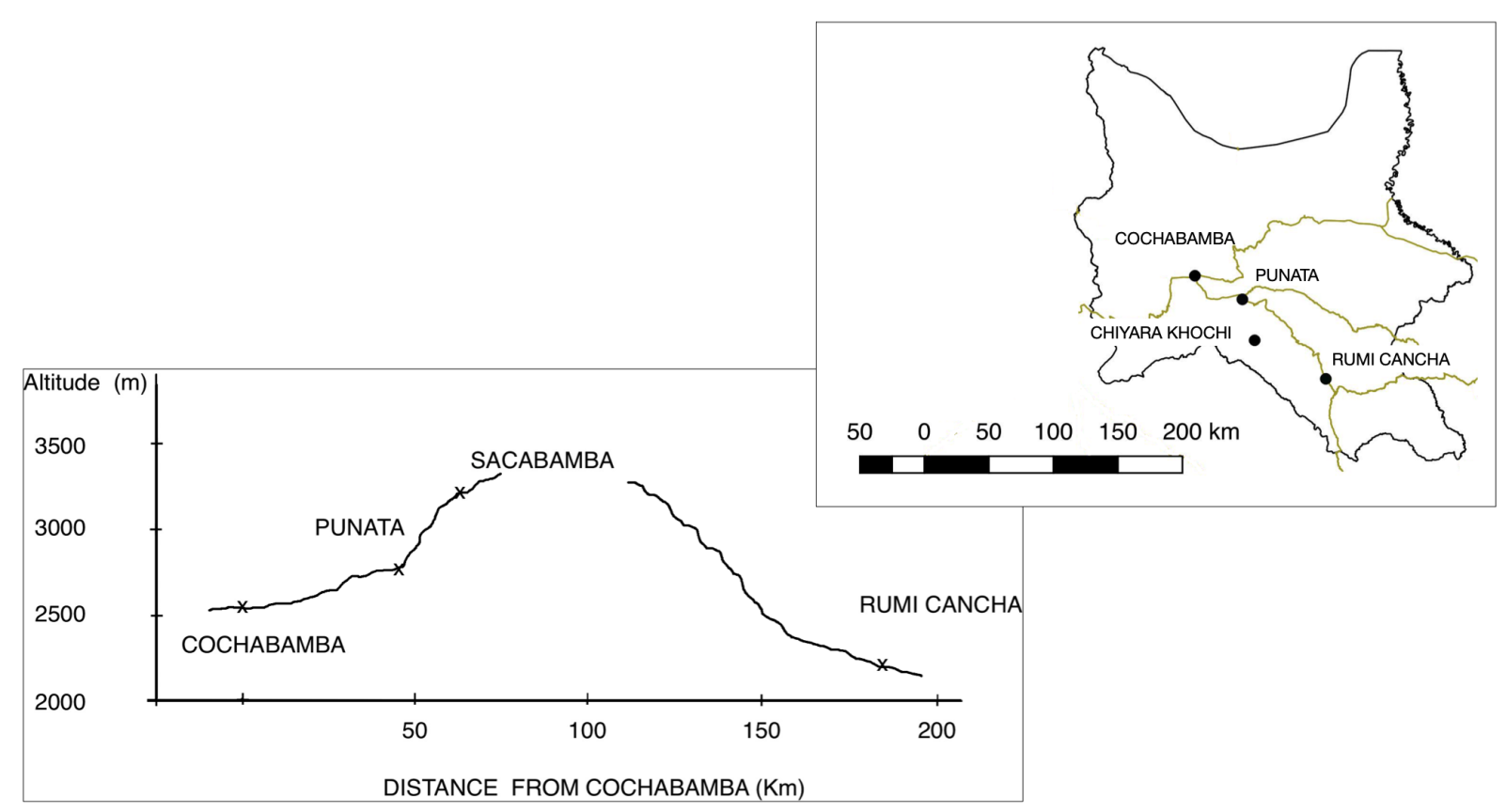

Figure 1-3. Geographical location of studied cases

Source: Prepared by the author

\section{Case 1: Irrigation systems in Punata.}

Punata is $45 \mathrm{Km}$ from Cochabamba, at an average altitude of 2720 meters above sea level. It is a relatively flat valley, formed by deposits of sediments from the Pucara River. Soils range from moderately deep to quite deep (north-to-south) and from silt-loam to clay. This means that in the northern zone, at the valley's headwaters, irrigation must be more frequent, and in the southern zone soils have greater storage capacity, but may have drainage issues. The climate is semi-arid, with average precipitation of $388 \mathrm{~mm} /$ year, $70 \%$ of that concentrated from December to March. The average annual temperature is $14.7^{\circ} \mathrm{C}$, with periods of frost from April to August (Servicio Nacional de Meteorología e Hidrología, 2014).

The population of Punata (2001 census data), was around 26,000, with 57\% urban and 43\% rural. The total population did not increase significantly between 2001 and 2012, but in 2012 the census reported a population of 28,800, with $68 \%$ urban and 32\% rural (Instituto National de Estadística, 2013). Agriculture is the main occupation of the population in Punata and this generates other activities: trade in agricultural products, tractor services, day laborers and others. However, for family economic strategies, such non-agricultural activities as informal trade, selling their labor force, agro-crafts, migration, public transport service, and others, are also significant.

The study zone includes 65 rural communities. Average land tenure in Punata up to 1995 ranged from 1 to 1.3 hectares per family (Gutiérrez and Claure 1995). There are no more recent data on land tenure in the zone, but these average values will have decreased as intra- or interfamily transfers or inheritances divide properties into smaller plots. The result is that a family commonly has several small plots distributed among different communities. 
Punata is one of Cochabamba's most important centers for agricultural produce exchange and trade. Farmers and traders currently come to Punata's weekly market fair from all over the Upper Valley, Central Valley, and Lower Valley of Cochabamba, from the high-altitude and tropical zones. Livestock is bought and sold (cattle, sheep, swine and small animals), as well as agricultural produce from the tropics, mainly fruits and coca; potatoes and other produce from the high altitudes, and vegetables and corn from the valleys.

Punata uses various water sources, forming self-managed irrigation systems covering different communities, overlapping in some zones and therefore resulting in differentiated access to water. This has also led to developing different production "vocations". Two zones are readily apparent: the northern zone, with more water available for irrigation, to grow vegetables, flowers, potatoes, fava beans and corn; and the southern zone, with less water available, emphasizing livestock; the main crops are corn and alfalfa (Rocha \& Mayta, 2007; Saldías et al., 2013). There are three types of water sources for irrigation: river water (direct runoff from rainfall, thawing of the upper basin, and a few springs); water from dams; and underground water.

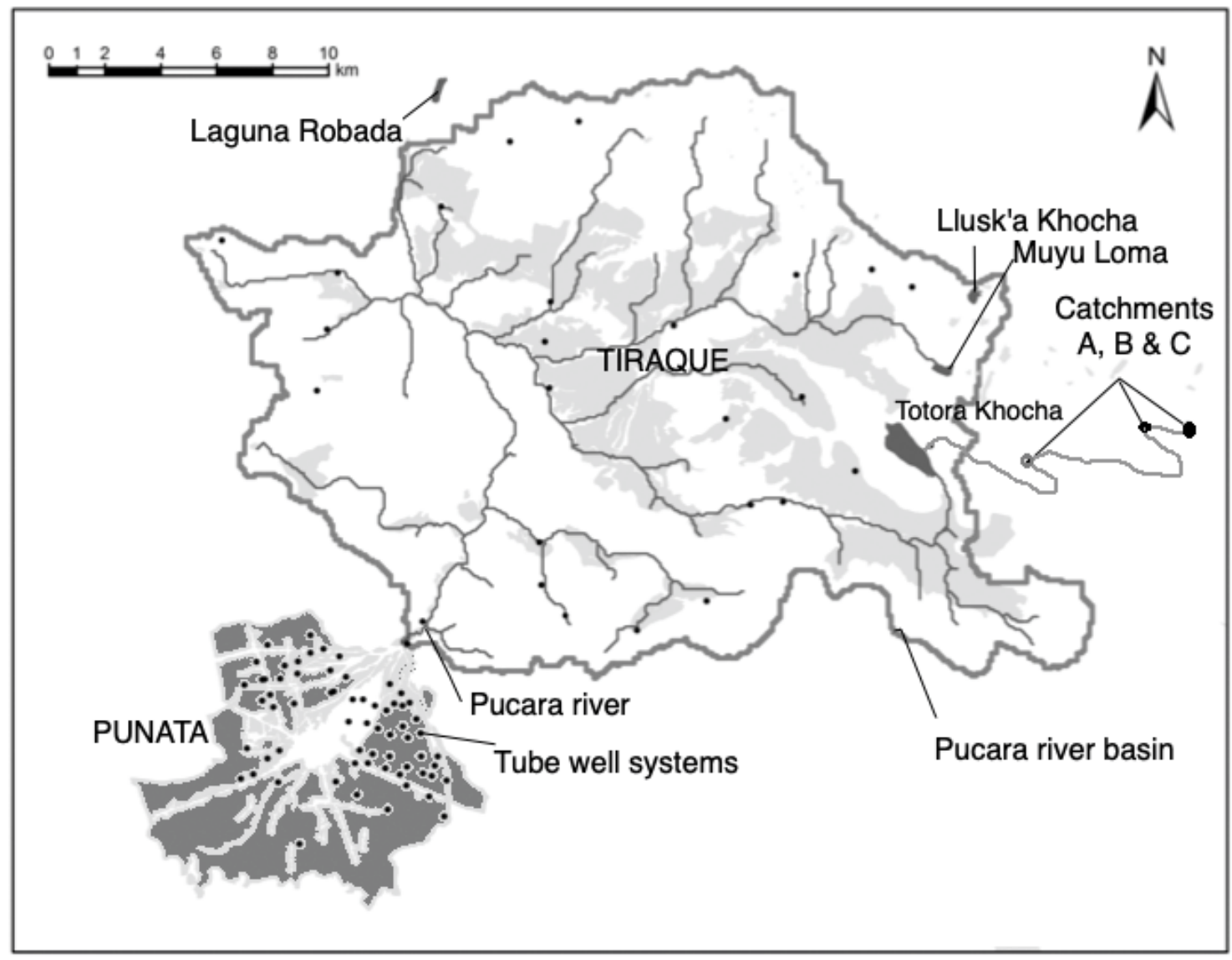

Figure 1-4. Punata's irrigated area and water sources

(Source: Prepared by the author)

Water from the Pucara River (Jatun Pucara Mayu). This source feeds several geographically "overlapping" (and often simultaneously operating) irrigation water distribution systems: 
Pilayaku, Mitha and Rol. Each of these systems begins providing water as the river's flow volume increases progressively during the rainy season. The Pilayaku system is used by only one community (at the top, near the main intake for Punata Valley) and uses the river's basic flow rate, that means, up to 50 1/s (Saravia, 1998; Vega 1996). Mitha water is clear and runs through the Pucara River from the upper basin (Tiraque) when flow rates are higher and enable communities to take this "extra water", from 50 to $300 \mathrm{l} / \mathrm{s}$. This is depending on the time of year and the rainfall distribution, which is quite variable in and between years. This system was used prior to agrarian reform by several haciendas and a number of farmer groups who purchased land from the hacienda owners. With agrarian reform, when land was distributed, Mitha water rights were also distributed among each hacienda's workers and among "free" farmers (piqueros) (Del Callejo, 1999). This system would appear to lack any formal organization, but any conflict will reveal water authorities (jueces de aguas) in each community, who resolve conflicts (Del Callejo, 1999; Delgadillo \& Lazarte, 2007a). The "Rol" system is relatively recent (after agrarian reform), and also uses the water of Jatun Pucara Mayu River. It is currently managed by the "Central Campesina de Punata" (Punata's peasant union organization). This system mostly benefits communities that have no right to Mitha and Pilayaku. It is used only in the rainy season, when flow rate at the intake is over 3001/s, and goes as high as 2000 1/s (Del Callejo, 1999; Delgadillo \& Lazarte, 2007a).

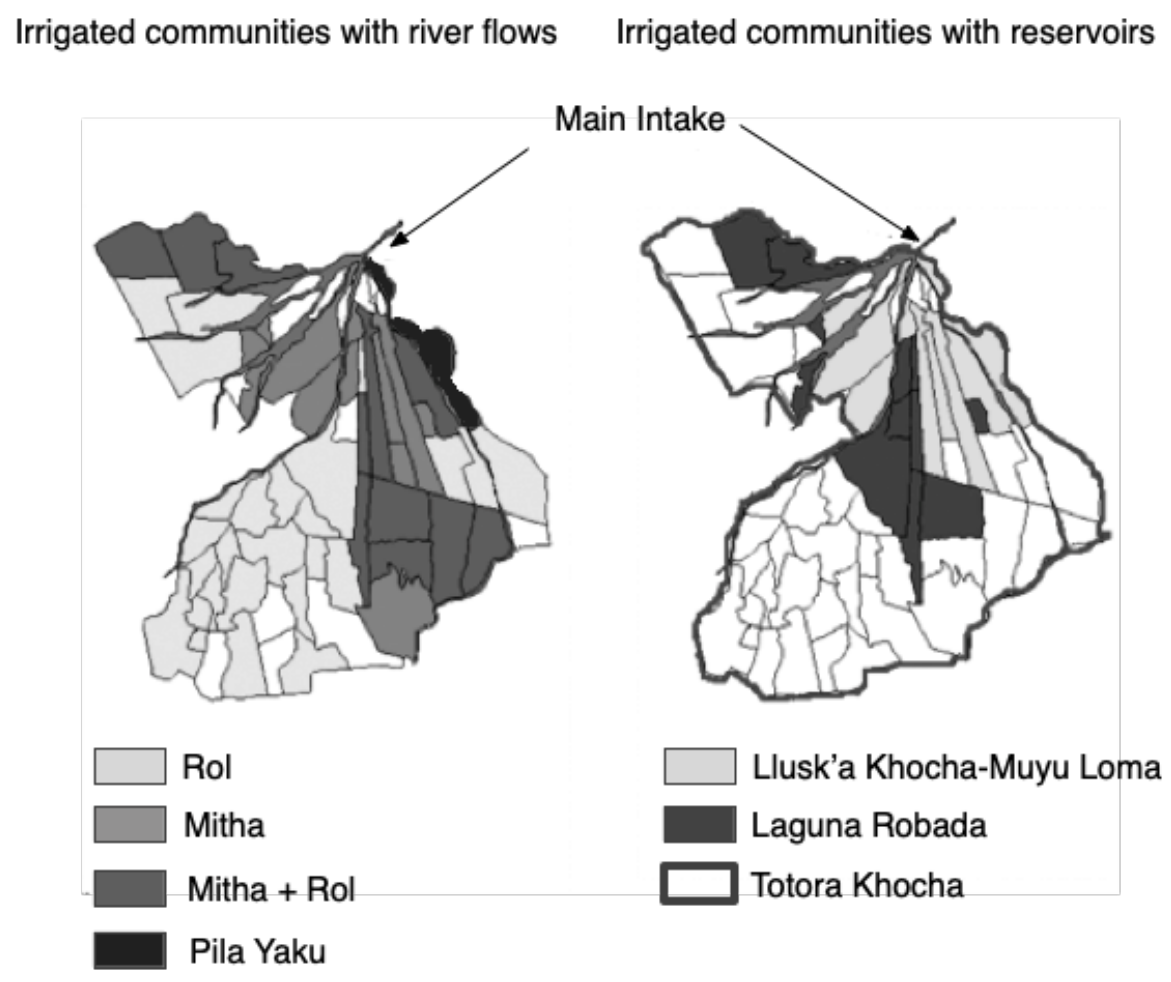

Figure 1-5. Area of influence of reservoirs and river waters in Punata

(Source: Prepared by the author)

Water from dams. The Punata zone has three dams (located in the higher zones of the region), which are connected but also operating autonomously: Laguna Robada, Llusk'a Khocha and 
Totora Khocha (see Figure 1-4 and Figure 1-5). Laguna Robada is a reservoir in the Corani basin. Before agrarian reform, in the 1920 s, it was rehabilitated by some hacienda owners to take water to Punata. During rehabilitation, the hacienda resident laborers did the work, so they demanded their rights after agrarian reform. Several rehabilitation projects in the 1980s through the Altiplano Valleys Irrigation Project (PRAV) increased the reservoir volume to $2.2 \mathrm{Hm}^{3}$, currently benefitting 10 communities in Punata. The system operates in periodic "largada" releases, ranging from 10 to 14 times a year. In recent years, communities from Aguirre (Municipality of Colomi), where the dam is located, have claimed a "territorial right" to this source, and have kept the water from flowing on to Punata several times. Llusk'a KhochaMиуи Loma is an interconnected system of lagoons located in the Municipality of Tiraque. Its construction began in 1968 with the support of the National Community Development Service (SNDC), beginning to operate in 1970. The Altiplano Valleys Irrigation Program completed the rehabilitation after interruptions, and resumed operation since 1988. This system currently benefits 10 communities in Punata ( 570 members), different from the ones served by Laguna Robada, in addition to two communities in Tiraque. This reservoir has a capacity of $2.0 \mathrm{Hm}^{3}$ and on average provides 6 to 8 largada releases per year, with flow rates from 100 to 250 1/s (Delgadillo and Lazarte, 2007a). Totora Khocha is the system with the largest capacity and coverage, and the most recent. The dam was built in the late 1980s as part of the Inter-Valleys Irrigation Program (PRIV), on a lagoon that was tapped by communities in Tiraque (the Ovejería Khocha lake). The idea behind this system was part of a major project to irrigate Punata. This project was planned in several phases, including expanding other dams in the area, constructing the catchment and distribution infrastructure in the Punata irrigation area, finally constructing the Totora Khocha dam, all this within an integrated management plan for water from Tiraque mountain range to irrigate Punata Valley and part of Tiraque. After several confrontations, conflicts and negotiations, an agreement was reached among communities from Tiraque and Punata to share use of and responsibility for system management, in a proportion of $40 \%$ for Tiraque and $60 \%$ for Punata. The reservoir has a capacity of 22 million cubic meters, although it is currently storing barely one third of its capacity, benefitting 65 communities in Punata and 35 in Tiraque. This system is managed by committees of the same name, in the two localities. The system is also operated through "largada" releases, dividing the flow volume reaching Punata into 8 flows or "irrigation groups" that all irrigate at once and distribute the water among the communities comprising the group, according to the time they are entitled to. The water from this reservoir used to be available two or three times a year for Punata, although in the last few years they have been able to do only one annual irrigation.

The dams' three irrigation committees comprise the Punata Irrigation and Services Association (ARSP) which, among other things, perform the function of coordinating and facilitating the three dams' operation. ARSP also helps irrigation committees to prepare each "largada's" irrigation turns, facilitating transport for the persons responsible for opening and closing the dams and the "tomero" watchmen to oversee water flow all the way from the source.

Underground water. Underground water is tapped in Punata Valley using semi-deep drilled wells and hand-dug wells. In general, most drilled wells are in the northern zone of Punata Valley and comprise systems managed by groups or communities. Hand-dug wells are family 
wells, mostly located in the south and southwest. In 1977, the project began to drill wells for the Upper and Central Cochabamba Valley, managed by what was then the Ministry of Rural and Agricultural Affairs (MACA), the Cochabamba Development Corporation (CORDECO) and the FAO. For some time, the project managed the pumps, providing fuel for their operation, but then they were replaced by electrical pumps and since then have been managed by the users themselves. Now, all initiatives to drill new wells and manage them are completely handled by small farmers. In most cases, farmers invested in drilling new wells, engaging private drilling companies. In other cases, they get help from some cooperation agency or apply for funding from the Municipality of Punata's "Public Participation" funds, or recently through governmental programs: "MI AGUA" and "MI RIEGO". According to the lastest inventories in the zone, the number of wells tripled from 2000 to 2012. There are currently between 100 and 300 wells, covering over 50 communities. This fact, and the increasing pressure on the basin's water, has influenced the flow rates that can be tapped, which have dwindled from 12 - 25 1/s in the 1990 s to $5-101 / \mathrm{s}$ at present (Ortiz, 2015).

\section{Case 2: The Chiyara Khochi irrigation system in Sacabamba}

The Municipality of Sacabamba is in the south of Cochabamba Department, at a distance of 85 $\mathrm{Km}$ from the city of Cochabamba and an altitude from 3000 to 3200 meters above sea level. The climate is cold and dry most of the year, making the zone arid. The average temperature is $11^{\circ} \mathrm{C}$, with an average high of $20.4^{\circ} \mathrm{C}$ and low of $2.4^{\circ} \mathrm{C}$. Relative humidity ranges from 25 to $60 \%$, with moderate to strong winds ( 3 to $6 \mathrm{~m} / \mathrm{s}$ ) and average precipitation of $600 \mathrm{~mm}: 75 \%$ concentrated from December to March (Vega \& Iriarte, 2003; Servicio Nacional de Meteorología e Hidrología, 2014). There are eight dry months (from April to November) when irrigation is indispensable for any agricultural activity. Even during the rainy season, the intensity, short duration and irregularity of rainfall may require complementary irrigation.

Another important physical characteristic of the region is fragile soils. These soils are shallow, with low organic-matter content, scanty plant coverage and with wavy terrain, which favors erosion, forming gullies (Pellens, 2006). Further, there are frequent problems such as droughts, hailstorms and killing frosts. The case study covers five communities in the Municipality of Sacabamba, namely: Ch'allaque Alto, Ch'allaque Bajo, Villa San Isisdro, Chimpa Rancho, and Pata Huerta. The first four communities are under the rural sub-central union of Ch'allaque and the last to the Sacabamba sub-central.

The main water source is runoff from the Chiyara Khochi and León Mayu Rivers, which then form the Ch'allaque River (see Figure 1.6). They are seasonal rivers, with heavy sediment load in the rainy season. This water is currently regulated at the Ch'allaque Dam, comprising the Chiyara Khochi irrigation system. Before agrarian reform, as in other regions in the valleys, land and water were under control and use by the haciendas. With agrarian reform, haciendas' territory was distributed among their workers and just a few peasants began using river water for complementary irrigation and to irrigate small fields of potatoes, corn and onions along this river or other rivers (Kobbi, 1995). There are also small springs that add up to a flow of about $2.51 / \mathrm{s}$. 


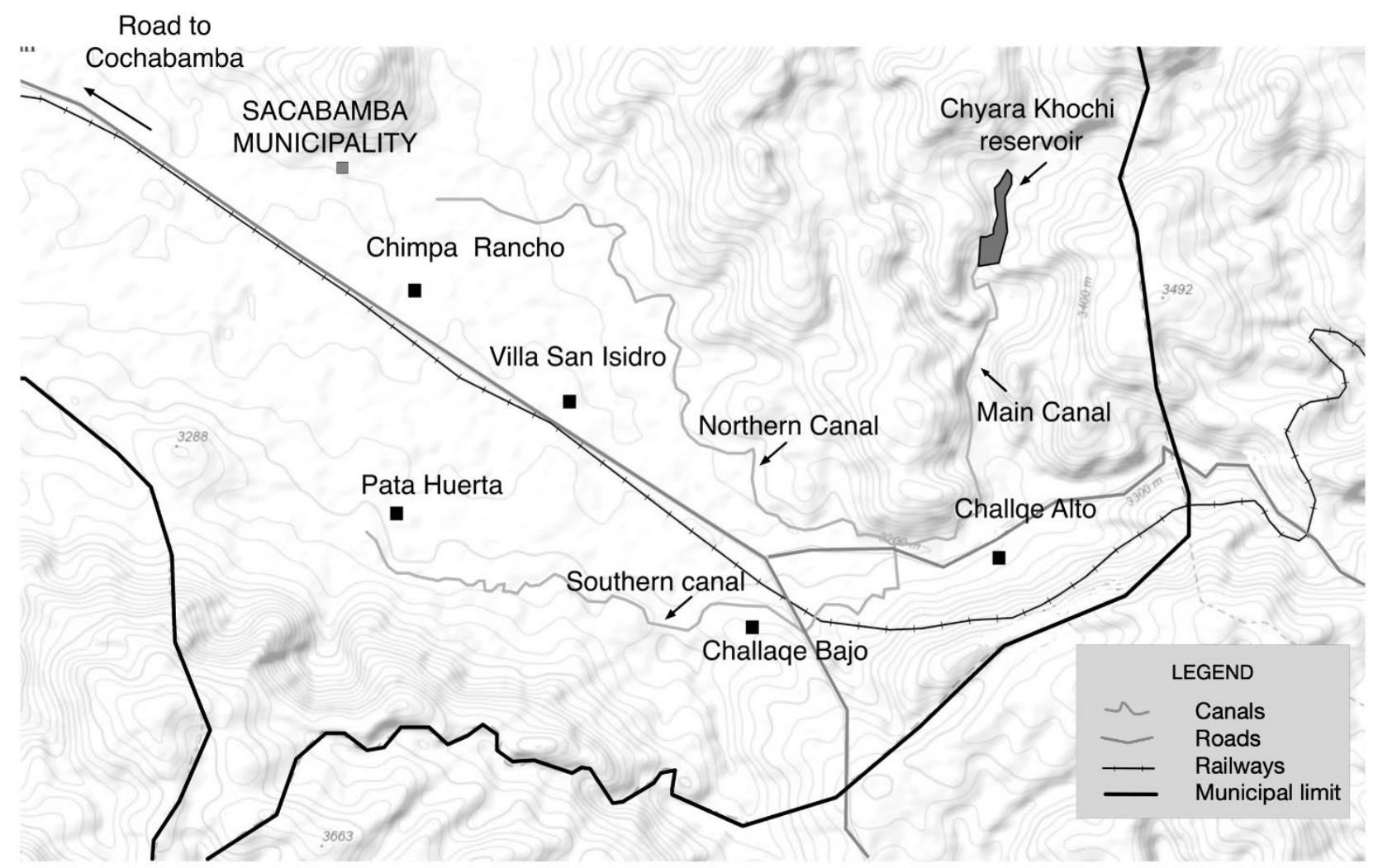

Figure 1-6. Chiyara Khochi irrigation system, Sacabamba

(Source: Prepared by the author, based on Vega and Iriarte, 2003

In the 1980s severe droughts forced communities to emigrate to urban centers, or to the tropical region of Cochabamba (Chapare). At the same time, the communities, coordinated by their main organization, the Ch'allaque Sub-central Union, demanded for the government to meet their water needs. These demands were also backed by CIPCA (Center for Peasant Research and Promotion), an NGO that began working in the zone in 1987 (Cossio, 2004). These actions consolidated ideas to implement an irrigation project to satisfy communities' water demands in the zone. So, in 1992, with technical support from the Inter-Valleys Irrigation Project (PRIV), they explored the zone and identified a feasible alternative to implement an irrigation project. The proposal, which was later partially undertaken by the National Irrigation Program (PRONAR), consisted of damming the Ch'allaque River and improving conduction infrastructure.

Chila and Delgadillo (2010), Cossío (2004) and Vega and Iriarte (2003) describe the intervention process, and the strategy pursued by the NGO, communities and municipality to make this project a reality. They subdivided the project into several phases, in order to implement works gradually as state agencies or other funding sources gradually provided the wherewithal. Later chapters will discuss a number of issues resulting from these successive 
interventions and communities' increasing empowerment. These interventions have granted five communities access to regulated irrigation water from May to November, for four or five (largadas) releases per growing season to irrigate around 400 hectares with flow rates between 5 to $101 / \mathrm{s}$. The system is managed by the Ch'allque Irrigation and Agricultural Services Association (ARSAC), formed during system implementation.

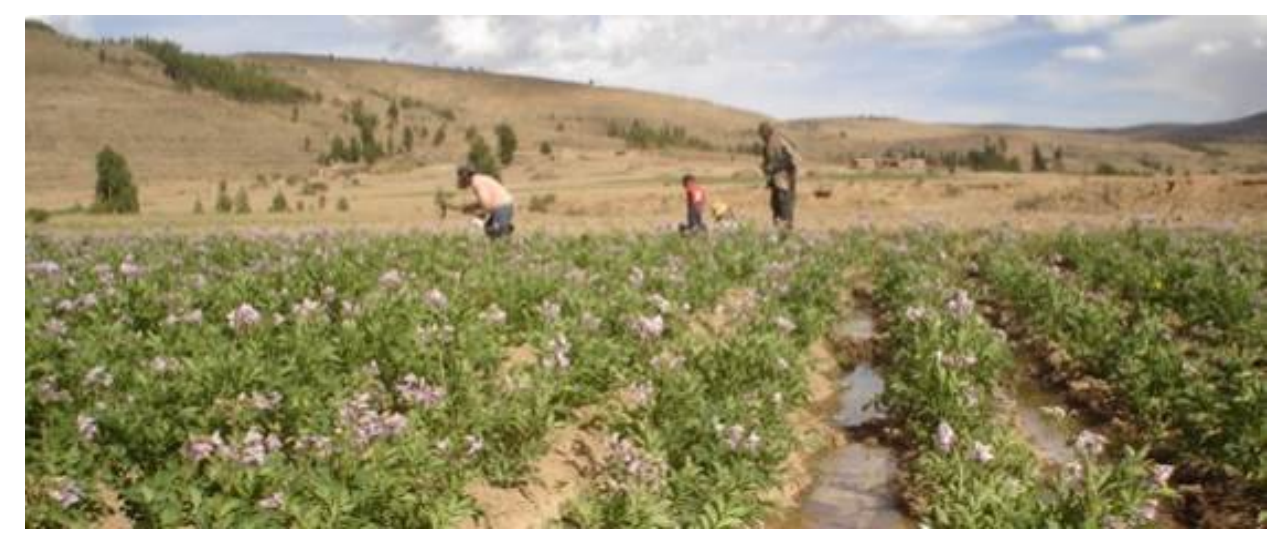

Picture 1-3. Developing potato irrigation experiences

Photo: G. Chila

\section{Case 3: Water harvesting systems. Atajados in the community of Rumi Cancha, Aiquile}

Rumi Cancha is a community in the southeastern part of Cochabamba Department, $14 \mathrm{~km}$ from the locality of Aiquile (Aiquile municipality, Campero province) and $180 \mathrm{Km}$ from the city of Cochabamba, on the main highway joining the towns of Mizque and Aiquile. It is one of the Department's most arid zones, receiving its heavy rains during a very short period (December to March). These conditions enable mostly rainfed agriculture and raising cattle and goats that browse on the bushy vegetation. Rumi Cancha is at an altitude of approximately 2200 m.s.n.m., with average annual precipitation of $550 \mathrm{~mm}$, an average temperature of $19^{\circ} \mathrm{C}$, an average high of $27^{\circ}$ and an average low of $10^{\circ}$ (Servicio Nacional de Meteorología e Hidrología, 2014).

Rumi Cancha, is a community representative of the region, in terms of agrarian history and patterns. Their ethnic group is unknown. Calvo et al. (1994) assume the Chuwis were the region's original dwellers, although they were displaced by conflicts with residents from the lowlands or by population reordering and the exploitation system imposed during the Spanish colonial period. By the end of that period and beginning of the Republic, this zone was peopled by migrants from different regions, who were absorbed or relocated by the hacienda system, leaving little or no vestiges of the original residents. During this period, haciendas and the Church controlled land and water in the region, as a strategic center for evangelization and administering church affairs, and as a commercial and political link between higher and lower areas.

Haciendas were established mainly in the region's valleys, so they controlled river water and the most fertile soils. They grew mainly to supply mining centers in Potosí or elsewhere in the 
region, such crops as corn, wheat, cotton, and sugar cane, plus meat, honey and other products. An important characteristic noted by Calvo et al. (1994) is this region's strategic mid-position as the "entranceway" to tropical land in the east. Although the region is bounded on the west by the Andes (Eastern Range), strong business and exchange relations were established with highlands (mining centers) and other valleys in Cochabamba.

Water resources are scarce in the Aiquile region, and under $10 \%$ of arable land is estimated to have continual access to irrigation (Cáceres, 2009). The water deficit or imbalance also increased after agrarian reform, because land was distributed among workers as water turns or "mithas". This did not leave enough water to distribute among many families congregated in communities along rivers.

The community of Rumi Cancha comes from a former hacienda near the Tipajara River, which is seasonal and dries up completely during the dry season. The community had only a few small springs to supply drinking water for a few families and small reservoirs (Khochas) created in gullies to store water during the rainy season to water livestock or for domestic use. When agrarian reform distributed land, the new agrarian union or community divided land among its members in the lower part of the valley and in the hills. Rumi Cancha comprises 70 families. As a result of land distribution, families have an average of around 2.5 hectares (CORACA, 1993) although there is also community land in the highlands and transition zones to tropical areas (hills with thorny vegetation), where each family can raise their cattle during part of the year.

The zone's vulnerability to changes or lack of rainfall is evident. The agricultural calendar is strictly subject to rainfall, which means that most agriculture is rainfed. Crops such as corn, beans, wheat, peanuts and potatoes can hardly be grown if the rain is late or stops in November. This forces families to apply different strategies, including staggered planting in November and December; migration to tropical zones or to cities during dry months; keeping livestock (cattle, goats and sheep) on community land, if possible combined with very small areas under irrigation.

In the 1960s, severe droughts forced residents of the region to migrate elsewhere, mainly to Cochabamba's tropical zones. Since then, migratory flows have been definitive and, more generally, seasonal to those areas. Further, most rural families and even whole communities from the region (including Rumi Cancha), have established properties (chacos) and belong to agrarian unions in the tropical part of Cochabamba as a major part of their livelihood strategies (Cáceres, 2009; CERES, 1983; Rodríguez, 1997). Migration has been viewed by the State as a serious problem to be resolved, due to the marginal living conditions of migrant populations in peri-urban zones and the cycle of poverty generated around them or in tropical zones linked with coca and cocaine production. Therefore, since the 1980s in the "Southern Cone" region (mainly the provinces of Mizque, Campero and Carrasco) the State and international cooperation have implemented development programs called "Alternative Development". The basic purpose of these programs was to reduce migratory flows to tropical zones, by improving production conditions and availability of water to reduce or create an "alternative" to growing 
coca. Part of these programs implemented projects to construct infrastructure for drinking water supply and irrigation, with other programs to support agricultural production (Calvo et al., 1994; Programa de Desarrollo Alternativo, 1992)

The programs most widespread in the zone included building micro-irrigation systems, consisting basically in implementing small catchment works for under-surface flow in rivers (filtering galleries) and multi-family or individual reservoirs to catch or "harvest" rainwater in gullies or on hillsides. These reservoirs have been called systems of ponds for rainwater harvesting or, more commonly, "atajados". At present, very few multi-family atajado systems are operating. However, many single-family systems have been built: the volume stored is less than $1500 \mathrm{~m} 3$ per atajado, which on average will provide irrigation to complement rainfall for small vegetable plots, no more than 0.25 hectares per family. In 2000, Rumi Cancha built 28 family atajados. This intervention was part of the Program to Support Earthquake Victims (PADT) funded by the German Government. The Program implemented projects to support production to mitigate the severe effects of drought in 1997 and 1998, in addition to disasters caused by the 1998 earthquake in the region (Tammes et al., 2001).

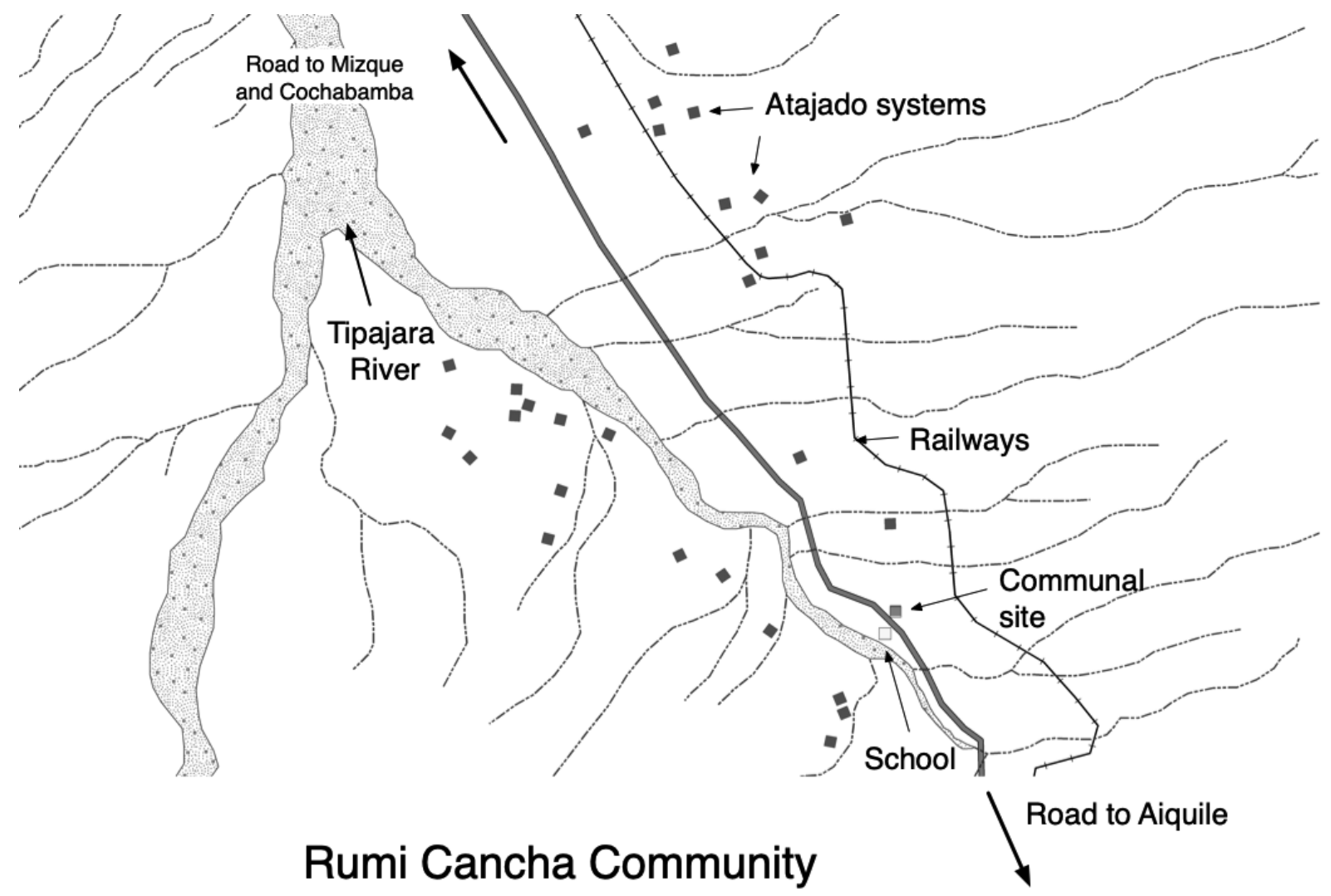

Figure 1-7. Atajados systems in Rumi Cancha community

(Source: Prepared by the author)

For some families involved in this project, it was the first time that they had irrigation water, others had experience or knowledge with crops under irrigation using small springs, and others because of working temporarily or having relatives in neighboring communities. Atajados are 
currently used for supplementary irrigation, guaranteeing first "seasonal production" (during the rainy season) and then production under irrigation (early planting or "mishkas") although on small plots, 1000 to $2500 \mathrm{~m} 2$ (Cáceres, 2009; Maita and Verweij, 1996). Preliminary results show that the zone has developed a new culture and technology of "rainwater harvesting", enabling rural families to have small-scale agriculture and livestock, but relatively more securely, and to meet their basic water and food needs (Cáceres. 2009; Lukat, 2012).

\subsubsection{Methods}

The research is based on the three irrigation systems cases, very different in size, agroecological characteristics, and above all in their experience and organizational capacities regarding water management. These three cases have not been studied comparatively. Rather, the three zones studied yield empirical evidence to help understand different principles underlying collective water management action, diverse results from water control, and particularly the outcomes from rural strategies for agricultural production and livelihoods.

Information was gathered and then processed by a combination of methods: reviewing and systematically summarizing studies, projects and publications on the study zones and systems, but also semi-structured and structured interviews with key stakeholders, and attending community and irrigation organizations' assemblies or meetings, as well as meetings between these organizations with financial and technical entities, including both governmental and nongovernmental support agencies.

Of the three cases studied, the irrigation systems in Punata were the most researched, as part of the working zones since 1991, when PERIAV ${ }^{9}$ and subsequently the Centro AGUA (to date) based their research on small-farmer irrigation in the Andes. Different research projects conducted in this zone by the author significantly informed this thesis. All that information, generated for several years, was complemented and updated by direct interviews with local leaders and technicians with organizations working in the zone. Interviews were mostly done from 2008 to 2013, complementing or updating information regarding irrigators' organizations throughout the years 2014 - 2018. In Rumi Cancha and Sacabamba, the author conducted basic research twice: first in 2000 and 2004. Then, this research was complemented from 2008 to 2013, by collaborative projects by the Centro AGUA under the Concertación Program. ${ }^{10}$

Two or three cases of rural production strategies under irrigation, basically strategies by family farmers, were studied in each zone. Case studies in all zones were initially based on semi-

\footnotetext{
${ }^{9}$ PEIRAV was the Teaching and Research Program for Andean and Valley Irrigation. It was implemented by the San Simón Major University with funding support from Nuffic from The Netherlands and collaboration by Wageningen University. In its third phase, PEIRAV became the Centro AGUA, a research center on water management in the Andean region.

10 The Concertación Program consisted of collaboration among research centers and institutional platforms from the Andean countries (Bolivia, Peru and Ecuador) and The Netherlands. It was coordinated by the Irrigation and Water Engineering Group of Wageningen University (IWE, now WRM). One knowledge project was on Peasant Irrigation in the Andes. This enriched the analysis of smallholder irrigation from a perspective of water control and security.
} 
structured interviews with family members. Initial access was generally with men or parents, but then it was possible to have interviews or less-planned or structured talks with different family members. These interviews first probed how small-farm production systems were organized, families' different activities to produce crops and livestock or transform their products, and the technical details of these different activities, including irrigated or dryland farming of different crops. To delve deeper into aspects of the logic underlying actions or decisions taken by family members or families as a whole, some of their activities were tracked in greater detail, such as planting, harvesting, some agricultural processing or artisanal activities, watering of their plots, families' participation in community work, and others. Different methodologies were used, such as participant observation, informal discussions, documentation by photographs, conversations about life testimonies, and others.

Especially in Sacabamba and Rumi Cancha, several interviews were done by research assistants who collaborated expressly in the field work; in all cases there were short research efforts with undergraduate or master's students. The research combined methods and therefore both qualitative and quantitative data and information. In collective irrigation systems, most analysis focused on qualitative analysis of interviewees' opinions, perceptions, stories or life experiences, as well as secondary information sources. However, to understand the technical operation of the systems, particular field work activities were directed at measuring or quantifying flow rates, irrigation volumes and times, efficiencies, water losses and others, helping in turn interpret the different dimensions of water control.

For family production systems research, quantitative analysis focused mainly on understanding how families organize their work and the different factors and production inputs, as well as production volumes, yields, prices and the profitability of production. This quantified the family's own labor, machinery or draft animals and inputs ("internal" resources or those acquired through non-monetary mechanisms or reciprocity) and those acquired using monetary resources (purchased on the market). This detail made it possible to analyze the logic of noncommodity operation, of market integration, or the combination of market and non-market relations in production processes. This analysis, combined with farmers' own (subjective) criteria as to how they would characterize their own production process, made it possible to identify and analyze different "production styles" present in each locality, also analyzing the role of irrigation in these styles. Each subsection in the empirical chapters (Chapters 3 to 5) took information either from a single case, from stories or information on all three cases, or just from two of them.

\subsection{Structure of the thesis and description of its chapters}

After this introductory chapter, which establishes the context, problem and research question, and the methodological approach, Chapter two develops the conceptual framework, in particular, the theoretical perspective to analyze "peasant dynamics" for collective and family systems, and their inter-relatedness. The main purpose is to systematically organize and summarize an array of concepts and analytical elements that enable analyzing irrigation from a broader perspective, i.e. a sociotechnical approach. This is to go beyond disciplinary representations of irrigation practice, solely from the agroproductive standpoint (e.g. water 
productivity), solely regarding irrigation infrastructure or technology (canals, intakes or other artifacts used in irrigation) or prioritizing solely a mechanical description of water management, disconnected from political, institutional, cultural, socio-economic, historical and biophysical contexts. This enables breaking away from the routine mechanical practice of Bolivian irrigation professionalism and the country's scholarly water development studies that focus on engineers' practices and how they prepare irrigation projects or participate in peasant irrigation system interventions. Usually these approaches concentrate solely on the formalistic purpose of such interventions - generally on building the infrastructure to increase "water availability" -, ignoring the existing complexity of small farming under irrigation, where collective and individual interests and practices merge.

Only by more thoroughly understanding inter-relationships among artifacts, the different elements of collective water management, interwoven with culture and politics, institutions and the biophysical context, can the actions or strategies be understood that rural families pursue to access water and other production factors. Similarly, this is crucial for understanding how work is organized on their property, and the support that rural organizations and families require to manage their resources sustainably, particularly water. As part of this analytical framework, I discuss and later operationalize two central concepts: the concept of water control as the basis for analyzing water management's multiple dimensions, and the concept of peasant strategies to understand the logic underlying agroproduction and constructing their livelihoods.

The chapter is organized around three themes: collective water management in irrigation systems, agroproductive strategies of households, and concepts to analyze the framework and institutional and political development of irrigation in Bolivia. These three themes are the basis for organizing the empirical evidence analyzed in the remaining chapters.

Chapters 3 to 5 contain the empirical material from this research in different analytical domains. Chapter 3 examines the local institutional context and its inter-relationship with "formal" state institutions. Chapter 4 addresses collective water management analyzed from the different dimensions of water control and expressed through different collective strategies. Chapter 5 then focuses on families and their strategies for production and for water access and management:

Chapter 3 discusses the context and institutional and political development of irrigation in Bolivia. After a brief historical review of how institutional arrangements for water and particularly irrigation have evolved, the starting-point is an analysis of the diverse expressions of the so-called "uses and customs". This concretely manifests water-management practices and consequently expressions of water control's different dimensions. It highlights the importance of concrete practices and problems underpinning such uses and customs. This shows the need to understand these practices in their current context and the risks or difficulties entailed in attempting to formalize these customary norms in official State normative frameworks. 
This contextualization and analysis of institutional development helps Chapter 4 understand how collective water management practices and actions are expressed in the different case studies. This chapter discusses in greater detail this diversity of actions expressed as collective strategies. These make the small-farmer sector visible vis-à-vis the State, and equally are a response to the uncertainties basic to accessing and managing their resources. This chapter shows that there can be different thrusts for coordination or motivations promoting collective action, which in turn shows that there are different peasant "principles" for managing their resources. One of the resulting principles is the quest for autonomy in managing key resources and livelihoods.

Chapter 5 concentrates on peasants' property and production system, the small farm. This focuses on how family labor is organized, on resource control, and on production and reproduction of the family farm. I will examine family's interaction in markets (for inputs and products) and non-market settings (their own rural organizations at different levels and in various forms, whether community organizations, water-user organizations, or other types of local institutions). The chapter discusses certain principles explaining the logic of peasant production, which in many cases reflects the quest for autonomy vis-a-vis the market, to enable or obtain sufficient control over their own production and thereby over the reproduction of their livelihoods.

Finally, Chapter 6 concludes by summarizing these discussions. Addressing the micro / familystrategy level, the collective level, and Bolivia's institutional and political development of irrigation. This summary shows the inter-relations between public policies and the "new" directions that small-scale agriculture is taking, vis-à-vis public policies themselves and global trends in the development of agriculture. It concludes with several public-policy challenges, suggesting that they be discussed in different circles, both academic and among policy-makers, considering above all the still preponderant role of smallholder agriculture in Bolivia. 


\section{Chapter 2 . Conceptual framework}

\subsection{Introduction}

Academic irrigation literature features different types of studies, focusing on particular problems of irrigated agriculture. In the Andes, besides the large body of studies describing technical and physical aspects of water management, two central themes and academic streams concerning "peasant irrigation" prevail.

The first, approached from different perspectives and disciplines, emphasizes collective water management and water rights repertoires in irrigation systems, mostly in relation to State bureaucracies and modernist (market-based) policies and legislation. The diversity of organizational forms, local institutional arrangements that enable water systems' operation, water rights in their different dimensions, the cultural and historical basis of local water management, and the socio-economic and political implications are some examples of the topics studied (e.g., Boelens, 1998b, 2008, 2015; Gelles, 1994, 2000; Guillet, 1995; Gerbrandy and Hoogendam, 1998, 2002; Lynch, 2012; Trawick, 2001).

The second group of studies and approaches tackles different themes regarding peasant agriculture. They strive to understand how peasant production and economies are organized, peasant households' livelihood strategies and their relation to the local, national and globalizing market (e.g., Gonzales de Olarte, 1990; Golte, 1980; Golte and de la Cadena, 1983; Mayer, 2002; Van der Ploeg, 2006, 2008; Zoomers, 1998, 2010, 2013). Other studies in this group, by development agencies, also analyze irrigation's effects on crop diversification or specialization and on family incomes, and how water management practices and technological innovation develop at farm and field level (Delgadillo, 2003a, 2003b; Pellens, 2006; Salazar et al., 2010; Vos, 2010).

Although not exclusively, these two currents tend to concentrate their attention on two different domains: the former as primarily collective (inter-family and inter-community) water control and the latter concentrating more on the domain of production units, i.e. peasant households. Few research documents and technical studies (e.g. Mayer, 2002; Van der Ploeg, 2006, 2008) have analyzed the relationship between these two domains in peasant irrigation. The reasons for this gap may be the two domains' inherent complexity and heterogeneous conditions, or the lack of theoretical and methodological instruments to integrate them. This constitutes one of the academic reasons motivating this thesis.

This chapter discusses a generic approach to analytically integrate these two domains by combining, adapting and complementing different perspectives toward studying peasant irrigation. This integration entails first breaking through the imposed disciplinary barriers that tend to separate the different elements of irrigation, into "technical components" from others of a more "social character" (see, e.g., Eggink and Ubels, 1984; Mollinga, 1998; Sanchis-Ibor et al., 2017; Zwarteveen and Boelens, 2014). 
First, this study argues the need to understand irrigation as a sociotechnical process and therefore the relevance of not "compartmentalizing" its analysis. This is an important starting point, given the tendency, in professional and academic circles, to speak of irrigation as something merely technical or a matter for engineers with some "social aspects" to be dealt with. This tendency results, in some cases, from unintended disregard and, in others, from disciplinary or professional bias that neglects the complexity of peasant irrigated agriculture and the need to integrate knowledge, concepts and analytical frameworks to better understand rural realities. Next, the chapter discusses collective action as the basis for water management, including the different forms and expressions of collective action that are manifested in Bolivian practice, and some of the principles that motivate it. Following this discussion, the third section will address water control as one of the key explanatory concepts related to collective action. Conceptual elements proposed by various authors will be addressed, identifying the different dimensions of water control in the collective but also in the individual $^{11}$ (household) domain. It also considers how these are immersed in particular socioeconomic, political and environmental contexts and how they are influenced by different types of relations with the state and the market. The fourth part of the chapter addresses concepts to analyze these interrelationships, first from an institutional perspective and then from the notions of organizational and collective action. Finally, the fifth section discusses further aspects of peasant economies, including their strategies of production, reproduction, livelihoods and the conceptual elements utilized to analyze their relationship with the collective, with institutions and the market.

\subsection{Irrigation as a sociotechnical process}

Irrigation is a complex process. To understand this complexity, there is the need to recognize that beyond the "physical component" of irrigation there is a "social component" in constant interaction: these dimensions are inseparable (Beccar, Boelens, and Hoogendam, 2001; Gerbrandy and Hoogendam, 1998; Gutiérrez, 2005). Irrigation practices do not simply mean opening the tap or gate to bring water to an agricultural plot. They also involve organizational activities, starting from constructing or rehabilitating infrastructure, agreements to allocate or access water, to distribute it among users, maintain the system and manage conflicts (Eggink and Ubels 1984 based on Coward 1980). The two next sections identify elements more commonly understood to be technical, followed by the social aspects or elements in order to finally demonstrate their inseparability.

\subsubsection{The "technical" as the privileged focal point of irrigation studies}

Focusing only on the "technical" elements of irrigation, we see that engineering has focused on three main areas. First, the physical infrastructure, secondly technical operations and tangible results arising from managing (manipulating) these physical elements, and relatively recently, considering interaction between these operations and the larger physical environment.

\footnotetext{
${ }^{11}$ In speaking of "the individual" throughout the text, reference is made to actions of individual peasant families as basic units that make up a community or social group, except when specifically referring to individual actors.
} 
The focus on these three physical/technical components has generally conducted analysis toward unidirectional causal relationships (see the discussion by Boelens and Vos, 2012; Gutiérrez, 2005; Mollinga, 1998; Roth et al., 2005; 2015; Veldwisch et al., 2009; Venot et al., 2017). Technical operations of irrigation systems or family plots have generally focused on physical or tangible elements such as flow rates, delivery schedules, operation of infrastructure, and irrigation practices on the plot (irrigation methods and devices used), as well as the results of all these physical processes in the soil and the crop growth response. Ultimately, the focus is on meeting plants' water requirements and especially trying to attain greater control over the results of irrigation: yields in response to water and water productivity ${ }^{12}$ (Eggink and Ubels, 1984; Molden, 1997; Molden et al., 2007; Sharma, et al., 2015).

Progressively, in the attempt to control nature and water to maximize profits in agriculture, different branches of engineering have also emphasized designing all components of an "irrigation system" at its different levels (Gutiérrez, 2005). Parallel to designing irrigation infrastructure and technical operations, irrigation interventions (as in new institutional economics) have elaborated on the interest of "optimizing" these operations, from creation and design, and evaluating organizational structures, to operating irrigation systems. Under these perspectives, although the major concern is with institutional issues (related to the administration, norms and policies), the main goal remains unchanged. It concentrates on technical performance and its economic outcomes (Boelens and Vos, 2012; Small and Svendsen 1990; Saleth 2004).

For the relationship between technical operations in irrigation systems and local ecologies, other studies focus on irrigation's environmental impact, especially on physical aspects such as erosion, soil salinization or groundwater contamination (e.g., Fernandez Gomez, 2004; Lana, 2007; Meireles, et al., 2003; Pannel and Ewing, 2006). These studies, rather than deepening 'interdiscipinarity', tend to be based on an 'adding on' of technical and ecological/agronomic discipines and studies.

\subsubsection{The "social"}

From the same engineering perspective, "social issues" have been discussed superficially, such as identifying cultural diversity and (poor) education of rural populations as "obstacles" to the technical system's full operation. This vision goes according to established protocols, designed beforehand by engineers. In some cases, "the social" is also considered as something related only to demographically- or occupationally-related indicators. Often so-called "integrated" approaches (e.g., Integrated Water Resources Management) tend to add a "participatory image" to what is basically a technocratic perspective; instrumentalizing "participation" and

\footnotetext{
12 Technical concerns regarding water use, water efficiency and ultimately water productivity have changed their emphasis. They started with concerns about irrigation management performance (linked to transferring irrigation management from the state to users), followed by issues of public investments and interventions; recently, a major concern is food security due to climate changes and variability and also due to the unexpected increase in irrigation water demand and the consequent water deficits and conflicts.
} 
"inclusion" to the needs of project implementation as foreseen by the technical staff and development agencies.

From the social sciences, however, other irrigation-related subject fields have been studied, such as organizational activities and political effects linked to issues that in principle could be understood as essentially technical, such as conceptualizing, designing, building, operating and maintaining the infrastructure envisioned and developed by engineers (Eggink and Ubels, 1984; Jansen and Vellema, 2011). In this field, as discussed by Boelens (2008, 2015), Eggink and Ubels (1984) and Mollinga (1998), other issues also have been addressed, originally from the professional literature on irrigation management but later from more academic and inter/trans-disciplinary studies:

- The internal rules governing system operation: basically, the social arrangements of the group using the water. This is central to defining, expressing, functioning and reproducing water rights (individual rights) (e.g., Achi, 2010; Beccar et al., 2001; Boelens, 2015; Boelens and Vos, 2014; Gerbrandy and Hoogendam, 1998; Roth et al., 2005; Seemann, 2014; de Vos et al., 2006)

- The rules and agreements governing the user group's relationship with third parties (individuals or other groups) (collective rights) (e.g., Bebbington, 1997, 1999; Boelens, 2008a, 2015; Hendriks, 2002; Mena-Vásconez et al., 2016, 2017; Rocha et al., 2016; Roth et al., 2005, 2015; Saldías et al., 2012; Seemann, 2014, 2016)

- The agrarian structure and social relations of production on- and off-farm. These are also related to water and irrigation activities (e.g., Boelens 1998, 2015; Guillet, 1995; Mayer, 2002; van der Ploeg 2008; Veldwisch et al., 2009)

- The system's relationship with broader contexts of the state, market and institutions (e.g., Gerbrandy and Hoogendam, 1998; Hidalgo et al., 2017; Hoogesteger, 2012, 2013a, b, c; Lynch, 2012; Mollinga, 1998; Perreault et al., 1998)

- Power relations, culture, norms and social dimensions that are intertwined or interlaced around technology and irrigation infrastructure (e.g., Andolina, 2012; Boelens, 2008a, 2015; Boelens et al., 2016, 2018; Gelles, 2000; Guevara-Gil et al., 2010; Hommes and Boelens, 2017; Hoogesteger and Verzij1, 2015; Meehan, 2013; Perreault, 2014; Pfaffenberger, 1988; Sanchis-Ibor et al., 2017; )

Irrigation technical actions always take place in the context of social relations, making the separation between "technical" and "social" artificial. Pinch and Bijker (1989) analyze the sociology of science and technology, and technological innovation studies, arguing that "technological artifacts" do not develop linearly. On the contrary, they are influenced and shaped by different meanings that "relevant social groups" give to these artifacts, according to the problems they face in their particular circumstances or according to their own interests. Technology, artifacts and science itself are conceived as social constructions. From this perspective, Latour $(1992,1994)$ and others, argue that technology and artifacts are no longer neutral elements; instead, human actors and nonhuman "actants" shape sociotechnical networks that ultimately define and are structured by people's modes of action. Boelens $(2008,2014)$, 
Pfaffenberger (1988) and Winner (1986), also argue that technology seeks to create "a social and political order", i.e. defining "normative meanings" and "political behavior", although in everyday life the defining-character of artifacts tends to be hidden and assigned a neutral value (Boelens, 2008a:251; Meehan, 2013; Pfaffenberger, 1988; Winner, 1978).

\subsection{Implications for this study to adopt a sociotechnical perspective}

Recognizing the complexity of irrigation and its sociotechnical character requires taking a broad view; it requires combining conceptual elements from different fields of natural and social sciences. Therefore, this thesis has used different concepts and analytical tools from the fields of agricultural engineering, economics, sociology and political economy.

\subsubsection{Organizing the conceptual framework and empirical data}

For analytical purposes, the complexities found in irrigation activities and their interrelationships will be divided here into several components. The first part will analyze collective action in irrigation systems, as the basis of shared water control activities that relate primarily (but not exclusively) to managing water in its different dimensions (regulatory, organizational, political, technical/operational). It is this collective action that structures and mobilizes the local irrigation institutional environment and animates the system's relationship with the state and other institutions. The second part of the analysis will focus more on households (individual family activities) as production and reproduction units, i.e. the peasant farm, since this is the "engine" where farming originates and in which the need for irrigation activities are created. These activities, related to farming and labor organization, are closely interlinked and are part of various livelihood strategies pursued by peasant families.

A main reason for collective action regarding water is to control it, not as a goal in itself, but to meet farms' water requirements in terms of quantity, quality and timeliness. It has close implications for water delivery and management, from the source to the field and, ultimately, implications for agricultural production and family life (Beccar et al., 2001). The subject of this study is to examine and understand how these "peasant dynamics", in both the community / group domain and the household domain, express collective and individual strategies to control water, and to control agricultural production and reproduction. Investigating these dynamics aims to scrutinize the various factors affecting water management and agricultural production, and in the end, peasants' livelihoods. In turn, these strategies manifest in different "directions" or, in other words, in a high degree of heterogeneity in agricultural practices and, therefore, in diverse "styles" of local development (van der Ploeg, 1985, 1990, 1994; Remmers 1998). Figure 2.1. helps to visualize some conceptual elements, which are further developed in this chapter but also illustrates the hypothesis and research questions that will be answered in the next three chapters. 


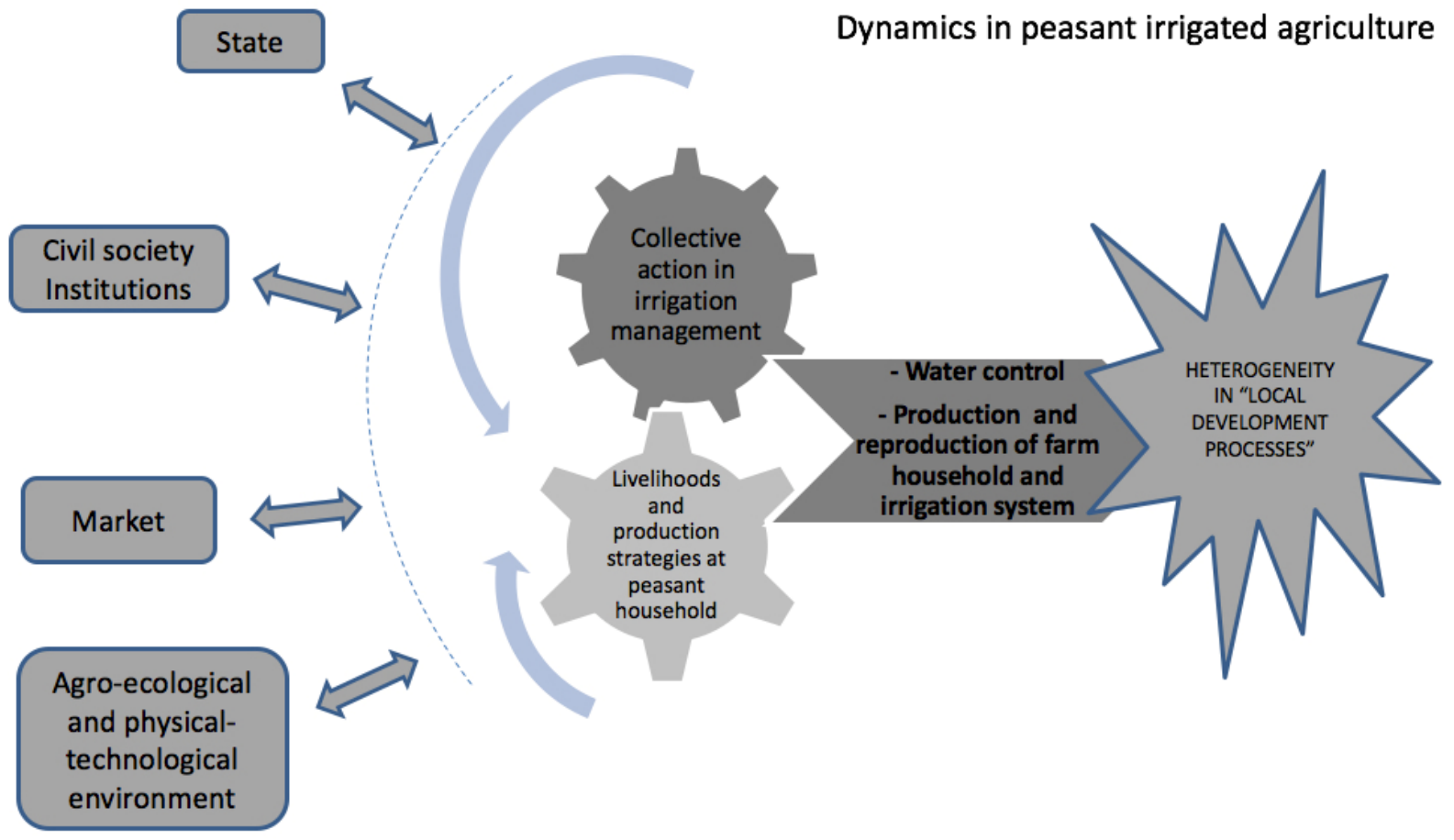

Figure 2-1. The study focus or study object

(Source: Prepared by the author)

\subsection{Collective action and social organization around water in peasant irrigation systems}

This section discusses some of the concepts and principles that underpin collective action and social organization, viewed from different perspectives. Then, after a brief discussion of academic literature analyzing situations of collective action in water management, especially irrigation, the concept adopted in the present study is summarized.

\subsubsection{The rationale for collective action and organization ${ }^{13}$}

Among the different approaches that address natural resource management, the influential group of perspectives labeled as "new institutional economics" associates collective action with economic rationality that is attributed to any individual using a resource. This rationality, manifested through cooperation, is understood as "transactions" between individuals within an organization. These "transactions" are usually explained as the quest to reduce risks or difficulties imposed by the environment and especially the difficulties of managing a common resource. Ultimately, this rationality entails reducing uncertainties and thus "transaction costs" involved in complying with norms (formalized if possible) governing the collective (water) resource management. Within this approach, organizations are conceived as "groups of

13 Throughout the text, the concepts of "collective action" and "organization" are used jointly and not as synonymous. It is considered, in principle, that tasks or activities carried out by an organization are supported by collective action, but not necessarily does all collective action involve the presence of (formal or structured) organizations. 
individuals bound by a common purpose to achieve objectives" (Ellis, 2000:38). Compared to state management, local organizations are seen as an attractive alternative, exactly because of the prospect of reducing these transaction costs (Ostrom, 1990, 2009).

Cleaver (2000: 363), Duarte-Abadía and Boelens (2016) and Roth et al. (2005), among others, argue against this approach of individual water control rationality motivated purely by economic objectives, suggesting rather different types of "incentives" or motivations that lead people to act collectively, while recognizing the predominance of this "pervasive functionalism" of neo-institutionalism, seeking direct causal explanations between motivation, behavior and resource management. An example of this causal explanation is the "rationality based on the logic of subsistence" attributed to rural people. Moreover, Beccar et al. (2001), Boelens $(2008,2015)$ and Suhardiman et al. (2017) suggest that collective action is based more on the need to work cooperatively to manage and control a resource such as water, whereby this need arises in various types of relationships of "interdependence" (economic, cultural, psychological, political, technological) between individuals or families and the organization (see also Boelens and Hoogesteger, 2017; Gerbrandy and Hoogendam, 1998; Verzijl et al., 2017). Families could not survive alone, reproducing their agrarian production cycles without establishing cooperative ties with other families or under the umbrella of a collective management of resources. On the other hand, community management "would cease to function without property relations that unite and motivate families to monitor and maintain their collective resources" (Guillet, 1995:3). Interdependence is understood, then, as a mutual need to cooperate.

Beccar et al. (2001) posed the following tasks or activities in which this relationship of interdependence is concretely manifested in an irrigation system's daily tasks:

a) Regulation and authorization. Grounded in creating water rights (expressed collectively and individually) and formulating, discussing and sanctioning rules and agreements.

b) Performance of operational tasks. That implies implementing and monitoring water distribution tasks, operating and maintaining infrastructure.

c) Internal organization. Mainly related to discussing the organization's functions, its objectives and coordination and planning of activities to be done, decision-making, and conflict resolution.

d) Reconstruction or readjustment of infrastructure.

e) Mobilizing available resources or those that the organization can access, including financial resources, products, equipment, infrastructure, internal or external resources, but also its own labor force and information.

f) Upkeep of social networks outside of the organization, to interact with the state, institutions, and development agencies or to represent and defend collective interests.

These tasks lead to two important aspects. The first is about the embeddedness of the communal and collective action in most irrigation activities or tasks. That is, it is impossible to conceive irrigation (in the Andes and elsewhere) as an individual activity. The second aspect is that all these collective irrigation activities are strongly linked to social relations established between members of the organization, starting by constructing infrastructure as the main mechanism to 
create water rights, expressed both individually and collectively (Boelens and Vos, 2014; Gerbrandy and Hoogendam, 1998; Gutiérrez, 2005). These tasks also reflect the diverse expressions of collective action to control different aspects of water management. Water control is just one of the central motivations for collective action. Moreover, these tasks also demonstrate organizational principles (see Boelens, 2015: 55), rooted in historical processes and the culture, specific to every particular (local) context and therefore expressed in very diverse forms of water management (Gelles, 2000; Guillet 1995; Lynch, 2012; Trawick 2001).

\subsubsection{Collective action, social cohesion and identity}

Interdependence relationships, as described above, seem to better explain the logic behind organization and collective action to manage a common resource, beyond just economic "incentives" or "utilitarian rationality" based on maximizing profits, by individuals within an organization. It would also be simplistic to assume that collective action and organization around water are grounded only on the needs or risks (physical or imagined) that are imposed on a region's inhabitants (Mosse, 2006). Without romanticizing collective action around a resource, Mayer (2002, quoting De la Cadena, 1989) suggests that many tasks that are performed collectively are organized, institutionalized and ritualized in order to create a sense of belonging to a social group; or of identity and "social identification" as discussed by Zwarteveen et al. (2005). This identity, as suggested by Montaña (2007), is not a given or essentialist attribute of a group, but is closely linked to the group's shared, dynamic history (Montaña 2007; Zwarteveen and Boelens, 2014).

There are different means, symbols, meanings or facts that contribute to "socially and historically constructing" these identities, which have a reciprocal relationship with collective action. This means that people act collectively to reaffirm identity, but that identity in turn motivates and energizes collective action. This is very visible and can be clearly verified in most irrigation systems. For example, constructing infrastructure represents a way to create water rights (property rights) and the constructed works, the effort and facts (and stories) of implementation will mark important traits of this collective identity or "sense of collectivity". It is therefore that irrigation necesarilly builds, and builds on, social and normative relationships. As Boelens and Vos (2014: 59) state: "Individual and collective water property rights are embedded (concretely) in infrastructure; therefore irrigation artefacts' social contents comprise operation and distribution mechanisms. Conversely, contributions to constructing and maintaining this infrastructure shape organizational and property relationships among these actors, a socio-natural and socio-technical process basic to constituting 'hydraulic identities' and 'hydraulic cultures'."

Other tasks or actions that are performed collectively, not necessarily related to irrigation, must be added, which often reinforce this sense of identity and organizational cohesion. An example is the community's work to build a school, a communal path or other "community duties": (non)compliance of these commonly have direct repercusions for membership and water rights and allocation practices within the collective irrigation system (Benda-Beckmann et al., 1998; Boelens and Hoogesteger, 2017; Gerbrandy and Hoogendam 1998). 


\subsubsection{Collective action as strategies of social recognition and empowerment}

Collective action both sustains and is sustained by present-day practices in Bolivian irrigation systems and peasant communities, and is often also motivated by different symbols and memories relating to specific historical struggles over water and other natural resources. Past injustices, or claiming ownership and defending collective interests against potential or present threats, may constitute an important source. These forms of collective action can take the form of water-based protests or demonstrations, marches and blockades in the streets, in the media, or shared action in different water governance decision-making arenas (see Bebbington et al., 2010; Hoogesteger, 2012, 1013a,b; Romano, 2016, 2017; Suhardiman, 2017; Verzijl et al., 2017).

Some collective action has been shaped over very long historical evolution, while others can be fleeting. These organizational mechanisms may or may not have a visible structure or organizational form (see Baud, 2010; Bebbinngton, 1997; Boelens, 2015). Collective action can manifest itself as happened in Bolivia during the "water war" and "gas war": in both processes, besides social protests, alliances were built with different sectors of society, with subsequent policy and political implications, reinforcing empowerment of previously marginalized sectors (Assies, 2003; Crespo, 2006; Perreault, 2006). Part of the strategic claims that were manifested in Bolivia from 2000 to 2003, besides recognition and defense of water access and management "uses and customs", sought to create a "history-based but new creative identity" for rural and indigenous presence in Bolivian society. That is, "uses and customs" and their vindication, were, among others, major symbols or icons that were used for that purpose (Andolina, 2012; Crespo, 2006; Perreault, 2005) and which constituted an important element of social integration (Bebbington et al., 2010; Escobar, 1995; Vos et al., 2006).

\subsubsection{Collective action and organization as a source of autonomy}

Collective action, cooperation and organization can be considered as a way for the group to gain autonomy, also for the families and individuals that make up the community (Guillet, 1995; Lagos, 1997; Mayer, 2002; van der Ploeg, 2008). Autonomy can be understood from different perspectives and expressed at different levels. These different perspectives, however, coincide in defining autonomy as the "desire for freedom" or to reduce (or remove) dependence on different factors, while trying to control them (Lagos, 1997; van der Ploeg, 2008). In the specific case of irrigation, this is directly related to control over water.

A basic understanding of the autonomy that an organization provides to its members in the Andean region is described by Lehmann (1982c) and Mayer (2002) in terms of cooperation interactions that are built from kinship (actual or ritual) within a community or between communities. Some authors discuss these relations, as supported by rituals and local institutions, as forms of domination and dependence. Lagos (1997), however, explains that this search for autonomy coexists as living together with relations of (inter-)dependence regarding resources such as land or water. This may involve peasant resistance to state control, thus 
giving, according to Mayer (2002), greater freedom to take on different tasks or risks. Long (2001a) expresses this, in terms of "room for maneuvre" that organizations and local institutions aim to obtain and proliferate. Bolivian peasant communities, and the families that constitute them, know that continued community existence - influenced by globalizing economy and multi-scalar politics - involves defending and expanding as much as possible this room for maneuvre. It is grounded in a collective identity, shared norms, and territorial control mechanisms, with physical-organizational boundaries (Boelens, 2015).

From the point of view of established irrigation organizations, the previous paragraphs argue for interdependence as one of the foundations around which collective action and the need for cooperation revolve. That "interdependence" is understood not in the sense of restricting freedoms for those involved, but rather as an opportunity, under certain conditions, to act together to regulate, manage and use water under principles and social codes that are known to, and to some extent can be "controlled" by the organization and its members (Guillet, 1995). This does not mean that (peasant) irrigation organizations do not experience uncontrolled situations, contingencies, dependence or injustices between different actors with different power. Rather, the search for autonomy, generated by the individual (family) and channeled into the collective, results in a number of strategies such as:

- The search for representation mechanisms (by different organized sectors of society) in political areas of the state to occupy new spaces of power and obtain management autonomy and social recognition (Albó, 2004; Bebbington et al., 2010; Crespo, 2006);

- Building partnerships with government organizations and development agencies to obtain direct benefits from "development projects" (improving infrastructure in the case of peasant irrigation systems) (Beccar et al., 2001; Hoogesteger, 2013a,b; Verzijl et al., 2017);

- Using (and organizing) the group's collective work (labor and knowledge) as the basis for "self-managing" their irrigation systems (Beccar et al., 2001; Boelens and Vos, 2014; Gerbrandy and Hoogendam, 1998; Suhardiman, 2017).

\subsection{Water control in the collective domain in irrigation systems}

Assuming that one of the most important objectives of collective action and organization in irrigation systems is to control water, at this point it is necessary to discuss this study's perspective regarding this concept. Irrigation water control in the Andean region involves more than solidarity - it is based on "obligatory reciprocity" (Boelens, 2015). Family units by themselves are unable to provide all of the social and material infrastructure required for water control. For this purpose, it is crucial that the community sets clear, shared limits and rules about belonging to, operating, and sustaining the system. Here, like any collective, irrigator collectives contain a diversity of families and individuals, who sometimes come into conflict with one another. As Boelens (2015) elaborates, they are however united by their intense mutual dependence to develop, use, and manage their shared resources. Thereby, the rights, norms, and rules that govern irrigation affairs are more than the sum of individuals' economic interests, rationally calculated, weighing up the costs and benefits of collective actions. 
Understanding collective and individual water control and use rights involves debunking the often dogmatic myths on which romantic, rationalistic, or economicist approaches are based.

In this study, water control is analyzed from the two domains discussed above: the collective ${ }^{14}$ or organizational domain, and the family or peasant production units. This intends to continually integrate or interrelate the different dimensions that may be present in water control activities, to analyze particular, contextrual situations. Different analytical elements to discuss water control as the core of collective action in an irrigation system relate to key activities such as water allocation and distribution, operation, maintenance, conflict management and constructing and rehabilitating the system -- all according to the rules (formal and informal) that water users have developed (Eggink and Ubels 1984). Mollinga (1998) argues for the need to distinguish analytically among the dimensions of technical, organizational and socioeconomic/political water control. Boelens $(2008,2015)$ adds to this the notion of the dynamic, continuous interplay of these technical, organizational and normative dimensions of water control, the ways these are linked by power relations, and the need to address them as intertwined and mutually constituting each other.

After combining these analytical elements and water-management activities and tasks as discussed in Section 2.2 (see also Beccar et al. 2001), this study identifies and discusses the three dimensions of water control. These three dimensions are defined by grouping technical or operational tasks, organizational roles and tasks, and regulatory or normative roles and tasks. This grouping is only an abstraction, an analytical exercise used in this research to understand the complexity of water control in irrigation systems, in both the collective and in the individual (household) domains.

\subsubsection{The technical dimension of water control}

The technical dimension of water control can be identified, starting from infrastructure design, construction, to the subsequent set of operational tasks that are implemented around (collective) water management and overall system functioning. For example, infrastructure operation (opening/closing gates at intakes and reservoirs), water distribution in the system (flow distribution), infrastructure maintenance and sometimes rehabilitating and constructing hydraulic works are some of the key operational tasks (Gerbrandy and Hoogendam, 1998; Gutierrez, 2005; Mollinga, 1998). Individual farms/fields' technical tasks consist of conveying or "accompanying" water from the diversion structure to the plot, and the array of ways to apply water to the soil. The technical/physical outcome of these practices materializes when a certain amount of water is applied to the field. These tasks have the role of "controlling" water

\footnotetext{
${ }^{14}$ In this study, the "collective domain" and "family domain" are distinguished for analytical purposes, as separate spaces or social settings. The former refers to the elements discussed about collective action and organization (interdependence and cooperation, identity, social recognition and empowerment) and the latter is the area in which kinship and affective relationships (actual or symbolic) prevail, and the unit where agroproductive work is organized: the peasant farm. These "domains" are distinguished and adopted here, in order to avoid using terms such as "levels" or "scales", which base their definition on structuralist concepts, which often make it difficult to define clear boundaries between them or that sometimes are associated with geographical scales or social or institutional structures that are not always well defined.
} 
through technical operations, resulting in physical aspects, such as flow rates from the source to the plot, irrigation times and frequencies. That is the physical expression of water supply, water infrastructure control at the system's different operational levels, and the result of this water supply (also in physical terms) as water available to the field/farm.

Besides the apparently purely technical (physical) criteria, actions and outcomes resulting from these tasks, from their design to field level water control, various authors highlight the need to also scrutinize the normative (e.g., prescriptive, often disciplinary) and political implications of such outcomes. They hint at the norms and prescriptions to control human behavior

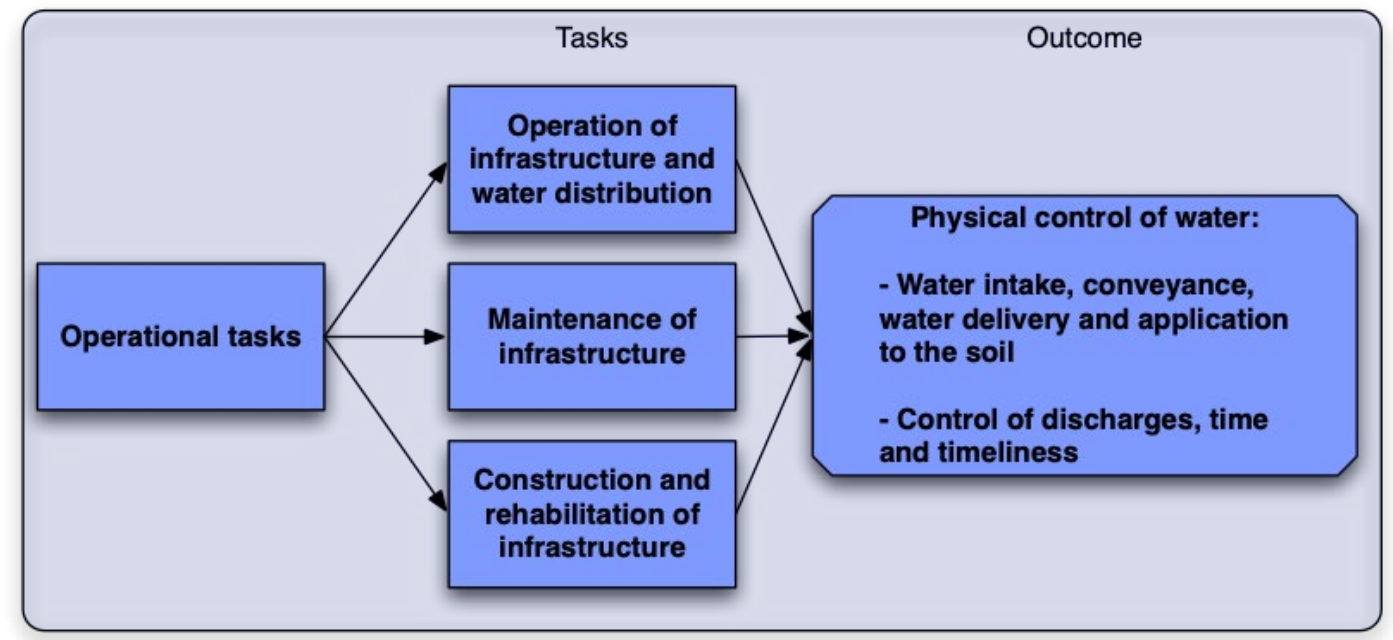

(Boelens, 2008a; Gutiérrez, 2005; Mollinga, 1998).

\section{Figure 2-2. Technical dimension of water control}

(Source: Prepared by the author)

Therefore, it is clear that, from a sociotechnical perspective, this technical dimension and the tasks involved are closely linked to the set of organizational tasks and to that of the regulatory (normative) elements of the system. All these elements or dimensions, in turn, are embedded in and influenced by culture, by the physical environment and by societal institutions and political relationships.

\subsubsection{The organizational dimension of water control}

Organizational tasks are expressed in different ways in irrigation systems. Some of these are linked, for example, to the group's internal organization, mainly its levels of coordination, planning and definition of its purposes, and its decision-making mechanisms (Beccar et al. 2001; Suhardiman, 2017). Other organizational tasks involve mobilizing the different types of resources that the organization has access to and can influence to achieve its goals. In addition to an organization's financial and capital resources, it is important to also consider its capacity to mobilize its "labor force". When speaking of labor, this is more than the physical effort required to perform tasks (e.g. infrastructure maintenance or construction). This study understands labor force as something inseparable from knowledge and skills, manifested as 
human capacities of different kinds (Bebbington, 1999) but also, collectively, as an expression of a "social force" (Eggink and Ubels, 1984). This social force is a key factor in the organizational dimension of water control, and can also be very significant for political negotiations. That is, the capacity to mobilize as an organization, will be a resource to negotiate (internally or externally) different aspects in tension, or explicitly and convincingly to show the organization's "strength" as an attempt to achieve different demands or manifest expressions of protest. Another group of organizational tasks involve water distribution or allocation. This plans and coordinates (organizes) water rights implementation in practice and is expressed in concrete water distribution tasks. Finally, irrigation organizations play a key role in managing water conflicts, either within or outside of the system. These different types of organizational tasks are ultimately attempts at "the regulation and control of human behavior, particularly in relation to forms of cooperation necessary to make irrigation systems work" (Mollinga, 1998:36).

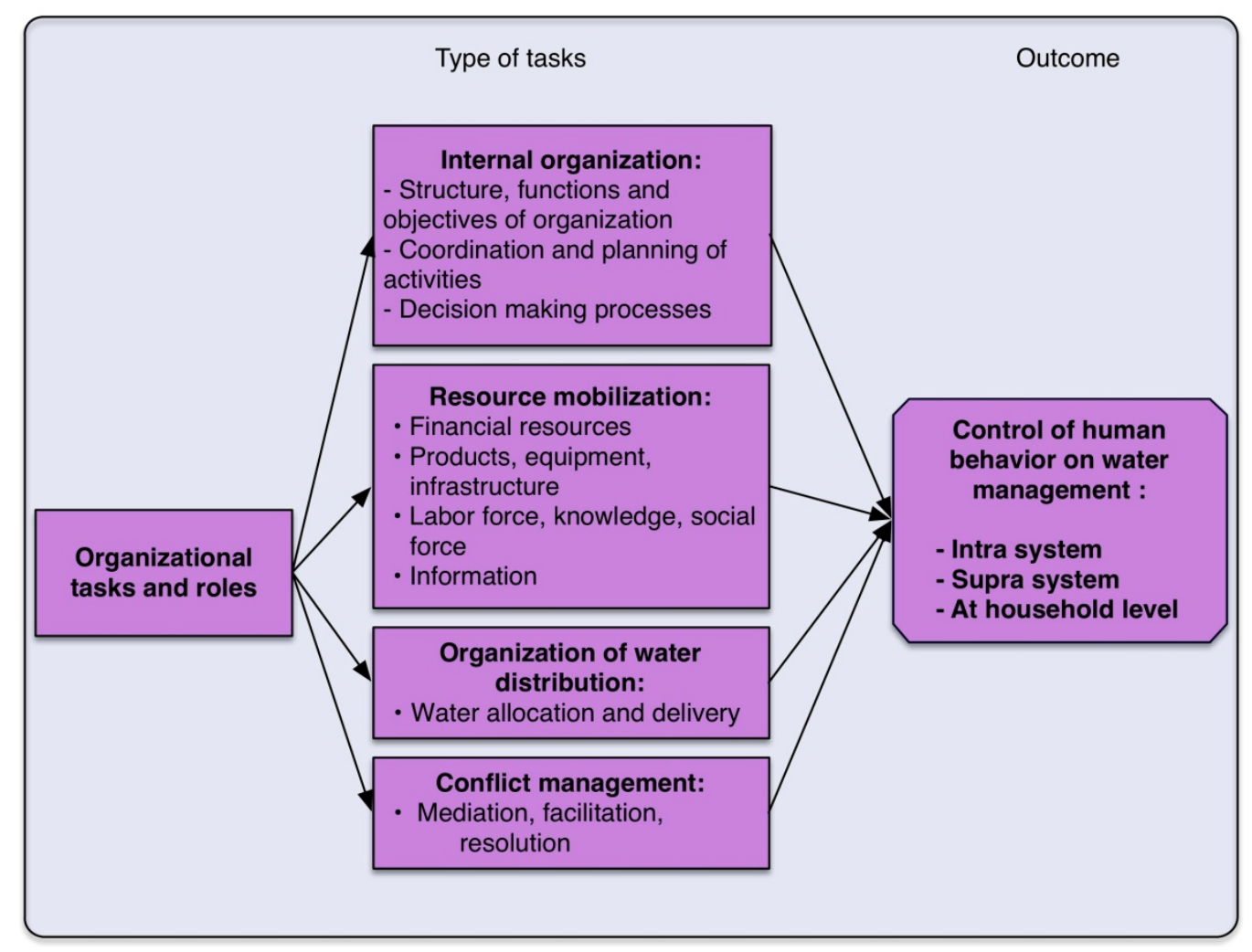

Figure 2-3. Organizational dimension of water control

(Source: prepared by the author)

Organizational tasks or roles can also be found in the family domain. These will be discussed in Section 7.3. under the concept of "organizing labor on peasant farms". 


\subsubsection{Regulatory and political dimensions of water control}

As water is a resource in constant dispute, water control becomes a matter of struggle, balances and imbalances of economic and political power. This not only occurs among members of an irrigation system, but also between different users or groups of systems disputing the same water source or demanding recognition or other concessions from the state. In this sense, water control involves "controlling people and their work" and controlling or regulating "social (and technical) processes" (Mollinga, 1998).

Boelens (2015), Roth et al. (2015) and Zwarteveen et al. (2005) suggest that water rights are a central element in regulating people and social relationships in an irrigation system. These rights are understood as "authoritative claims about the beneficial flow of a water source..." (Gerbrandy and Hoogendam 1998:113) that, based on social relationships, define who can and who cannot use water. They also further define irrigation infrastructure use and participation in management and decision-making, obligations and sanctions and defining criteria to resolve disputes about the scope and enforcement of those rights and obligations. These water rights may be grounded in different legal systems, formal and informal (Gerbrandy and Hoogendam, 1998).

Water rights in an irrigation system, and their relationship with organizational tasks and techniques, help analyze the political and normative dimensions of water control (Beccar et al., 2001). That is, these norms, rules and agreements seek to control people's behavior to organize collective work, how they comply with obligations and access the "benefits" of that work, penalties for not fulfilling these tasks, and how the infrastructure will be operated and maintained. This shows political and normative elements' close link and relevance to other operational (technical) and organizational elements of water control.

In Bolivian irrigation systems, these rules may or may not be formalized in the state's legal and institutional framework. They might be legitimized only within the user group or between them and third parties. However, these water rights and constitutional norms are not static or interpreted by everyone in the same way. Boelens (2008) and Zwarteveen and Boelens (2014), in this context, argue that to understand the dynamics of (collective) water management and its relation to water rights, a distinction should be made between:

- Formal rules, expressed as referential water rights;

- the way in which these rules and norms are supposed to be implemented, what they call "activated rights" (or "rights in action"), and

- the rules as they occur in practice ("materialized rights").

Considering these different expressions of water rights, and how they are being shaped, interpreted and materialized, helps understand the relationships between organizational and operational tasks, and formal and informal rules. It also enables understanding the influence of power relations and culture on how collective water management is put into practice and continually recreated. 


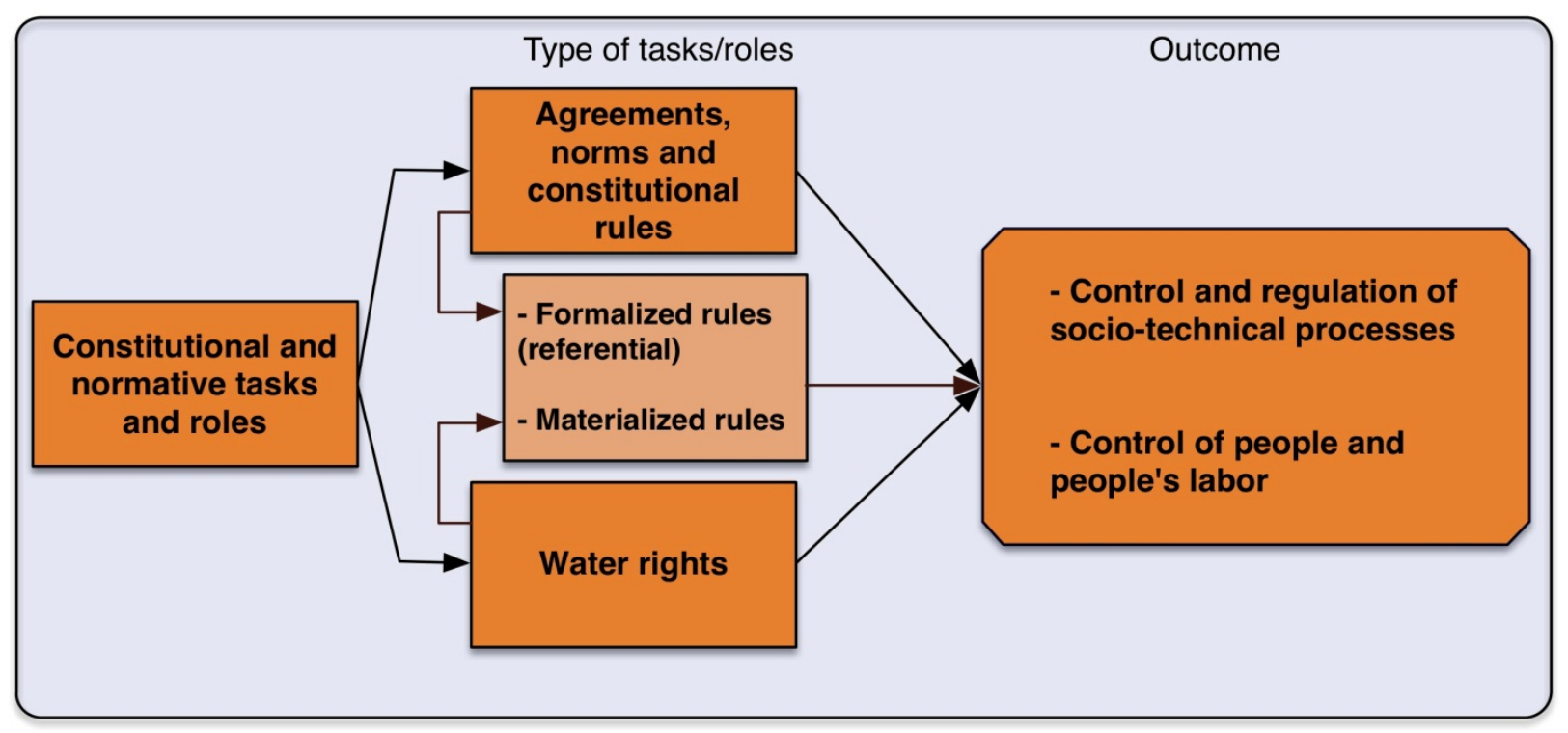

Figure 2-4. Regulatory and political dimension of water control

(Source: prepared by the author)

From the discussion in the last three sections, the concept of water control can be summarized as follows (see Figure 2-5):

Collective water management implies various activities and tasks in which water organizations play different roles. These tasks, which for analytical purposes can be classified or grouped into technical, organizational and regulatory, are considered closely interrelated and therefore should be treated simultaneously. These different tasks and roles are influenced by the context - civil society institutions, the state, the market, culture and the agro-ecological and physicaltechnological environment - and are being continuously modified and readapted according to contextual changes and power relations. Peasant irrigation systems in Bolivia are managed independently by users' organizations, with their own rules and regulations; however, these rules and regulations may change according to environmental changes, state interventions through infrastructural projects, changing relationships and agreements between irrigation systems that share the same source, new agreements within the system by modifying the water rights framework, or new water demands for agro-production. This in turn may provoke changes in infrastructure operation, maintenance requirements, water flows, distribution rules, etc. 


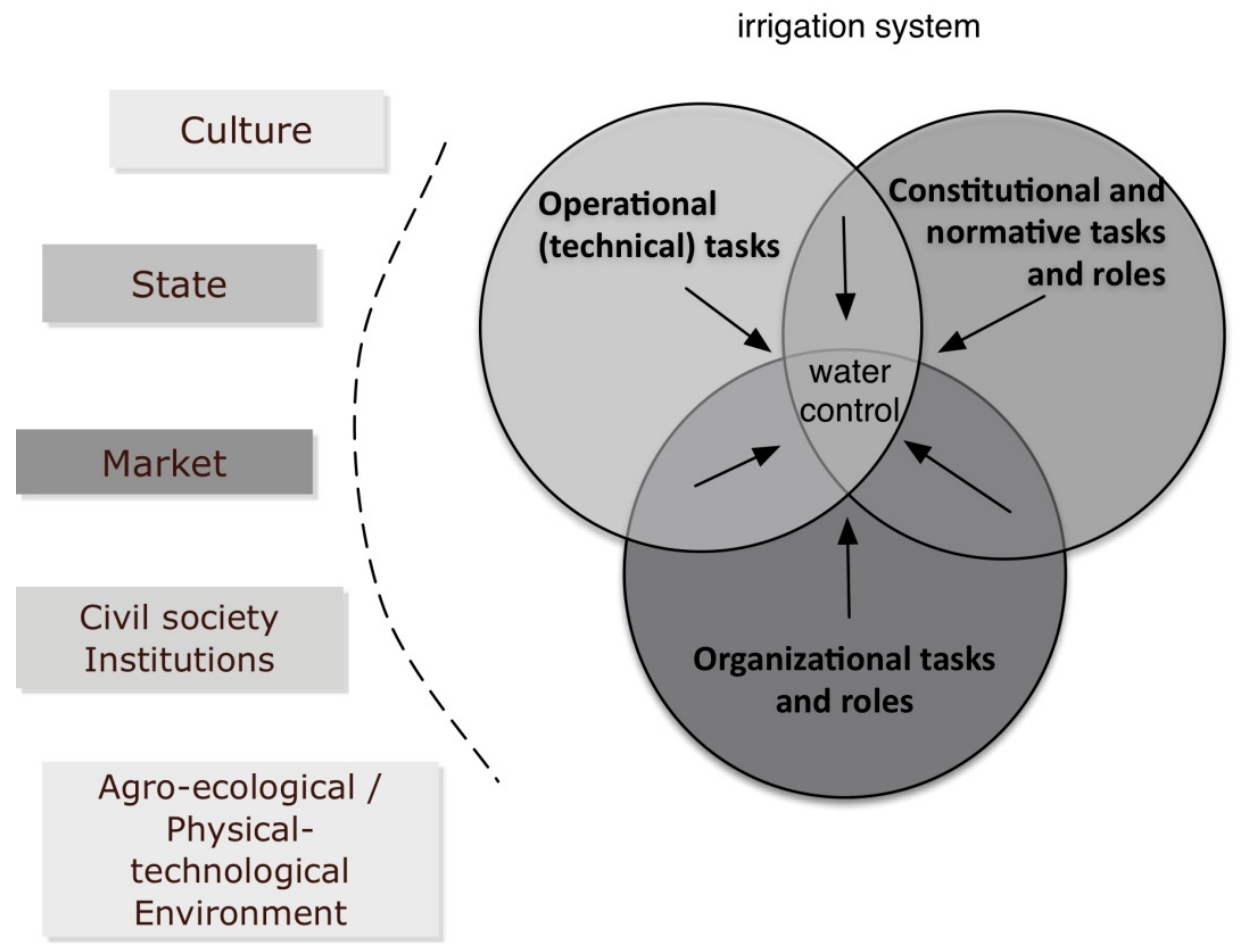

Figure 2-5. The multidimensional character of water control in irrigation systems

(Source: Prepared by the author)

As a result of these tasks, activities and relationships, the different dimensions involved in water control can be identified and expressed, for example:

- In physical terms, as available water at the farm level, as a result of materializing water rights and water supply and infrastructure characteristics.

- As control of labor and collective action, defining the time, space, intensity or rhythms and forms of collective work.

- As a relationship with work organization by peasant farms and outside of them. This influence will occur not only because collective work demands (or competes with) individual or family labor, but also because of the direct effect on the availability of water, which defines the "degrees of freedom" or production conditions in which a family runs its farming system.

\subsection{Water institutions and institutional processes}

This section discusses some concepts that will help understand institutional development of irrigation in Bolivia (Chapter 3) and its interface with water control and peasant community dynamics. 


\subsubsection{Perspectives and approaches for institutional analysis}

Following up on the discussion on "collective action"in 2.4.1., four main groups of studies or approaches are scrutinized that are common to find in water control studies that analyze institutional development: new institutionalism, an approach on common-resource management (common-pool resource management), an empowerment approach and finally an approach called "post institutionalism" by Cleaver (2000) and Mehta, Leach, and Scoones (2001).

New institutional economics (new institutionalism) is an approach that has its theoretical foundations mainly in neo-classical economics. It assumes that human behavior is grounded in individuals" "economic rationality", and that they seek to maximize profitability (costs and benefits) in all actions or choices they make (Seemann, 2014). It considers that natural resource use and management can be improved and therefore made more "efficient" by creating incentives through markets and institutions, minimizing or controlling any kind of "externalities" (unforeseen factors and outcomes). A key element is formalizing or legally incorporating water rights into the normative and administrative system and creating mechanisms to "facilitate market-based water allocation..." (Saleth and Dinar, 1999: 30; Duarte-Abadía and Boelens, 2016).

This makes it essential to create and formalize institutions that define the "rules of the game" and "reduce uncertainty by establishing a stable structure for human interaction" (Ellis, 2000: 38 quoting North 1990:6). Institutions are then understood, as "the formal rules, conventions and informal codes that comprise restrictions on human interactions..."(Ellis, 2000: 38). They are designed as "...entities defined by a configuration of legal, policy, and organizational rules, conventions, and practices that are structurally linked and operationally embedded within a well-specified environment" (Saleth, 2004:3). That is, institutions structure organizations and their socio-economic, political, cultural and environmental contexts (Saleth and Dinar, 1999). As economic criteria are the core of this approach, cost recovery, accountability, and financial autonomy are leading concepts (Roth et al., 2015; Seemann, 2014).

Common Property Resource Management (CPRM). Although often largely based on the previous approach, CPRM emphasizes local institutions' potential to efficiently manage common-pool resources (Ostrom, 1990, 1992) and therefore the importance of local forms of regulation, cooperative behavior, and collective action. It is assumed that regulatory mechanisms and cooperative behavior can be designed in collective resource-management systems. A central concept within this approach is "property", recognized as social relations between people who have "the right" to use and get benefits from using a resource or goods, versus those who do not have that right (Seemann, 2014). From this perspective, managing common resources implies rights to use the resource but also obligations or responsibilities and procedures regarding its management (Boelens et al., 2010). An important argument to sustain this approach and promote it as a model for a sustainable (water) resource management is that, since local people depend on natural resources for their livelihood survival, there is a strong incentive to conserve the resource (Seemann, 2014). 
As part of this approach or model, it is common to see that some "design principles" are proposed, assuming that "robust institutions" are established with "clear rules", based on "welldefined" property rights, on "well-established" boundaries and roles for the organization, with effective sanction mechanisms that prevent abuse of the resource or non-compliance with norms, and create financial mechanisms that are assumed to ensure efficiency and accountability (Ostrom 1992). The most widespread expression of this global approach, as a recipe for the water sector, has been to form water-user associations that are considered as "appropriate instruments (policy instruments) ..." and "...an innovative institutional arrangement" to implement water reforms (Bromley et al., 1980:381).

This approach and especially its design-oriented focus, has been questioned by several authors (Mayer, 2002; Mollinga, 1998; Roth et al., 2015; Zwarteveen and Boelens, 2014), arguing that it may not be applicable in many cases due to the complexities of collective action to manage a common resource; communities' non-homogeneity and non-unity (in terms of interests, socioeconomic differentiation, culture etc.); excessive focus on locality, neglecting localregional-national-international relationships and influences; and overlooked power relations (Cleaver, 2000; Duarte-Abadía and Boelens, 2016; Roth et al., 2005; Seemann 2014; Steins et al., 2000).

The empowerment approach emerges as a direct reaction to the "new institutionalism" approach, suggesting that the latter neglects injustices, inequities, favoritism, etc., which are present in any form of management and access to natural resources. This approach considers institutions, seen as rules and regulations, as dynamic processes in which different interest groups meet, confront and negotiate to include their ideas and interests in a system's organizational, technical and normative design (Boelens, 2015; Gelles, 1994). For irrigation, although interest groups can be part of the same user group, it is necessary to identify the explicit and implicit interests of "external" parties that intervene in irrigation design. Basically, empowerment through participation must come "from within", manifested as self-mobilization and creation of autonomy (Boelens, 2015; Suhardiman, 2017; Verzijl et al., 2017).

This analytical approach focuses, among others, on two angles: (1) the regulatory complexity of governing access to resources, reflected primarily in culturally and politically embedded property rights, and (2) power relations, expressed at both the individual and collective level. Different from neoinstitutionalism conceptual frameworks, where law is seen as an overarching key issue because of its supposedly mandatory nature as a safeguard for social relationships, determining most interaction among people, natural resources and state, on the contrary, empowerment approaches consider the law not as something that is "absolute and unequivocal". Law is part of a broader regulatory complex, as a "social resource" (Roth et al., 2005). Law is hybrid and is subject to the different interests, options, limits, dilemmas and choices that are played out in societal arenas. It is deployed as a part of the strategies that people develop to achieve their goals. It is this normative complex that shapes so-called "legal pluralism". Under the perspective of legal pluralism, law is not recognized as the exclusive prerogative of the State. Rather, it is recognized as social practices that shape local and national 
standards forming a group of co-existing and mutually interacting regulatory frameworks (Benda-Beckmann et al., 1998).

Regarding (water) institutions' power relations, Roth et al. (2005) argue for the importance of examining these relationships in policy decision-making but also in actual control over water and other associated facilities in the field. Unlike the neo-institutional approach, which considers relevant financial mechanisms as the basis to create "accountability", the empowerment focus highlights the political mechanisms that are generated.

The post institutionalism approach focuses on social behavior dynamics and the way institutions are constantly shaped and readapted by collective action. Therefore, forming institutions is re-conceptualized as a socially-integrated process, rather than a deliberate, transparent administrative activity (Cleaver and Franks 2005). Such a vision requires different levels of analysis, starting from family or group-level institutional arrangements or agreements up to agreements within irrigation systems or within municipalities and the river basin. A key concept in this approach is "institutional bricolage" (Cleaver and de Koning, 2015). The approach conceives institutions not as static or "robust" structures in which it is assumed that human behavior is rather rigidly defined. Rather, institutions are conceived as an overlay (bricolage) of different rules, social norms and power relations formed by continuous collective action and resulting in a variety of agreements at different levels. This argument refutes the possibility of "designing institutions from outside" and especially making institutions that are expected to be "permanent and stable", as proposed by Ostrom $(1990,1992)$.

Based on the concepts introduced by Boelens (2015), Cleaver (2000) and Mehta et al. (2001), and contrasting them with the ways in which institutions have been shaped in Bolivia and especially around water, it is important to consider the following elements of analysis:

- The dynamic (not static or fixed-structure) character of institutions, because they are immersed in sociopolitical processes.

- The importance of considering confrontation and negotiation of ideas and interests, mediated by power relations, in shaping institutions.

- The importance of historical processes and diversity of cultural repertoires, of meanings, rules and identities that come into play.

- The multipurpose nature of institutions.

Finally, by considering that institutions are neither fixed nor developed in static socio-political and environmental contexts, but rather uncertain, requires us to consider uncertainty as another important element for institutional analysis (see also Cleaver, 2018). Uncertainty, in turn, motivates people to develop collaborative strategies and/or use different institutional repertoires (legal and institutional shopping, as suggested by Zwarteveen et al. 2005). 


\subsection{The agro-productive domain in peasant irrigation systems}

This section focuses on the domain of peasant farms or household agro-productive units. It discusses analytical elements that can be utilized to discuss peasant dynamics in houshold resource management, how this is linked with the collective domain, the significance of water control and its relationship with localized expressions of agrarian systems.

\subsubsection{Peasants and peasant agriculture}

Peasant agriculture has been studied from different theories and approaches. Most tend to separate it or differentiate it from entrepreneurial agriculture, based on some key features, typical to both, or sometimes based on what they are supposed to be. Some of these approaches, on the contrary, tend to define what peasant agriculture is not or cannot achieve in comparison with modern entrepreneurial agriculture, as if the latter were the only ultimate goal to attain.

There have been two main groups of approaches. Within the first, Marxist currents analyze peasant economy as part of a larger economic system, linked to broader social processes and regulated by "social relations of production." These approaches concentrate on politically analyzing these relationships in terms of labor-force exploitation and transference of surplus to a ruling class. The second group, neoclassical approaches, analyze peasant agriculture from an individual level, from the economic rationality of maximizing returns by maximizing productivity and reducing costs (Lehmann 1982a, 1980; Ellis 1998, 2000).

These theoretical discussions reveal a "scale" or "continuum" of conceptions and judgments about peasant agriculture. At one end are those who consider it excluded from the global economy or in some respects subordinate to the capitalist system (and to capitalist ruling groups) and therefore doomed to disappear (Kay, 2006). These approaches often say that these farms are operated "... almost devoid of capital and technology" (SOS FAIM, 2004:2). Approaches at the other end of the "scale" claim they survive and reproduce, because of their non-capitalist production relationships. Others take a more "transitionalist" approach, arguing that they are in a sort of transition from "primitive" to "modern" forms of production, progressively constructed on market relations (Lehmann, 1982b; Mayer, 2002).

These and similar approaches have also been adapted for the Andean region, influenced also by currents of economic anthropology, and others that could be called indigenist or "Andeanist" approaches. The latter describe peasant agriculture as a core activity of life in the Andes, expressing this notion (often in romanticized ways) as "Andean agrocentrism" (Grillo, 1993; PRATEC, 1996; Valldolid, 1994). Some authors explain this agrocentrism and "Andean cosmovision" by the close relationship of the Andean human community with the natural environment and its intangible world of deities. This relationship is manifested concretely in the "peasant field" (la chacra campesina), which is the center of life in the Andes. One of the principles that this approach proposes is the reciprocal interplay between these three domains (humans, deities and Nature) and diversity and heterogeneity as predominant features (Valladolid, 1994). 
In this section, peasant agriculture is approached with several analytical elements considered central to understanding what was identified as the focus of this study: "peasant dynamics". The unit of analysis will be discussed, including its key features (Section 2.7.2). Section 2.7.3 introduces the concepts of peasant strategies and styles of farming, as analytical categories to understand peasant agriculture, its dynamics, and its expressions as localized patterns of agrarian landscapes.

The unit of analysis in peasant agriculture. Production decisions - about what, when, how and what for - in peasant agriculture are made within the family production unit. Different approaches raise different theoretical elements of how to conceive this production unit (see Ellis, 1998; Golte, 1980; Lehmann, 1982b; Mayer, 2002) and the analytical possibilities of linking peasant agricultural production with the national economy, or to attempt to explain this unit's functioning or internal coherence.

For instance, approaches based on "hard" systemic models conceive the peasant production unit as a "black box" converting inputs into outputs, looking how to value the economic implications of that process. Others focus more on individual behavior, looking to attribute or assess this unit's economic rationale for optimizing resource use to maximize profits and cash flow. ${ }^{15}$ From these neoclassical economic approaches, (peasant) families are conceived as purely economic units, void of any socio-cultural or political link with the broader context. Under this perspective, production functions (equations) are perceived as a faithful representation of production and technological processes, however, issues such as family labor and consumption within households are unresolved aspects. These however, paradoxically, constitute the essence of peasant farming units (van der Ploeg, 2008). Other studies focus on cultural and social elements embedded in production processes, for example on kinship and authority governing those processes (Mayer, 2002; Sanchez, in Lehman, 1982).

This study summarizes the following elements and arguments to define the "peasant family production unit" as the crucial unit of analysis:

- It is a unit based primarily, but not exclusively, on blood or ritual kinship. According to the context of the cases analyzed, this defines some flexibility between the "nuclear family" and the "extended family". According to their own dynamics, sometimes families move between these limits, without an absolute division (Mayer, 2002).

- Access to land is defined by various mechanisms that may coexist simultaneously. These may be based on collective agreements and communal norms, or on individual property regimes, which may or may not be officially recognized by the state. These property rights, or other forms of access to land are attributed to an individual (usually the man or "head of household"), sometimes to various family members (e.g. through hereditary succession to

\footnotetext{
${ }^{15}$ Mayer (2002) discusses the weakness of neoclassical approaches in sustaining the logic of individual economic rationality to analyze peasant agriculture, for example in understanding flows of goods and services based on commercial and non-commercial relations and also analyzing energy flows in various productive areas.
} 
the wife and husband), or to the entire family unit. Despite access or tenure mechanisms, land constitutes a key factor (not only a quantifiable asset) to mobilize labor, water, knowledge and other interlinked resources around peasant agriculture (Zoomers, 2001).

- It is the household production unit where production decisions are made about what, how, when, where and what for. Besides, this is not only a production unit but also a consumption unit, where products themselves have both a monetary exchange value and an important use value (Boelens, 1998).

Therefore, contrary to a capitalist entrepreneur, Andean peasants see their household as a production unit that is strongly related to their home and consumption unit: the market logic of decreasing marginal benefits cannot be applied as in a commercial enterprise, because peasants face the need to satisfy household necessities. In times of crisis, (low prices, low rewards to labor), the peasant family increases its labor efforts instead of decreasing them as would the capitalist enterprise. It also means that peasant irrigation systems always try to find a balance between production for self-consumption and for the market, and that the user organization cannot and should not be structured in a similar way to purely mercantile organizations. The often made distinction between 'domestic' and 'productive activities' generally blurs, since they combine and overlap, and boundaries tend to be very fluid or not even existent. Contrary to static presentations, Andean peasant households and communities are not relatively closed, corporative units of consumption and production, but highly dynamic, transcultural and even transnational migrant entities. In other words, reference to the peasant family as the unit of analysis does not intend to isolate it from the larger context in which it operates, but rather, to understand its dynamics and relationships with the communal context, socio-cultural repertories, and the broader economic context.

Indeed, the Andean peasant household (and peasant economy) expresses itself in relation to specific interactions and relations of exploitation between peasants and social groups in the wider society. It is characterized by a variety of mechanisms of unequal exchange. Andean peasant households are neither autarchic nor self-sufficient, but interwoven in the commoditized/mercantile and community/non-mercantile spheres of production, reproduction and consumption (Boelens, 1998; Boelens and Hoogesteger, 2017; Golte and De la Cadena, 1983; Zoomers, 2013).

\subsubsection{Multiple dimensions and key elements in the analysis of peasant agriculture}

Based on this study's focus and unit of analysis, as discussed in Section 3.1 and in this section, "peasants" and "peasant agriculture" are defined by the interplay of three dimensions that are merged into this concept: the peasant as a sociocultural identity; the peasant as a condition and way of life; the peasant as a way to produce, or do agriculture. Understanding these three dimensions simultaneously helps to explain rural logic and life, beyond economic or only cultural concepts. 


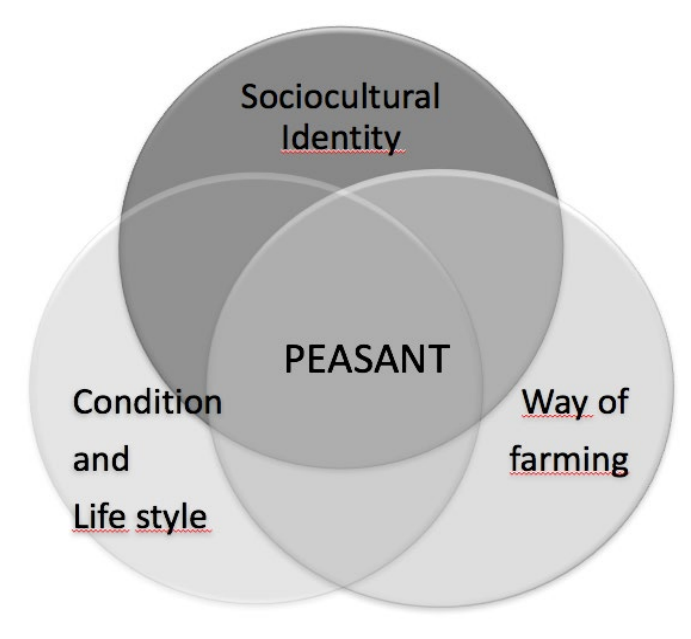

\section{Figure 2-6. Peasant as a multidimensional concept}

Source: Prepared by the author

It is necessary to argue that these multiple dimensions are usually intermixed and expressed, some more strongly than others, in different areas of Bolivia, according to the historical process and the socio-political context. This forces us to take them simultaneously when analyzing rural dynamics and changes.

\section{The peasant as a sociocultural identity}

When we speak of the peasant as a sociocultural identity in Bolivia, it is important to highlight the historical process constructing this notion. Several authors agree in identifying the formation of this identity from claims and struggles for liberation from forced labor to which (primarily) mestizos and indigenous people were subjected through the hacienda regime (during and after the Spanish colonial period), and also from claims for access to land (Albó, 1987a; Dandler, 1984; Larson, 2000). During the colonial period and even the first century of the republic, a "peasant identity" was almost nonexistent, as there was a marked separation that segregated rural inhabitants, natives and mestizos from the rest of society as "Indians" (indios) (Albo, 1987a).

Only from the 1930s up to the national revolution in 1952, such social claims were gradually accentuated, strengthening peasant-class identity. So in 1953 land reform was popularized under the slogan of "Land to the Workers". This new identity was consolidated collectively as agrarian unions or peasant communities, based on its initial cell, the peasant family. At the same time, this social identity was reinforced by cultural elements such as language, physiognomy, and customs in different regions of the country. When land reform was implemented, farmers became visible as an important rural social sector, concentrated mainly in the west of the country, in the Andean region (Dandler, 1984). That was different in other rural communities, such as indigenous groups from eastern Bolivia's lowlands (which were distinguished more for their ethnicity). 


\section{The peasant condition as a way of life}

When speaking of peasants or of "the peasant" in the Bolivian context, this study also refers to a way of life in the countryside (e.g., Zoomers, 1998, 2010). This way of life is often characterized, from an urban perspective or modernity, as a limited life context of "dependence, marginalization and deprivation" (van der Ploeg 2008:23). The condition of peasant life features several aspects:

The lifestyle is based on meeting basic needs, where comfort, urban models or lifestyle may or may not be present. Communication facilities such as cell phones, television and radio are becoming increasingly common. However, other welfare standards and comforts such as "adequate" housing, provision and use of basic services (potable water, sanitary toilets, showers, health services, etc..) depend on the culture, facilities and public policies to access to these services, the family's available resources, their life cycle, access to information and contact with other realities (Le Grand, 2014). In short, we can say that it is a "modest" lifestyle, where the priorities are food, maintenance, and reproducing activities in the household and on the farm (Mayer, 2002).

Van der Ploeg (2008) proposed as a central element of the peasant condition (and lifestyle), a constant struggle for autonomy. In the case of Bolivia, before agrarian reform, in addition to the struggle for social recognition, a key demand was to access land and abolish tributes to landowners. This was an important step, an initial emblem to achieve autonomy, to have control over land and over their own work. Lagos (1997:182) however mentions the peasantry's vulnerability "...against new forms of domination and exploitation". This is increasingly addressed through alliances and political struggles to upscale and reach new "spaces of power" during different government regimes.

The quest for autonomy is evident in the agro-productive domain and daily life, through the different strategies used to control or access inputs or production factors or other family needs, employing practices of reciprocity, ritual relationships, share-cropping, borrowing money, temporary migration and others. These strategies however, in an apparent paradox, are seen by other authors as "relations of dependence" to achieve autonomy (Lagos, 1997; Mayer, 2002). At the same time, striving for autonomy also means reducing dependence on different factors restricting rural possibilities to produce and reproduce life. One of these factors, as discussed by van der Ploeg (2008), is markets. Relationships in practice are dynamic and constantly changing and establish various types of exchanges. In some commercial relations prevail, in other cases they are based on social relations not mediated by money.

The relation of the rural inhabitants with the land and with nature is another important feature of the peasant condition and peasant life. This obviously is basic to in agricultural activities (agriculture, livestock, forestry, processing products, crafts), accessing and managing natural resources and organizing production, mechanisms which in turn build social relationships and cultural expressions. All this is presented by van der Ploeg (2008) as expressions of "co-production". Important feature here is, in many cases, the interconnetion of humans and huge biodiversity. For instance, an outstanding feature of rural life in many 
Andean communities is "verticality", managing diverse ecological tiers where different resources are accessed and managed. Hereby, social relations are established and cultural expressions, knowledge, information flows, services and supplies are re-created through agroproductive strategies (Boelens, 1998; Lehmann, 1982; Mayer, 2002).

The resource base available to families is another important element defining the condition of peasant life. These resources are based on family labor, land, water, seeds and plant materials, animals, tools and machinery, money and other items. These resources are generally limited, change along a family's life cycle (Le Grand, 2014; Zoomers 1998, 2010, 2013), and are combined in the labor process in different ways and in different combinations and types of exchange with the external environment (e.g. the market), defining thus different "farming styles", as proposed by van der Ploeg (2008), or "pathways" as framed by Le Grand (2014). The resource base, under different circumstances, can be used directly in production, can be stored for future use, or be traded or eventually sold or exchanged. This means that families' resource bases "are not only converted into a range of goods and services, but they themselves are reproduced as resources" (van der Ploeg, 2008). This constitutes an important difference between peasant farming systems and agro-business enterprises. In the latter, there is a clear division or distinction between inputs or production factors and products. The former are generally acquired from the market and the latter are produced in order to then be sold through the market. This range of farming resources simultaneously enters into productive and reproductive spheres, an essential feature of this form of production, which will be discussed later.

Cooperation and collective action, as already discussed in Section 2.4.1, is another important attribute, characteristic of the peasant condition and lifestyle, particularly in the Andes. There are various reasons for this type of action, whether as a way to cope with "hostile" natural or social environments, or as a condition for mobilizing "social force" to manage a particular resource. They are also important strategies to access otherwise nonexistent or limited familybased resources (labor, land, water, etc.) or finally as a set of actions based on kinship ties or cultural identity, which in turn reinforce peasant identity. The clearest manifestation of these forms of cooperation and collective action is present in various forms of rural organizations: in Cochabamba's valleys' agrarian unions, peasant communities and irrigation systems. While the peasant organization is where social relations happen (cooperation and sometimes conflict), it also constitutes the framework, which sets certain standards of conduct and actions for the community, on which families base their actions. In short, collective action, as discussed above, may constitute the area in which they develop cooperative relations and interdependence, it represents an area of social cohesion and identity, it constitutes an important mechanism of social recognition and empowerment vis-à-vis the rest of society and the state, and it can also be an important source of autonomy.

Finally, another crucial feature shaping the peasant condition is pluriactivity. Farmers are involved in different types of activities, such as wage labor (agricultural or non-agricultural, rural or urban) and providing services such as transport, handicrafts, trade, and others (Le Grand, 2014). These activities may change over time and also have a spatial dimension. These 
different activities tend to supplement family income to meet their needs, but also enable investments in agricultural production activities (Ellis, 2000; Mayer, 2002; van der Ploeg, 2008). Several authors discuss the results and implications of pluriactivity in different ways. Some argue that combining agriculture with other farm activities can lead to "depeasantization", i.e. progressive disappearance of the peasantry, especially for small farmers (Colque et al., 2015; Kay, 2006). Others argue that, due to the mechanism of income diversification, peasants will always exist (Figueroa, 1981). According to this view, more emphasis should be put on peasants' resilience under different circumstances, and on their farming strategies' great flexibility, including the use of new opportunities to enhance their livelihoods and farming (Bebbington, 1999; Le Grand, 2014; Zoomers, 1998).

\section{Peasant agriculture as a form of production}

Peasant agriculture, closely interwoven with the peasant condition, as explained before, has some characteristics that differentiate it from other forms of agricultural production, such as entrepreneurial agriculture. Van der Ploeg (2008), discusses several of these features:

One of the most important features is the centrality of (family) labor on the farm. Family work involves not only labor (physical force) as such, but also entails knowledge behind every action in the labor process (van der Ploeg, 2008). Family work includes spatial and temporal organization of the different activities that family members perform in an agricultural cycle, possibly combined with hired (paid) labor which can be done through various social relations of production or reciprocity such as share-cropping, the "ayni" and "minka" (reciprocity practices), and others (Lehmann, 1982). Labor organization implies therefore control over the labor force and the work rhythms or cycles, and over knowledge and skills.

The centrality of work on the farm also demonstrates yet another important feature of peasant production: labor-intensity in agricultural production. It is recognized in general that peasant production practices tend to use large amounts of labor, especially in the work of planting and harvesting. Mayer (2002) discusses various expressions of peasant labor-intensity. In principle, the difference between the intensity of land use and inputs according to the output destination, show a relationship (though not exclusively) of higher-intensity products primarily for market and less-intensity products for self-consumption. Anyway, regardless of products' destination and land-use intensity, peasants use large amounts of labor, family or hired labor, which may change in quantity and quality according to crops, from one year or cultivation cycle to another, or according to production systems' complexity as a whole. In turn, this intensity of field work is highlighted by several authors as part of a peasant rationality of maximizing return or the value added to work (Le Grand, 2014; Zoomers, 1998).

The fact that productive and reproductive domains are mediated by market and nonmarket relationships is one of peasant production modes' salient features. Peasant agriculture is immersed in two inseparable areas: production processes as such, but also reproducing family work and resource base. Van der Ploeg (2008) suggests this relationship between the productive and reproductive domains across three fundamental processes of agriculture: mobilizing resources, converting resources into finished products (production itself), and sale 
or reuse of products (van der Ploeg, 2008:28). He emphasizes that market relations increasingly mediate these processes, though it is possible that each has a different relationship with the market, being an important feature of variability over time. This link with the market (through monetary exchanges or links to local institutions that generally prevail in trade and flows of goods and non-monetary services) can be visualized in various activities and with respect to each of the resources and inputs involved in production. For example, work inputs such as seeds, fertilizers, manure, or final products or derivatives from animal husbandry or crop harvesting come in different ways and in different proportions in circulation in market and nonmarket spheres (Bradby, 1982; Mayer, 2002). Different forms of integration with the market or community or local institutions, in turn constitute a strategy to control their resources and therefore achieve autonomy (Golte and De la Cadena, 1983; van der Ploeg, 2008).

Diversification in agricultural production. Finally, another feature of peasant agricultural production, demonstrating the peasant pluriactivity but this time expressed in farming, is diversification. In general, it can be said that peasant agriculture tends to diversify production by planting different crops, breeds or by processing products from these crops or livestock. As discussed below, this feature can be understood in turn as an answer, or risk coping strategy against different and/or insecure biophysical factors, or factors related to reproduction and family needs or in response to the market. Fundamentally, peasants seek to be employed in a variety of productive activities since it is impossible within subsistence agriculture to guarantee survival when engaging in only a few activities of marginal output. Diversification is sought both within farming itself (e.g., agriculture, animal husbandry, forestry, market and domestic consumption, irrigated and non-irrigated crops, crops at several ecological altitudinal zones, associated crops, paid labor in the hacienda's irrigation and non-paid labor in the community's system) and in non-farming activities (marketing, handicrafts, temporary migration, etc.). In the domestic unit the available work force is divided among the diverse activities. Furthermore, diversification also relates to space and time: the household activities are not necessarily carried out in the same space (this is, the peasant holding), nor at the same time (because of the strategic distribution over the agricultural season and its migration periods).

\subsubsection{Peasant strategies and farming styles as analytical categories for understanding peasant dynamics}

Being aware of the multiple dimensions of the concept of "peasant", it is necessary to discuss the implications and content of such dimensions expressed in peasant life dynamics.

To define the dynamics of peasant irrigation, this study investigates two central elements: peasant actions in the collective domain and in the domain of peasant households. It examines the outcomes of such actions in terms of local agrarian development.

Two concepts or analytical categories have been used in this research to analyze each element: the concept of "peasant strategies" as suggested by Zoomers (2001); and the concept of "farming styles" as proposed by van der Ploeg (1994). 
Peasant strategies can be understood in general as peasants' livelihood strategies, comprising different kinds of activities, both agricultural and non-agricultural. Zoomers (1998) suggests four factors that may be related to changes in peasant households' short-term dynamics, and consequently their immediate strategies:

The life cycle: a factor directly influencing availability and quality of labor for agro-productive activities (including skills/knowledge) but also people's expectations as individuals and as a production unit. Young families with or without children have different strategies, or those with small or elder children can be distinguished, even from those families that are being "dismantled" for different reasons. Life cycle is also an important factor in resource base availability and capabilities to mobilize resources (Zoomers, 1998).

Access to information and social networks refers to the fact that change or innovation are closely linked to information flow and access, and to facilities or conditions that can be imposed/developed through social networks.

Interconnected activities (complementarity and competence) refer to the fact that, in general, peasant families in their daily lives perform many activities. Some of these activities may complement each other but others may compete for limited factors. It is important to identify them because they explain the dynamics of farmers' strategies and therefore their decisions regarding agricultural production.

Access to reserves and/or re-distributive mechanisms: the degree to which peasants can access and use these mechanisms may represent "degrees of freedom" to react against hazards or external changes. Some of these mechanisms are, for instance: food storage, monetary savings, animal husbandry, transformation products, etc., which in some cases can be converted into new assets or into cash. Social relations among households within a community may also be considered part of these mechanisms.

Although the concept proposed by Zoomers (1998) is applied to analyze households' livelihood strategies, it can also be adapted to broaden its applicability to also analyze collective peasant strategies (see also Le Grand, 2014). For that purpose, the concept adopted here has been adjusted as follows: A peasant strategy is the way in which households or peasant organizations respond to opportunities and limitations imposed by the external context (agroecological conditions, market, state institutions, infrastructure), based on priorities and needs defined in advance, organizing their available resources and assets, and resulting in a certain combination and sequences of interrelated practices or actions (adapted from Zoomers, 1998).

Three important remarks or clarifications should be made regarding this concept:

- Peasant strategies do not necessarily mean a conscious, anticipated, systematic planning process, or as Zoomers states: "it does not imply a freedom of choice but an adaptation to internal and external circumstances that change constantly". In this sense, a peasant strategy should be understood as a practice rather than solely as conscious planning of 
future activities; or as Richards (1993) argues: in terms of "performance" and farmers' "improvisational capabilities" in front of different productive and living circumstances.

- The second remark regards resources mobilized by peasants. Academic and professional discussions prevailing on "rural livelihoods approaches", analyze peasant strategies by focusing on the assets available and mobilized by households, expressed as five types of capitals: natural, physical, human, financial and social capitals (Bebbington, 1999; Ellis, 2000). Regarding the suitability of these concepts to development processes (as discussed by de Haan \& Zoomers, 2005; Scoones \& Wolmer, 2003; Toner \& Franks, 2006), in this study the concept of "resources" was kept as an ample notion of material and non-material assets. They "are not simply resources that people use in building livelihoods: they are assets that give them the capability to be and to act". "...(they) should not be understood only as things that enable survival, adaptation and poverty alleviation: they are also the basis of agents' power to act and to reproduce, challenge or change the rules that govern control, use and transformation of resources" (Bebbington, 1999: 2022).

- A third consideration is the contextual and contingent nature of peasant strategies. Households' and organization's priorities and needs are flexible and may change in time, and so do living conditions and contextual factors. In this sense, peasant strategies are not constant and may or may not be repeated in time. This denotes the very dynamic character of peasant strategies.

As explained before, peasant strategies are conceived as individual or collective actions. Therefore, attached to the concept of peasant strategies is the concept of "human agency", as proposed by Long (2001), which "attributes to the actors (individual or social groups) the capacity to process social experience and to devise ways of coping with problematic situations". Agency is "composed of social relations and can only become effective through them..." Finally, "effective agency, then, requires the generation/manipulation of a network of social relations and the channeling of specific items (such as claims, orders, information, technologies and goods" (Long, 2001a: 182).

Styles of farming: The concept of farming styles has been used in this research to explore the different responses that farmers (production and reproduction units) assume and how these are locally expressed in a diversity of agricultural and development patterns. Farming styles involve a certain way of organizing labor at the farm level (labor process), implying a certain degree of interaction or "maneuvering room" between technology and markets, and express an important element of identity of "the peasant way of farming”. Van der Ploeg (1994:17) defines farming styles as follows: "a complex but integrated set of notions, norms, knowledge elements, experiences, etc. held by a group of farmers in specific region, that describes the way farming praxis should be carried out"(...); farming styles represent a specific unity of farming discourse and practice, a specific unity of mental and manual labor (...); farming styles entail specific structuration of the labor process, of the organization of time and space as concrete dimensions and processes of production (...) and in particular structuration of the development process at farm (enterprise) level". Consequently, styles of farming might be defined in terms of their scale, and level of intensity; the implied interrelations between capital and labor and 
the specificity of particular technical-productive aspects and relations. "... farming styles represent specific connections among economic, social, political, ecological and technological dimensions" (van der Ploeg 1994: 18).

Long and van der Ploeg (1994:4-5) suggest that “ ... the presence of differentiated development patterns may reflect the different influence of external and internal forces, but it is impossible to adscribe this wide range of patterns to one dominant set of 'driving forces' located in markets, agrarian policy and technology development". (...) "The dynamics of agrarian development, then, implies a careful analysis of the social relations of production as located in town-country relations, in the intersections of agriculture with local, regional, national, international economies, in historically-produced landscapes, in local culture, etc. As Long and van der Ploeg (1994: 5) argue, the social relations of production do not only shape the way farming is connected to markets, policy and technology, but they also imply a constant negotiation, mediation and transformation of the goals, instruments, and logic that are embedded in these market policy and technological forces. They result then in differentiated development trends and the reproduction of heterogeneity. 


\section{Chapter 3 . Institutional development of the irrigation sector in Bolivia. From local practices to state restructuring}

\subsection{Introduction}

This chapter discusses institutional development of the irrigation sector in Bolivia. Important milestones show the encounter between local forms of water management based on customary norms and practices, and the various attempts by the state to control and regulate these practices are also identified.

On the basis of concrete examples from the field, the study identifies the different expressions of "uses and customs" and how they shape the different dimensions of water control. According to specific biophysical, socio-political, cultural and historical contexts, these uses and customs may materialize as physical control mechanisms to guide water flows; in other cases, they may manifest as more organizational elements; while in others, they may emphasize in particular the normative aspects, or clearly denote the political dimension of water control. These different expressions of customary practices show how dynamic they are, how they are continually re-created and re-adapted: far from being "traditional norms" or "historical rules from the past", obsolete and static.

The second part of this chapter discusses the most impactful attempt implemented by Bolivia's state: institution-building in the sector, explicitly recognizing uses and customs as the main foundation for water management in Bolivia's peasant irrigation. This recognition "formalized" customary rights and therefore collective and individual water rights, by including this concept in the official state legislation (2004 Irrigation Law). Normative and decision-making bodies are also established, with predominant participation by irrigators' representatives.

Finally, this chapter discusses the challenges posed by the new institutional structure, its current operational possibilities, and the consequences of this process for local water management and governance.

The chapter's analysis focuses on the following research question:

How have irrigation institutions developed from local practices, how do they conflict with official views and policies concerning irrigated agriculture; and how do these mismatches in turn influence water control? 


\subsection{The new institutional framework for irrigation. Reconfiguring local institutions and empowerment.}

This section discusses two aspects of the new institutional framework of Bolivia's irrigation sector. First is the configuration of formalized irrigation institutions and its implication in practice. The second aspect is the new balance (or imbalance) in terms of power relations between different actors and between the various levels of the new irrigation institutional structure.

\subsubsection{Configuration of the new formalized institutional setup}

Since the so-called "water war" in 2000, social mobilizations and empowerment of peasants, associated with different sectors, predominantly of rural and indigenous origin, were of great political relevance when conforming the state's new structure, particularly in irrigation sector institutions. During this process, the irrigation law was installed. This law and its regulations were meant not only for general recognition of the usos y costumbres as the foundation of peasant organizations involving water, water management and water-use practices. This norm also granted (at least on paper) decision-making rights to communities where water sources are located (territory-based water rights) and the right to participate through local and regional representatives in the Departmental (SEDERIs) and the National Irrigation Service (SENARI), respectively. Both instances, besides formally granting (or revoking) water use rights through "registrations" and "authorizations" 16 , also have a planning function in terms of implementing policies, coordinating with various agencies, administrative functions, and executing programs and current projects (Cossio, 2009; Seemann, 2014).

Crespo (2006:9) discusses critical issues and questions that are relevant for the implementation of the law and the new institutional framework for irrigation. The law was enacted as a means to prevent the sale of water sources and to protect (collective) water rights of small farmers "... challenged by other sectors and users, particularly private users, industry and consumption by cities." At the same time, the norm seeks to assure the water-users' participation in the "the sector's development, by exercising collective water rights, expressed in the so-called usos $y$ costumbres..." based on participation by irrigation-sector representatives at different levels or planning spaces. However, some sensitive issues are also present in the law. For instance, that "... the law does not guarantee equitable access to and use of water resources, particularly by the poorest sectors (peasants and indigenous without irrigation) ...", and by concentrating decisions in the sector that already has water. Another aspect stressed by Crespo is that the law is mostly concerned with the public and non-mercantilist character of water and water-use rights, however, "... there is no mechanism to prevent the creation of devices (formal and informal) for the commercialization of water and monopolies, as is already happening in some parts of the country ... ". By contrast, implicitly, the law restricts direct intervention by the state as to regulate water access and use in more equitable ways (Crespo, 2006:9).

\footnotetext{
${ }^{16}$ Registrations and authorizations are the administrative instruments provided for in the law to formalize collective water rights (formalizing "usos y costumbres").
} 
The new institutional framework poses new interrelationships between different actors of the state and social organizations. It formalizes participation by (peasant) irrigation sector representatives within Departmental and National Irrigation Services, with a majority of representatives: seven representatives of irrigators and water committees (ANARESCAPYS), one of the national peasant organization (CSUTCB), one representative from the agricultural sector and four from government. A similar structure is defined for the departmental service (Consejo de Ministros, 2006; Honorable Congreso Nacional, 2004). Currently, after several years of uncertainties in implementing the institutional setup, and growing conflicts between groups of irrigators, most of the Departmental Services and the National Irrigation Service are established, although in most cases with many limitations (technical, administrative and financial) to fully execute their functions. SENARI at Central level has been in charge of formalizing collective rights by awarding "registrations" to collective (peasant) users, however, in almost ten years since the law was enacted, less than $10 \%$ of the irrigation systems have formalized their registry (Seemann, 2014).

State institutions to implement this institutional framework and enforce the Irrigation Law are evidently weak, for example, regarding technical and administrative capacities to implement water-rights registration, or enforcement capacities and power, and the legitimacy to act if conflicts arise. In such cases, they would have to defend one sector of irrigators against another, because of disputes about water sources. In practice, however, no concrete results are seen regarding water security, which this norm was supposed to strengthen by recognizing usos $y$ costumbres. The study by Seeman (2014), for example, shows that actual access to water, and rules for distributing water, have not been changed. Defense of usos y costumbres versus water rights held by other user sectors has not improved, either. On the contrary, it seems that the possibility of registering user rights has been interpreted by irrigators' organizations as a chance to recognize "ownership rights" to water sources, exacerbating other neighboring organizations' suspicions within a given watershed, and creating new conflicts and disputes over water sources, based on territorial claims (Perreault, 2008; Seemann, 2014, 2016).

In terms of irrigation relationships and institutions, substantial changes have included gradual empowerment of user organizations and their leaders engaging with different decision-making spaces, from local to national. By contrast, apparently the state is weakening in regulating the water sector and especially the irrigation sector (Rocha et al., 2015, 2016). Although watermanagement practices in peasant irrigation systems are consolidated (self-management, or intra-system management), the emergence of leaders and representatives from the irrigation sector appears not to be accompanied by legitimate representation and accountability mechanisms downward (Perreault, 2008; Seemann, 2014). In the medium term this may pose a threat and destabilize their own irrigation institutions, especially concerning the representation required at intermediate levels (regional, watershed) and above (to the national level). This happens in a context of growing hydrological constraints, especially in upstream areas and valleys of Bolivia, making water sources scarce, if not non-existent, that can be tapped for new irrigation systems. Further, growing financial constraints and technological difficulties in many cases are increasing water conflicts during new irrigation project 
formulation and implementation; there are recurring tensions between upstream and downstream users in river basins; and ongoing re-negotiation of agreements, which in general tend to favor headwaters communities. This potentially threatens local levels, which cannot currently be resolved by central government agencies, by local governments, or even by the irrigation organizations themselves.

\subsection{Local institutional expressions of water control as usos y costumbres}

In recent years, and even more since the water war in Cochabamba in 2000, the aboveintroduced term "usos y costumbres" entered into circulation in different socio-political spheres, especially among rural sectors, in public policy discussions, in natural resource regulation, and its inclusion in the new Bolivian Constitution in 2009 (Perreault, 2008, 2014; Rocha et al., 2015, 2016; Seemann, 2014, 2016). In the irrigation sector, it is also one of the central foci, currently embodied in the new irrigation law (2004) and its regulations (2006). This section discusses the three cases and other relevant illustrations of what irrigators themselves call their usos y costumbres in the irrigation institutional setup: the different meanings, values and connotations that are implicit or explicitly claimed through this concept. Finally, we discuss policy or norm implications in Bolivia, including their significance for water control in irrigation systems. Usos y costumbres in irrigation systems in Bolivia can be understood as concrete, local expressions of water rights. They are a "set of rules, principles and procedures governing access to water" (Urteaga, 2006:130). They have divergent practical connotations (such as operational rules related to irrigated crops) within the communities or groups of irrigators who defined them. At the same time, they represent the body of customary law that legitimizes collective (i.e. communal) rights to water and its sources, or even as "property rights" over those water sources, vis-a-vis the state, other institutions and other sectors of society (Perreault, 2008; Urteaga, 2006).

To explore and discuss uses and customs, and their direct link to water control, two cases are used as empirical evidence: Punata, where different irrigation systems with different water sources overlap (river flow, reservoirs and groundwater) and the rain-harvesting (atajados) systems in Rumi Cancha (see detailed introductory descriptions in Chapter 1).

\subsubsection{Usos y costumbres - more than only "traditional" water distribution systems}

Rivers' waters can be considered as the most representative of the Andean irrigation tradition which was then combined with Spanish rules established during colonial times, conforming thus the first water distribution systems based on costumary norms and practices. Despite its "traditional" or "ancestral" origin, its contemporary and dynamic character is evident (Bustamante and Gutiérrez, 1999).

In case of Punata, three autonomous but interrelated irrigation systems run using the source of water as the flow increases in the river during the rainy season. The Pilayaku system distributes the basic flow upto 201/s, the Mitha system distributes the river flow if it reaches between 20 
to $300 \mathrm{l} / \mathrm{s}$ and the Rol system when the flow exceeds 3001/s (see detailed description in Section 1.4.2). The Mitha system extends not only in areas of former haciendas like Punata, but also in communities from the highlands, or in areas known in the colony as "Pueblo de Indios" (Indian villages) (Gerbrandy and Hoogendam, 1998).

The Mitha system in Punata means a complex system of water allocation based on turns with established dates and times for distributing the entire river flow (monoflux). The definition or specification of these turns is not set in writing but has instead been transmitted orally from generation to generation. Some users or "mitheros" have regular turns every 21 days, while others in multiples of that interval. Some others can use water during fixed dates only once or a few times a year. Every user of Mitha knows the timing and the duration of the turn for the community and within this, his/her own turn (individual timing and duration). While the dates and duration of turns do not change along the year, the amount of water (the physical dimension of water control) is changing (decreasing). For some users, this water right is becoming insignificant and others have abandoned this right. Other users on the contrary, maintain this water right "latent" for some emergent situation, as part of family strategies to access other benefits either from another system or in terms of trade (exchange) for other resources. Water control in the organizational and operational dimensions of this system seems to be diluted over time, or at least is not present with equal force and visibility in all communities in Punata. In terms of physical (technical) water control, this system represents a lot of uncertainty for water users who rely only on the river flow.

Geographically overlapping in the Punata area, in the "Pilayaku" framework of rights (see Section 1.4.2) the usos y costumbres represent "old" rights. They were created since the hacienda regime or even before. After the agrarian reform, these rights were claimed and controlled by former hacienda workers (colonos) in the community at the head of the Punata valley (Pucara community). Flow in this system was more or less constant throughout the year. Being a basic flow of the river, and based on the "tradition" that this system had a permanent flow, water users claim a permanent and if possible fixed flow even while reservoir systems are operating. (Reservoris (dams) are located in the same river). This makes water distribution at the main intake difficult and conflictive, where all the suface irrigation systems share the same infrastructure.

A typical situation is when Pilayaku and reservoir systems overlap their operation schedule. Before a reservoir starts its operation (largada), the flow of Pilayaku system may be less than $20 \mathrm{l} / \mathrm{s}$ and this will be the flow that is distributed. However, when water from a reservoir reaches the water intake, Pucara community demands the return of their basic (traditional) flow of 20 $1 / \mathrm{s}$. This is continually negotiated and many times granted by the different reservoir systems in Punata, although in recent years this situation is involving more conflict.

Agreements may be further complicated especially when there is snow or rain on the mountains which increases the base flow in the river. In this situation, the Pilayaku and Mitha water-rights systems operate simultaneously, but if water is released from a dam, new negotiations and disputes between the "mitheros" and users of the dam will take place about how to distribute 
their respective flows at the main intake. Most of the time, an agreement is reached; sometimes to the benefit of Mitha users and other times for the dam users, depending on the flow at the main intake. Here, Mitha and Pilayaku systems show the strength of these traditional rights or traditional water distribution systems of the river flow. The usos y costumbres in both systems are expressed as the right to irrigate with river water, under an established distribution schedule based on sequential rights of the communities near the main intake (Bustamante and Gutiérrez, 1999). Although the Pilayaku system tends to claim a given flow rate, especially when several systems are in operation simultaneously, the flexibility is evident in that these collective rights can be negotiated in relation to other rights frameworks. This demonstrates the dynamic nature of the usos y costumbres demarcated by social relations and the flexibility that they lend to peasant irrigation systems' functioning overall. They also show the flexible definition of collective water rights regarding these sources, although with a more accurate definition for individual rights. Despite the precise definition of individual rights (as "reference rights"), daily practice within communities, or in inter-communal distribution, also features high flexibility and water mobility. This all materializes as adaptive variations in flow rates, irrigation times, water demands, agreements for exchanging water turns, etc. which ultimately results in an apparently chaotic water distribution system ("materialized rights").

\subsection{2 “Usos y costumbres" -- physical and organizational dimensions}

The system called "Rol" in Punata, uses the river flow water when it exeeds 3001/s at the main intake. Despite its seasonality and uncertainty, is a very important water source for remote communities, for many of them their only resource to prepare (fallow) land and eventually to irrigate maize. The physical dimension of water control is perhaps the most important in this system, as it will come into operation only when river flow is greater or close to the indicated discharge. Once this is foreseen or physically verified, it depends on the organizational capacity of communities far away from the Punata intake to assert this right and operate the system. Communities that are entitled to this system define a distribution sequence at the main intake. According to the number of members, they can get water for 12 to 48 hours (per community). Internally, each community mobilizes people to clean ditches and streams, and "accompany" water from the main intake down to the community. They organize distribution of water among themselves.

Access to water in this system is increasingly difficult, partly because the communities at the head (near the main intake) are demanding and using more water from this source, but changing rainfall patterns also affect the river's hydrological regime. So, communities far from the intake annually claim and defend their rights to this source, and exercising these usos y costumbres has been and remains a source of confrontation, protests and conflicts between Punata communities (Gandarillas et al., 1993; Saldías et al., 2012). Negotiations ever continue to move or readjust the main intake, to ensure water enters into the Pucara river's main courses.

In organizational terms, the Rol system did not have a visible (formal) structure. This led to tensions and conflicts between communities with rights to the system, especially between upstream and downstream communities. In response to downstream communities' claims, the 
peasant organization in Punata (Central campesina) intervened in coordinating water distribution to reduce conflicts. This has revitalized this organization's legitimacy.

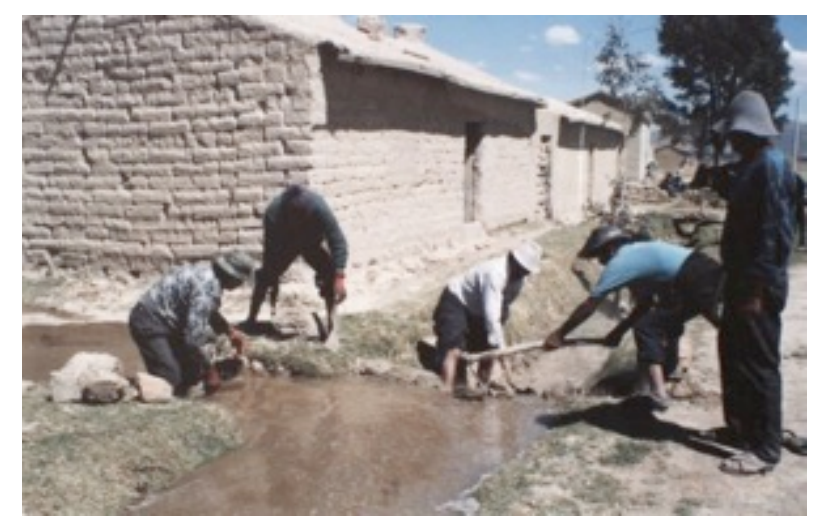

Picture 3-1. Water distribution within communities in Rol system

Photo: I. del Callejo

The "usos y costumbres" under this Rol system, unlike Mitha and Pilayaku systems, represent peasant communities' practice, effort and mobilization by physically controlling large river discharges to convey water from the main intake to a community, after having negotiated and reached agreements with other communities. These usos y costumbres therefore also represent important, dynamic negotiation mechanisms - the political dimension of water control between the communities associated around the irrigators' organization and those communities without irrigation (that is, without regulated irrigation). Currently, these communities outside Punata dams' area of influence are called "communities without irrigation", because they have no rights to these regulated systems and face strong limitations on accessing any source, either surface or groundwater. These communities have access only to Rol or to river floods during the rainy season, which are increasingly difficult to access because of the distance from the main intake and because that water is used by communities upstream and by those closest to the main intake. The next chapter will discuss how they developed collective strategies of "reorganizing communities" to access more water from this system.

\subsubsection{The territorial dimension of the "usos y costumbres" in Punata reservoirs}

As was mentioned above, uses and customs denote specific features of water management in peasant irrigation systems. These features are molded by or adapt to physical-environmental, cultural and socio-political conditions in each locality, and are continually renegotiated when such conditions change. Ultimately, one of the most concrete expressions is in water rights, both collective and individual, defining who can and cannot use water and existing infrastructure. These usos y costumbres are also manifested in day-to-day practice in the system and reinforce the perceptions or images that water users have of themselves vis-à-vis other people or groups that do not use their system's water (Gerbrandy and Hoogendam, 1998; Boelens, 2008a; Seemann, 2014). This section discusses these different expressions or images 
of usos y costumbres, taking as illustrations irrigation systems in Punata again that receive the water from three different dams (Totora Khocha, Laguna Robada and Llusk'a Khocha) (see Figures 1-4 and Figure 4-7) showing their multi-tiered (nesting) nature and the different repertoires that comprise such expressions.

The Totora Khocha system's usos y costumbres are perceived and project different images for different actors. Among users of this system in Punata, the image of usos y costumbres is the investment that water users must assure, year after year, both in work and in monetary contributions for system operation and maintenance, to have access to one or at most two irrigation turns per year. This image could be summarized as communities and water users' effort, investment and sacrifice. Some users view this effort as beneficial, others as an "overload" because only one or two turns a year offer them somewhat disappointing benefits. This "internal" expression is different for different user communities. For users in remote communities far away from the main intake, who have access only to Totora Khocha, water is essential for land preparation (fallow) and/or complementary irrigation ${ }^{17}$ of maize or alfalfa. Work and money investments for these users are then essential to cultivate at least one cycle of grains or fodder crops. For users and communities located near the main intake, other water sources in the zone are more secure. Totora Khocha offers these peasants an additional resource to negotiate with third parties about water, agricultural products or any need that families may face.

Also for Laguna Robada, usos y costumbres are expressed among irrigators in Punata as resulting from sacrifice, effort, organization and self-management. It is a right that they inherited from their grandparents (with historical roots, based on communal heritage and family effort), and have a direct link to their own family history, reflecting the abuses suffered during the time of the hacienda regime. Stories about this dam tell about the deaths that occurred during its successive restorations, which increases the historical and symbolic value of these usos y costumbres.

For Llusk'a Khocha-Muyu Loma system, the water source's usos y costumbres and the link with their grandparents' efforts are less visibly expressed. Ten communities in Punata use this source. Because of the long distance to convey water from the reservoir to the irrigated area and due to new settlements along the river, water availability is decreasing year after year. Some users claim that in this system "the organization is declining" and that they have to invest increasing efforts to control water conveyance. The next chapter, on collective action for water control, will discuss this case in terms of the close link between organizational and operational (technical) water control.

In Punata, 65 communities use Totora Khocha. These communities feel their reservoir's usos $y$ costumbres reflect "ownership", vis-à-vis communities without irrigation surrounding

\footnotetext{
${ }^{17}$ Complementary irrigation is understood here as the irrigation that is practiced just before or during the rainy season. In this case, water application to plots, either for land preparation or for a specific crop, plays a complementary role, together with rainfall. Neither the irrigation nor the rainfall are enough to fulfill water requirements.
} 
Punata: Totora Khocha “... is our dam...” which has been built "...for us", “...with funding directed to us..." and built "through our own efforts". "We got funding..." (...) "and those who did not take the risk, or who dropped out at the beginning...have no right to use these waters...". These fragments of a local leader's testimony in Punata express the clear image that Totora Khocha's users want to project towards "external" communities. Their usos y costumbres mean ownership.

For a decade, as part of discussions to possibly extend the Totora Khocha system (by building the Vandiola water transfer project), these expressions of usos y costumbres show increasing notions of ownership. Communities with water rights to this system argue that, if the dam is extended, their children and those with no water rights in their communities would be new beneficiaries, but not people from other (external) communities ... "we do not negotiate with non-users".

The territorial dimension of usos y costumbres. Punata's reservoir systems have their dams and the catchment located outside the jurisdiction of the user communities. They are located in communities at the upper part of Pucara watershed, in the jurisdiction of other municipalities outside Punata (Llusk'a Khocha-Muyu Loma and Totora Khocha in Tiraque and Laguna Robada in Colomi). In recent years, the demand and interest of communities in the upper parts of the watershed in using water from these sources, has notably increased, and therefore tensions and conflicts between them and the users in Punata are more and more evident. The upstream communities are forcefully increasing their demands and claiming "territorial rights" over water sources. They use different mechanisms to exert pressure on downstream communities. They started requesting the diversion of a small portion of the flow, a practice that every year was accepted by Punata organizations, but not without going through long negotiation processes. In recent years however the upstream communities prevented the passage of water crossing their lands and did not allow Punata irrigators to even approach to the dams. These conflicts have been mediated in some cases by municipal authorities, by government agencies and by the Federation of Irrigators of Cochabamba (FEDECOR).

As a strategy, irrigation organizations from Punata also claimed "territorial rights", not originating from their own but from the former landowners' hacienda, arguing that "... these dams belonged to our bosses ...", "... they were people from Punata not from Tiraque, they were the owners of those dams and we have inherited those water sources... " (interview with Punata user). Here, peasant leaders use different regulatory frameworks plus historical "images" and symbols, which can sometimes seem contradictory. An image of the hacendados as exploiting peasants may be replaced by an image of "ownership and control" attributed to those same hacendados, yielding their usos y costumbres and especially territorial rights over these sources.

In recent years, these rights or territorial claims, in Tiraque, in Punata, and other dam systems in the valleys, are being fiercely contested, placing historic agreements between upstream communities and lower-basin user communities back on the table. This is exacerbated by the irrigation law which demands water rights (usos y costumbres) registration for formal 
recognition by the national irrigation authority (the National Irrigation Service), and for new investments to construct dams (Seemann, 2014).

In short, collective water rights, expressed as usos y costumbres in irrigation systems in which water sources are located in places other than where water is actually used, are in growing dispute, based on territorial claims. Although there are no cases (yet) in which downstream communities have lost their rights, conflicts are evident. These conflicts show a change or new imbalance in power relations between upstream and downstream communities. Irrigation systems that seemed to be strong in their organizations and in consolidating their water rights, as is the case of Punata's organizations, are increasingly vulnerable to new water demands (real or fictitious) in the headwaters. Ultimately, claims based on territorial arguments, and the physical control that upstream communities have over these water sources, appear to control water more effectively than (only arguments based on) usos y costumbres regarding current use or historical agreements between upstream and downstream communities.

Complexity in expressions of usos y costumbres, rooted in culture, in social relationships between the group of people sharing a water source and their history, or between these users and third parties, show how important relations are between and within irrigation systems. Social networks intermingled with water networks and the water cycle reveal hydro-social networks and territories (Boelens et al., 2016), transcending geographical, politicaladministrative or hydrological boundaries. The results of these complex inter-relationships show that hydro-social networks' boundaries are not fixed in physical-geographical terms, much less in political-administrative or social terms. In time and socio-space, these boundaries are re-defined continually. We also see that territorial arguments are increasingly important in defining usos y costumbres, as a foundation for defining water access, water rights, and in general water management. This, in turn, shows how different territorial notions "overlap", molded by water management and control, assuring that some have water access and others are excluded (cf. Hoogesteger et al., 2016).

\subsubsection{The multi-level character of usos y costumbres}

This section summarizes some characteristics of the organizational and water allocation practices, showing the multilevel character of water control in a reservoir system such as Totora Khocha in Punata. This will help identify distinctive expressions of usos y costumbres at the system's different levels. These usos y costumbres have different meanings, in terms of social relations and power relations, depending on the level of social aggregation and the current socio-political contexts. Water rights define social relationships among those who can (or are entitled to) use water and also between them and those who cannot use water. Therefore, rules between water users and third parties are defined.

The Totora Khocha irrigation system in Punata is as an example of multilevel expression of usos y costumbres, in both organizational terms and operational elements. This expression of the usos y costumbres is different for individual users, communities, irrigation groups, or the whole system. In Totora Khocha there are several organizational and operational levels: at the 
highest level, the irrigation committees of Tiraque and Punata are each backed by a large organization in their provinces (the Tiraque Irrigation Association and the Punata Irrigation Association, respectively). The relationship between the two organizations is governed by an agreement that defines the benefits (water allocation) and obligations (operation and maintenance) at a proportion of $60 \%$ for Punata and $40 \%$ for Tiraque. In Punata, water is distributed among eight groups according to the water infrastructure division (main channels), each group comprising a similar number of communities, so that the 65 communities composing the system are served. Within each group, user communities distribute water internally according to each community irrigator' shares. These shares and how to organize them through governance agreements is subject of continuous negotiation, at multiple scale levels. The multilevel character and territorial dimension of usos y costumbres clearly demonstrates institutional boundaries' flexibility or permeability in Bolivia's peasant irrigation systems. This shows again, as argued by Cleaver (2000) and Mehta, Leach \& Scoones, (2001), how inappropriate it is to view institutions as a fixed structure within well-demarcated boundaries.

Considering usos y costumbres as expressed at their different levels becomes relevant, for example, when implementing irrigation projects, when contributions from farmers (irrigators) are defined either in cash or in working days (labor shares), or when re-defining collective rights in systems that are already operational. It is also important to specify information flows and perceptions at these different levels, for example to support negotiation between conflicting parties over a particular water source.

\subsection{5 "New" usos y costumbres in groundwater systems. Individual efforts, collective principles}

In several regions of Bolivia, as in Cochabamba and Punata Valleys, groundwater use has increased rapidly as an alternative to the physical and financial constraints on implementing large-scale irrigation systems. Most groundwater systems that are implemented in Cochabamba, and especially in Punata, are generally small multi-family systems. They start when a group of families decide to collectively invest to drill a well in order to meet their water requirements, in response to water demands unmet by other systems, to a drought event, or to new demands created by intensifying irrigated agriculture in the area. For almost two decades in Punata (1990 to 2010), these family groups took full funding responsibility to implement and then operate these systems by themselves. These groundwater systems in Punata are mainly used for irrigation and some for domestic supply, but there are a variety of other productive and non-productive uses of these waters (Del Callejo \& Vásquez, 2007).

When wells are drilled in Punata, their usos y costumbres are the set of rules or specific agreements that a group of people have established to extract groundwater, usually near their plots. To implement the system, a first contribution (investment by each family willing to participate) is necessary in the beginning. The group, depending on their relationships and, of course, on funding opportunities, can eventually get support from the municipality, the central government or any NGO working in the area. This support may help cover the costs of drilling, 
the pumping system, and electrical installation. But the most important basis for creating water rights to these systems is each family's monetary investment. Water rights are called "shares", and can be fractional (e.g. half shares, one share or at most two shares). Most tube-well system users have only one share. Arrangements for water allocation in tube-well irrigation systems are system-specific but are generally distributed through a fixed-turn system, defining the runtime equivalent to a share. Irrigation distribution mainly diverts the whole discharge (mono flow) to each user during each turn. There is some flexibility, allowing other families (users or non-users) to access water through irrigation turns from other water users or from the system. This can be done by buying (paying in cash) or by any other mechanism (loan, exchange, lease, or different types of arrangements based on reciprocity practices).

In terms of water control, a certain degree of risk and uncertainty is present in initial stages, in choosing the well location and engaging the drilling company. Once the well is operational, it may represent in practice a relatively stable, secure water source, with minimum management requirements, although with high operating costs (electricity) and eventually replacing or repairing the pump. All these practices, strategies, investments, construction of rules, cultural and monetary values and the final possibility of accessing water as a key element of their livelihoods are reflected in tubewell-particular notions of usos y costumbres. In groundwater in Punata and elsewhere in Cochabamba Valley, this is all relatively recent but is already claimed and defended as traditional usos y costumbres.

What becomes apparent in these examples of usos y costumbres in drilled-well systems is the growing importance of commoditization and socioeconomic differentiation that is associated with implementing these systems. To be part of this kind of systems, a necessary requisite is peasant families' cash investment possibilities. Not all households can afford this investment, and therefore they will be directly excluded from the system. A later section will discuss the different possibilities and strategies to afford this kind of investments. Next, despite their individualistic character, these system's organizational and mobilization capabilities are still very strong, showing unavoidably the collective prerequisite of water management. Many examples in Cochabamba and Punata valleys have shown this: people collectively or individually using tubewells can and do mobilize jointly to defend their water rights, under the slogan of defending their usos y costumbres against the threat of their water being used by others, or being licensed to private companies, as was the case of the "water war" in Cochabamba (Boelens et al., 2010; Perreault, 2006).

\subsubsection{Uses and customs in atajados systems in the community of Rumi Cancha, Aiquile.}

Relatively recently, especially after the droughts of the 1980s, thousands of micro-irrigation systems using "rainwater harvesting" have been built in arid regions which have little chance to implement other technologies for irrigation water supply. These systems, called "atajados", are constructed in particular for individual families. Very few collective systems are currently working. Built for individual households, the systems are managed independently of the communal organization. While it is not usual to specifically speak of usos y costumbres in managing these systems, local norms are certainly important issues. This shows, for example, 
in developing reservoir construction practices, learning and developing technology to capture water and irrigate the family's crops, consolidating the catchment area and the reservoir's structure in itself.

One key aspect defining these water-harvesting systems' success is managing the catchment area. This is precisely the meeting-point between farmers who manage their atajado individually, where the community's role may be crucial. When such systems are implemented, they agree to delineate catchment areas and channels that feed the reservoirs. In some cases, depending on the catchment area's characteristics (not only its area but also natural barriers that hinder conveyance and water storage) these agreements may be more or less conflictive. In other cases, positioning of the atajados constructed may also influence the benefits for those who built them. The community supervises all these situations.

Physical control over water is closely linked to the spatial distribution of land, individual or collective access to this land, or to internal norms that the community has established for land management. Examples of these norms involve defining individual and communal land (plots), but also which parts of community land are meant for cultivation or for grazing animals or even for water harvesting. This means that access to water in these individual systems, can partly be defined by usos y costumbres that have been developed or will be adjusted according to land access and land management. An important factor also defining physical water control is the investment capacity (in work and eventually in money) that a family has, as well as the availability of external funding.

\subsubsection{Technological artifacts that re-define usos y costumbres}

An interesting case, showing the dynamics in the usos y costumbres in relation to population growth, pressure on land, and technological innovation, are the peasant communities in the Mishka Mayu river basin. In this place, technological adaptation from surface to sprinkler irrigation has developed and has direct implications for the expression of usos y costumbres, reason for which this case is mentioned here as an illustration.

The Mishka Mayu river basin is a neighboring basin to the upper part of Pucara river basin, where Punata is located. Communities have a long tradition of intensive potato growing, using irrigation on very steep slopes. Their water source use, canal construction and waterdistribution practices date back to the hacienda period. Haciendas established a distribution system for springs and river water, along the entire basin, defining 24-hour irrigation turns for different sectors. After land reform in 1953, land was distributed among hacienda workers, and peasant communities or unions were formed. The hacienda's usos y costumbres were adopted by communities, expressed in the form of irrigation turns for user groups located along main canals. Each user had a 24-hour opportunity to use and, over five decades since the reform, new families were gradually incorporated into the community. Unlike the other cases studied in this thesis, in Mishka Mayu the only prerequisite to be part of the community and hence to get water rights in one of the systems was to form a new family and meet the age requirement 
(21 or 23 years). This continually redistributes water (rights) among former families, and new families when they inherit land.

In the early 1990s, promoted by an NGO but then taken up by the peasants, sprinkler irrigation was introduced and then massively used by communities in the whole river basin. Currently, almost $100 \%$ of the farmers use this technology, taking advantage of the pressure generated by their steep slopes. Delgadillo (2003a) and Rodríguez (2003) explain the technological adaptation process in detail, showing water distribution practices and ingenious adaptations and modifications of sprinkler devices and accessories, with very common materials found in any local shop in Cochabamba. The case shows how peasants introduced and adapted artifacts to generate their own technology, reduce erosive effects of irrigation on steep slopes, and reduce stress and irrigation problems at night, while shortening irrigation turns and thus the irrigation interval for each user. Besides, the artifacts and adjustments in irrigation practices and water distribution clarified and gave new expression to usos y costumbres, under increasing pressure on water, due to communities' population growth. What were once 24-hour successive irrigation turns along channels have now become 12-hour turns per user, applying water during the daytime (not during the night), with a maximum of three sprinklers without secondary nozzles ${ }^{18}$.

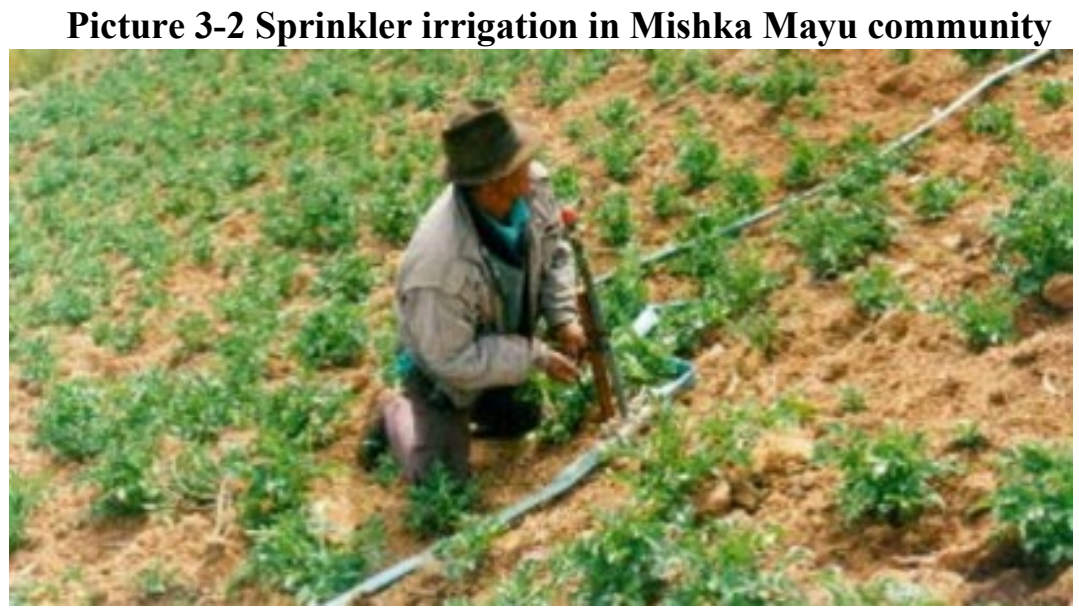

Picture: J. Jimenez

\subsubsection{Summarizing the different expressions of usos y costumbres}

In Bolivia, usos y costumbres prevail in everyday water management and particularly in peasant irrigation. Before the irrigation law was enacted, official norms, formalized laws or other written regulations had been absent or did not pertain to irrigators' rules and knowledge systems. As demonstrated, usos y costumbres have value and meaning only in practice, and between those people and organizations that have built that set of rules, regulations and

\footnotetext{
${ }^{18}$ Technological adaptation of sprinkler irrigation included removing one nozzle from sprinklers to increase the discharge and reduce their pressure requirements and also reduce irrigation time. By removing or enlarging the nozzle, they increase the discharge and also the drop size, increasing the risk of soil erosion. To avoid this, Mishka Mayu peasants adapted a piece of wire in front of the secondary nozzle to intercept and distribute the waterjet in smaller drops, improving the sprinkling effect.
} 
agreements. They are also dynamic and variable in space and time. That is, usos y costumbres regulate social relations in specific space-time contexts (Boelens, 2015; Rocha et al., 2015, 2016; Seemann, 2014, 2016).

The usos y costumbres tend to reflect different values about water as such, but also about water as an element integrating different actors. Thus, in some cases, usos y costumbres will privilege water's value for peasant families' food production. In other cases, they represent ancestral or historical claims, while other expressions make it possible to claim identity and territoriality. They may also represent the effort, collective work or monetary investment; and in some cases, they embody "water source ownership" by those who practice such customs. The examples illustrated in the previous sections show the contents of usos y costumbres in their material, socio-cultural, political and economic dimensions.

In addition to the above, we must also emphasize the "permeable" character and flexibility of usos y costumbres, which are continually being recreated and readjusted to the physical conditions, to new agreements between their creators and even to third parties. They also interleave with territorial dimensions and notions of ownership, and sometimes are mediated by technology. These limits are not absolute but constitute flexible and strategic water control institutions.

The various examples and illustrations described in this section also show how prevalent customs are in Bolivia, as the foremost way to regulate access to and control over natural resources including water, especially in rural areas. The state's absence, indefinitely postponed water legislation, and especially the volatility of the "state" concept for rural communities, have all reinforced local institutional construction (Seemann, 2014). Thus, usos y costumbres, beyond just a range of normative and rules governing access and use of water, have become a key tool to achieve autonomy for peasant communities in terms of physical, social and political control over their resources. This control is not managed by external agents through "external rules" but rather is a part of a set of rules, norms, practices and agreements under codes and local peoples' own language. It frees them from state control, or from other agents.

Finally, these organizational practices, social mobilization, collective work, resource investment, control of organized groups' behavior and the defense of group's interests vis-àvis other sectors or groups of society and the state, in turn have transcended the field of natural resources. Now they are part of the practice for different marginalized sectors of Bolivian society to make different types of demands, or as strategies to reach new spaces of power in local spheres and in new government structures.

\subsection{Constructing normative frameworks from local practices.}

The previous section discussed several examples that demonstrate the validity and prevalence of customary rules around water management and water control in peasant irrigation systems. This section describes two examples showing the formal implementation of "legal resources" 
by peasant organizations. The examples show how organizational capacity, demonstrations, lobbying and influence from their representatives in government spheres can turn demands by farmer organizations into official norms, to influence water control. Some difficulties and requirements for practical implementation are discussed at the end of the section.

\subsubsection{Illustration 1: The law on extracting aggregates}

In the valleys of Cochabamba, rivers are the main source for irrigation water. Their marked seasonality defines a fairly short irrigation period and therefore they are complementary to rainfall. Peasant communities, who use rivers as their only water source, are subject to various types of adverse factors: "the capriciousness of rivers" because of their seasonality, their unpredictable flows, either as excess or shortage, resulting in increased insecurity and risks to crop production, or because of the physical security of the communities themselves. The overflow of mountain rivers, with large amounts of material, sand, stones and water, could be fatal to surrounding villages or communities if anything affects their course.

A continuous struggle for peasant communities, settled along the rivers, has been the extraction of materials such as sand, stone or gravel, often carried out illegally and sometimes legalized by concessions granted under the national mining code. This scheme granted rights to extract aggregates for construction (sand, stone, gravel). With the rapid growth of cities and peri-urban areas, demand for construction aggregates has also grown significantly and this has increasingly affected natural watercourses. The rivers of Cochabamba's upper and lower valleys are quintessential deposits of these materials.

One example is in the "Lower Valley" of Cochabamba, communities located between the municipalities of Capinota and Parotani. The area developed very intensive agricultural activities, thanks to reliable flows from the Tapacarí and Arque rivers. This area produces large areas of vegetables very intensively, up to three harvests a year. To achieve these levels of intensity and yields, farmers use chemical fertilizers intensively, but also combine with their widespread practice of "lameo" which is to irrigate their plots with the first arriving river flow, laden with large amounts of lime and clay sediments. This practice replenishes soil nutrients and raises and consolidates these plots year after year, as they have literally been "reclaimed from the river". Farmers in the region have become experts in "building" soil terraces along the river. They annually control river flow, build retaining walls, irrigation canals and other drainage and protection works. For this purpose, they form cooperatives to organize work to build the necessary infrastructure and to coordinate distribution of the land that has been "built". They invest their own resources, but also negotiate some support from municipalities or NGOs, for implementation.

Practicing lameo as land reclamation has been increasingly affected by aggregate extraction concessions (mainly fine material such as sand or fine gravel). This activity creates ponds in different parts of the river, and changes its path and behavior, which can flood areas that are being recovered (new areas), or undermine and collapse protection walls, or even flood agricultural areas with established populations. 
In the Upper Valley, the Jatun Pucara Mayu (Pucara river) is a seasonal river, with less water than the Lower Valley. It is located in a steeper zone, and features extraction of coarse material, gravel rather than sand. This river overlaps water from the different irrigation systems used in Punata Valley, mainly water from the three dam systems, subsurface flow (Pilayaku), basic river flow (Mitha) and flood flow (Rol and Riada). Especially water from dams is transported through the river for considerable distances, 20 to $40 \mathrm{~km}$. Large discharges are released from the reservoirs so the flow arrives as quickly as possible to the irrigation area, to reduce conduction losses and prevent water theft along the river course. Aggregate extraction directly affects all these systems. In the case of reservoir systems, the ponds dug in the river course to quarry gravel cause delays and losses in water transport. Mitha and Rol systems are also affected by blocking the specific points where water is diverted, or in critical situations changing the river's flow regime endangers protection works built along the river.

Through their representatives within the Cochabamba Departmental Federation of Irrigators (FEDECOR), and with the Federation's support and mobilization capacity, especially irrigation organizations from these two valleys (Punata and Capinota) got the attention of regional and national political authorities. After different actions (marches, public protests, lobbying, and especially alliances with municipal governments), irrigators got a law enacted to regulate the extraction of aggregates from rivers. Law 3425 finally was enacted on June 20, 2006 and its regulations in April 2009. This law grants rural communities, irrigation organizations and communities around aggregate extraction sites, the possibility to decide over these resources. A local regulatory body was established, in which these groups have direct representation with voice and vote together with the municipal authority, with full powers to grant or extend operating licenses for aggregates extraction, revoke them, and decide about management plans for rivers and watersheds.

\subsubsection{Illustration 2: Groundwater regulations in Punata}

In Punata municipality, irrigators have had longtime internal conflicts over unrestricted groundwater extraction. In the 1970s, under special programs by the Ministry of Agriculture and the United Nations, the first wells were drilled. Later, since the 1990s, this process has accelerated. Data from previous studies (Delgadillo \& Lazarte, 2007b; Ríos, 1999) show an increase of over $200 \%$ in the number of wells drilled in less than 15 years, increasing extracted volumes by almost $100 \%$.

In 1998, a new water-users' organization was formed in Punata, by groundwater-users committees (for both irrigation and drinking water). This initiative covered all Punata systems plus well systems for irrigation and drinking water throughout the Upper Valley of Cochabamba, encompassing approximately five municipalities. This organization, headed by Punata systems, pressured the municipality to implement a municipal norm to regulate groundwater exploitation, given the lack of any national norm, or norms from their own organizations, and because several conflicts had emerged. Confronted with conflicts among peasants and especially among irrigators, about a subject that was not regulated in their usos $y$ 
costumbres, without mechanisms in public institutions to further clarify, regulate or issue a legal opinion on this situation, the Deep Wells Association (Asociación de Pozos Profundos) had to resort to lobbying Punata Municipal Council members for approval of a municipal ordinance, which was approved in April 2005. Three important elements can be identified in this ordinance that show the complexity of regulating a "non-visible" resource such as groundwater:

First, water users saw this ordinance as a safeguard against possible interference, and therefore conflicts, among tube-well systems. Simple, concrete, measurable criteria had to be introduced to regulate groundwater extraction. Thus, for northern Punata, where there is greater groundwater potential, wells should not be drilled closer than 500 meters and, in the south, at distances of 1000 meters, because this is considered a more vulnerable area. While these limits are not based on strict hydrogeological criteria, they were proposed as a solution to avoid confrontations between water users (not just irrigators). The second important element is this municipal norm's transitional nature. It recognizes the gap in national regulations, stating "... until the national government by law, regulates the use of groundwater" (Gobierno Municipal de Punata, 2005). The third important element is the role granted to this peasant organization, the Deep wells Association, "to approve" drilling activities in Punata municipality.

An interesting part of this story are the opportunities that water user organizations deploy and combine from different institutional repertoires, either from state structure or their own institutions, to reassert water control. Additionally, this could be interpreted as a concrete measure to counter Hardin's assumption regarding the "tragedy of the commons". Enforcement of this norm is mediated by different mechanisms. On the one hand, the organization of well users found no national or other official regulations to help them sustain their own practices; they were obliged by circumstances to look outside their scope, to the municipal level, to create the necessary regulation ("legal shopping", Benda-Beckmann et al., 1998). However, this norm requires specific control mechanisms by municipality, toward communities and toward private drilling companies, to enforce the norm. Moreover, there are no mechanisms or coercive sanctions, or the technical capacity or staff to play this monitoring role. Enforcement of this rule seems to elude municipal control; rather, this role was returned to communities and organizations, so they are in charge of "social control" to enforce this norm.

This norm may be strictly enforced or not. In many cases Punata irrigators already know this local regulation and have begun to use it, although with some "flexibility". In many cases, this was succesful; in others it encountered severe restrictions. The Deep Wells Association has no resources (technical, financial, administrative) to regulate well-drilling. Thus, over the last decade, about 100 new wells have been drilled (Mayta, 2012). Moreover, paradoxically, according to testimony by some irrigators in Punata, the Municipality has started breaching its own ordinance: during elections, as part of their political campaigns, or recently, as part of national programs such as "Mi Agua" or "Mi Riego", municipal authorities have helped communities drill new wells, regardless of technical criteria and their own ordinance. 
Almost ten years after enactment of the municipal ordinance, the groundwater situation in Punata is becoming critical, because of water table depletion and growing conflicts between water users. During the last years, given the absence of national regulations about groundwater use and the relatively new institutional setup under the new Law on autonomies and decentralization (Ley Marco de Autonomías y Descentralización “Andrés Ibáñez”), Punata's well organizations and other water users' organizations in Cochabamba have resumed mobilizations to exert pressure on local and regional government ("gobernación") in order to discuss a new Departmental Law to regulate groundwater use.

\subsubsection{Reflection on regulating and formalizing local practices}

Both examples (the national law on aggregates and the municipal ordinance on deep wells) show the importance of local organizations and their experiences with certain problems that pose risks or threaten communities' water control as a basis for people to resort to different strategies to promote building their own institutions. In these processes, the examples show that formalizing local practices or "putting norms on paper" is neither the only nor the most important requirement for institutional development. What these examples show is the need to consider the multi-dimensionality of the problems that must be solved to support everyday water control practice.

Part of the political dimension, institutional development and locally managed rules aim to effectively or sometimes symbolically control people's behavior. In Punata's groundwater case, promoting this protective norm has meant searching for a different domain aside of the usos y costumbres, that will enable some preventive measures that cannot be easily manipulated. Further, this norm affects both irrigators and urban populations. Therefore, the most logical way to tackle the problem seemed to be a municipal ordinance. This meant that the rules governing collective resource use were transferred out of the scope of customary norms (usos y costumbres) and put under official (formalized) state regulations.

In the organizational domain, to fully implement customary norms and practices through state institutions, these institutions should have operational, administrative and technical mechanisms to enforce norms. Local organizations were urged to use their own representation and social control mechanisms to enforce both norms. However, local organizations lack such mechanisms and capabilities, despite their organizational and mobilization strengths.

These two cases show that written rules "normalized" in state structure, though generated from people's practical experiences, "from within", have no guarantee that they will be fully implemented. The reason seems to be the historical separation and mutual denial between local institutions and state institutions. This has created parallel structures with different logics, codes, practices and purposes, leaving large gaps (in both state and customary frameworks) when implementing the norms. In these two cases, implementation was taken away from local organizations or institutions, into the realm of state bureaucracy with all its weaknesses. 
In Bolivia, institutionalizing water governance by the state has always proven to be very fragile. Local institutions' recognition and progressive incursion into state institutions is assumed to mean an important step forward. However, it is difficult to predict how long it can take to make the two frameworks compatible and achieve results. An immediate consequence of "institutionalizing" local norms and practices in the state is potentially many procedural and public management errors, bureaucracy, corruption, or simply that the rules and public management procedures are ignored locally because few understand and apply the rule, or because some begin to use "flexible" and sometimes discretionary practices to manage public bodies and resources.

Another drawback of explicitly recognizing customary law is the difficulty or impossibility of putting it into practice with all its implicit elements (which come from daily practice), because local norms tend to focus on very specific, practical problems (and contexts). Therefore, they require very detailed regulation of all administrative, legal, financial and technical backups for their actual implementation. In Bolivia, these backups or institutional mechanisms to enforce formal regulations are being (re) constructed or in many situations they are simply absent, resulting in a very unstable, changing institutional situation (see also Del Callejo, 2010; Rocha et al., 2016; Seemann, 2014).

\subsection{Concluding remarks: Collective action and institutional development of the irrigation sector}

Peasant agriculture in Bolivia is still the sector that uses most water resources in the country, governed by local norms and practices under a changing, incipient state institutional framework and grounded in highly dynamic local institutional arrangements. Policy support for the agricultural sector, particularly that of peasant irrigated agriculture, has been implemented in different periods, from different development models, but with some common features. Some of these policies have emphasized the state's role in the productive sector, others have been more liberal, leaving agriculture and irrigation, to the "free play of market forces".

What remains as a result of state and nongovernmental actions is irrigation infrastructure and attempts to "re-regulate" the sector. In the institutional realm, on the one hand, water users, especially peasant irrigator leaders, have engaged in remarkably occupying power spheres and influencing national water institutions. On the other hand, irrigation systems, from below, are continuing to reproduce and recreate water-management practices and interactions between systems in complex ways, often in conflicting situations.

The new institutional framework, in an ongoing adjustment, poses several challenges and questions about its influence to create favorable conditions for greater water security for Bolivian peasant farmers. Important challenges and questions are, for example:

- Issues of equity between irrigators and non-irrigators, because the norm and the process of implementation of the new institutional framework appear to favor the irrigation 
sector; leaving impoverished peasant sectors with limited or no access to water (Crespo, 2006). Further, there is a lack of institutional mechanisms to improve management, distribution and access to state resources (funding, grants, technical assistance).

- While the state has favored the water sector by creating water-government agencies, mechanisms favoring inter-sectoral water management in river basins or at least coordinated action among all levels of government and water use sectors, nonetheless are incipient or remain absent.

- The drive to involve farmers and irrigators leaders in state agencies and creating supra organizations (national federations or associations of water users), seems not to be accompanied by mechanisms to ensure full legitimacy to represent peasants in such spaces. The same happens with these representatives' accountability to their constituencies. This has resulted in conflicting attempts to establish most of the Departmental Irrigation Services (SEDERIs) and, for example, internal conflicts and divisions in the Cochabamba Irrigators Federation.

In Bolivia, formalizing practices and norms under the state's official framework goes beyond just their "recognition"; rather, it implies a sense of "recomposing" the image and content of the usos y costumbres - even though it is supported by the image (and arguments) that this process is grounded in social demands, mobilizations and historical claims about recognition of customary norms. At the one hand we see a state that aims to take over control through "recognition politics". At the other, practice often shows the prevalence so far of usos $y$ costumbres and local institutional arrangements, without any need for formal recognition.

This chapter has shown the differences between policies and institutions in Bolivia, in comparison with other countries in the Andean region. In Bolivia, historically a strong organizational culture was built and revived after the 1952 national revolution through labor and agricultural unions and later by water-user organizations. Additionally, decentralizing the state such as in the 1990s has strengthened these organizations, this time around natural resources, particularly water. This has deconstructed the state apparatus, to extend its operational arms to lower levels, and in the opposite direction encouraged peasant mobilization to form national organizations. Before the MAS government came to power, this has raised a new structure for water governance and managing other natural resources, scaling-up peasant power and prevailing local forms in resource management and institution formation (Perreault, 2005, 2006; Roa-García, 2014; Rocha et al., 2016; VRHyR, 2013).

Meanwhile, local irrigation institutions have been built and are continually recreated through "uses and customs" including more than only rules, regulations and agreements for access to resources: they interrelate organizational practices, administrative arrangements, mobilization of resources, election of officers and representatives, etc. (Albo, 2004; Andolina, 2012; Hendriks, 2006; Perreault, 2008). In irrigation systems, they may include very specific operational aspects, such as water-distribution criteria and practices and system operation. These meanings and implications show water control as essentially a part of peasant organizations' "struggles for autonomy" (van der Ploeg, 2008), challenging state institutions and norms that seem to create more uncertainty and lack of control over managing their 
resources and livelihoods. Ongoing development of usos y costumbres also shows the importance of "legal shopping" and "institutional bricolage" as core elements in irrigation governance -- hence norms, rules, practices and thus institutions, are continuously recomposing (Benda-Beckmann, 1981; Benda-Beckmann et al. 1998; Cleaver and de Koning, 2015). They regain meaning in local contexts, because the different "localities" give their own meaning to the official institutional framework by using several resources: local interpretations and application of practices and customs, including also "normalized" rules (see also Boelens, 2008a, 2015; Long, 2001b; Roth et al., 2005, 2015).

In recent years, "normalizing" usos y costumbres under Evo Morales' MAS government raises several contradictions in Bolivia. The goal of explicit recognition by law was to defend peasant irrigators against other use sectors (giving them legal security). Generic recognition of usos $y$ costumbres seems to create several problems. One is that this recognition is "attached" to technical-administrative instruments (water-rights registration and authorization) yielding control to state institutions and local organizations. That issue is currently "in limbo" since neither national nor departmental irrigation services have technical facilities, trained and stable personnel, or the information to make decisions about it. This meant promoting the irrigation law for generic recognition of usos y costumbres and thus of water rights, though specific instruments are nonexistent. To a large extent, the current legal framework appears to be fictitious, and practice is different. In practice, these rights remained supported by the peasant mobilization forces that have prevailed. This shows again that the "usos y costumbres" (rather than registrations or authorizations) were and are locally regulating water management in practice. Here, an important aspect that determines uncertainty in the irrigation-policy institutional framework and, at the same time, the prevalence of customary ruling, is that state support (if present at all) is usually intermittent, depending on financial and political circumstances, e.g., being restricted to political elections. 


\section{Chapter 4 . Collective action for water control in peasant irrigation systems}

\subsection{Introduction}

This chapter discusses the various forms of organization through which collective action has been and is mobilized for accessing, controlling, maintaining and managing water for irrigation in the study area. I do so based on the notion of "social cohesion nuclei", defined as symbols and bastions of belonging which, in addition to family, historical and ethno-cultural ties, have facilitated the formation of peasant organizations for collective action in the Bolivian Highlands. These organizations initially mobilized for freedom, land and water. Yet once the first two objectives were achieved, accessing and later managing irrigation became one of the central social cohesion nuclei for peasants and communities.

Unlike most other Andean regions in Bolivia, communities in the valleys of Cochabamba do not come from a specific ethnic group or any particular "lineage". Instead, they are the result of complex relocation schemes and migration which started before the Spanish colonization. The composition of the communities is influenced by the valley's geographical location, its favorable characteristics for agriculture and its strategic position in terms of trade and transit of commodities and agricultural products between highlands and lowlands. Around this valley, as Barnes and Torrico Angulo (1971), Dandler (1984), and Lagos (1997) agree, communities have historically built social alliances of opposition and resistance against the hacienda regime or as a reaction against the state through the formation of social cohesion nuclei that change over time. Though initially organized against the hacienda system and for accessing land, in recent decades water has become one of the main social cohesion nuclei for rural communities and water users organizations and has led to the creation of broader water centred federations (see also Perreault 2005, 2006, 2008).

This chapter shows how in first instance community organizations and broader peasant unions mobilized around the 'peasant' or 'campesino' identity for accessing external investments for the construction of irrigation infrastructure that would allow for irrigated agriculture. For these broader organizations the claims related to accessing water for irrigated agriculture initially formed just one of the many demands they struggled for. Once water and infrastructure for irrigation materialized the organizations changed under the influence of the intervention projects and because of the changing internal dynamics that managing and controlling water on a day-to-day basis demands. This resulted in the creation of a large and very diverse array of organizational arrangements in and around water control. As is further described in this chapter I show that these arrangements are not fixed but that these co-evolve with the changing environmental, social, technical and political transformations that take place in the area. 
These processes of organizational development also challenge conventional discussions about participation The academic and professional literature on irrigation and development interventions often discusses (and encourages) the need to promote user participation, from the initial project idea to design and implementation (Cleaver, 1999; Gow and Vansant, 1983; Hendriks, 2002). This paradigm is based on several assumptions which in turn originate from different approaches and discussions on participation. Under a more instrumental approach, it is assumed that intervention outcomes will be "more appropriate" to local contexts and needs and more sustainable over time, inasmuch as local people get involved in the whole process. Other approaches view participation more from an empowerment perspective, no longer just a means to achieve certain goals but rather as an end, "empowering people to make their own activities and development projects" (Parfitt, 2004:539). Yet as I show in this chapter, the local populations are often already a participant in struggles for irrigation water before external intervention projects come into the area to develop irrigation systems. Therefore it is strange that intervention projects actively aim to incorporate 'them', 'the locals' in projects while in fact it is the external intervention projects that temporarily participate, transforming the local realities. Therefore in this chapter I discuss irrigation organizations' development, in a few case studies. This analysis shows amongst others the confrontations and conflicts during interventions, showing local organizations' progressive involvement. It shows how water users deal with, internalize and transform the ideas of intervention projects to make them fit to their own socio-cultural and environmental reality. This sets important question marks around the relations between users and their organizations vis-a-vis development and intervention projects. It also sets important question marks around notions of collective action and participation and how these are understood, lived and translated into water control in irrigation systems.

In this chapter's last section I also show how, through the creation of networks and alliances, the water users organizations have been able to up-scale their struggles (see Hoogesteger and Verzij1, 2015) and demands for water and for other state's services. These concentrate not only on water access but also and importantly to voice in decision making on matters that concern their day-to-day water use practices.

This chapter's discussion focuses on answering the following question:

How do the various forms of collective action in peasant irrigation systems become manifest and how do they inter-relate with the different dimensions of water control?

\subsection{Changing demands and organizations: From freedom to access to land, to water control}

\subsubsection{From "haciendas" and "piquerías" to peasant unions and communities}

It was fundamentally in and from the Upper Valley of Cochabamba (and particularly from the village of Ucureña) where Bolivia's mid- $20^{\text {th }}$ century peasant liberation movement emerged and succeeded. Many scholars, such as Barnes and Torrico-Angulo (1971), Dandler (1984), 
Kohl (1978) and Larson (1988), sustain this idea, elaborating on the success which resulted from this first peasant movement union formed long before land reform in the "Valle Alto". These authors also show that the peasant movement was growing simultaneously but with varying intensity in other regions of the country, either among hacienda workers (colonos), or outside haciendas, around them, promoted by "free" peasants who acquired land before the agrarian reform. Dandler (1984) describes how peasantry mobilization and "social consciousness" emerged and developed through the encounter among different social sectors such as workers, peasants and soldiers during the Chaco War in the early 1930s, and subsequent events that ended in the so-called "national revolution" of 1952. The peasant movement's leadership and increased visibility spread from Cochabamba's valleys to the rest of the country. At its base was the organization of communities that were struggling to defend their freedom and gain and maintain access to land, water and the means of production that would enable peasant communities to be free. This connection was based in part by the need of labourers to coordinate and upkeep water distribution within and between haciendas, and with local communities with access to water (Zimmerer, 2000). ${ }^{19}$ The political-economic context was given by relationships of exchange (barter), trade and production generated within and outside haciendas, especially with people in the main villages (pueblos): haciendas, merchants, craftsmen, etc. These included exchanges based on principles of reciprocity, but also relationships of dominating and controlling the work force and the surplus generated by peasants (Lagos, 1997). Protest against exploitative relationships contributed to the movement toward agrarian reform. Influenced by the political situation at that time which favoured peasant organizations, many labor movements across the region and the country as well as many indigenous rural communities took the form of agricultural unions. This trend also predominated in highland areas and other regions where indigenous communities existed before the Spanish colonization (Albó, 1987b). After the reform, there was a period of readjustment in rural social relations of production. Hacienda workers became peasant owners of small plots in the valley, under an individual land ownership regime, but under collective water management.

For decades, this shift also meant a gradual construction of the identity of the peasantry, as a social-organization structure, and this image was projected to the rest of society. Baud (2010), Kohl (1978) and Lagos (1997), among others, mention the search for creation of a new identity as a way of breaking with the prevalent image of "indios" (Indians) which had, and still has, a strong racist, discriminatory connotation. Farmers' unions used the peasant or 'campesino' identity as a symbol in social and political struggles for land and liberation and, simultaneously, it was deployed and deepened as the self-image of peasant communities. Its use appealed to the sense of cooperation for agricultural work in its different aspects, or to become visible when seeking other social vindications from the state. The formal structure and some organizational practices have been maintained to the present by peasant unions, even when developing new contents and creating new links. Despite all changes, the identity of peasants (campesinos) as

\footnotetext{
${ }^{19}$ Zimmerer (2000) states that in the Cochabamba valleys, during the Spanish colonial period but also before and after agrarian reform, water was one of the ordering factors for occupying land and, to some extent, for distributing land between communities and haciendas.
} 
workers of the land has remained strong. This identity as peasants has also been boosted by official sectors during Bolivia's agrarian transformation, as part of the rhetoric of liberation and alleged social equality. Officialdom or revolutionary movements have often used it as a political strategy to gain more support from rural areas; by adding an agrarian argument to the mobilizations. As part of this, most mobilizations have and still use the slogan: "Land to the tiller" (“La tierra para quien la trabaja”).

The country's peasant-union structure has followed the state's political and administrative division (as counterparts and, simultaneously, counterpowers, to state structures). At the national level, there is the Trade Union Confederation of Peasant Workers of Bolivia (CSUTCB). The second level (at the Departmental level) are the Departmental Federations of Peasants. Within these, the so-called "Centrales Campesinas" exist, corresponding to the provincial level, followed by the "Subcentrales Campesinas" (in what were cantonal subdivisions) covering a variable number of agrarian unions or communities, which are the lowest organizational unit.

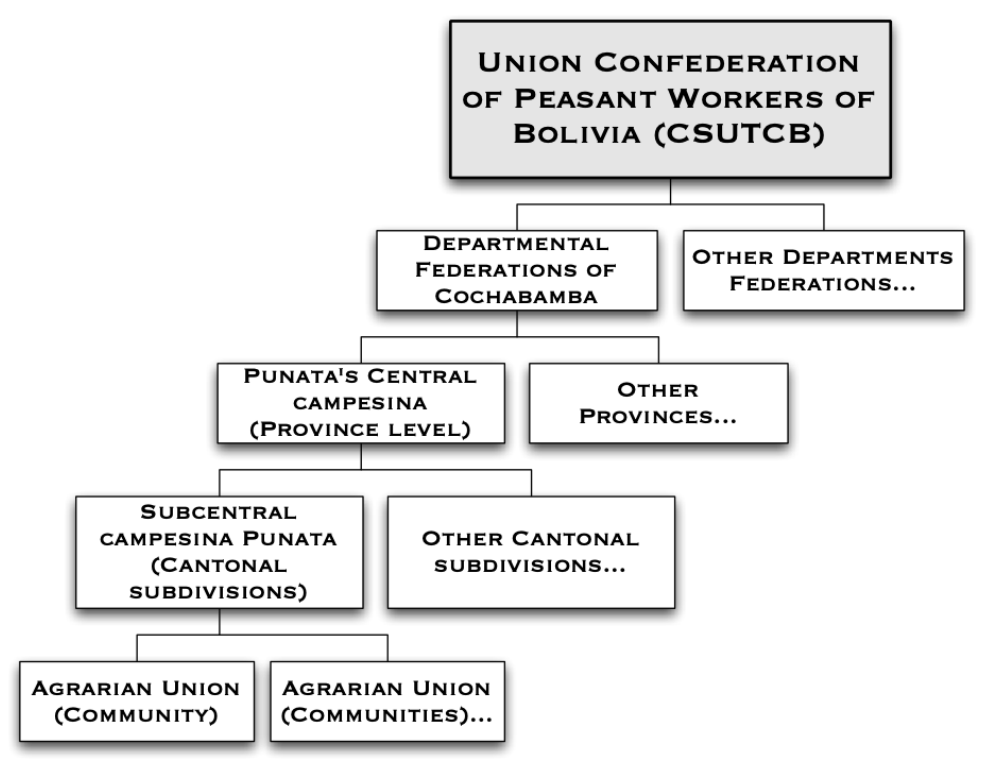

Figure 4-1. Organizational structure of agricultural unions in Bolivia

(Source: Prepared by the author)

In Punata and in most western regions of the country, agrarian unions' presence as an agent and instrument of political negotiations is still important, even though their relevance and importance in many areas has been overshadowed by other peasant organizations. De Morrée (1998) describes the different functions that communal peasant organizations perform, highlighting the dynamics within them, resulting in constant readjustment of organizational structures, positions and functions, and the creation and coexistence of various types of parallel 
peasant organizations. In general, these are promoted by new political circumstances, for specific community needs or in response to interventions by development projects.

Immediately after land reform, an important function of peasant unions was (officially) receiving land endowments to distribute among their affiliates. Other functions were (and still are) related to formal representation in dealing with actors and institutions "external" to the community; namely other peasant organizations, state institutions or NGOs. Another visible feature is to defend their communal land, territories and other resources. Internally, several functions have also been defined, in different regions, such as managing their resources (e.g. water and forests), organizing communal tasks, such as the building, rehabilitating and maintaining roads, schools, health centers, drinking water systems, etc. These tasks are usually coordinated with the technical and financial support of local governments or NGOs.

In this process of building what are now rural communities in the Cochabamba valleys and more broadly, three complementary elements of identity and cohesion favored strengthening of the community organization: land claims, social vindications and recognition (building a rural identity) and access to power spheres and government by means of approaching through political alliances the central government (Albo, 1987a). This whole process of organizing and unifying the region's peasantry has not been harmonious or conflict-free. Nor has there existed homogeneity and equality among peasants. On the contrary, in building their organizations or in different vindicatory mobilizations, there have been internal conflicts, reflecting imbalances in power relations (Lagos, 1997).

\subsubsection{From agrarian unions to "water communities"}

Punata Valley offers important illustrations of water-based peasant mobilization and collective action. This demonstrates not only its agricultural importance but also the organizational capacity to mobilize around water. Organizations and collective action were formed and driven by demands, conflicts and vindicatory movements associated with reform. These were facilitated and supported by existing ties and relations around collective water management. In Punata several irrigation systems and related water distribution arrangements were already operated (many in conjunctions between haciendas and free communities) before the land reform that started in the early 1950s.

After land reform, in Punata, several peasant irrigation organizations or water committees formed transforming the hacienda-based water management arrangements into collectively managed systems. In the 1960s new peasant committees were formed around the Laguna Robada system and later for the Lluska Khocha dam. Communities from Punata also made the first attempts to capture and harness the lagoon waters of Ovejeria Khocha that later would become the Totora Khocha system in the late 1980s (Gandarillas et al., 1993) (see Figure 4-7). As part of the Inter-Valley Irrigation Project (PRIV) that aimed to implement irrigation projects to improve the infrastructure of the existing systems in the valley, in 1993 the water users organizations that had managed the Laguna Robada, Lluska Khocha and the new Totora 
Khocha irrigation system, joined organizationally and created the user based Punata Irrigation and Services Association (ARSP).

At the local level, farmers from different Punata communities, particularly in the northern valley, organized into small committees to get support from various governmental and nongovernmental organizations to invest in drilling wells to access groundwater for irrigation. These systems started in the 1980s with state support and international cooperation to cope with severe drought conditions during that decade. Additionally, many farmers invested their money to create a new tube-well system. Thereafter groundwater use increased progressively in Punata, promoting formation of self-managed systems for irrigation, domestic drinking water or combined-use wells (Delgadillo and Lazarte, 2007b). In the late 90s, the groundwater dependent committees organized into the "Drilled-wells users' association of the Upper Valley” (AUPVA). AUPVA includes almost all Punata irrigation systems, several drinkingwater or combined-use systems and also similar systems in other provinces. In Punata there are currently more than 300 systems with well committees.

Some communities in southern Punata, in the peri-urban area, started using wastewater from the urban area during emergencies. After the municipality installed a sewage system and wastewater treatment plant in the late 1990s and early 2000s, a new organization was formed, the "Association of Irrigation with Wastewater", which includes five communities that created their rights to use this source (Camacho, 2007).

In the end, Punata Valley's different water sources are not able to cover water demand, and even less, distribute it uniformly for different areas and communities (Saldías et al., 2013). Beyond the 65 communities associated with the Totora Khocha dam and organized in the ARSP, there are many other communities downstream, south and southwest of Punata. These communities have no secure irrigation water, only sporadic flows when large river discharges arrive and fill the main river branches. To implement several new projects for the valley, they have formed a new organization, the "Association of Communities Without Irrigation" (Asociación de Comunidades Sin Riego). This organization continually competes and challenges existing organizations; making claims to get the Government's attention and get funding for their projects aimed at accessing irrigation. What is crucial to understand is that all this organizational development in Punata has resulted in an overlapping of organizations in different socio-territorial spaces. These organizations co-exist, compete and complement each other in different spaces of representation and political mobilization. Besides the participation in their own communities, this research has found that all peasant families living in different zones of Punata participate in at least two of these organizations. Families that are "closer to the water" may belong to four to seven of these organizations. Participation in these different organizations is an important strategy to sustain collective water-control which stands at the basis of household strategies for farm reproduction (see next chapter). 


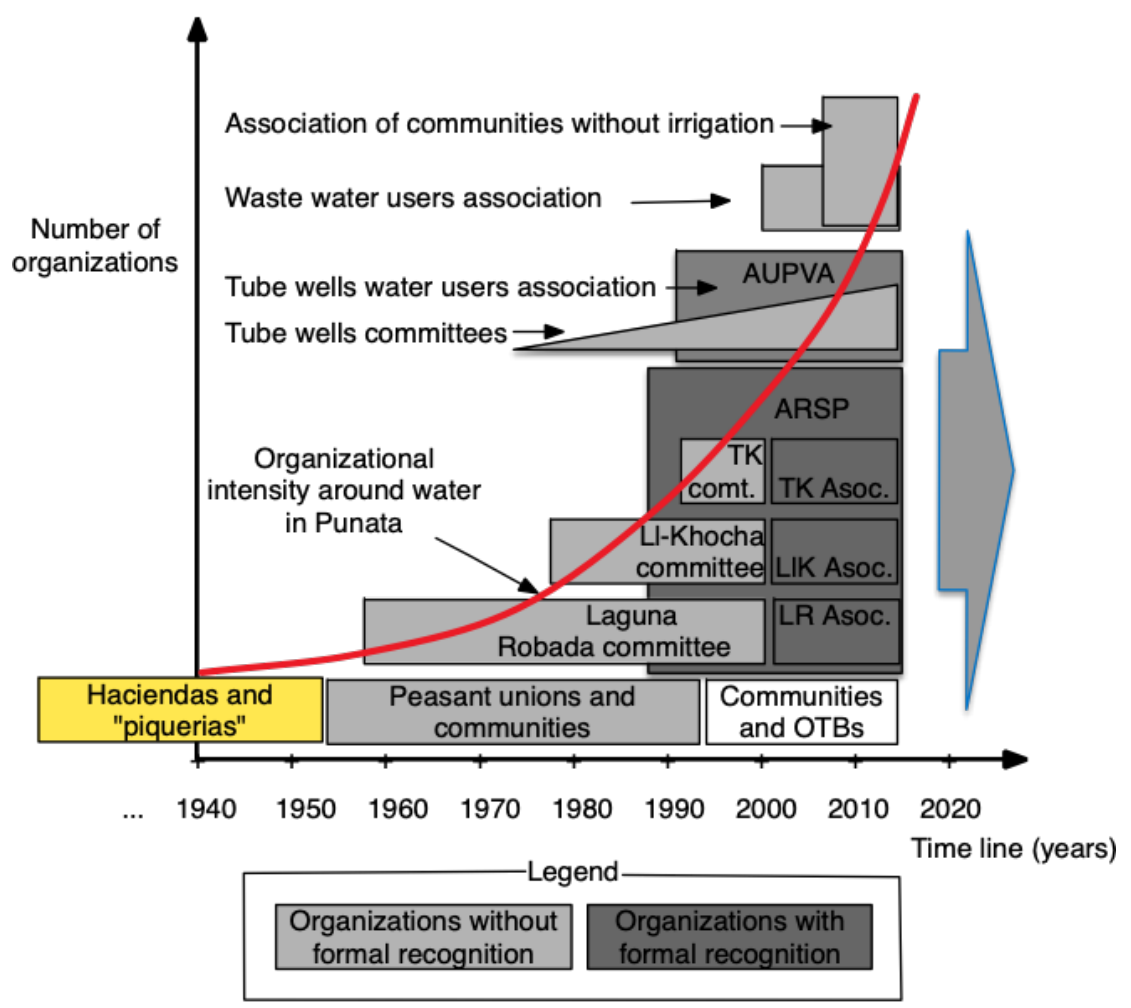

Figure 4-2. Social organizations for water in Punata

(Source: Prepared by the author)

Figure 4-2 shows how, over the last three decades, organizational dynamics in Punata regarding water, and especially irrigation, have increased. It highlights the progressive development of an increasing number of organizational structures in Punata. These different structures overlap, compete, negotiate and complement each other in a context of increased organizational multiplicity. The following sections analyze specific examples of the organizational forms that have developed in this area and through which collective action for water control is mobilized in the area.

At present irrigators in Punata argue that the traditional agricultural and peasant unions "have lost their strength" due to the increased influence of water centred organizations. However, in the northen communites of Punata these organizations are still active and alive, in particular to organize water distribution for the Mitha system (basic river flow). Here, within each community (peasant union) there is a "committee" to distribute water from different sources (especially Mitha and water from reservoirs). As a result, at community meetings, the main topic addressed is irrigation. Other topics, such as basic infrastructure, schools, roads, etc. are also discussed, but in the background or in passing. That discourages some community members without water rights from attending community assemblies. The weakening of communities organized as solely agricultural unions coincides and contrasts with the 
emergence of what we can call "water communities", which have surpassed boundaries, geographical, timing and other ties rooted in the peasant organization. Some examples that illustrate this are the well systems in Punata and elsewhere in Cochabamba. In these, 20 to 50 families organize to invest, drill and operate a well system. This organization makes its own rules. These small collectives that comprises farmers from various communities are no longer linked with their community organizations to guarantee their access to water. Another clear example is the peri-urban water committees along all Cochabamba's valleys (including Punata). There, communities or formalized Territorial Grassroots Organizations (OTBs) lost functionality, making room for water committees or associations (usually for domestic watersupply systems). These new organizations now deal with water and other communal tasks. They participate in municipal politics to demand resources and have in some way replaced OTBs and peasant unions.

In South Punata, in communities that have little or no irrigation water, communal organizations (agricultural unions) have still greater "force". This is because they are still the organizational basis to claim water whenever available, for instance to control the Rol-system water, sewage water, or claims for new (water) projects. Communal organizations, here, are the only hope that one day they also can join in water control benefits. This has also been visible in recent years, since these communities have begun to take control of Punata's top-level organization (Peasant Sub central), dividing this valley's peasant sector between irrigators (grouped in their own organizations) and communities without irrigation, strengthening union organizations and their supra-organizations. A similar situation to southern Punata is occurring in other zones of Cochabamba Valley, especially those with little water, such as Aiquile and Sacabamba, where paradoxically water issues are the main topics discussed at communal meetings.

\subsection{Organizational diversity and development: change and adaptation for water control}

This section discusses how usos y costumbres are expressed in organizational and operational tasks and in collective action at different levels. To illustrate how water control is organized and dynamically changes to deal with new socio-political and environmental conditions it presents cases from the irrigation systems of Sacabamba, Punata and Rumi Cancha (atajados systems). In addition to demonstrating the different water-control tasks, it also identifies key elements of collective action and how these are organized and have changed over time. The description of the cases and their dynamics shows how changes in technologies and in environmental variability, are accompanied by collective action and active participation of users in water control related activities and in organizational adaptations as the basis to ensure the sustenance and socio-technical sustainability of the irrigation systems. 


\subsubsection{Atajados systems in Aiquile: Land management related to water control}

Atajados systems consist of small reservoirs for harvesting rainwater from small catchment areas. These are used for either small scale irrigation or as water supply for cattle. Atajados are mainly constructed by individual families sometimes with the support of external projects. In Atajados systems three operational levels can be identified (see Figure 4-3): micro water catchment, including the canals to convey water to the reservoir (atajado); small dams, locally also called atajados; and the application zone (household farm fields) (Tammes et al., 2001). Decisions on how and when to capture and use water are also made by families. A key aspect of water control in these systems is access to catchment areas, which may be owned by the family, by other families, or in many cases, a portion of the catchment or the feeding canals to the atajados may be under communal control. In these last two situations, these areas may be disputed.

In Rumi Cancha, during the atajados project implementation, an organization was created ("the laguneros committee"), since not all members of the community would be project beneficiaries. To facilitate collaborative work among families the committee led the construction phase. Currently, this organization is latent, although it could meet again to resolve any dispute or problem between atajado users. However such disputes are usually discussed and solved by the communal organization. The committee, and especially the communal organization (farmers' union), played an important role in the negotiations and mediation among disputants.

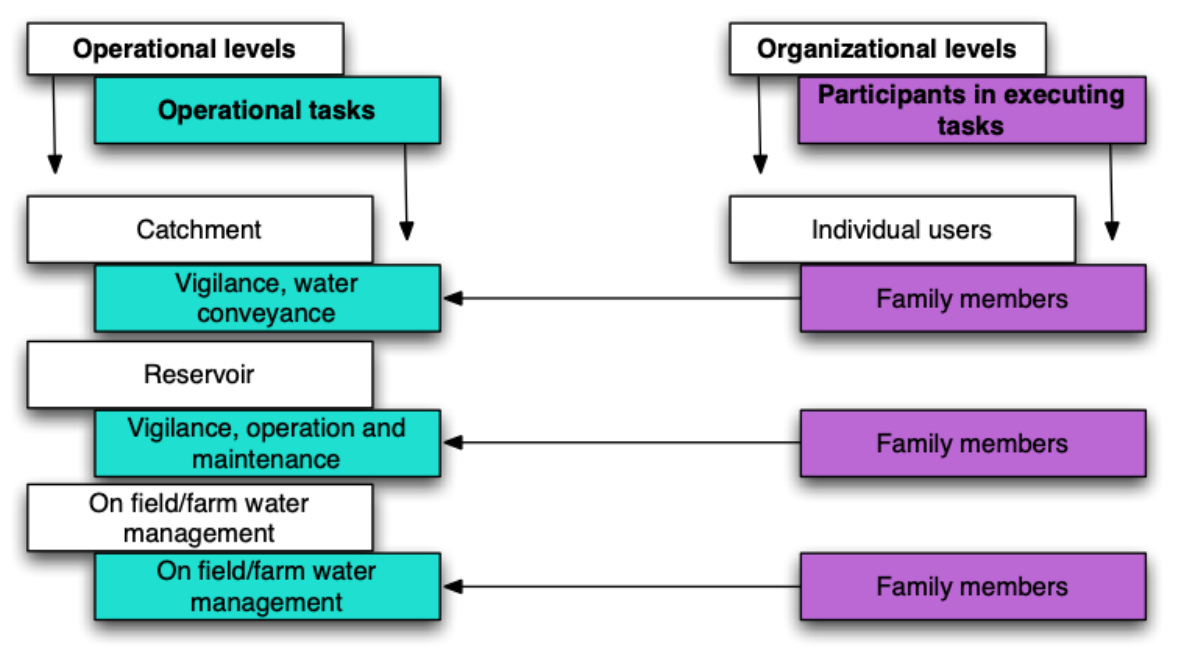

Figure 4-3. Operational and organizational water control in Rumi Cancha Atajados systems

(Source: prepared by the author)

Therefore, the technical and organizational dimensions of water control in practice in atajado systems rests primarily on the mobilization of family labor at the individual level. However, to 
solve problems among irrigators and with non-irrigators the community organization has played an important role. It has mediated in the resolution of conflicts. For several years, negotiations were facilitated between families, to coordinate the location of catchment channels that interfered with each other. In other cases, a more definitive solution was land exchange between users or sale of portions of land, so the capture area can be completely controlled by each family. The communal organization's commitment and actions were to raise funds and manage new projects to benefit families with no atajados. This case shows an example of individual water management and water control under the umbrella of a well-functioning communal organization.

\subsubsection{The Chiyara Khochi irrigation system, Sacabamba}

The case of the Chiyara Khochi irrigation system in Sacabamba, shows an interesting trajectory in developing irrigators and rural communities' organizational capacity. In this area that initially had no experience in water management, its organizational capacity revolved around the peasant unions, which played a fundamental role and became empowered.

Three main milestones can be identified in the development/adaptation of this water user's organization: The first one was the project's design and approval, in which peasant's union played a key role; the second was around project's implementation until the initial system's functioning in which an irrigation association was formed; and the third important milestone was the organizational and operational adaptations linked to the new interventions implemented in the system for lining main distributaries (north and southern channels). In this section, these changes, and the organizational development are discussed in front of the (new) technological and environmental conditions present in the area.

Cossio (2004) discusses the role played by the peasant subcentral of Challaq'e in negotiations, first with the Central Campesina of Sacabamba and then with the municipality. This highlights the pivotal role of farmers' organizations in rural municipalities' decision-making, which may define communities' fate, according to their leaders' capacity and the "organizations' strength" in these negotiations. As quoted by the same author, leadership by a representative of the Subcentral Challaq'e in the peasant Central (the region's parent organization) facilitated the creation of an alliance with an NGO (CIPCA) that was working on irrigation projects in the area. Their collective strategies of political pressure facilitated the approval by the Sacabamba municipal council to support the project.

These negotiations also defined which communities would be project "beneficiaries", excluding at least two communities that then expressed their interest in also being part of the project. As described in Chapter 1, four of the five user communities in the Chiyara Khochi system belong to the Challaq'e Subcentral and one to the Sacabamba Subcentral. The latter was included in the Project, partly because the Mayor had land in that community and could influence final selection of beneficiaries, since the municipal council is the entity that channels public funds or cooperation to finance such projects (Cossio, 2004). 
The limited possibilities of developing irrigation in the area, because of the scarcity of water resources, environmental constraints due to soil fragility and climatic constraints (frost), and the size of the population to be benefited (about 150 families), initially raised doubts about the feasibility of implementing irrigation projects in the area.

At this stage, one of the key elements for project approval was the political conditions prevailing at that moment of history in which administrative decentralization process started in Bolivia through the implementation of "Law of popular participation" since 1994. In Sacabamba as in most of other rural municipalities, local governments were gradually controlled by grassroots organizations (peasant unions). So, it was the best scenario for Challaqe and Sacabamba subcentrals to put their demands in first order in the municipal agenda.

After project approval and because of the high amount of investment and relatively small target population, the Challaqe subcentral, with CIPCA and the municipality, adopted a key strategy to make financing and project implementation viable. This strategy divided the project's various components as if they were separate projects, negotiating each component with different funders.

The irrigation organization started along with the implementation of the irrigation project in Sacabamba (in 1994), initially as "the project steering committee", under the control of the peasant union organization. Once the successive stages of the project were concluded, in 1999 it adopted the form of the Challaque Irrigation and Agricultural Services Association (ARSAC). This was the first irrigation organization in the area, and as in many other places in Bolivia, they adopted the structure of an agrarian union, although it was conceived as a parallel autonomous organization from peasant unions. The highest authority of the ARSAC consists of a general assembly of members, then a board in principle comprising a president, vice president, and four secretaries (operation and maintenance, recording minutes, finance, and conflicts).

Operationally, when the system started running, two canaleros (channels keepers) were included to assist in distributing water in the north and south channels; and an accountantsecretary for the administrative affairs (Vega and Iriarte, 2003).

Finally, the last organizational adaptation was crucial to reconcile the demands of water and irrigation practices in accordance with environmental and socioeconomic conditions. Vega and Iriarte (2003) identified three operational levels, although the first level, corresponding to the catchment area, can be differentiated into two: the water storage (dam) and the main water intake (diversion dam) from which water is captured and chanelled to the distribution system. The other level corresponds to the irrigated area (distribution between head-system, northern and southern sectors, see Figure 1-6) and finally irrigation blocks within communities. Water is used through "largadas" (reservoir water releases) defined as a total time in which all users have irrigation water according to their water rights. During a largada the dam is closed every night because irrigation is done only during the daytime. This is possible due to the relatively 
short distance between the reservoir and the irrigation area, so that not much water conduction time is needed.

Organizationally, the Chiyara Khochi system has a relatively simple structure, with two levels directly related to collective system management and one as individual users. The first level corresponds to the irrigators' association as a whole (ARSAC), then irrigation groups within the three sectors (header, north and south channels). These groups were organized some years after the system's initial operation, basically to support the work of canaleros (canal keepers) at fixed points, where water is distributed to groups of families. Individual users are directly served by canaleros.

As discussed by Cossio (2004), ARSAC began with a structure similar to a union organization (sindicato), but after some years of functioning some positions in the organization were cancelled because they were not functional at all. This was the case of the operation and maintenance secretary and the accounting secretary. Subsequently, new positions were created to meet operational requirements. These were the positions of a "vocal mayor" (major assistant) and five "vocaleros" or representatives of each community. Two commissions were also started (one per channel), with representatives from the five communities, to support the overloaded canaleros' work.

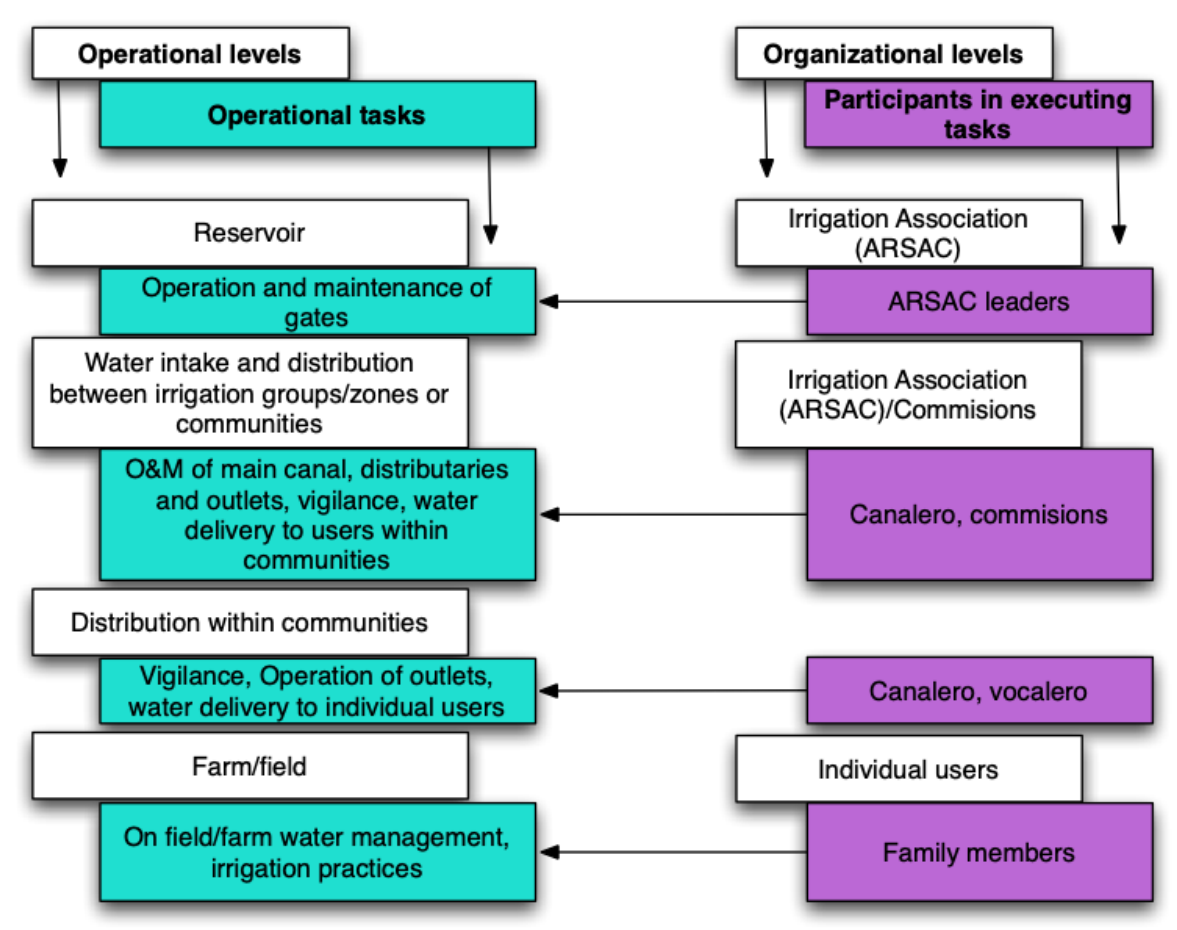

Figure 4-4. Operational and organizational water control levels in Chiyara Khochi system

(Source: Prepared by the author) 
The studies conducted by Vega and Iriarte (2003), Cossio (2004) and Chila and Delgadillo (2010) and the field work of this study, show that the system is in continuous process of management adjustments.

In addition to the organizational levels directly involved in management (as depicted in Figure 4.4.), trade unions (peasant unions and peasant sub-central) retain a fundamental role in the area, especially in the political arena. These organizations have directly influenced the system's creation but also indirectly through the municipal government. Cossio (2004) describes how these organizations' peasant leaders and representatives influence the municipality to include a community as project beneficiary. Currently, these organizations' role is important. While not directly involved in water management, they demonstrate their presence and interest in consolidating existing water rights. Possible compensation for injustices or inequities, through direct negotiations with the municipality, and new projects for communities not currently benefited, are aims they seek to accomplish. In turn, this is connected with these organizations' growing interest and control over the local government, which they view as an opportunity to access and negotiate greater benefits for their communities.

\section{Trial and error in the Chiyara Khochi system. The materialization of physical and organizational water control}

Today the Chiyara Khochi system is composed by various user communities and an irrigators' organization that have to coordinate to manage the irrigation system which depends on a dam. The Chiyara Khochi irrigation system is relatively young in its experience and operation. Being a new system, it is still in the experimental stage, making adjustments in water management and therefore in developing water-control practices.

In order to demonstrate the close link between organizational requirements and adaptations and current irrigation practices, the main characteristics of the system are summarized as follows:

- System's water source is located relatively close to the main intake and to the upper part of the irrigation area (less than $1 \mathrm{~km}$ ), with no irrigation communities along the route, or at the reservoir's basin, so there is no direct interaction with other water systems and organizations.

- Soils in the irrigated area are highly susceptible to erosion because of their texture, structure, reduced plant cover, steep slopes and shallow depths. This condition imposes that field irrigation should be performed with small discharges, long irrigation times, only during day time and with large labor requirements (two or more family members).

These conditions have progressively marked the way the system is operated and all the organizational adaptations.

The system runs by water releases (largadas) from the dam, lasting 4 to 5 days. Water allocation is performed by different water flows simultaneously leading to different sectors (header, north and south) and among them to different irrigation blocks. Each user receives a 
flow of 5 1/s for 8 hours, this amount being referred to as an "irrigation share". The irrigation system operates only in the daytime, hence the dam's gate must be closed late every afternoon. A year can have only 10 to 12 water releases (largadas), scheduled from June to December (Vega and Iriarte, 2003).

The flows that are handled in the plot do not exceed $51 / \mathrm{s}$, therefore the application times are long. This form of application matches the sandy soil types that could not stand larger flows and consequently defines the requirements for water distribution and operating and organizing the entire system. The result is a high operational intensity (technical and organizational dimensions of water control) at all levels: starting from the daily opening and closing of the dam during a water release (largada) and also for water-distribution tasks such as dividing flows and delivery to each user. This, in turn, requires high organizational accompaniment by the Irrigation Association. For instance, leaders have experimented with organizing irrigation groups or including community commissions to help canaleros with water distribution, since this task is beyond the canaleros' current capacities.

At the plot level as well, irrigation practice may be intensive, despite the small discharges applied to the fields. At least two, but sometimes three or even four family members, participate during field irrigation. It is not an exclusively male task but usually the couple and children participate in irrigating family plots.

This Chiyara Khochi system case shows the tension between the physical elements of water control (expressed as the need to apply low flow rates for long times during day times only at the plot level) and the organizational elements. Physical-technical requirements generated very high organizational requirements (daily opening and closing of dam gates, dividing water into two or three main flows, subdividing flows for groups and to individual users) which were implemented through successive organizational adaptations.

Finally, in an effort to improve the system's infrastructure since 2010, ARSAC and communal organizations (peasant unions) started new rounds of negotiations and actions to get new projects for their communities and families. Through the current support from state programs on water (MI AGUA and MI RIEGO programs), they executed new canal-lining projects in southern and northern canals and some of the distributaries as well as projects to build secondary regulation systems through individual reservoirs (atajados).

\subsubsection{The Punata Irrigation Systems}

The case of Punata is the most emblematic in terms of development and empowerment of local organizations. This empowerment began after the land reform, when several communities assumed the management of dam systems by "committees" organized by themselves. Later, starting in the 1960s, various irrigation "improvement projects" (construction of irrigation infrastructure) were implemented. Some were directly demanded by the irrigation committees to the central government (Ministry of Agriculture) at that moment. These projects, and especially the experience from the "Inter- Valleys Irrigation Project" (PRIV), unveiled Punata communities' organizational and self-management capacity. 
Gandarillas et al. (1993) recount in great detail the experience of the Punata Inter-Valley Irrigation Project (PRIV). This experience has been a very important contribution to understanding irrigation in Bolivia and the Andes, by exposing or uncovering what previous engineering approaches had treated as a "black box". Among the aspects that stand out is the clash between technocratic approaches adopted at the start of interventions versus peasant organizational and irrigation practices. Gradually, mutual learning has developed new capabilities in organizations, as a result of ongoing negotiations, conflicts and confrontations with new experiences, resulting from interaction between different groups of irrigators and the project's technical staff. Within this, the main issue has proven to be the process of defining "water rights", their different forms of creation, expressions, content and operational implications. This definition mainly applies to subsequent irrigation infrastructure re-designs and construction and water distribution in practice, all immersed in what Coward (1990), Gerbrandy and Hoogendam (1998) and Boelens and Vos (2014) call "creating hydraulic property" (see summary in Box 4.1).

Table 4-1 summarizes some important milestones in irrigation interventions and the different organizational adjustments and strategies employed by Punata's irrigators. Some interventions by the state, development agencies or irrigation organizations, pursued strategies initially based on social mobilization. These mobilizations were demands and protests against projects that violated water rights, hampered organizational and irrigation practices, or in other cases limited the flexibility required to handle the infrastructure to manage several systems simultaneously. The undeniable presence of large numbers of peasants when providing labor input, building and reaffirming their water rights during the works, was also important.

Table 4-1. Main irrigation interventions and organizational adaptations and strategies

\begin{tabular}{|l|l|l|l|}
\hline Year & $\begin{array}{l}\text { Description of } \\
\text { interventions }\end{array}$ & $\begin{array}{l}\text { Organizational } \\
\text { development/adaptation }\end{array}$ & $\begin{array}{l}\text { Collective strategies during } \\
\text { interventions }\end{array}$ \\
\hline 1952 & Land reform & $\begin{array}{l}\text { Social alliances with labor unions } \\
\text { and other social sectors }\end{array}$ \\
\hline $\begin{array}{l}1968- \\
1970\end{array}$ & $\begin{array}{l}\text { Konstruction of Llusk'a } \\
\text { Khocha dam }\end{array}$ & $\begin{array}{l}\text { 10 Communities organized } \\
\text { around a new water source }\end{array}$ & $\begin{array}{l}\text { Collective work for creating new } \\
\text { water rights }\end{array}$ \\
\hline $1982-$ & $\begin{array}{l}\text { Improvement (expansion) } \\
\text { of Laguna Robada and } \\
\text { Llusk'a Khocha dams } \\
\text { (Punata Project phase I) }\end{array}$ & $\begin{array}{l}\text { Autonomous irrigation } \\
\text { committees structured for each } \\
\text { reservoir system }\end{array}$ & $\begin{array}{l}\text { Mobilization, Organization and } \\
\text { execution of collective work }\end{array}$ \\
\hline $\begin{array}{l}1989- \\
1991\end{array}$ & $\begin{array}{l}\text { Execution of Totora } \\
\text { Khocha project } \\
\text { (Construction of the dam, } \\
\text { and main channels (Punata } \\
\text { Project phase II) }\end{array}$ & $\begin{array}{l}\text { Punata Irrigation and Services } \\
\text { Association conformed (ARSP) }\end{array}$ & $\begin{array}{l}\text { Collective work, Mobilization } \\
\text { (demonstrations of “social force"), } \\
\text { Protests against water rights } \\
\text { definition and main infrastructure's } \\
\text { design) }\end{array}$ \\
\hline
\end{tabular}




\begin{tabular}{|c|c|c|c|}
\hline $\begin{array}{l}1992- \\
1994\end{array}$ & $\begin{array}{l}\text { Operation and maintenance } \\
\text { and support to on farm } \\
\text { irrigation }\end{array}$ & $\begin{array}{l}\text { Internal adjustments to ARSP's } \\
\text { operational structure }\end{array}$ & $\begin{array}{l}\text { Collective work, } \\
\text { Organizational adaptations (internal } \\
\text { tensions in the ARSP) }\end{array}$ \\
\hline $\begin{array}{l}1994 \\
- \\
1997\end{array}$ & $\begin{array}{l}\text { Self management of dams } \\
\text { systems }\end{array}$ & $\begin{array}{l}\text { Crisis within ARSP: unbalance } \\
\text { in power relations among the } \\
\text { three dam systems } \\
\text { New restructuring of ARSP: } \\
\text { Council of Committees } \\
\text { conformed }\end{array}$ & $\begin{array}{l}\text { - Organizational adaptation: } \\
\text { Laguna Robada and Llusk'a } \\
\text { Khocha committees threatened to } \\
\text { quit ARSP } \\
\text { - Lluska Khocha and Laguna } \\
\text { Robada transformed themselves } \\
\text { into new Associations } \\
\text { - Rotation of ARSP's leading } \\
\text { positions by committees }\end{array}$ \\
\hline $\begin{array}{l}1997- \\
2004\end{array}$ & $\begin{array}{l}\text { Negotiations and execution } \\
\text { of new projects by ARSP: } \\
\text { Mora Mora and Warmi } \\
\text { Waqana Projects } \\
\text { New projects of drilling } \\
\text { wells }\end{array}$ & $\begin{array}{l}\text { New tube wells committees and } \\
\text { tube wells association formed }\end{array}$ & $\begin{array}{l}\text { Demands and new projects } \\
\text { negotiations with regional and } \\
\text { national authorities, lobbying }\end{array}$ \\
\hline $\begin{array}{l}2004- \\
2006\end{array}$ & $\begin{array}{l}\text { Improvement of tertiary } \\
\text { channels ("Project Punata", } \\
\text { implemented in various } \\
\text { phases) }\end{array}$ & $\begin{array}{l}\text { Association of "Communities } \\
\text { without irrigation" formed }\end{array}$ & $\begin{array}{l}\text { Demands, } \\
\text { Project management, } \\
\text { Political alliances with regional } \\
\text { government }\end{array}$ \\
\hline $\begin{array}{l}2007- \\
2010\end{array}$ & $\begin{array}{l}\text { Design of Vandiola Project } \\
\text { (expansion of Totora } \\
\text { Khocha system) }\end{array}$ & $\begin{array}{l}\text { Vandiola steering committee in } \\
\text { Punata formed. Tensions } \\
\text { between Punata and Tiraque to } \\
\text { negotiate new distribution of } \\
\text { water shares. }\end{array}$ & $\begin{array}{l}\text { Demands, mobilization and } \\
\text { protests. Conflicts and negotiations } \\
\text { of agreements (with Tiraque and } \\
\text { Koari , Irrigators federation - } \\
\text { FRIA) } \\
\text { Aliances with other irrigation } \\
\text { organizations }\end{array}$ \\
\hline 2010 - & $\begin{array}{l}\text { Irrigation projects under } \\
\text { MI AGUA and MI RIEGO } \\
\text { Programs }\end{array}$ & $\begin{array}{l}\text { New tube wells systems formed } \\
\text { and lining of secondary/tertiary } \\
\text { channels }\end{array}$ & $\begin{array}{l}\text { Demands to municipal and regional } \\
\text { government (lobbying) } \\
\text { Elaboration of project profiles }\end{array}$ \\
\hline
\end{tabular}

Source: Prepared by the author

The Punata Irrigation and Services Association (ARSP) was formed to support the management of all Punata dam systems (Laguna Robada, Lluska Khocha and Totora Khocha) although during the early years, its tasks were mainly (only) focused to support Totora Khocha's operation.

Initially, the ARSP was formed under a typical corporate structure, plus traits of the union structure predominant in the Cochabamba valleys (see figure 4-5). The directorate (directorio) had a president, vice president, and various technical and administrative functions or portfolios. The highest decision-making level was the General Assembly of Members, although this was not in the original design. Additionally, an intermediate function between the assembly and the 
directorate was occupied by representatives of each community in what was called a Junta Directiva (board of directors). After a few years of operation, now without the Project's intervention, the organization took its own form after an internal crisis in 1997.

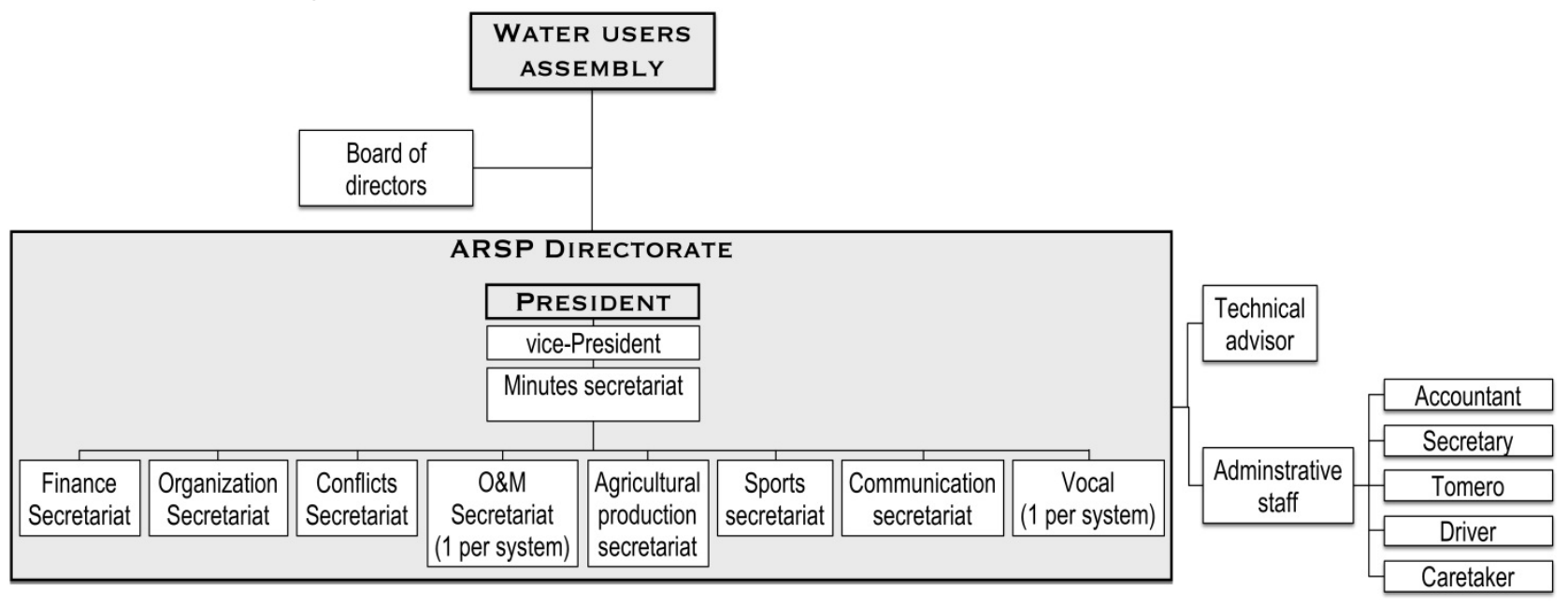

Figure 4-5. The initial organization structure of the ARSP

(Source: Prepared by the author based on Montaño, 1995)

The Laguna Robada and Llusk'a Khocha irrigation committees that existed years before ARSP's birth, threatened to retreat from that organization and to set up their own associations, because they neither received the benefits to which they were entitled by belonging to ARSP, nor occupied the expected position on the decision making and power structure within that organization. Some examples of the conflicts or the complaints of these organizations were about the difficulties to receive actual support (transportation or other facilities) from ARSP for inspections or the operation of the dams, but also because in successive elections of the ARSP's directorate, main positions were always chosen to Totora Khocha's leaders and not to people from the other two systems.

At the beginning of this organizational crisis, the irrigation committees changed their names, also becoming associations of irrigators for each dam. That is to say, at one point there were two "associations" that were part of the ARSP. Then, after long rounds of negotiations, they implemented the following settings as depicted in figure 4-6: 


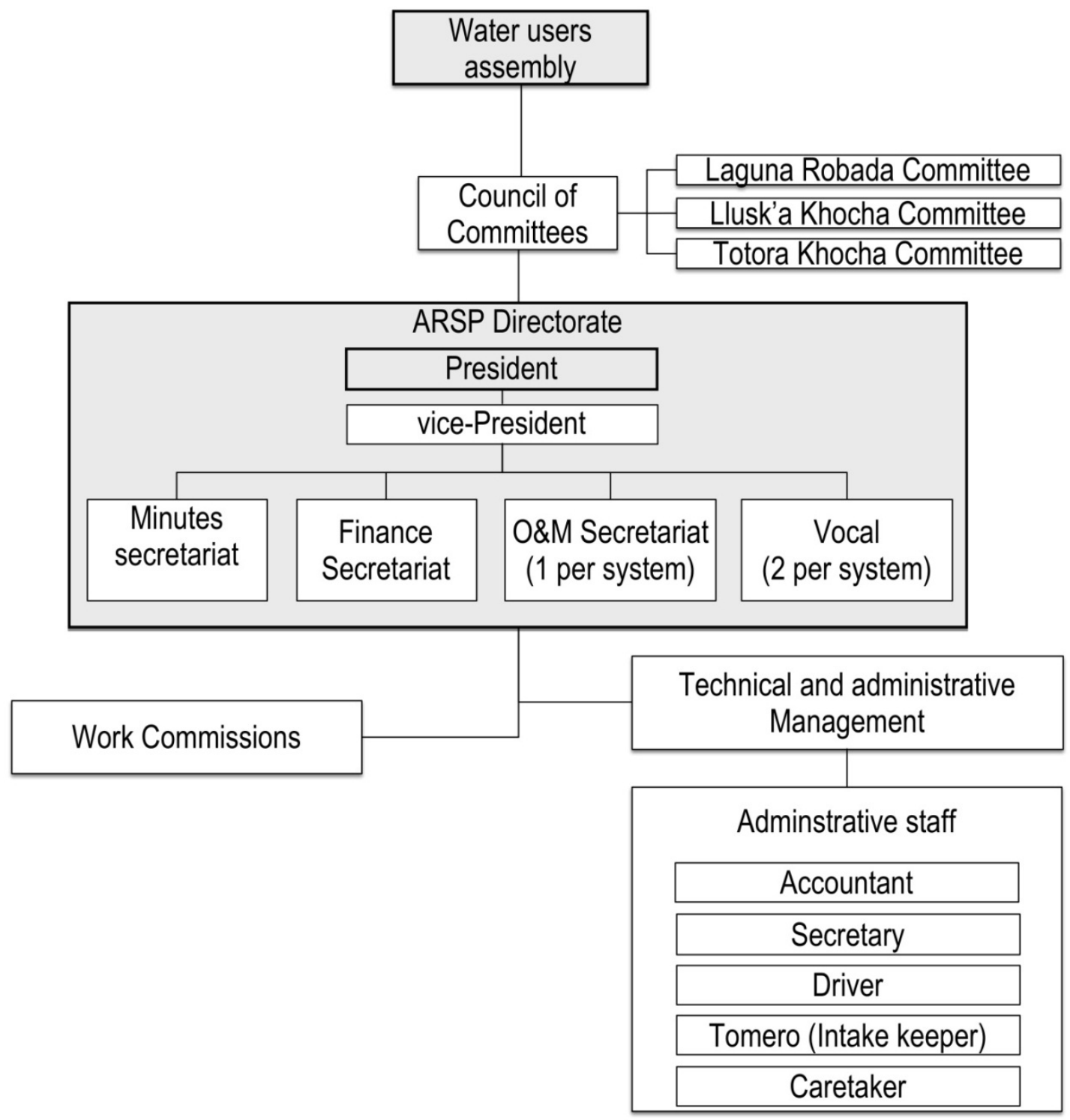

Figure 4-6 Current organizational structure of ARSP

(Source: Prepared by the author based on Ampuero, 2007 and Saldías, 2009)

1. Some functions within the Directorate structure disappeared, because of their reduced, unclear or not functional tasks.

2. The general assembly is recognized as the highest decision-making body, although at the beginning it was not clear how this body might work because of the number of affiliates (more than 3000). Ultimately, the Assembly is an important representation mechanism for raising demands from both communities and individual users to the Association's board, and also as a mechanism of accountability to the communities for actions by the ARSP Directorate. In this case, it was agreed that the assembly has one representative out of each ten community members. Each community is responsible for exercising this right.

3. The Board of Directors, consisting of representatives from all user communities plus the ARSP officers, was replaced by a "Council of Committees." This was because of 
the apparent duplication or confusion of roles between the assembly and the board of directors and the very limited participation of committees from Laguna Robada and Llusk'a Khocha in making ARSP decisions. The board, created from the ARSP's start, was one of the first adjustments proposed by farmers, as a social control instrument, to "monitor" leaders' work. Its role was crucial, especially at the ARSP formation stage, seen as a new way of organizing and uniting farmers and other peasant organizations. Being responsible for managing systems that were being intervened was an important role, too, which later became less crucial. Currently, the Council of Committees comprises representatives of the three irrigation dams' committees, which was an important step to balance the benefits and obligations they owe to the association, as well as to achieve equity among ARPS member organizations and to balance power in decision making.

This shows that the organizational model influenced (or promoted) by the project was not consistent with the irrigators' organizational logic. They sought equal support for all three committees, besides balancing these organizations' status, with none subordinate to another, all having the same rank: A question of image, hierarchy and equity.

It is interesting to see, in this case, that irrigation organizations in Punata (Laguna Robada and Llusk'a Khocha Committees), used the model or icon of an "irrigation association" as promoted also by the project as a "stronger" organization. So, they changed the status of their own organization from a committee to an association, as a strategy to improve their political position and try to balance power relations within ARSP.

After completing the main interventions in Punata and transferring management to users, the latter started searching for government and international donor support to implement more projects, to improve their systems or to build new ones. Some strategies also involved political alliances with the Cochabamba regional government (at that time, the Prefecture), to meet their demands. Between 2004 and 2007, several projects improved channels, with funds from the prefecture and directly managed by the ARSP as the "executing entity". Riding electoral situations or other political confrontations in the country and the region, irrigators in Punata and the Cochabamba Upper Valley were continuously demanding even more ambitious and expensive projects. These included the Yungas de Vandiola project, to cover the Totora Khocha system water deficit. This project especially reveals the management and negotiation skills developed by the Tiraque and Punata associations. These associations are directly related to other organizations in the basin, to the central government, the provincial government and even international donors' representatives. Other examples are the Kewiña Khocha project, or the Lope Mendoza project, to transfer and regulate flow from other basins to irrigate different areas of the Upper Valley. In all these cases, project approval, design and implementation go through many negotiation stages and cycles. The first stage is negotiations between potential users and then between different, mainly peasant organizations, claiming territorial rights over water in the watershed. 
Box 4-1. Synthesis of the experience gained while implementing the Programme and Inter-Valley Irrigation Project (Prav and PRIV) in Punata*.

In 1977, Prav (Highland and Valleys Irrigation Program) started, based on an agreement between the Governments of Bolivia and Germany. In the Valleys, it included building dams in Tiraque, to irrigate Punata and Tiraque.

The project started with an ambitious plan to integrate all the river basin's sources into a single system, with the following objectives:

- Reduce migration to urban centers

- Promote food security

- Raise peasants' standard of living

- Create new jobs

- Increase agricultural production and productivity (Source: PRIV final report, 1996).

Timeline:

- In 1978, reconstruction of the Laguna Robada dam

- Construction of the Koari dam

- Since 1982, construction of Lluska Khocha / Muyu Laguna Loma dams and expanding Laguna Robada

- From 1985 Khocha Totora design, starting construction in 1988

- In 1988, a specific project began (called Proyecto MAYOR) to provide technical assistance in agriculture and field irrigation

- In 1990 main works were completed. Khocha Totora started operating in 1991.

- In 1990, and due to gradual restructuring of the Ministry of Agriculture and its relationship with German cooperation, the PRIV (Inter Valley Irrigation Project) began, to complete all works from previous phases and "... prepare and support system operation and maintenance by users organized into water-user associations. Through its extension service, the project seeks to improve the economic and productive use of irrigation ..." (Gandarillas et al. 1993: 22).

- The program concluded in 1994, with final transfer of infrastructure and management to users.

\section{Major disagreements, re-encounters and reversals along interventions}

- Difficulties with the works design. Farmers "did not allow engineers to work."

- Several works in the irrigation area had to be re-designed and rebuilt as being inappropriate to socio-territorial demarcations or constituting obstacles to current practices: breaking communal boundaries and avoiding "traditional irrigation practices" such as "lameo" (land recovery near river banks).

- Long conflicts and negotiations between projected water users and the supposed "water owners" (Punata and Tiraque). - Repeated failures in agricultural extension services (new crops) and technical assistance in farm irrigation: The engineers believed that peasants did not know how to irrigate and farmers thought that engineers did know. After some time, both changed their minds.

- A first project turning point was to "promote" their activities more, organize more meetings, newsletters, media, new communication strategies. The results appear to be the same.

- A new project turn-around: try to listen and understand what was happening in the field.

- The final stage was changing the engineers' role, from "development promoters" to "companions of peasant projects". Finding organizations' progressive empowerment.

\section{Some lessons learned from this experience:}

- The highly responsive capabilities of farmers to address problems, redefinitions or decisions to be made in designing and implementing works.

- The need to first understand their practices and the context in which they take place before implementing extension programs or technical assistance.

- The need for flexibility in project implementation time.

- Engineers need to be prepared for understanding "farmers co-design".

- Despite being an eminently infrastructural engineering project, its dynamics showed that, in this case, it was more important to define water rights' many dimensions: practical or concrete but also symbolic and political.

* This experience is discussed in detail in the PRIV 1992 publication: "God gives water - What do projects do?" (Gandarillas et al. 1993).

Later, negotiations with the central government and international cooperation, to channel the required funding. Further, negotiations, pressuring and lobbying the regional government through peasant representatives in the departmental legislative assembly or direct negotiation with departmental authorities for project approval. 


\subsubsection{Organizational requirements for operational/technical water control in reservoir systems in Punata}

Reservoir systems in Punata are operated through water releases (largadas) from the dams. These largadas last from one to two weeks depending on the source, until all users with water rights to these sources have been served according to their corresponding "shares" (water rights). The three dams (Laguna Robada, Llusk'a Khocha and Totora Khocha) deliver relatively large discharges to individual users (between 80 and 200 1/s). As explained in Section 1.4 , the main irrigation principle from these sources is applying large discharges in a short time (a few minutes up to 30 minutes) also referred to as "wild flooding" (Bos and Nugteren, 1990). The logic behind the practice and interplay between the different operational and organizational levels can be explained as follows:

Water releases (largadas) from the dams should be for the shortest possible number of days. This is because of the water losses due to the distance to convey water through the river from the reservoirs to the irrigation zone $(25-40 \mathrm{~km})$ and also because of the agricultural settlements along the entire route. The only way to reduce losses is to send large flows from the dams. In the irrigation area, it would be possible to divide "more manageable" flows, however this would extend the run time by a ratio inversely proportional to the decrease in the flow rate or the increase in the number of people who irrigate simultaneously with reduced flow. This means that besides the control along the river, control and surveillance in the irrigation zone would also have to be increased proportionally.

In this case, water control is expressed organizationally in different ways: Organizing groups of "tomeros" (intake keepers) is a way in which users make sure there is no water theft along the entire route from the source to the irrigation area. Crucial also is maintenance work at the community and system level, as in the case of Totora Khocha, where the community organizes brigades that monitor the inter-basin conveyance channel. They also monitor the irrigation area through community groups that irrigate simultaneously, in addition to organizing turns within each community. At the family domain, this also involves organizing work, determining who is watching the water's path and who is managing water on the plot.

Socioeconomic and political dimensions are expressed by the original agreements and ongoing negotiations between irrigation committees of Tiraque (on the upper part where the reservoirs are located) and Punata, and the agreements, negotiations or conflicts with populations along the river. 


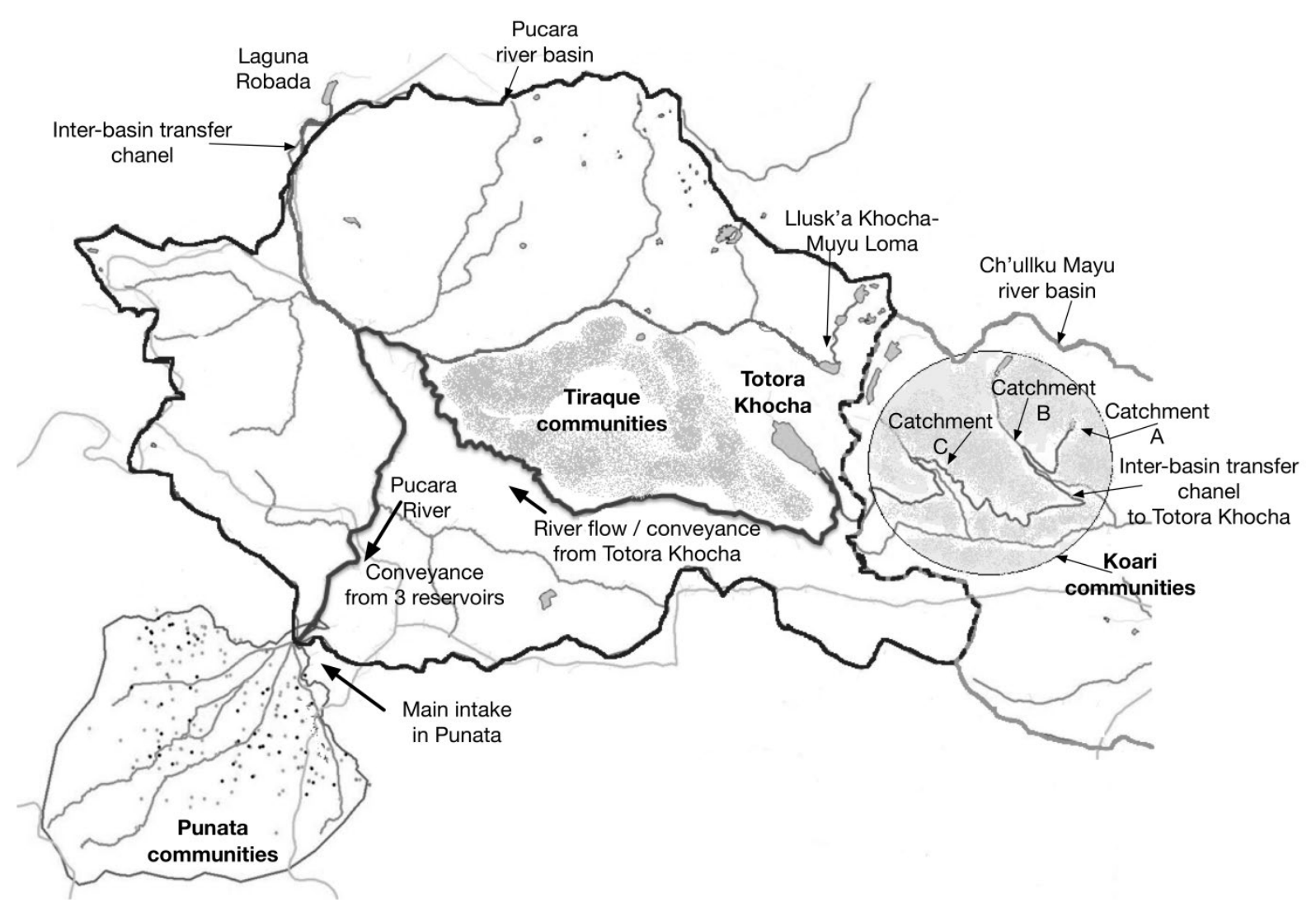

Figure 4-7. Punata's reservoir systems and inter-basin water transfers

(Source: Prepared by the author based on Delgadillo and Durán, 2012)

Internally as well, there are mechanisms used to define largada water release dates, the watersharing agreements, and fines or charges for selling the remaining water flows at the end of the largadas (called "tails" ${ }^{20}$ ). In the technical dimension, there are activities starting with opening dam gates, operation of the main intake in the river, flow division and driving water through the correct channels to deliver water to each user to apply on their plot.

The reciprocal relationship between the levels of individual and collective water control in the Punata reservoir systems is evident. Thus, simply by changing (sub-dividing) the delivery flow, the necessary operating levels in the system (distribution points) are also increased. This also has direct organizational implications for the irrigation system and for organizing family labor. All these management and organization practices mean that large discharges are delivered for short periods to each user. An important water control factor has proven to be soil characteristics. Water users prefer whenever possible deeper soils with high water-storage

\footnotetext{
20 The dams operate by discontinuous flow or largada water releases and not as continuous flow. Due to the distance between the reservoir and the irrigation area, some hours before the end of an irrigation turn, the dam gate is closed and the residual flow of water is used to complete irrigation for the last communities in turn. However, most often, after finishing an irrigation turn, a reduced flow remains in the river for some hours. This flow of water is called the "water tail" (cola de agua) and is sold by each committee as a turn according to a certain order of request made from irrigators. The directors of each irrigation committee define how and when to start selling those turns. The funds generated are to operate the irrigation committee itself.
} 
capacity - this way, irrigators in Punata try to "store" their water share in the soil, which has direct technical, organizational and normative consequences. This practice also partly explains why crops are produced with relatively long irrigation intervals (Del Callejo and Vásquez, 2007). Considering the different water control dimensions and levels also helps understand the results of irrigation practices in terms water-use efficiencies. At the plot level, irrigation efficiencies are relatively high (70-80\%) (Delgadillo, 2003b; Romero, 1998). They are accompanied by water and soil management practices that farmers have developed over years of experimentation to optimize water use (Delgadillo, 2003b).

Different management and water control capabilities are seen at the level of irrigation systems. For example, the dams of Laguna Roboda and Lluska Khocha show different reservoir management practices, water conveyance, and water distribution and response to their systems' physical and socio-territorial conditions. The committee of Laguna Robada has demonstrated high organizational capacity for negotiating with communities upstream. Therefore, this results in reliable, relatively stable operations over the years, making it well-recognized and valued as a system in the Punata valley. Lluska Khocha, by contrast, has undergone a gradual "decay" for several years, resulting in greater water-access insecurity in terms of frequency and flow. This is due to the increased pressure from communities around the dam, the physical condition of the reservoir's water feeding channel, in addition to losses along the river. In both cases, a decrease in overall conveyance efficiency is observed, being much more critical in the case of Lluska Khocha (with efficiencies as low as $20 \%$ ).

Figure 4-8 shows a trend to increase flow rates at the dam gates and decrease the flow that reaches the main intake in Punata. This shows "water losses" along the path, which in fact reflect irrigation systems' increased vulnerability to territorial claims by communities upstream and water theft along the water course, especially in the Lluska Khocha system and, to a lesser degree, in Laguna Robada.

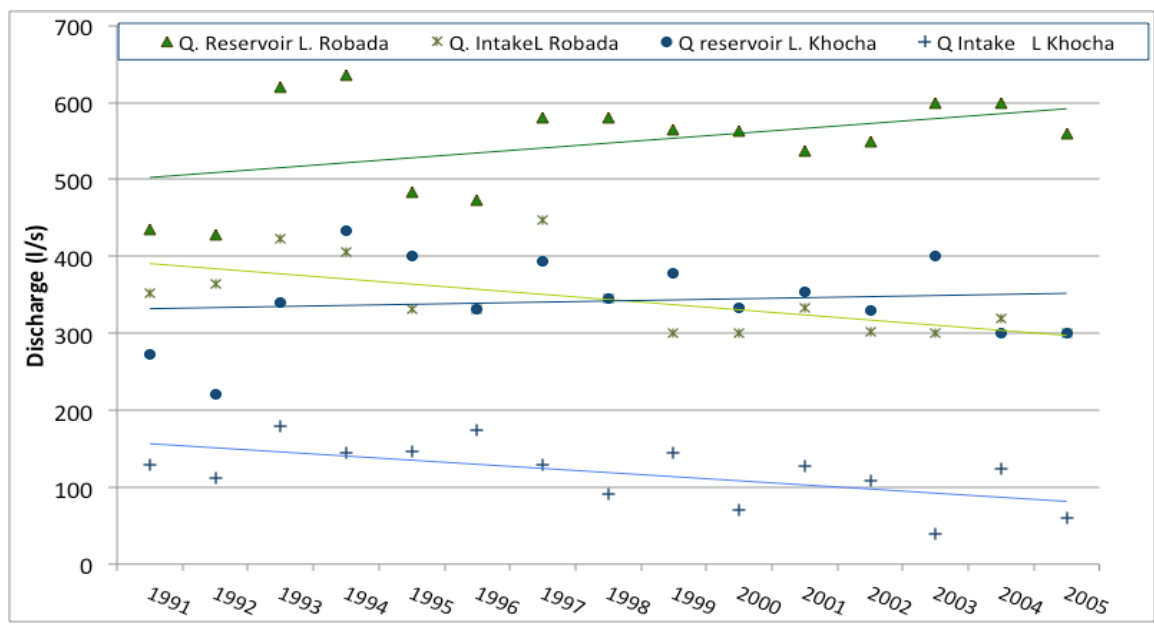

Figure 4-8. Variation of discharges between the dam and main intake for Laguna Robada and Llusk'a Khocha systems in Punata

(Source: prepared by the author based on Del Callejo and Vasquez, 2007) 
This provides insights into the systems' capabilities to cope with these insecurity factors, and indicates that technical measures/tasks at the damsite works are not sufficient to deal with the area's broader, prevailing organizational and sociopolitical conditions.

\section{Totora Khocha in the Punata System}

The Totora Khocha surface water irrigation system is a reservoir system that is fed mainly by water transfers from other basins (called "sistema de aducción"). Once in the basin, water must be transported along the river for nearly $30 \mathrm{Km}$ before entering the distribution system in the irrigation area where 65 communities make use of its waters for irrigation. The system has six operational levels and up to four organizational levels. The organization that manages the irrigation system is the Totora Khocha Committee, which is part of the Irrigation Association of Punata (ARSP). For Totora Khocha, all these levels require an impressive capacity to mobilize people. Unlike other systems that can be managed through their representatives or specific operators, this requires the participation of grassroots users at practically all levels.

The inter-basin water transfer level and conveyance to the irrigation area are the most demanding because of the distance and the settlements along the water courses that demand constant monitoring during reservoir operation. First are the so-called "emergency brigades" that must remain at the basins and their conveyance channels 24 hours a day, every day, for four months. This is organized by the Totora Khocha irrigation committee and supported by the Irrigation Association, calling on communities to cover 24-hour oversight turns for that purpose. To convey water from the reservoir to the irrigation service area, it takes the same form, nominating "tomeros" (water intake keepers) at key points of the river. This shows they can monitor during irrigation period and prevent water theft by the communities living along the route.

When water reaches the irrigation area, it is divided into eight streams (nowadays nine branches are being tested) distributed into "irrigation groups" of communities that can be served by one of the main channels. Division within the group is controlled by sequential turns, following communities (within each group, one community irrigates at a time) according to individual water rights expressed in time (the sum of the shares of families with water rights).

Inside the community, each appoints a "water judge" who handles water distribution to each individual user according to their "shares" (water rights). In this work, it is up to every single family to convey and monitor the water flow from the delivery point to its plot.

Throughout this long journey of water from the river, all these organizational levels and operational tasks are being adjusted over time. These adjustments have been implemented to try to control "insecurity factors". Physical/technical water control, is therefore mutually interrelated to the organizational, socioeconomic, and political dimensions of water control. 


\subsubsection{Tube well systems in Punata}

Well systems, by contrast to dam systems, are located near each irrigation area. These systems include family groups from one or more communities. The average number of users is 40 families. Each well operates independently and has no link with the Irrigation Association (ARSP), though some of them are organized in the "Tube-well users' association" (AUPVA). These systems are very simple in operational and organizational terms, with only two operational and two organizational levels: well operation, and transport from there to apply water at each irrigation plot by individual users. For well operation, a "motorista" (pump operator) is appointed from the group of irrigators. An individual user requests the motorista to include her/his name on the list, according to a predefined order. The motorista is in charge of switching the pump on and off at the beginning and end of the turn or when the system has agreed on a daily stopping time. Water users go to the well or to a specific point where water is and convey the flow to her/his plot. These systems represent a relatively "secure" source of water, although there are clear indications of interference between wells and over-extraction of groundwater in Punata. An insecurity factor of underground water also involves other sources in Punata, because groundwater recharge is related to dam operation and water runoff during the rainy season. This seems to be a key incentive for well users to also continue working for Totora Khocha system management.

\subsection{Creation of supra-organizations: Scaling-up collective action and empowerment}

The three cases in this study show collective action through different organizational forms, but all basically have taken a union structure. Under these distinct forms, social organizations play different roles, with different priorities and under a variety of strategies, in which water has proven to be a key element. The cases of Rumi Cancha, around the "atajado systems" and Chiyara Khochi in Sacabamba, show transition in water organizations' experience and development. In these locations, experience is gradually being built on agrarian unions' organizational strength. For Punata, organizational development around water has exceeded organizational limits by single communities or peasant unions, and also the territorial limits in which these organizations were developed, inextricably overlapping hydrosocial territories and networks (Rocha et al., 2015). This section will discuss the creation of water supraorganizations as a very important strategy for water control and the quest for autonomy, implemented by Punata organizations.

As mentioned above, Punata irrigation systems depend almost entirely on sources outside user communities' territory. Moreover, successive interventions in river basins to rehabilitate and construct irrigation infrastructure have reinforced collective water rights. This made visible the agreements between communities located at the water sources and downstream user communities or organizations. These agreements are, however, not static, and have been marked by intense negotiations and conflicts between organizations. 
A first example of these conflicts, negotiations and organizational strategies is implemented in the Totora Khocha inter-basin water transfer system (sistema de aducción) in upper Tiraque (See Figure 4-7). Koari communities traditionally used the water basins (referred to by the project as basins A, B and C). After a long process of negotiation (Montaño, 1997), these communities agreed to convey water in the rainy season (November to March) to Totora Khocha, while they would use the water and the built infrastructure the rest of the year. As part of this negotiation process and in order to assert their rights, Koari communities formed in 1992 the Koari Irrigation Sub-Association (SARK). This however was inserted as one of the (subordinate) irrigation organizations within the Irrigation Association and Services of Tiraque (ARST). Koari communities decided to form a new association, independent of ARST, because of problems in operating the inter-basin transfer channel (overflows, land erosion), the growing demand for water in Koari communities, and the limited benefit of belonging and being subordinate. In 1998 they obtained legal status as the Koari Irrigation and Services Association (ARSK).

This strategy was implemented by Koari irrigators to achieve autonomy and management decision-making capacity, and avoid being subservient to ARST. It was also a symbolic response to show the same level of "hierarchy" as the Tiraque and Punata associations, which were "taking their water outside their jurisdiction" (Del Callejo et al., 2012).

Later, as a result of efforts by Tiraque and Punata irrigation associations (ARST and ARSP, respectively), to improve or expand irrigation systems, there was a new reaction by communities in the upper Tiraque. Conflict began regarding design of the Yungas de Vandiola Project. This project proposes a transfer from more distant river waters to cover a current deficit in Totora Khocha storage, benefiting Punata and Tiraque communities. Water would pass through the upper Tiraque communities and complement the water transferred from basins A, B and C. Given this, the upper communities, led in part by the Koari Association (ARSK), formed the Cochabamba Irrigation Federation of Indigenous Farmers (FRIA). This organization seeks to bring together several irrigation organizations (associations), mainly in Tiraque. This strategy leveled power relations between irrigators from around the valley and made current "small" or "weak" organizations more visible vis-à-vis "strong" organizations such as the Punata and Tiraque Associations (ARSP and ARST). At one point, they even tried to reach the same level of importance as the Cochabamba Federation of Irrigators (FEDECOR), since they did not feel clearly represented or assisted in their demands. The stronger actions that demonstrated the upper communities' new positioning through the FRIA took place during the negotiations to enable completion of final design studies for the Vandiola project and for new projects to improve water transfer from catchments $\mathrm{A}, \mathrm{B}$ and $\mathrm{C}$. This new positioning motivated organizations like ARSP to consider joining the new federation (FRIA), in order to have a say in decisions made from within this "supra-organization," especially those that might affect their own interests.

Again, as part of collective strategies, organizations dealing with water have used different organizational resources, not limiting their actions to their own organization, but expanding their coverage and scope to higher spheres. For the organizations in upper Tiraque, creating a 
"supra-organization" was an important strategy to reaffirm and make their "territorial rights" for water visible to outsiders. In the case of the ARSP, trying to associate with the new federation would enhance this new organization's legitimacy and effectiveness as an additional resource to also strengthen their control over water sources, reinforcing their traditional agreements with Tiraque organizations.

\subsection{Social mobilization}

There are countless manifestations of mobilization capacity or "social force" (Eggink and Ubels, 1984) that peasant organizations utilize or are developing to manage their resources. These also defend them in dealing with "external parties" (state, transnational or national private companies, or other water-use sectors) or to make their demands visible to generally put pressure on local, regional or national government authorities (Hoogesteger 2013a). This section analyzes examples showing irrigation organizations' mobilization capacity. In day-today water management activities, this mobilization capacity is expressed in a wide variety of actions, such as in the work of operating and maintaining infrastructure, or at annual meetings of members to elect new leaders or to make important decisions for the organization. However, this mobilization ability can also be expressed beyond these management activities. The cases of Chiyara Khochi and particularly in Punata illustrate the different situations in which this strategy is exercised, beyond the irrigation system's area and projecting the socio-political and normative dimensions of water control as part of social or class demands.

The first examples that came to light in the case of Punata organizations were during project implementation between the 70s and 90s (see Gandarillas et al. 1993). At critical moments, such as when defining the Totora Khocha system's area of influence, seemingly disorganized or nonexistent communities downstream from the area of influence were the first to mobilize and protest at being excluded from the project. During the works, concrete demonstrations by these same groups of peasants included protests, mobilizations and threats to blow up the intake works if the design did not change. This is because the infrastructure in the river kept water from passing on to Punata's southern communities, mainly to those who would not benefit from the project (Gandarillas et al. 1993). Due to the great number of project beneficiaries (at that moment around 52 communities) numbering more than 3000 irrigators, these protests could be "neutralized" by those who did benefit from the water. Another reason was that many peasant families from the excluded communities were related to "beneficiary communities" through family or ritual ties, which gave them some hope of water access in the future. This was a clear example of a confrontation of powers: those chosen as beneficiaries and those that were not. The first group exceeded the second not only in number but also in other organizational capabilities, in economic power and in capabilities of relationships with government and political spheres.

Other examples of forceful demonstrations, and more successful outcomes, were the marches staged by Punata well users. Initially there were complaints to the electricity company in Punata, but then, once the Upper Valley Tube-Well Users' Association (AUPVA) was 
organized, another large contingent of irrigators joined from other parts of Cochabamba valley. This time, promoted by the Cochabamba Federation of Irrigators (FEDECOR), and after taking over the electricity company's buildings in different provinces, and occupying the central office in Cochabamba, irrigators were able to get electricity rates reduced for all community groundwater systems. They could demonstrate that communal irrigation, and even drinkingwater systems, were being charged commercial or industrial rates. Although since 2004 the electricity rates have been reduced, this remains a sensitive issue to watch for the irrigation organizations (Perreault, 2008).

To some extent, the Punata irrigation organizations' mobilization capacity, especially the ARSP, can also be seen in their demonstrations and subsequent political alliances with the Cochabamba regional government from 2004 to 2007. Irrigators used this mobilization strategy to gain support for implementing various irrigation projects in the Punata jurisdiction. In "retribution", for several months irrigators provided political support for the regional governor (at that time called Prefecto) when he was facing criticisms and complaints from other sectors of society and mainly from the central government. However, in 2007 this alliance faced a crisis because of political struggles between the central government and Cochabamba's regional government. Punata irrigators then had to divide their support: first attending concentrations convened by the Prefecture but then attending the Cochabamba Irrigators' Federation demonstration against the Prefect. The result of these demonstrations, joined by other sectors of farmers, coca producers and workers related to the central government was the Prefect's resignation, after a recall referendum.

The first examples show the mobilization capacity to resolve internal problems or tangible issues or in response to interventions that will alter conditions or internal balance in the intervened areas. These last examples show that, rather than being static or with restricted functions, local organizations have developed broader capacities that encompass political negotiations and that demonstrate they are immersed in organizational and political networks far beyond their own communities or their irrigation systems. This in turn, requires extensive knowledge about and involvement in the local, regional and national institutional and political context, the state and the market. Increasingly, peasants "walk in different worlds": those of their own institutions, the world of the bureaucracy of the state, and even in international spheres.

\subsection{The co-evolution of endogenous water development processes}

This chapter has presented how grassroots organizations have stood at the basis of the development and later management of the irrigation systems in the case study area. As shown most irrigation systems have their origins in either local collective action for the construction and operation of small irrigation works and/or the demands that peasant unions made for the development of irrigation infrastructure in the area. Many such intervention programmes came with their own sets of demands and guidelines in terms of organizational structures; most of which promoted the creation of water users' organizations that were separate from the unions and other local organizations. The cases of Punata and Chiyara Khochi in Sacabamba illustrate 
the organizational structure adaptations and the different reasons that led to the specific structures that are there at present. In Punata, political-organizational elements internally prevailed to balance the benefits and control over decision-making in a larger organization such as the ARSP. This reorganization also affected the dam operating-system aspects. For Sacabamba, on the contrary, the reorganization was motivated by operational requirements, because the organization initially created by the project did not meet these requirements, and it also left out the local organizational forms. In any event, although the two organizations followed different paths and also made particular adjustments, in both cases we see the importance, validity and progressive strengthening of the organizational capacities that were gradually generated under the form of water-user associations. These organizations have to a large extent displaced the peasant unions in the water control domain.

This development of peasant organizations and their (growing) capabilities to manage and negotiate their projects also show the elements that go into negotiating and interacting during and beyond interventions. This, as suggested by Long (2001a), "...factors that originate externally are then mediated, and often substantially transformed by cognitive and organizational structures ... and so come to form part of the resources and constraints of these social strategies that are developed" (Long 2001a:45, 46). The cases also show that interventions do not take place separate from the local population. These are often the initiators of the projects through the advancement of their demands, the creation of networks and the negotiation of projets once these are implemented. As stated by Long and van der Ploeg (1989), interventions do not take place within a linear cycle; they take place within ongoing cycles of new interventions that overlap and are partly born, internalized, reformulated and readapted as part of peasants' own projects. This constitutes rather a "confrontation or interpretation of different worlds of life and socio-political experiences, which can be significant to generate new forms of social practices and ideology ..." (Long and van der Ploeg 1989: 230). Thereby, the examples reported in this section show that the actual outcomes of these interventions are the result of the interactions between and among the different communities of the area and the intervening agencies. A combination of different strategies in the organizational, political and technical domains is essential in redefining "water control systems": their different components and levels. In the valley, the cases show organizational empowerment, resulting in a gradual change where organizations began to manage their own projects. Water control is therefore not only about participation / involvement or project management, but also about managerial power and controlling its various components. Skills which the users have developed based on their own endogenous development strategies which are shaped by their own initiatives and their interaction with external interventions. 


\section{Chapter 5 . Water control and spheres of production / reproduction on peasant farms}

In this chapter, I will discuss the peasant farm or the "chacra campesina", the importance of farmer-driven water control and its inter-relationships with key factors influencing the irrigator's household reproduction. To analyze these inter-relationships a specific research question was addressed:

How do different peasant families' farming strategies relate to water control and control over production?

Discussion starts by identifying some strategies used by families to access and control water, then other agroproductive and livelihood strategies linked to the market and to reproducing farming are analyzed. The discussion reveals interactions among and within market and nonmarket spheres, as well as the relationships between collective and individual (family) domains, all mediated by local institutional arrangements and cultural repertories.

Given the heterogeneity and diversity of peasant production, this chapter's central topics will be illustrated using case study findings at the household level, in the three areas of study described in Chapter 1 and analyzed in the collective domain in Chapter 4. Again, rather than seeking a comparative analysis, this chapter illustrates the diversity of peasant agriculture, as a result of local (endogenous) development processes. This agriculture is based on family / collective strategies that seek to control certain physical, organizational and socio-economic production conditions. Therefore, this chapter intends to develop a comprehensive approach to understand complex cultural-institutional and socioeconomic processes involving irrigated agriculture.

For this purpose, after briefly describing and contextualizing the cases studied, strategies for accessing water are a key starting point to implement different peasant farming systems. Next, we discuss some productive strategies regarding water control and control over production. Finally, an analysis of peasant production units' organization of labor will explain manifestations of heterogeneity and different farming styles and local agricultural development patterns.

\section{1 The cases studied}

Three to four cases were selected in each area studied (three in Punata, four in the Chiyara Khochi irrigation system in Sacabamba, and four in Rumi Cancha community). The following table summarizes the most important physical characteristics differentiating these three areas and directly influencing peasant-farming characteristics: 
Table 5-1. General characteristics of the area studied

\begin{tabular}{|c|c|c|c|}
\hline $\begin{array}{l}\text { Case study } \\
\text { Physical } \\
\text { Characteristics }\end{array}$ & Rumi Cancha & Punata & $\begin{array}{l}\text { Sacabamba } \\
\text { (Chiyara Khochi } \\
\text { system) }\end{array}$ \\
\hline Altitude (meters) & 2200 & 2720 & $3000-3200$ \\
\hline $\begin{array}{l}\text { Annual rainfall }(\mathrm{mm}) \\
\text { Rainy season }(80- \\
85 \% \text { of total rainfall) }\end{array}$ & $\begin{array}{l}549 \\
\text { December-February }\end{array}$ & $\begin{array}{l}389 \\
\text { December-March }\end{array}$ & $\begin{array}{l}701 \\
\text { December-March }\end{array}$ \\
\hline $\begin{array}{l}\text { Temperatures } \\
\left({ }^{\circ} \mathrm{C}\right)\end{array}$ & 19 & 14.7 & 11.4 \\
\hline Soils & $\begin{array}{l}\text { Loamy clay, moderate } \\
\text { deep }\end{array}$ & $\begin{array}{l}\text { Silty loam, loamy } \\
\text { clay, moderate deep to } \\
\text { deep }\end{array}$ & $\begin{array}{l}\text { Sandy loamy, silty } \\
\text { loamy } \\
\text { Shallow }\end{array}$ \\
\hline $\begin{array}{l}\text { Sources of irrigation } \\
\text { water }\end{array}$ & $\begin{array}{l}\text { Atajados (small } \\
\text { individual-family } \\
\text { reservoirs), } \\
\text { galerías filtrantes }\end{array}$ & $\begin{array}{l}\text { River flow } \\
3 \text { Reservoirs } \\
\text { Tube wells }\end{array}$ & Challaq'e reservoir \\
\hline $\begin{array}{l}\text { Main cropping } \\
\text { patterns }\end{array}$ & $\begin{array}{l}\text { Maize, beans peanuts } \\
\text { (rainfed) } \\
\text { Onions, tomatoes, } \\
\text { potatoes (irrigated) }\end{array}$ & $\begin{array}{l}\text { Maize, alfalfa, broad } \\
\text { beans, carrots, onions, } \\
\text { potatoes, flowers } \\
\text { depending on the } \\
\text { available water }\end{array}$ & $\begin{array}{l}\text { Wheat, barley, oats } \\
\text { (rainfed) } \\
\text { Potatoes, broad beans, } \\
\text { small areas of } \\
\text { vegetables (irrigated) }\end{array}$ \\
\hline $\begin{array}{l}\text { Average land tenure } \\
\text { (Ha) }\end{array}$ & 3.3 & $1-1.3$ & 1.8 \\
\hline
\end{tabular}

Source: Prepared by the author

After a short description of the studied areas, 7 out of the 11 cases studied are summarized in the next paragraphs as the most illustrative for the purpose of this chapter.

\subsubsection{Agriculture in Punata}

Agriculture in this valley has a long history and diversification. One of the most important crops in Punata has been (and still is) maize, with a great number of varieties. Some are eaten roasted, others to make flour, others are eaten fresh (cob), others are cooked dry (mote), or used to make "chicha" (an alcoholic beverage). Along with corn production, people have developed different experiences and vocations with different crops such as vegetables, legumes and fruits. 
Progressive control of different water sources has enabled agricultural intensification in the area. This intensification ${ }^{21}$ however, has not resulted in a homogeneous pattern of crops and agricultural practices, but rather in a variety of production systems. As shown in the north, given the soil conditions and the availability of regulated water (two or three reservoirs and wells), intensive horticultural production systems tend to predominate. Going southward, water availability decreases (only one reservoir and occasionally water from a seasonal river) and thus cropping intensity is lower. In these areas, more extensive production systems will predominate, based mainly on producing alfalfa and maize (see Del Callejo, 1999; Del Callejo and Vásquez, 2007; Rocha and Mayta, 2007). This intensification has been accompanied by cycles of either specialization or diversification in different areas: some mainly flowers, others with vegetables, sometimes with fruits or other crops and different varieties of maize or forage for milk production (Del Callejo, 1999).

Besides these characteristics of agricultural production, in Punata, like in other areas in Cochabamba's valleys, migration (to Argentina, the United States, or in the last decade to Spain) has been a very common livelihood strategy for more than four decades. Searching for better opportunities to get an income, given the great uncertainty in Andean agriculture due to small land-holding, droughts and market prices, migration has been important to livelihoods, in terms of income, and also as part of social mobility, access to services and information, possibilities to save money to invest in agriculture, and also to send remittances home to family. Intricate social networks at both origin and destination back these strategies, which in many cases enable peasant migrants to broaden their farming systems at their destinations (Benencia and Geymonat, 2005; Dandler and Medeiros, 1985; Vargas, 1997).

For the Punata area, this chapter studies three illustrative cases: the Ubaldo family, the Montes family and the Soto family. ${ }^{22}$ They are introduced below. The first family grows vegetables intensively, the second produces corn and milk semi-intensively, and the third is a "semirainfed" milk producer.

The Ubaldo family has six members: the parents (ages 66 and 61) and four children (two daughters, 30 and 28, and two sons, 25 and 23). Currently the two daughters are abroad, the elder in Argentina and the younger one in Spain. The two sons studied and graduated in Cochabamba and occasionally come home over the weekends to help their parents.

\footnotetext{
${ }^{21}$ This document assumes the criteria defined by Rocha and Mayta (2007) to differentiate degrees of land-use intensity. Intensive systems are those in which a family produces three or more harvests a year; semi-intensive at least two crops a year; semi-rainfed is only one harvest and may use complementary irrigation. Later, we discuss intensification as linked with increased use of inputs.

${ }^{22}$ In this document, the names of the families who cooperated with this research are fictitious, to protect their privacy, and because the description or interpretation of their activities, practices, decisions or the rationale behind them are illustrations of reality: manifestations of the broader understandings by families of the complexity of the socio-cultural, economic, and kinship relations in which family members are involved.
} 


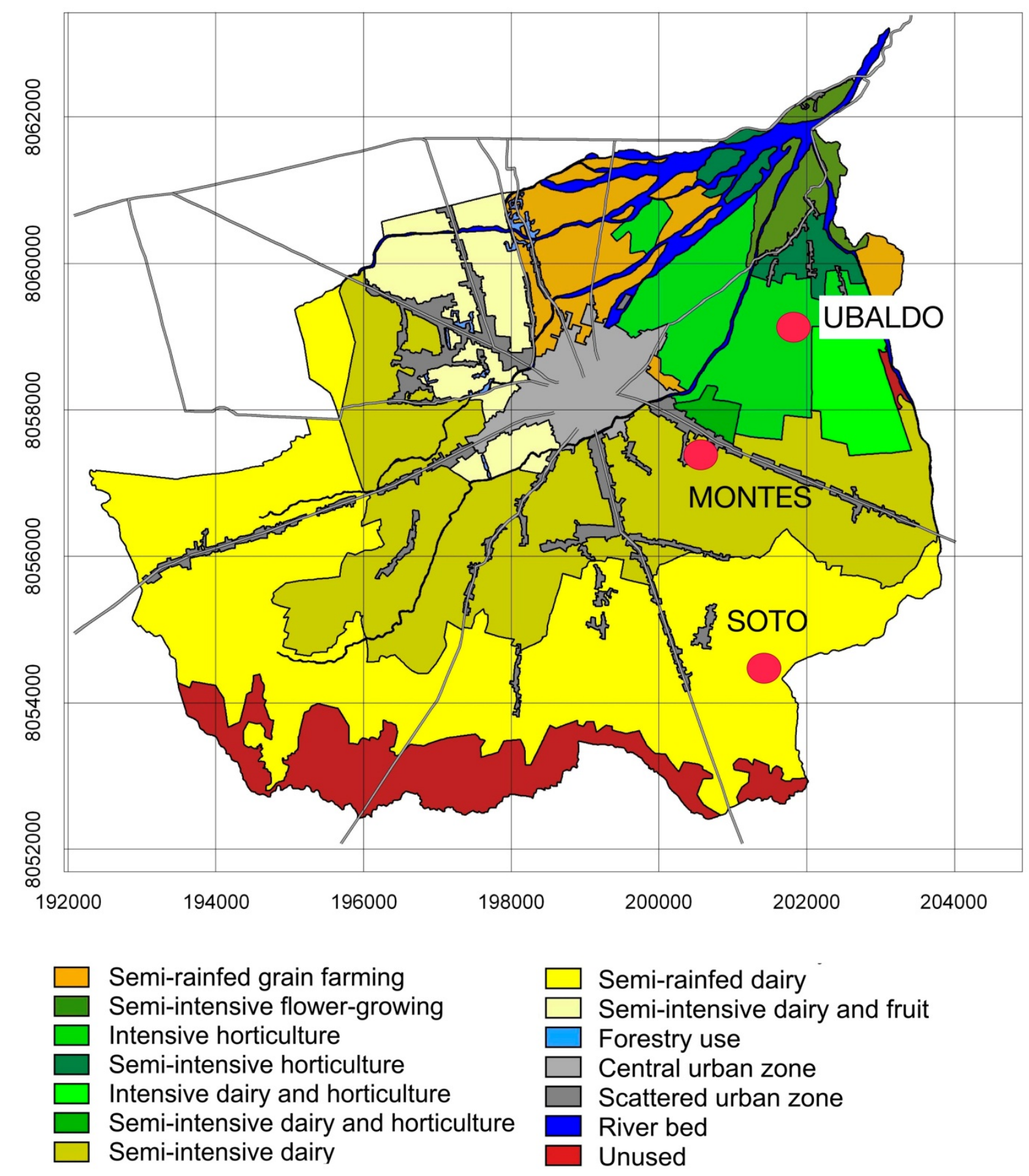

Figure 5-1. Spatial distribution of production zones and the studied cases in Punata

(Source: Rocha and Mayta, 2007)

The couple inherited land and water rights from their parents, who had worked on different haciendas, although Mr. Ubaldo's father also had plots in an area of "piquería" - areas under individual ownership by "free peasants", without any obligation to the haciendas. Initially, they had 0.7 hectare of land, and also worked in "compañia" (share-cropping) or through other landleasing. Gradually they were able to buy more land and they currently have 2.5 hectares. As for access to water, when they married they had, by inheritance, water from the Lluska Khocha and Mitha systems. Mr. Ubaldo also worked to secure water rights in Lluska Khocha and later 
in Totora Khocha. About twelve years ago, they invested to obtain shares in tube wells. Currently, they have water rights to two dams, the Mitha system and three wells around their community. Moreover, in recent years they gained access to Laguna Robada by "anticrético", which is a type of contract to access a good (in this case, water) by lending a sum of money that, upon completing the agreement or contract, is returned by the owner to the contractor (anticresista).

The Montes family lives in the community of Tambillo Centro, close to the boundary between northern and southern Punata. Currently the family consists of the couple and their granddaughter, as their six children migrated to Argentina. Mr. Montes is 68 years old, Mrs. Montes 57 and their granddaughter is 16 . The family concentrates its activities on agriculture, animal husbandry and a specific task which Mr. Montes performs some years, as operator of one of the community's wells.

Mrs. Montes comes from a neighboring community and in her youth she sold alfalfa at the Punata market. Mr. Montes began working in agriculture from an early age, as his father was a peasant leader who was traveling continuously. After agrarian reform, hacienda lands were distributed among the farmers living there, although landowners also kept some plots, which later reverted and were distributed among the ex-colonos' children. Thus, when Mr. Montes was still young, he had access to a small plot. In his youth, he also participated in constructing the Laguna Robada dam and thus acquired water rights. Mr. Montes reports that when he was married he had children, and water, but had such small land area that they could not survive. For this reason, he had to migrate to Argentina. They saved some money to purchase more land in their community.

After nearly 20 years of successive migrations for different-length stays in Argentina, he saved sufficient money, bought more land in the community and also invested in collective well drilling, along with other local families. Currently, the family has 1.4 hectares, mostly acquired by purchase. They also have a plot in Tiraque (upper basin) where they work by share-cropping with "compadres" or acquaintances in the area. The family has communal water from two wells, Laguna Robada, Totora Khocha, and river water (Mitha and Rol).

The Soto family currently consists of three members: the couple, both age 58 and a son 15 years old. Seven children (four daughters and three sons) have migrated to Argentina and Spain. The family's main activity is dairy farming, growing maize and alfalfa for feed.

The couple is from the same community, and both inherited land from their parents, and Mr. Soto also received about half a hectare after land reform (called the "youth provision"). In total, they have approximately 3.8 hectares, $40 \%$ purchased and the rest inheritance and the provision. They make their milk into fresh cheese (locally called "quesillo"), which they sell to merchants who collect it locally. Sometimes Mrs. Soto sells quesillo directly on the market, sometimes also with cooked corn (mote) and her own family did not migrate anywhere. Mr. Soto has also worked as a bricklayer in nearby communities and he is primarily in charge of working their land and feeding cows. Because they live in a community far away from the main 
water intake of Punata, they receive water only from Totora Khocha and sometimes river water (Rol). About a decade ago, they invested in a "share" of water in a well system and a couple of years ago in a second well. This additional water complements their water supply for their main crops, especially alfalfa.

\subsubsection{Agriculture in Rumi Cancha community, Aiquile.}

Livelihoods in Rumi Cancha community are based on various activities: agriculture, livestock raising, trade, transport and migration. Agricultural activities consist mainly of rainfed cropping of corn, beans, and peanuts and small areas of irrigated crops such as onions, tomatoes and occasionally potatoes. Irrigated agriculture develops as small oases around water sources, such as atajados or infiltration galleries, which capture very small subsurface flows.

Agricultural activity is complemented by raising animals, mainly cattle, sheep and goats. These cattle are fed with the "challa" (the leftover cornstalks and leaves, used as fodder), stover and other crop residues and by grazing and browsing shrubs in the surrounding hills. Since rainfall is concentrated mainly in the three summer months, agricultural activities in community areas without irrigation last no more than 6 months a year. In the other months, people migrate to Chapare region (tropical areas), where they settled on colonization land. ${ }^{23}$ There, they grow crops such as fruits and coca. In recent years, the frequency and timing of migration to this region has been changing, depending on the availability of water for irrigation in the community. Irrigated areas in the region have specialized in onion production. This vocation dates back a long time in this region, especially in the province of Mizque (adjacent to Aiquile), and has even led to an onion variety called "mizqueña" widespread in the valleys of Cochabamba.
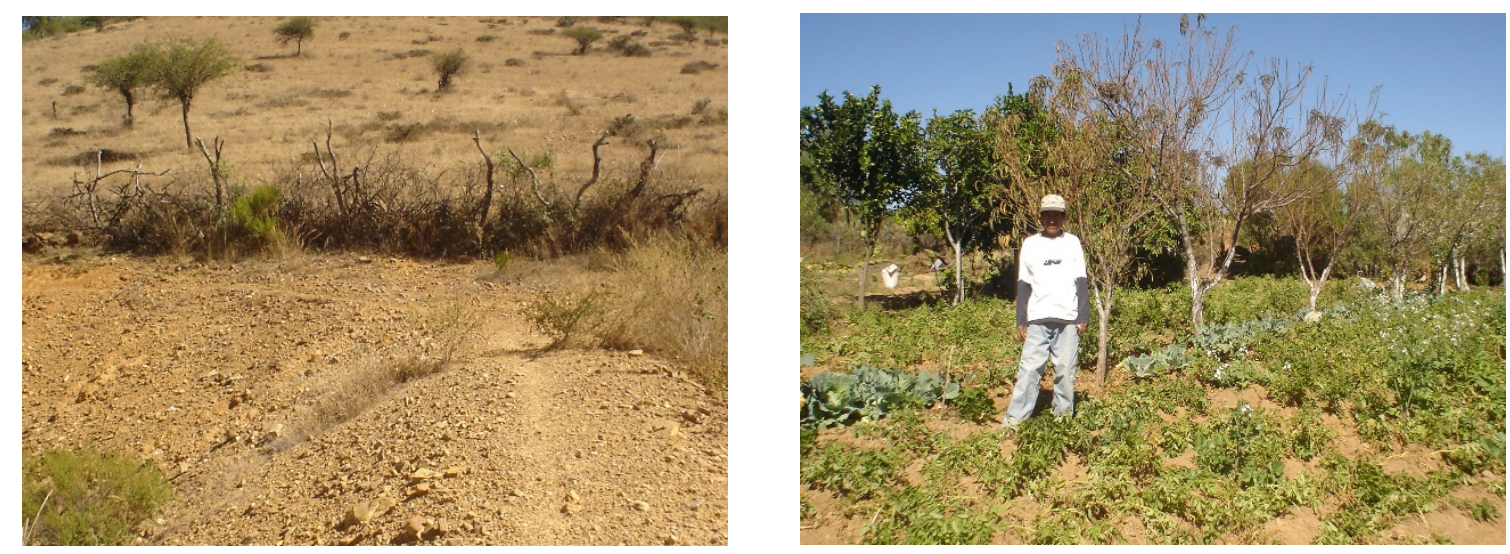

Pictures 5-1. Contrasting landscapes in Rumi Cancha. The oasis effect of atajado systems

Photo: W. Caceres

Two of the four studied cases are described below as the most illustrative of this area.

\footnotetext{
${ }^{23}$ Between the 70 s and the 90 , as part of a social and agricultural development policy, there was a process of directed migration (colonization) from various regions of the country to the tropical region in Cochabamba. In many cases, communal organizations from those regions were replicated almost entirely in the tropics.
} 
The Lima family are peasants from the same community of Rumi Cancha, with five members: the couple (Mr. Lima, age 36, and Mrs. Lima, 32) and three small children (12-year-old son and two girls, ages 8 and 5). The family has an area of 1.25 hectares divided into four plots with rainfed crops, which they purchased. They now also have an atajado, enabling them to irrigate approximately a quarter hectare. This family, like most in their community, has a plot of land in Chapare, and they constantly travel there to "keep their right" to their plot. According to Mr. Lima, their greatest revenue comes from coca production, which allows them to have a relatively steady income every three months. In Rumi Cancha community, they produce corn, peanuts and small areas of irrigated crops, rotating potatoes, onions and tomatoes. They also raise cattle (10 head) and sheep (30).

The Roldán family has five members: Mr. Roldán (58) comes from the same community and Mrs. Roldán (54) from a neighboring community. Currently they live in Rumi Cancha with three of their children (a son, age 26, and two daughters, 24 and 22). They have another daughter who is already married and lives elsewhere. Mr. Roldán says that not long ago all agriculture in the area was rainfed, producing only maize, peanuts and occasionally potatoes. Since 1985, the first atajados were built in the area and they started producing other crops, such as onions and then tomatoes, garlic and "mishka" potatoes (early sowing of potatoes under irrigation). This family has had two periods of substantial changes in their livelihoods. Before 1985, they lived on corn and peanuts combined with some livestock and cultivating coca in Chapare. After 1985, they reduced migration periods to 4-5 months and since 2001, after the second atajado was built, this migration was further reduced. Mr. Roldan explains that, by diversifying their production, they do not have much time to travel. They leave only sporadically to keep their land in the Chapare region. An important part of the farming system is also raising animals, having around 6 cattle and 200 sheep.

\subsubsection{Agriculture in Sacabamba}

As mentioned in the overview of this case (see Chapter 1), the Sacabamba irrigation area is located at 3000 to 3200 meters above sea level, with rains concentrated from December to March. These two factors have conditioned this area for a long time, to rainfed agriculture based on wheat, maize and potatoes. Since 2001, the Chiyara Khochi irrigation system (Challaq'e dam) was launched, and agriculture in the area has been changing gradually, currently producing irrigated crops such as potatoes (mishka), onions, beans and occasionally complementary irrigation of maize and small fruit areas.

Agricultural activity is combined with raising animals: cattle, sheep, transport animals (donkeys, horses, mules) and other small animals. The importance of cattle is increasingly widespread in the region, as draft animals to till the land, and some families are experimenting with raising a few cows to produce milk. Each family also raises sheep in significant numbers, although in recent years this has decreased because of labor intensity in irrigated crops and reduced grazing, both resulting from agricultural intensification. Sheep raising is still important to provide guano (manure). The illustrative cases were selected for this zone because they offer 
contrasts in terms of water and land availability (one case with reduced water availability and the other with greater availability).

The Juvenal family has of 10 members: the couple, both age 49, and eight children. The eldest daughter (26) no longer lives with them but works in Cochabamba. The rest of the children live with their parents, four daughters, ages 23, 18, 12 and 11, and three sons of 22, 20 and 6 . This family inherited all their land from their parents, a total of four hectares of rainfed land and two hectares of land that can be irrigated. When the Chiyara Khochi system started implementation, Mr. Juvenal contributed his work to acquire water rights. They now have one "irrigation share" equivalent to 12 hours at a flow rate of $5 \mathrm{l} / \mathrm{s}$ every turn (water release or largada). This family, like many others in the area, grows rainfed wheat and potatoes, complemented with sheep raising and temporary migration. Currently the family is changing its production strategy to plant "mishka" potato (early sowing), but without specializing only in that crop. They maintain significant areas of wheat, maize and recently they are experimenting with small areas of vegetables and fruits.

The Gamez family also has 10 members: the couple, both aged 51 years, and eight children. The three older daughters live away from home with their own families. Three sons stay at home (26, 18 and 12 years) and two daughters (22 and 8). All the family land was inherited from their parents. Currently they have half a hectare of rainfed land and approximately two hectares that could be irrigated. During Chiyara Khochi system implementation, both spouses worked and each acquired one "irrigation share". That means they have two 12-hour irrigation turns each water release (largada) with about 5 1/s flow rate. This family has its team of oxen, a donkey and chickens, and a decreasing number of sheep, now no more than 10. Previously they considered themselves potato and wheat growers. Currently, they are more concentrated on the mishka potatoes, reducing their wheat area and diversifying with maize, beans and small plots of vegetables and fruit, especially peaches.

Below are some details of the families studied. Table 5-2. highlights the small areas of land under irrigation available to families (between 0.13 and $2.4 \mathrm{ha}$ ). Family size averages seven members, but due to each family's life cycle and some members' migration, current labor availability averages only three members. 
Table 5-2. Household's land and labor

\begin{tabular}{|c|c|c|c|c|c|c|c|c|c|}
\hline $\begin{array}{l}\text { Id_ } \\
\text { Case }\end{array}$ & $\begin{array}{l}\text { Case } \\
\text { study }\end{array}$ & $\begin{array}{l}\text { Case } \\
\text { Location }\end{array}$ & Crops & $\begin{array}{c}\text { Land } \\
\text { holding } \\
\text { (Ha) }\end{array}$ & $\begin{array}{l}\text { Cultivated } \\
\text { land } \\
\text { (Ha) }\end{array}$ & $\begin{array}{l}\text { Irrigated } \\
\text { land } \\
(\mathrm{Ha})\end{array}$ & $\begin{array}{c}\text { Family } \\
\text { size }\end{array}$ & $\begin{array}{l}\text { Current } \\
\text { members }\end{array}$ & $\begin{array}{l}\text { Permanent } \\
\text { family labor }\end{array}$ \\
\hline 1 & Ubaldo & Punata & $\begin{array}{l}\text { Vegetables } \\
\text { (onions), flowers, } \\
\text { maize, alfalfa }\end{array}$ & 2.6 & 2.4 & 2.4 & 6 & 4 & 2 \\
\hline 2 & Montes & Punata & Alfalfa, maize & 1.1 & 1 & 0.7 & 8 & 3 & 3 \\
\hline 3 & Soto & Punata & $\begin{array}{ll}\text { Maize } & \text { (grain), } \\
\text { maize } & \text { (sweet), } \\
\text { alfalfa } & \end{array}$ & 4.2 & 2.4 & 1.5 & 10 & 3 & 3 \\
\hline 4 & Roldan & Rumi Cancha & $\begin{array}{l}\text { Maize (grain), } \\
\text { onions, peanuts, } \\
\text { beans }\end{array}$ & 2.25 & 2 & 1 & 6 & 4 & 4 \\
\hline 5 & Lima & Rumi Cancha & $\begin{array}{l}\text { Maize (grain), } \\
\text { potatoes, peanuts }\end{array}$ & 1.25 & 1.25 & 0.25 & 5 & 6 & 2 \\
\hline 6 & Estevez & Rumi Cancha & $\begin{array}{l}\text { Onions, maize, } \\
\text { beans }\end{array}$ & 5 & 5 & 1 & 6 & 6 & 5 \\
\hline 7 & Rogelio & Rumi Cancha & $\begin{array}{l}\text { Onions, maize } \\
\text { (grain), peanuts }\end{array}$ & 3.25 & 2.25 & 0.75 & 4 & 4 & 2 \\
\hline 8 & Franco & Sacabamba & $\begin{array}{l}\text { Potatoes, wheat, } \\
\text { maize }\end{array}$ & 4.5 & 2.75 & 0.5 & 5 & 5 & 4 \\
\hline 9 & Alvarez & Sacabamba & Potatoes, maize & 0.5 & 0.5 & 0.13 & 5 & 2 & 2 \\
\hline 10 & Juvenal & Sacabamba & Potatoes & 6 & 1.5 & 0.37 & 10 & 9 & 6 \\
\hline 11 & Gamez & Sacabamba & Potatoes, maize & 2.5 & 1.83 & 0.25 & 10 & 7 & 5 \\
\hline
\end{tabular}

Source: Prepared by the author

\subsection{Strategies for access to water}

The cases studied, under very different hydrological conditions of water availability and socioorganizational environment, illustrate various strategies that peasant families pursue to access and control water. These strategies show that, beyond those conditions that to some extent can be determined collectively through water rights and collective water management practices, water access ultimately depends on how each peasant household is able to manage other factors, such as social relations (social networks), economic resources (money and other assets) and physical factors (access to water infrastructure).

This section discusses several of these forms of access to water, analyzed in this chapter as "water access strategies", expressing water control in the family domain. "Strategies" do not 
mean something necessarily structured or planned in advance by families. Rather, they arise as actions and decisions that peasant families are often taking contingently, and in some cases only based on improvisation. ${ }^{24}$ As shown below, most of these water access strategies are based on gradual, purposeful construction of social networks and relationships in the communal or extra communal domains. Ultimately, different strategies coexist.

\subsubsection{Family relationships and social networks}

Peasant families develop highly dynamic actions around agricultural production to access water and other resources, in order to configure their livelihoods. This dynamic is based on social relations in the family domain and beyond.

Especially the Punata cases, then Sacabamba and to a lesser extent Rumi Cancha cases, show the broad variety of possibilities regarding water access forms. For Punata, the confluence and overlap of several irrigation systems at different times and covering different irrigation areas, the infrastructure shared by these different systems, and flexibility in managing them, enable families to "maneuver" or play in space and time with water availability and access beyond what their own water rights define.

Under these conditions, peasant families have access to water through different strategies, for example:

- Strengthening family networks. It is very common to continuously construct and use family networks as a strategy for water access. In the cases studied, for example, the Ubaldo family appeal first to their relatives, to get water for some of their numerous plots. This is done either by exchanging water turns, buying irrigation turns, or setting up another type of reciprocal relationships with their relatives (ayni mutual labour exchanges). Furthermore, the fact that the couple come from different communities means their respective families have access to water to irrigate plots in these communities. Relationships of godfathership, ritual kinship relations benefiting compadres with access to water, and other family members or neighbors in the community, are also important (see also Del Callejo 1999; Soto, 1997).

- Social networks in the communal or extra-communal domains. The community to which a peasant family belongs is the first social space favoring social networking to access water. As discussed in Chapter 3, belonging to a community strengthens possibilities for cooperation in this regard. Additionally, previously studied cases in Punata (Del Callejo, 1999; Soto, 1997) show that these relationships become strategic to access water through "those who are near the water"; that is, with leaders but also with irrigators located at the head of the system or near the intake or in key positions (socially and physically) in the same or other communities. Scattered distribution of

\footnotetext{
${ }^{24}$ Improvisation does not connote random, unintended or non-rational actions. Rather, this is "adaptation to internal and external circumstances, which are constantly changing"... "improvisational capabilities" (Richards, 1993).
} 
plots in different communities also plays a very important role. The Ubaldo and Estrada families, having plots in various communities ( 5 and 3 communities, respectively), has meant that they can buy extra irrigation turns from different sources and exchange or borrow turns. This does not mean that scattering plots automatically guarantees access to water. This depends more on the social relations involved, which may be favored by these plots' location in the territory of one or different communities, and mainly by each irrigation system's water management "flexibility".

- Relations of reciprocity and agro productive complementarity for access to water. Families' social relations develop different mechanisms for resource mobilization. Reciprocity relations, expressed in the Andean region as "ayni" involve mutual aid for work (exchange of labor for labor). These relationships can include a whole range of productive and non-productive activities, agricultural products, labor, money or any resources or assets that a family needs at some point (Boelens, 2015; Mayer, 2002; van der Ploeg 1990). The case studies show, for example:

- Water for Water: Borrowing Lluska Khocha turns and giving back well water (Ubaldo family) or Totora Khocha turn for well water (Estrada family)

-Water for work: Work on planting and harvesting for a water turn from Laguna Robada (Soto family)

- Water for money: money loan (for migration) for water right in Laguna Robada (received by Ubaldo family).

- Water for companionship: Estrada family's daughter helped her grandparents for a few turns from Laguna Robada.

Agroproductive relationships also include share-cropping. Share-cropping is a clear mechanism to access scarce or missing resources such as water, land or labor. In previous research, Del Callejo (1999) and Vega (1996) show that this arrangement was very common, as a strategy to gain access to land when the family has small areas to cultivate, to maximize the use of family labor, to maximize water use, or even as a strategy to access to better-quality land or a better location relative to irrigation infrastructure, thereby facilitating water access by other mechanisms.

Currently in the study areas, there is evidence of a reduction in share-cropping, especially in areas where farming is becoming more labor-intensive due to irrigation. For Punata, this has been further affected by high out-migration by young people and adults (20 to 40 years), consequently increasing labor cost in the area. Mr. Ubaldo eloquently explains: "... now it is not worth it to practice share-cropping, because you work alone and provide your own water and besides you need to hire laborers... and wages have increased so much... at the end of the day, the other partner earns money by doing nothing".

In the other cases studied, the Chiyara Khochi system and especially Rumi Cancha, the above strategies are not as visible or they are mediated by other factors, which although seemingly obvious, need to be discussed. For Chiyara Khochi system, one could argue that, because irrigation is relatively recent, agriculture and water management are at an intermediate stage of 
mutual adjustments: peasants are testing aspects of water distribution to meet productive initiatives (demands), but also the interest in developing certain productive innovations, require water management adjustment.

This also means a close relationship between activities and strategies of experimenting with new crops and new practices in the peasant farming system, while adjusting infrastructure operation and water distribution as part of collective strategies. This is a very good example of how collective interests and actions are negotiated and then determine decisions made in the family agroproductive domain. In the Chiyara Khochi system, families avoid running risks related to share-cropping, precisely because they are in an adjustment phase. Under these conditions, sharecropping does not necessarily offer to cover or share such risks, but only complements the resources both parties have. Labor cost is another issue, and has also increased, although to a lesser extent, in the Sacabamba area.

Because atajados are highly localized systems, located practically next-door to each plot, physical constraints and water availability to irrigate very small surfaces allow no flexibility in shared access or other water-access strategies. When atajados systems began implementation, these micro-irrigation systems' individual character generated some conflicts over control of the water catchment area (communal lands, individual lands, or areas shared by several families). However, after operating these systems for some time, heavy rainfall and the need to act immediately to "harvest" rainwater has promoted the "need for cooperation" among neighboring families. Thus, there are fewer conflicts and more agreements reached, to assist in water uptake into atajados that share catchment areas, the most important strategy for these individual systems.

\subsubsection{Family investments in irrigation: workforce, the role of migration and off-farm work}

There are several ways by which water rights are created in Bolivia's peasant irrigation systems. Among the most common is community membership plus "investment" of work during infrastructure construction (state interventions or their own) (Gerbrandy and Hoogendam, 1998; Gutiérrez, 2005). In the last three decades, money investment has also become a common way to create water rights, especially in groundwater systems (Delgadillo and Lazarte, 2007b; Rocha et al., 2016). Once an irrigation system is formed by collective effort (family investments that create "hydraulic property"), during system implementation and operation other mechanisms are often put in place that change the overall pattern of water rights established at the beginning. For instance, transfers by inheritance, sale of water rights, temporary sale of water turns, exchanges from one community or one subsector to others, are the most common. In other systems, even cash payment is permitted or monetary calculation of wages spent by users who started working to construct the system, as a basis for calculating the cost of new water rights. This situation is rare but can occur. Of all these various forms, what is important to discuss now is labor and monetary investments from families' perspective: investments seen as family strategies. 
Investing family labor to create water rights in general depends on the family's ability to take on that workload. The labor investment is highly variable, depending on the size and complexity of the work or the number of users who initially decide to "risk" this investment. Depending on how much effort they have to invest, the risk or uncertainty foreseen by peasant families, and their ability to solve them, they can decide to make such an investment or not. Commonly, irrigation interventions (building new systems or upgrading existing systems) typically last much longer than planned and therefore require much more effort from future system users. This causes many families to withdraw and therefore lose their water rights before the end or even at relatively early stages.

Table 5-3 shows average values of families' contribution in work and in cash, to create their water rights in various systems. Two features of these cases are remarkable:

The first is the high labor requirement in systems such as Chyara Khochi and the restriction that this investment means for a peasant family, ultimately meaning they can access water or they will be marginalized. In this case, construction work involving families happened mostly during three years which were critical for families. As discussed already in Chapter 4, work investment to acquire water rights has value in terms of identity (collective) and as individual and collective effort. Ultimately, it represents a balance between risking the family's livelihood and the hope, usually uncertain, to get water. Peasants, often based on their knowledge of the weather and local conditions, may doubt future possibilities to irrigate. In other circumstances, a family consisting of a couple and several children, or an elderly couple, may simply not be able to afford such a work investment. In all irrigation systems studied, there are stories about the effort that investing work or money meant to creating their water rights. For Sacabamba, during construction of the Chiyara Khochi system, extreme situations were reported, in which some families, having worked to construct the system, were unable to grow enough food to cover their needs, having to enter into relations of long-term ayni with other communities to get food for part of the year.

Table 5-3. Labour and monetary investments in creating water rights in the systems studied.

\begin{tabular}{|l|l|l|l|}
\hline $\begin{array}{l}\text { Characteristics } \\
\text { of the investments }\end{array}$ & Chiyara Khochi system* & $\begin{array}{l}\text { Irrigation systems in } \\
\text { Punata** }\end{array}$ & $\begin{array}{l}\text { Atajados systems in Rumi } \\
\text { Cancha*** }\end{array}$ \\
\hline $\begin{array}{l}\text { Amount of working days per } \\
\text { family (per water share) }\end{array}$ & 150 working days & $\begin{array}{l}\text { Wells: between 0 to 90 days } \\
\text { Reservoirs: 130 days }\end{array}$ & $\begin{array}{l}\text { Most atajados: 50-70 days } \\
\text { Extraordinary cases: 32, 146 } \\
\text { days }\end{array}$ \\
\hline Source of labor & $\begin{array}{l}\text { Overall family labor and } \\
\text { "ayni" } \\
\text { relations). In many cases } \\
\text { men and women worked to } \\
\text { acquire separate rights }\end{array}$ & $\begin{array}{l}\text { Wells: In general family } \\
\text { Oork systems: combining } \\
\text { family work and hiring } \\
\text { laborers }\end{array}$ & $\begin{array}{l}7 \% \text { only family labor } \\
14 \% \text { only hired } \\
50 \% \text { "ayni" (reciprocity) } \\
\text { and family labor } \\
29 \% \text { combining diferent } \\
\text { ayni (reciprocity) schemes, } \\
\text { family labor and hiring labor }\end{array}$ \\
\hline
\end{tabular}




\begin{tabular}{|c|c|c|c|}
\hline Type of work & $\begin{array}{l}\text { Road construction, } \\
\text { excavation and lining of } \\
\text { canals }\end{array}$ & $\begin{array}{l}\text { Channel construction. Many } \\
\text { wells should not require any } \\
\text { channel building, using only } \\
\text { existing infrastructure. }\end{array}$ & $\begin{array}{l}\text { Compaction and settlement } \\
\text { of embankments, headworks } \\
\text { and atajados protection. }\end{array}$ \\
\hline Period of investment & $\begin{array}{l}1995 \text { road construction } \\
1997-1999\end{array}$ & $\begin{array}{l}\text { Totora Khocha system: } \\
\text { calculated } 130 \text { days; } 30 \\
\text { executed at the beginning } \\
\text { and } 20 \text { in money. The rest } \\
\text { was distributed in } 10 \text { years. }\end{array}$ & $\begin{array}{l}\text { Concentrated in } 2-3 \text { weeks } \\
\text { after construction. Then } \\
\text { every rainy season until } \\
\text { embankment consolidation }\end{array}$ \\
\hline $\begin{array}{l}\text { Required monetary } \\
\text { investment }\end{array}$ & None & $\begin{array}{l}\text { Wells: } 40 \text { to } 700 \text { USD } \\
\text { Reservoirs: } 6 \text { USD per year }\end{array}$ & 50 USD per atajado \\
\hline $\begin{array}{l}\text { Possibilities of water rights } \\
\text { acquisition by monetary } \\
\text { investments only }\end{array}$ & $\begin{array}{l}\text { Currently no new water } \\
\text { users. At the beginning of } \\
\text { operation new users were } \\
\text { admitted by paying } 500 \\
\text { USD }\end{array}$ & $\begin{array}{l}\text { In some wells at a cost } \\
\text { between } 300 \text { and } 500 \text { per } \\
\text { "water share". } \\
\text { Other systems do not admit } \\
\text { new users }\end{array}$ & None. \\
\hline
\end{tabular}

Prepared by the author based on the following sources:

* Cossio (2004); Vega and Iriarte (2003)

** Delgadillo and Lazarte (2007a); Gutiérrez and Claure (1995); Montaño (1995)

*** Cáceres (2009)

The second striking feature is regarding cases where monetary investments are made to build drilled wells systems, in Punata and in other areas of the valleys of Cochabamba. The use of groundwater for irrigation has become very common in these valleys, according to their potential and despite the initial investment costs.

The Punata Valley is an example of this. As explained in Chapter 4, to start with this type of undertaking, a group of peasant families gathers and begins to discuss the physical and financial possibilities. Identifying a communal place near a road, or on a vacant lot, usually solves the physical part, provided that it meets with the approval of some local "expert" in detecting groundwater by dowsing methods. The company can verify this after drilling. Other groups hire a company to make hydrogeological studies before drilling. Excepting the first wells drilled by a FAO program in the 70 s, and a few others under some cooperation program, most Punata wells have been drilled with co-funding by peasant families. Such funding covers 50 to $100 \%$ of the drilling and pump installation costs. This has meant an investment per family of 40 to 700 dollars (Ortiz, 2015), depending on the percentage of support from some institution, the well's costs (related to depth) or the number of families associated to invest.

A peasant family is commonly unlikely to achieve this investment directly. Previous studies (Del Callejo, 1999; Delgadillo and Lazarte, 2007 Soto, 1997; Vega, 1996) show different strategies to achieve these investments:

- Investing savings from migration (mainly to Argentina or recently to Spain). In many cases, this investment and land purchase are the main reason motivating middle-aged migrants (25-35 years) to migrate temporarily (for example, the Estrada family above). 
- Access to credit from relatives, friends or some godparent. Often this is paid for with savings from migration, demonstrating again the importance of family networks.

- Access to financing from rural microcredit organizations. Currently, this mechanism is common to cover immediate needs or emergencies. In most cases, these loans are also paid with savings or remittances from migration.

- Sale of a plot of land to reinvest in well water.

- Investment of extraordinary earnings from agricultural production (Ubaldo family case).

From the different strategies listed above, the first three forms of investment to acquire water rights (water shares) in well systems are linked to migration. Dandler and Medeiros (1985) show that up to $54 \%$ of migrants from the valleys of Cochabamba to Argentina returned and invested in ventures such as land and other assets (in this case water), to establish themselves as "autonomous households" (Dandler and Medeiros, 1985: 52; see also Le Grand, 2014).

For atajados systems in Rumi Cancha community and all intervention areas with this type of system, their construction has been based mainly on community members' interest in participating in the project and their physical possibilities (land availability and suitability for building such infrastructure). This interest often reflects a household's immediate investment capacity and possibilities to assume the risk of such investment. The atajados in Rumi Cancha have meant an investment of 50 USD per family, besides the labor investment. Again, in this case, migration to Chapare region and off-farm work has been the only way for families to afford that investment.

\subsubsection{Involvement in water organizations: "knowing where water is"}

Holding a position as a community authority or any water organization occurs through different mechanisms, rotating positions being one of the most common in Andean irrigation systems. Gutiérrez (2005) also mentions nominating or selecting people with more experience to hold key positions. From some community members' point of view, these positions can mean a "heavy burden", since in most cases there is no payment or only token compensation (monetary or communal work on the leader's fields). This is also directly subtracted from the time a person (man or woman) can devote to their crops or family. However, other families see service as community officers as an important strategy to access water. The Ubaldo and Estrada families show such strategies.

In the first case, Mr. Ubaldo tells his story, about how he learned from his father, besides agriculture and irrigation, the "business" of leadership. Walking around with his father, who was an important leader in Mitha system distribution just after land reform, Mr. Ubaldo acquired that knowledge about Mitha water management and has repeatedly been chosen as his community's leader in that system, as a water judge. That experience has enabled him to determine water's location very precisely and who is irrigating at some point from that source. This has enabled him to access Mitha water turns, by dealing with other irrigators, to further expand their "hydrosocial networks" for water access. This knowledge led Mr. Ubaldo to also 
make the decision, several years ago, to exchange water rights with his brother: water from the Lluska Khocha system exchanged for Mitha water. The exchange was positive for a while because of his site-specific knowledge on water turns, although in recent years the Mitha system has become more insecure due to settlements along the river that interfere or steal water from this system.

Similar strategies happen with Punata's reservoir systems. Being a leader in committees, or at the community level, acquaints leaders with water mobility. They learn which people are willing to exchange turns, transfer water flow from one community to another, or to buy water turns or "water tails" (the flow remaining in channels after "largadas"). Such examples demonstrate that social networks and mobilization and control mechanisms for family resources, such as their water access strategies, transcend communal boundaries, irrigation systems, or other socio-territorial domains in which peasant families commonly move. Families use a very complex combination of social, ritual or institutional work relations, combining these with exchange relations mediated by money. This emphasizes the dynamics and importance of social networks, which are not restricted to re-creating (only) reciprocity based on non-market relationships. Complementarity and reciprocity in the Andes have often been romanticized, thereby ommitting the complex and dynamic interactions between commodity and non-commodity speres in every Andean families' water control strategies (Boelens and Albó, 2007; Vos, 2010; Zoomers, 2013). Many actors are involved in this web of relationships: family members, friends, godparents, neighbors, leaders, public authorities, financial institutions, loan officers, and also businesses that handle remittances from abroad.

\subsection{Range of agro productive strategies. From water control to farming security}

This section discusses agroproductive strategies, closely related to irrigation practices and water management. We will illustrate these different strategies to show their relationship with water control, and how collective water control will influence family-domain production decisions. Very common practices, as part of broader strategies, such as (fallow) land preparation, are extremely significant factors that a family can actually control at the farm level, given other physical, environmental or socio-organizational conditions or constraints.

\subsubsection{Water and soil management practices. Fallowing to cope with water shortage}

One of the first practices, a set of arrangements to deal with water scarcity in the Cochabamba valleys, has been preparing the ground, fallow preparation. Fallow preparation here ranges from primary tillage / plowing the soil, irrigation application and then successive plowings to "soften" the soil and homogenize the moisture contained therein. In some cases, this practice begins with the last irrigation for a previous crop, or an irrigation just to moisturize the soil if the ground is too dry for the first plowing. Usually these practices end with the "wisk'ada" or "closing" of the preparation work (Delgadillo, 2003b), which may include dragging a wooden plank to "seal the ground" and prevent excessive evaporation from allowing it to "warm up" before sowing. 
In areas such as those studied, these practices have different objectives and are also performed differently. These practices as a strategy also deal with water scarcity differently. Delgadillo (2003b) classifies land preparation methods according to the time between tilling the soil and planting/sowing. This period may be short (one to two weeks), intermediate (one to two months) or longer (3-8 months). Systematically analyzing practices in the Cochabamba valleys and the names used locally, we may identify these three groups as "land preparation", "fallow preparation" and "annual fallowing" or "watabarbecho", respectively.

In rainfed lands, soils are prepared with the first rains. The purpose of land preparation practices under these conditions is basically to loosen and aerate the soil, and then to wait for successive rainfall to be stored in the soil to enable sowing, germination and subsequent crop growth. In irrigated areas, depending on water availability or insecurity, various practices have been adapted differently and for different purposes. The cases described in this study provide good illustrations of these variations and strategies used to control water by agronomic practices and strategies.

The objective of land preparation (called "short fallow"), is not necessarily to store water in the soil profile but rather to provide the minimum or necessary moisture for sowing/planting. This practice is usually implemented in areas with high water availability (such as the well area in Punata). It is also applied in areas such as the atajados that do not have high water availability, but families have their individual water source next to their land and therefore do not need to prepare the soil too early: in both cases, it involves a relatively "high degree" of technical water control. Another factor influencing these practices are soils' physical characteristics. In areas of shallow soils or coarse texture (sandy loam or sandy) it makes no sense to irrigate long in advance, because the water (little or much) applied to the soil would be lost.

"Fallow preparation" (intermediate fallow) is practiced in areas with a relatively secure water source, if possible a few months before the rainy season. The aim, in this case, is to prepare the soil, to reach favorable temperature and moisture for seeds, for uniform germination and plant emergence. In addition, it attempts to store a significant amount of water in the soil profile, to ensure the crop's initial growth until the first irrigation is applied or the regular rainy season begins. This practice is part of a productive strategy, to advance sowing/planting timing by "playing" with the complementarity between irrigation and rainfall and reducing the risks posed by uncertainty in the annual rainfall regime. This is very common and strategic in a situation where cultivation is not possible with only irrigation or rainfall alone.

Currently, under this logic, the Khocha Totora reservoir system is a very important source for fallow preparation in southern Punata (used by the Soto family and many others in this area) and to a lesser extent to the north, which has also other dams and wells (for example, the Ubaldo and Montes families, which have intermediate access to water). A similar situation occurs with potato sowing in the Chiyara Khochi system. Part of productive strategies that are being adapted by peasant families consists of "adjusting" the early potato sowing campaign ("mishka" season) by preparation irrigations (observed in all cases studied). This, in turn, 
requires adjustments in dam operation and water distribution, to enable such preparation irrigations (larger discharges).

Besides climate factors, crop characteristics, and especially water availability, the soil's high water-storage characteristics are important to success with this practice. The partial uncertainty in water and rainfall availability is "controlled" to some extent, by complementarity between rain and irrigation, storing water in the soil profile. Again, this practice would not make sense and is not practiced in areas with shallow or very permeable soils, such as Rumi Cancha or some areas in the Chiyara Khochi system.

Finally, it is the "watabarbecho" or annual, long-fallow treatment, commonly practiced in areas where the only irrigation available is "storm irrigation", i.e. irrigation during the rainy season as "complementary" irrigation. This is the case in southern Punata or remote areas that have no water rights to any of the dams. In these areas, very large volumes of water are applied to the plots, with the last rains in March or April. This can be done even while the previous crop is still standing in the plot (Centellas, 1998; Delgadillo, 2003b). Water should be stored in the soil for long periods, between six to eight months. Only very deep soils with high water storage capacity will serve for this purpose (capacities greater than $150 \mathrm{~mm} / \mathrm{m}$ ). This practice is almost exclusively for growing maize.

Beyond the effects or physical explanations of these practices, this technology involves knowledge and work organization: recognizing the appropriate soil type, the time to irrigate, combining machinery (tractors) with other implements and calibrating them for proper tillage depth and land leveling, using oxen and a wooden plow, with three to four people driving the water within the plot, and other practices: a range of different skills required to perform the full range of practices involved in this "water-scarcity control technology". In turn, this technology is an integral part of an array of productive strategies to grow grain, fodder and all derivatives (e.g. corn) under conditions of hydrological water insecurity and uncertainty. These practices generally involve mobilizing knowledge and family labor; collective work by the irrigation organization the families belong to is also a crucial component to assuring water access. Starting by "collecting water" from the main intake and conveying it several kilometers up to the irrigation area, is hard work that communities are forced to do if they want to irrigate but have less access to water. This combines individual and collective knowledge and activities to control the water flow from the source to the final use on the plot.

\subsubsection{Successional or staggered planting}

Staggered planting is an important productive strategy for work organization and production (harvest) scheduling on a peasant farm. In literature however, it is only or primarily explained for marketing purposes. The case studies nevertheless show that, in addition to this, the approach again is to play with complementarity between rain and irrigation and, to some extent, to control weather factors such as frost or drought periods. That means, the effort is to have some "control" over uncertain water availability: sowing or planting a crop on various plots, some weeks or months apart. One of the cases studied (Ubaldo family) shows that this is also 
an important strategy to distribute family labor available along the cropping season, making it less intensive at certain times.

For Punata, in the area served by tube-well systems (the northern zone), water availability is relatively controlled. Therefore, staggered plantings are meant to extend the growing season and thus to break constraints on market prices and uncertainties in rainfall distribution. Usually, the first plantings do not have enough water availability to irrigate large areas, so that it would not be possible to cultivate with irrigation only. The last plantings, on the contrary, exactly match the beginning of the rainy season. In this way, the family can cultivate a larger area without facing the risk of water shortages. The first plantings rely more (but not exclusively) on irrigation and the last ones more on rainfall.

The Ubaldo family's strategy consists of planting onions on different plots, times and places. In most years they plant onions on six different plots located in three communities. Mr. Ubaldo explains that he rotates and plants at different times, from October to March, because on some of their plots the crop is more susceptible to being attacked by a fungal disease (Kamanchaca). The same applies for carrots and flowers.

Staggering planting also involves organizing family labor. The Ubaldo family, during this study, managed its land, divided into 27 small plots with different crops. With only the couple, and their children's help on weekends, they have no choice but to reduce labor intensity. This applies particularly to growing vegetables, which are very demanding in planting and harvesting times.

The Chiyara Khochi system is undergoing a major transformation in the cropping pattern and production strategies under irrigation. Today one might say that peasant families are still experimenting, testing and adapting some of those strategies. In this area, potatoes have become the "leading crop" of irrigated agriculture (Vega and Iriarte, 2003). Potato planting extends from June through August. The same family grows at least twice, "mishka" sowing and "chaupi mishka" (early and intermediate sowing, respectively), to balance the benefits of selling potatoes in November or December, with the risks of early sowings that could be affected by the last (late) winter frosts.

Irrigation has enabled them to experiment in this direction. According to earlier information collected by Vega and Iriarte (2003) and comparing with the data from this study, we can see that there is a tendency to reduce this period of staggering (successional planting), tending to cultivate not as early as June, but closer to July (practised by the four families studied). The staggered planting was also made possible by the system's flexibility, although there is a constant tension between the high management demands and water requirements for such staggered plantings. This has been constantly discussed in the association of irrigators (ARSAC). Vega and Iriarte (2003:68) mention a testimony that reflects this tension, expressed by a user against the irrigators association "... you decide when to release water, but you cannot oblige us to plant". In more recent years this strategy is still in practice, but many families have adjusted (and facilitated) this requirement by implementing small individual reservoirs. 
This enables them to store their water shares (turns) and then to stagger any planting with even more flexibility.

The situation of Rumi Cancha community, with atajados systems, is completely different. This strategy of successional planting is not used for crops that are going to market, such as onions and tomatoes (irrigated) and obviously is impossible for rainfed crops. What the community does is to plant small areas (only a few square meters) of vegetables that families grow exclusively for their own consumption: lettuce, carrots, tomatoes and others. Some of these vegetables are planted or sown by families in stages or rather scattered through the year to have food available for as long as possible. This is, on a very small scale, staggering planting selfsupply.

\subsubsection{Strategies to optimize water use: combined use and prioritization of water sources}

Current knowledge about field-level water management in Punata is the result of many years of farmers' experience, experimentation, and testing by trial and error. This knowledge exists and develops along with the conditions that have also been established collectively in managing various irrigation systems -- systems that often overlap spatially. From the family domain this strategizing happens in a finetuned calibration practice, whereby many families have their plots scattered among locations all with different water availability. This shows that the "art of irrigation" in Punata is the result of different strategies of combining water sources at different times and in different places. This is done in order to irrigate certain crops in different (specific) ways or rather to prioritize or almost exclusively use a certain source for a specific crop or specific purpose.

For example, the Ubaldo family prepares soil for maize, potatoes or broad beans with priority especially for water from reservoirs, particularly in two of the four areas where their plots are scattered, based on their knowledge of the soil and its moisture retention capacity. They use plots that are closer to home more intensively to grow vegetables, preferring to irrigate with tube-well water. For these plots, they generally do land-leveling every year. All these plots are perfectly leveled, as small terraces where the water (well water) is distributed very evenly and is "ponded" at the end of irrigation (technical irrigation literature could classify this as border irrigation; Brouwer et al., 1990)

Allocating different water sources to specific plots (although not always strictly) also helps use the family's available time and labor better, as they can calculate how long these plots are irrigated with a particular source. In general, peasant families in Punata already know how long they should apply water to each plot (and crop) with every source of water, also differentiating the time required either for soil preparation or for crop irrigation. In the case of well water, Mr. Ubaldo and others in the zone have to assure water's first entrance to the plot at the beginning of irrigation time, and then they can do other tasks. At the end, they cut off the flow and check if water was evenly distributed on the plot. 
The Ubaldo and Estrada families access to different water sources, leading them to use them as part of their practices to manage and prioritize irrigation in different places. This also enables them to differentiate those plots' "vocation" based on different characteristics of microclimate, soil and "accessibility" 25 to water.

Table 5-4. Main irrigated crops with different sources of water in Punata

\begin{tabular}{|c|c|c|}
\hline Source of water & Main crops & Specific uses \\
\hline Laguna Robada & $\begin{array}{l}\text { Alfalfa, broad beans, potatoes, maize } \\
\text { Onions, carrots, peaches, other vegetables }\end{array}$ & $\begin{array}{ll}- & \text { Crop irrigation } \\
\text { - } & \text { Fallow irrigation ("empanto") } \\
\text { - } & \text { Land preparation (short fallow) }\end{array}$ \\
\hline Lluska Khocha & $\begin{array}{l}\text { Alfalfa, broad beans, potatoes, maize, occasionally } \\
\text { vegetables (onions, carrots) and flowers }\end{array}$ & $\begin{array}{l}\text { - } \quad \text { Fallow irrigation ("empanto") } \\
\text { - } \quad \text { Crop irrigation }\end{array}$ \\
\hline Totora Khocha & Maize (grain) alfalfa & $\begin{array}{ll}\text { - } & \text { Fallow irrigation (empanto) for } \\
\text { maize } \\
\text { - } \quad \text { Crop irrigation (different crops) }\end{array}$ \\
\hline Hand-dug well & Alfalfa, potatoes & $\begin{array}{l}\text { - Small plots of potatoes and } \\
\text { alfalfa }\end{array}$ \\
\hline Drilled well & $\begin{array}{l}\text { Onions, carrots, beet, cabage, other vegetables, } \\
\text { flowers } \\
\text { Alfalfa, peaches, broad beans, potatoes }\end{array}$ & $\begin{array}{l}\text { - Transplanting irrigation (onions, } \\
\text { beet, cabage) } \\
\text { - Sowing irrigation (carrots, } \\
\text { flowers) } \\
\text { - Crop irrigation }\end{array}$ \\
\hline Rol & Maize (grain) alfalfa, barley, wheat & $\begin{array}{ll}\text { - } & \text { Fallow irrigation (for maize) } \\
\text { - } & \text { Occasionally, crop irrigation }\end{array}$ \\
\hline Pilayacu & Onions, broad beans, potatoes, flowers & $\begin{array}{l}\text { - Transplanting irrigation (onions, } \\
\text { beet, cabage) } \\
\text { - Sowing irrigation (carrots, } \\
\text { flowers) } \\
\text { - Crop irrigation }\end{array}$ \\
\hline Waste waters & Maize, alfalfa, broad beans & $\begin{array}{ll}\text { - } & \text { Fallow irrigation (for maize) } \\
\text { - } & \text { Crop irrigation (alfalfa, and } \\
\text { occasionally broad beans) }\end{array}$ \\
\hline
\end{tabular}

Source: Adapted from Del Callejo \& Vásquez (2007); Del Callejo (1999); Vega (1996)

While Punata may be a unique situation, in which different irrigation systems overlap, and together complicate the analysis of the actual water availability in different communities or areas, the above table shows that water availability, as a result of collective and household water control, will ultimately determine the type of crop to grow or the production system to implement. Areas with water availability only from rivers will tend to produce maize and alfalfa for cattle raising. On the contrary, areas with dam systems tend to diversify production,

25 Accessibility means closeness and infrastructural "facilities" for a plot to be irrigated from a given water source. 
while areas with high availability (such as wells, and Pilayaku) also grow a variety of crops but with some predominance of vegetables and flowers. In the other study areas, with only one source for irrigation, water availability and therefore the possibilities of extending the irrigated area, to expand the agricultural calendar, or to intensify production, are very limited.

\subsubsection{Combined use of different water sources and diversity in water uses}

Water as such has a very important meaning in peasant life, as a vital element for agricultural production (for irrigation), and for other purposes. The case of Punata, and cases in Sacabamba and Rumi Cancha, illustrate the different functions of water for peasant families. These different functions are closely related to the characteristics of water availability in terms of quantity (volume or flow), timing (when water is available), and quality.

As rivers are mostly seasonal sources, their main function is "complementary irrigation" of crops at the beginning and during the rainy season. In Cochabamba's valleys, maize is the main crop irrigated with this water. This same source, as already indicated in Chapter 3, is used by riverside communities in Cochabamba's Upper and Lower Valley for "lameo" or soil recovery, applying water with sediment, either to restore soil fertility or to form new plots on river-banks by terracing.

Other water sources, such as dams, play an important role in watering animals (some small animals but mostly cattle), or to prepare bricks for construction. It is also used in Punata by artisans to wash leather or for car-wash services.

Groundwater systems in Punata have more controlled flow and generally better water quality. Therefore, these sources are used for many applications. In Punata they are used for making "chicha", watering animals, washing vegetables after harvest, car-washing and many other domestic uses besides agro-productive uses.

Among the multiple uses of groundwater, in many cases this water is used as the main source for domestic consumption. However, in peasant households, human consumption and other domestic uses may be outweighed by other productive uses, such as irrigating small family orchards, watering animals (cows mainly) or making "chicha" (Del Callejo and Vásquez, 2007). Although these uses are important in terms of volume and for peasant families' livelihood strategies, they are however rarely considered in designing water systems for domestic consumption. 


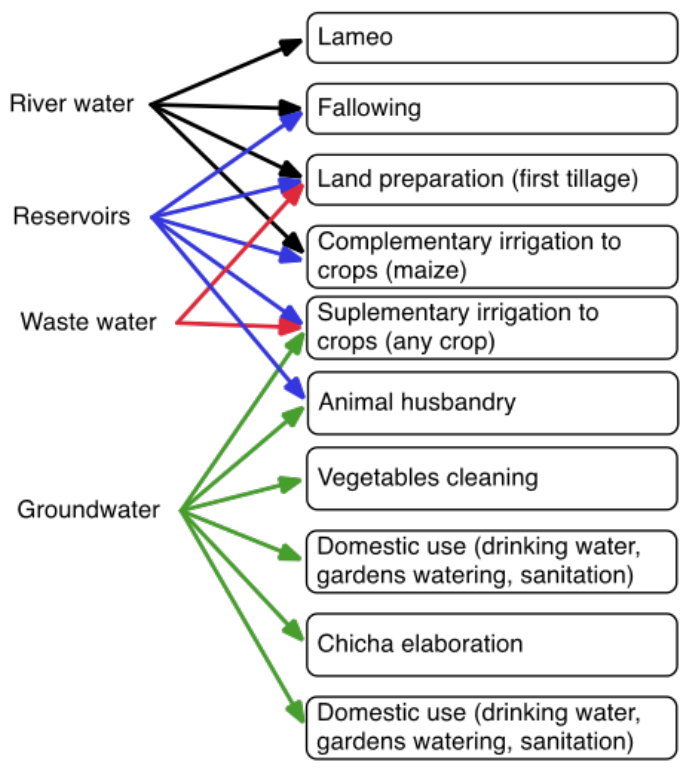

Figure 5-2. Multiple uses of water according to the water source

(Source: Prepared by the author)

In Chiyara Khochi and Rumi Cancha, watering livestock is the most important use besides irrigation. In the Chiyara Khochi case, this use has already been internalized in system management. This can be seen when someone uses water during someone else's turn, to fill a small reservoir (pond). It is almost considered as animals' right to water and not as water theft or serious misconduct.

Under conditions of scarcity it is also an increasingly common situation to (re)use wastewater, even if this water is not treated adequately or at all. In growing towns such as Punata, this is also becoming a serious health risk and source of disputes in communities that do not have alternative sources. Here, there is an increase in the demand for this water to irrigate different crops, included vegetables.

\subsection{Organization of labor in peasant irrigation. Dynamics in institutions, technology and markets}

One of the distinctive features of how peasant-farming systems function, different from business production systems, is how labour is organized on the farm and beyond. As discussed in previous chapters, peasant irrigation also implies very demanding collective work: the tasks individuals (or individual families) perform to accomplish their duties to keep the system functioning and as a way to maintain their water rights. This section discusses family labor organization for collective irrigation systems as well as for individual production systems, particularly the way families and their production systems integrate with broader socioeconomic spaces. Markets, governmental and non-governmental institutions, and technology 
importantly mediate this integration. The analysis focuses particular attention on the collective level of water management as an important factor in those inter-relationships.

\subsubsection{Organizing family labor to control water}

Family labor in peasant farming systems is intensive. This intensity in farming is further increased by the work around irrigation, with all that this activity involves. Table 5-5 summarizes the type of work that peasant households, in the different areas of study, must perform to ensure that they can irrigate according to each crop's and/or plot's requirements and under the conditions or requirements of the irrigation systems' collective management. Irrigation involves activities and practices that families do individually on their farms, and also relates to how the same families, along with others, perform a number of tasks outside their farm, with the common irrigation infrastructure. Those tasks are what is usually called "collective work" but it does not mean that collective work is just the sum of individual work. Ultimately, peasant families have to devote a significant amount of time and work (one or more family members), depending on the case, to make the whole system run and then assure that water reaches their plots.

Table 5-5. Organizing family labor around irrigation

\begin{tabular}{|c|c|c|c|c|c|c|}
\hline $\begin{array}{l}\text { Case } \\
\text { (Id- } \\
\text { Name) }\end{array}$ & $\begin{array}{l}\text { Main water } \\
\text { source } \\
\text { /system for } \\
\text { main crop }\end{array}$ & Main crops & $\begin{array}{l}\text { Number of } \\
\text { irrigations } \\
\text { for main } \\
\text { crop }\end{array}$ & $\begin{array}{l}\text { Family labor } \\
\text { requirements at } \\
\text { field/farm level }\end{array}$ & $\begin{array}{l}\text { Family labor } \\
\text { requirements at } \\
\text { system level }\end{array}$ & $\begin{array}{l}\text { Management } \\
\text { requirements } \\
\text { (collective/system) }\end{array}$ \\
\hline 1 Ubaldo & Tube wells & $\begin{array}{l}\text { Onions, } \\
\text { vegetables }\end{array}$ & 10 & $\begin{array}{l}\text { Plot leveling, } \\
\text { Eventually on } \\
\text { field application }\end{array}$ & $\begin{array}{l}\text { Once a year canal } \\
\text { cleaning }\end{array}$ & $\begin{array}{l}\text { - Electricity } \\
\text { - Attending monthly } \\
\text { assemblies }\end{array}$ \\
\hline 2 Montes & Reservoirs & Alfalfa, & $2-3$ & $\begin{array}{l}\text { Fallowing } \\
\text { On plot ditches } \\
\text { Field application }\end{array}$ & $\begin{array}{l}\text { - Canal and } \\
\text { intakes cleaning } \\
\text { - Main } \\
\text { conveyance } \\
\text { vigilance } \\
\text { - Distribution } \\
\text { points vigilance }\end{array}$ & $\begin{array}{l}\text { - Agreements on water } \\
\text { releases (largadas) } \\
\text { - Organization of } \\
\text { maintenance and water } \\
\text { distribution } \\
\text { - On time operation and } \\
\text { water distribution } \\
\text { - Attending assemblies } \\
\text { (monthly) }\end{array}$ \\
\hline 3 Soto & $\begin{array}{l}\text { River flow } \\
\text { (Mitha, Rol) }\end{array}$ & Maize & 2 & $\begin{array}{l}\text { Fallowing } \\
\text { On plot ditches } \\
\text { Field application }\end{array}$ & $\begin{array}{l}\text { - Once a year } \\
\text { ditch cleaning } \\
\text { - Distribution } \\
\text { points vigilance }\end{array}$ & $\begin{array}{l}\text {-Intercommunal } \\
\text { agreements for water } \\
\text { distribution } \\
\text { - Accompanying water } \\
\text { to communities }\end{array}$ \\
\hline $\begin{array}{l}4 \text { Roldán } \\
5 \text { Lima } \\
6 \text { Estevez } \\
7 \text { Rogelio }\end{array}$ & Atajados & $\begin{array}{l}\text { Onions, } \\
\text { Maize }\end{array}$ & $\begin{array}{l}6-10 \\
2\end{array}$ & $\begin{array}{l}\text { Plot preparation } \\
\text { Crop irrigation }\end{array}$ & $\begin{array}{l}\text { - Agreements on } \\
\text { micro catchments } \\
\text { use }\end{array}$ & - None \\
\hline
\end{tabular}




\begin{tabular}{|c|c|c|c|c|c|c|}
\hline $\begin{array}{l}8 \text { Franco } \\
9 \text { Alvarez } \\
10 \\
\text { Juvenal } \\
11 \text { Gamez }\end{array}$ & $\begin{array}{l}\text { Chiyara } \\
\text { Khochi } \\
\text { reservoir }\end{array}$ & $\begin{array}{l}\text { Potatoes, } \\
\text { Maize }\end{array}$ & 2 & $\begin{array}{l}\text { Plot preparation } \\
\text { Crop irrigation } \\
\text { (on plot water } \\
\text { conveyance) }\end{array}$ & $\begin{array}{l}\text { - Distribution } \\
\text { points vigilance }\end{array}$ & $\begin{array}{l}\text { - Organization of } \\
\text { maintenance and water } \\
\text { distribution } \\
\text { - On time operation and } \\
\text { water distribution } \\
\text { - Attending monthly } \\
\text { assemblies }\end{array}$ \\
\hline
\end{tabular}

Source: Prepared by the author

Table 5-5 also shows that some systems require more work than others, in some cases regularly, and in others contingently and sometimes even randomly. Initial work investments to acquire water rights, as was shown in Table 5-3, can be also significant. These may often compete with regular farm tasks or even prevent families from doing their normal agroproductive work.

In conclusion, irrigation contributes directly to intensify agriculture in general and labor employment (family and/or hired) in particular. Crops such as onions, potatoes, flowers or other vegetables in general, can represent up to four times more labor requirements compared to rainfed crops or even to maize and alfalfa under irrigation. This explains why conversion of rainfed agriculture to irrigated crops is not "automatic" or immediate. In many cases, it may take two, three or even more years (as in the case of Sacabamba) to achieve the necessary adjustments in the irrigation system's management, families' labor requirements and peasantfarm organization. This in turn, denotes the family labor conjunction and organization in controlling both production and water.

\subsubsection{Cyclicity in organizing labor for peasant irrigation}

Irrigated agriculture is the result of combining or to some extent managing various natural cycles, such as plant and animal life cycles (Le Grand, 2014; van der Ploeg, 2008; Zoomers, 1998), and the hydrological cycle ( Molle et al., 2007; Molle and Wester, 2009). In turn, these natural cycles are also superimposed on peasant families' life-cycles (Boelens, 2014; Zoomers 1998), and on water management social dynamics, "hydrosocial cycles" (Barnes and Alatout, 2012; Boelens et al., 2016; Linton and Budds, 2014; Molle and Wester, 2009). Year after year, cycles start: land preparation, planting, cropping and harvest practices or raising animals, their care, breeding and production. Also, as part of the hydrological cycle, water sources are "recharged" (e.g. springs or groundwater) or flow through streams and rivers, starting with the first rains. In other cases, the water is stored in reservoirs, either natural or artificial, or finally, in subsequent years water is also stored in the soil as an outcome of the rain cycle.

Human, physical and organizational work on agriculture and irrigation, will also follow these as well as their own "rhythms" or "irrigation cycles", parallel and also intertwined with them: starting from organizing for cleaning ditches and channels where water is conveyed to irrigate, building defenses in some cases, and decisions on when and how to operate dams, wells, headworks, etc. (Boelens, 2008a; van den Dries, 2002; Gelles, 1994). Linked to these movements we see, for example, the flow of agricultural products resulting from the crops, or 
before them, the flow of inputs such as seeds, agrochemicals, fertilizers, or the workforce, whether peasant family or hired labor. These inflows ultimately result in periods and cycles of higher or lower demands and supplies in the different markets for products and factor inputs. All these overlapping cycles are organized by productive and livelihood strategies that families are building, often also cyclically. These are manifested through periods when family labor on the farm is more intensive, or less intensive, periods of greater or lesser need for money, seasonal or medium-term migration, periods when the family focuses more on processing agricultural products, or marketing, etc. (e.g., Borras, 2009; Le Grand, 2014; van der Ploeg, 2008; Zoomers, 2013).

Figure 5-3 exemplifies, as a calendar, the different types of agricultural activities for major crops, irrigation and water management activities in irrigation systems, and case studies in Punata. It should be noted, however, that these cycles are not static or necessarily repeated in the same way year after year. This example intends to emphasize the complexity of interrelationships among these cycles.

The different water sources to which the Ubaldo family has access gives them greater water availability in quantity and in time. This enables high-intensity agriculture and irrigation, combining the different agroproductive, hidrosocial and market cycles creatively. On the other hand, the Soto family relies more on water from one reservoir (Totora Khocha) and occasionally from the river, apparently reducing their combination of cycles. Also, maize production and particularly milk production lead to another type of relationship with the market and the community. In general, one could say that success in timing and possibly controlling these cycles will make it possible to not only reproduce but also to produce new production cycles in following growing seasons or years. This combination of overlapping cycles around irrigated agriculture are a key part of reproducing the farm and peasant families' livelihoods.

Similarly, at the collective level, and often cyclically linked to the activities performed by families and leaders of organizations, are the regular meetings and negotiations that occur between water users from Punata. Communities at the upper part of the basin, where the dams are located, also take part, integrating territory-based cycles of cooperation and negotiation over water. 


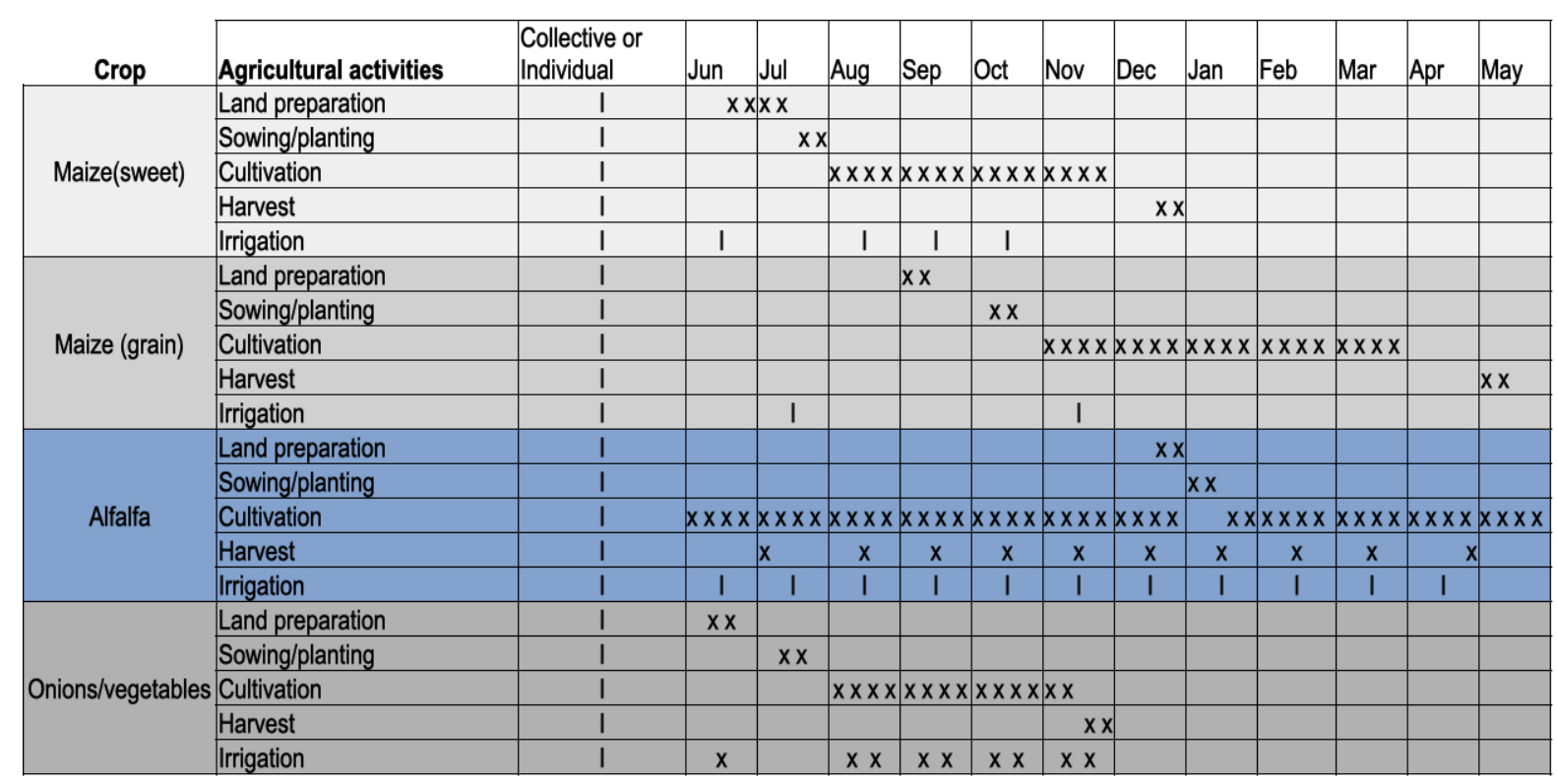

\begin{tabular}{|c|c|c|c|c|c|c|c|c|c|c|c|c|c|}
\hline Water management activitie & $\begin{array}{l}\text { Collective or } \\
\text { Individual }\end{array}$ & Jun & Jul & Aug & Sep & Oct & Nov & Dec & Jan & Feb & Mar & Apr & May \\
\hline Main canals cleaning & C & & & $x$ & & & $\mathrm{x}$ & & & & & & \\
\hline General maintenance & C & & $\mathrm{x}$ & $x$ & & & & & & & & & \\
\hline Ordinary assemblies & C & $\mathrm{x}$ & $\mathrm{x}$ & $\mathrm{x}$ & $\mathrm{x}$ & $\mathrm{x}$ & $x$ & $\mathrm{x}$ & $\mathrm{x}$ & $\mathrm{x}$ & $\mathrm{x}$ & $\mathrm{x}$ & $x$ \\
\hline General assembly & $\mathrm{C}$ & & & $\mathrm{x}$ & & & & & & & & & \\
\hline
\end{tabular}

Off farm employment

Casual or fixed employment

RAINFALL $\times \times \times \times \times x \times x \times x \times x$

Figure 5-3. Example of labor organization, irrigation practices and water management practices expressed as annual cycles

(Source: Prepared by the author)

\subsubsection{Organizing family labor in production}

Despite the diversity of crops and agricultural and non-agricultural activities undertaken by peasant families, they usually organize their farm work around one or two main crops. In this study, these main crops are conceptualized as "ordering crops". These "ordering crops" reflect certain agrarian vocation in each area or community and irrigation system. Peasant families prioritize these crops to organize their resources (land, water, inputs, labor and capital). These crops are the most important in terms of family livelihoods, either because of the direct cash income they earn, because they are the family's staple food crops or they play an important role in other productive and economic activities.

Table 5-4 (Section 5.3.3) summarizes the main crops cultivated by the cases studied in the three regions. For Punata, crops are onions (Ubaldo family), alfalfa (Montes family) and maize (Soto family). Although all three families produce alfalfa and maize, these crops' purpose and importance are different in all three cases. The same happens in the other areas. In the case of Rumi Cancha, maize is the "ordering crop" for two families (Roldán and Lima families) while 
it is onions for the other two (Estévez and Rogelio). For Sacabamba, potatoes are the most important in all case studies, although they differ in maize (Alvarez and Gamez) and wheat (Franco) as a second crop. For each case, we have studied in detail how the family organizes the work for these crops: technical itinerary, from planting to harvest, irrigation practices, the use of inputs, machinery or animals, the costs incurred and the products' destination. This makes it possible to analyze various aspects of technology, family work organization, and the expression of different "farming styles".

In the 11 cases studied, families are at different "stages" of their life cycle, with varying availability of resources (land, labor, knowledge, capital, animals, and others) and pursuing agricultural activities under different agro-ecological and socio-cultural contexts. Therefore, it is obvious to expect them to organize their work differently. However, there are some aspects of organizing family labor that call for attention. If we see the extent of use of family labor in the main crops, there is a trend or growing correspondence between two variables: the larger the family, the higher percentage of family labor use. Next, analyzing land availability and the way these families farm, they tend to deploy more family labor on larger farms.

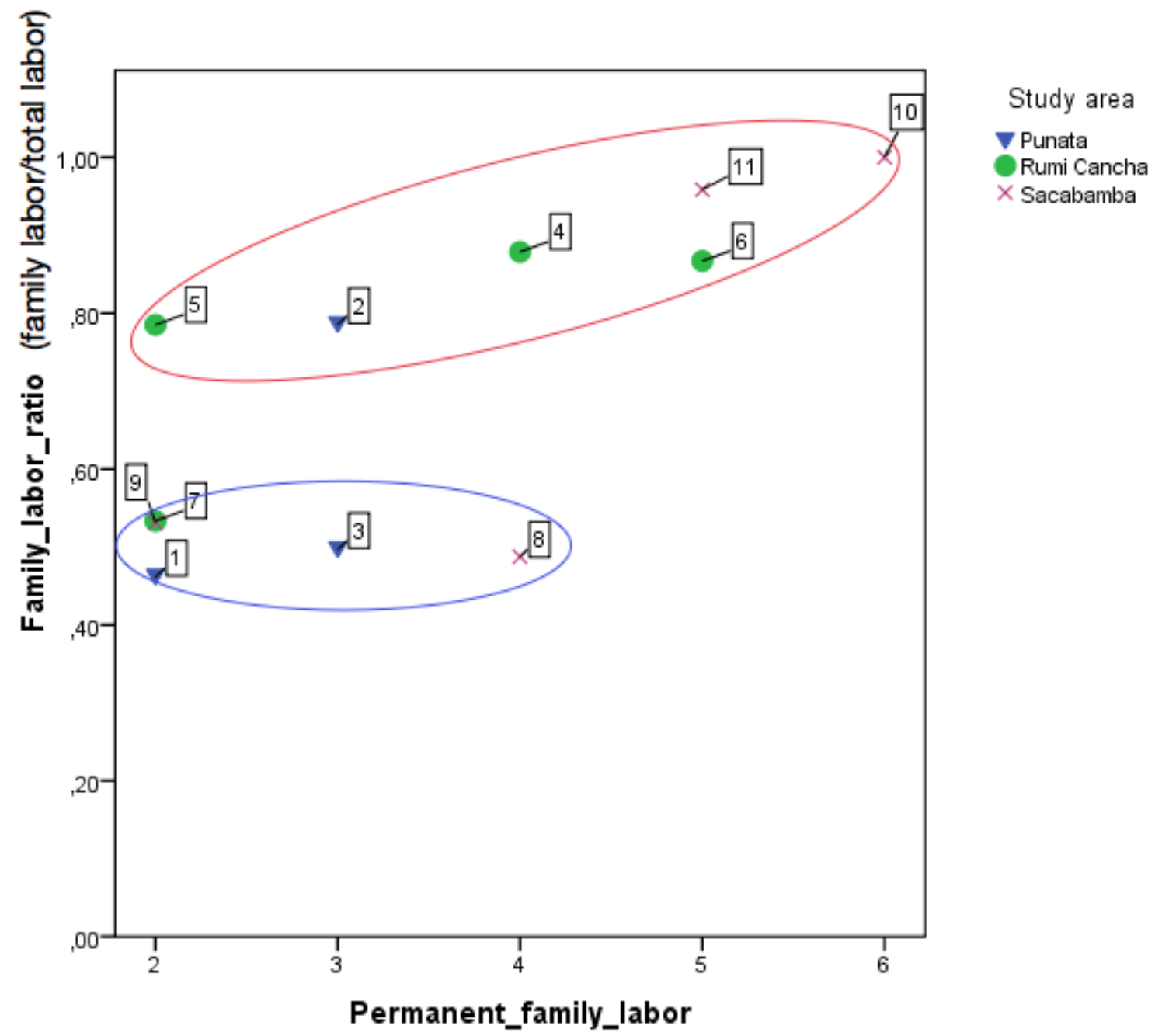

Figure 5-4. Family labor investment in main crops

(Source: prepared by the author) 
However, there is a group of families who, regardless of the number of family members and the intensiy in the production system, produce their (main) crops with about $50 \%$ of their family labor and therefore also employ hired labor (paid in cash). For Punata, this form of organizing work concerns two very different types of production systems as in the Ubaldo and Soto cases (cases 1 and 3, respectively). The former grow vegetables intensively and the latter grow maize more extensively. In any event, while some families use more family labor, it is also common to hire workers. This hiring means that the peasant families cannot fully cover the work required by the different crops they grow. This already indicates that, even when the average land size in the different study areas is relatively small, agricultural production is very laborintensive. What also becomes apparent is the strong heterogeneity in how peasant farmers organize their labor for production, as is discussed in the following sections.

\subsection{Heterogeneity in shaping different styles of farming}

Heterogeneity in resource access or availability in a household commonly expresses "economic inequalities in wealth, income or access to credit" (...) and other resources (Ruttan, 2008: 980). From this point of view, heterogeneity as a starting condition for farming practices entails a problem. Some authors would argue that therefore, necessarily, heterogeneity slows (economic) development and has "negative effects on collective action" (Ruttan, 2008: 980). Other authors, on the other hand, while recognizing the fact that wealth differences and socioeconomic inequality constitute major problems, point at the fact that heterogeneity in itself may enhance various forms of cooperation "based on interdependence and complementarity of skills and resources" (Boelens, 2008a). Meinzen-dick and Raju (2002), for instance, specify that social heterogeneity (ethnic, class or caste) can mean a significant barrier, unlike heterogeneity in the resources available to families. In the agricultural production domain, it is also common to find high heterogeneity in the "initial conditions" of peasant families' resources (e.g. quantity and quality of land, water, labor) that are directly related to priorities and the objectives, and therefore, the results of their production.

This section discusses heterogeneity, focusing on understanding the diverse ways in which production and work are organized on peasant farms. These manifestations of heterogeneity will be discussed through three key concepts or indicators that can be linked to help understand the interplay of peasant agriculture under irrigation with water control and its various manifestations in different localities. These interactions between the individual and collective domains in irrigation and agroproductive processes are understood here as "localized expressions of irrigated agricultural development".

The three variables that relate to heterogeneity and which are highlighted here are: (1) the intensity of work organization, expressed as strategies to increase or decrease intensification; (2) the degree of production specialization or diversification; (3) the market relationship based on the commodification / non-commodification of different production factors (van der Ploeg, 1990). Here, water's fundamental role is discussed as a key factor in all three aspects and its relevance for understanding reproduction of production and of peasant agriculture in general. 
These three variables of heterogeneity in peasant agriculture are discussed from the notion of "farming styles" presented in Chapter 2 (based on van der Ploeg, 1990, 2008).

In literature on agricultural economics, particularly regarding farm management, intensification and specialization (to specialize in one or a few products, preferably one item) are usually identified and currently promoted as the best way to optimize production. These "technological and productive options" enable more "efficient" use of factors and inputs, to achieve maximum production and hence maximum returns. Sometimes intensification and "extensification" or specialization and diversification are treated as opposite and mutually exclusive. From another point of view, "extensification" is analyzed as a starting point for peasant production systems, which then will "evolve" into more intensive production systems (see the discussion by Erickson (2006) based on the postulate of Boserup, 1965) or from diversified production systems into specialized systems.

This section discusses these patterns or production schemes present in peasant agriculture, as part of agroproductive strategies. I argue that they belong to a broader set of peasant-family strategies aiming at achieving some degree of autonomy. This autonomy is to cope with the market or other factors that create dependence and uncertainty (or risks) for reproducing their livelihoods, particularly to reproduce their farming system - which may also be related to water availability and water control.

\subsubsection{Intensification and "extensification"}

The case studies show family-strategy cycles, subject in turn to families' cycles and livelihoods but also to other (limiting) factors such as access to land, water or labor force or family members' other priorities. Here, agricultural intensification involves the use of inputs, labor and other production factors. Van der Ploeg (2008) defines intensification as a "constant but steady process to increase production per unit area of land (or animal) by increasing the use of inputs and production factors or by improving technical efficiency" (Van der Ploeg, 2008: 45). This study has adopted this concept, emphasizing the concentration or increased work in productive activities.

Figure 5-5 depicts the amount of labor devoted by families to their main crop (onions and maize for Punata and Rumi Cancha and potatoes for Sacabamba). For an area between 1/3 to 1/2 hectare, the total amount of labor ranges from 20 to almost 80 persons*day (working days, locally called "jornales"). The amount of labor in Sacabamba and Rumi Cancha is remarkable, almost double the amount of labor in Punata's cases. Rumi Cancha and Sacabamba have very recent experience with irrigated agriculture. The difference in labor-intensity compared to Punata's cases can largely be attributed to experimentation and adjustments of labor organization by these families. In fact, they are following a progressive change from an extensive-rainfed cropping pattern towards more intensive land use and production. Irrigated crops need more intensive work for sowing, cultivating, weeding, irrigating and harvesting. New knowledge and technologies are part of this shift. 


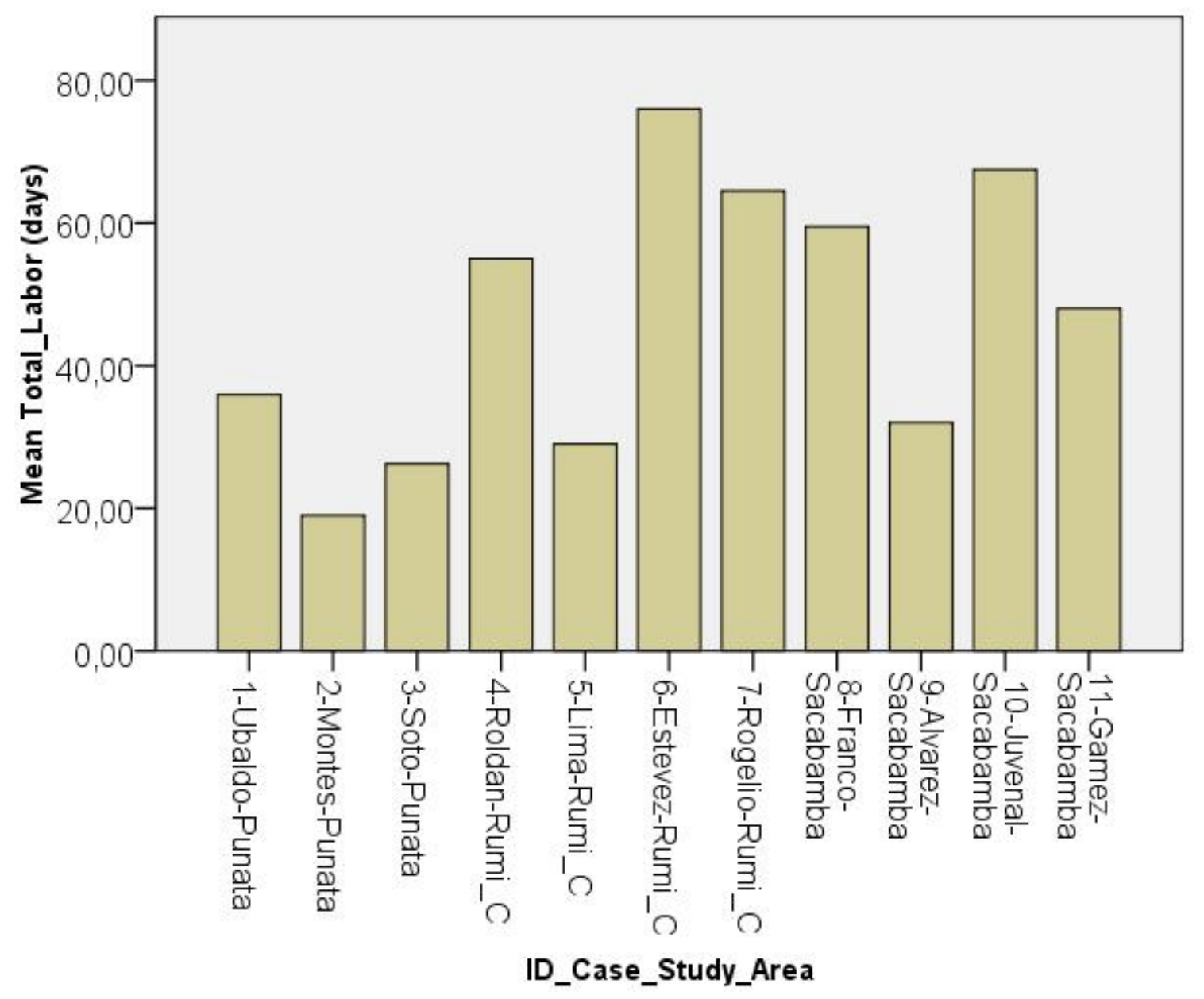

Figure 5-5. Total labor used by families on their main crop per season

(Source: prepared by the author)

Figure 5.6 shows the distribution of labor along the cropping season. In Punata, for instance, the Ubaldo family uses approximately 10 person*days for planting, cultivating and harvesting onions and a small amount (4 person*days) for land preparation. On the contrary, Rumi Cancha cases show, for the same crop, 25 to 35 person*days of work just for cultivation. This big difference reflects a different way of growing onions: a labor-intensive production technology.

Sacabamba families use more labor for harvest, typical of potato production in the Andes, which requires huge amounts of labor as part of the technology but also as a cultural practice developed for this crop. Potato harvest is almost a celebration, in which some families cooperate with the owners. Some of them are hired solely for that purpose, some are paid in cash and others with an agreed amount of the harvest, but all enjoy the food and "chicha" prepared for that important event. 
Figure 5-6. Distribution of labor during the different cropping stages

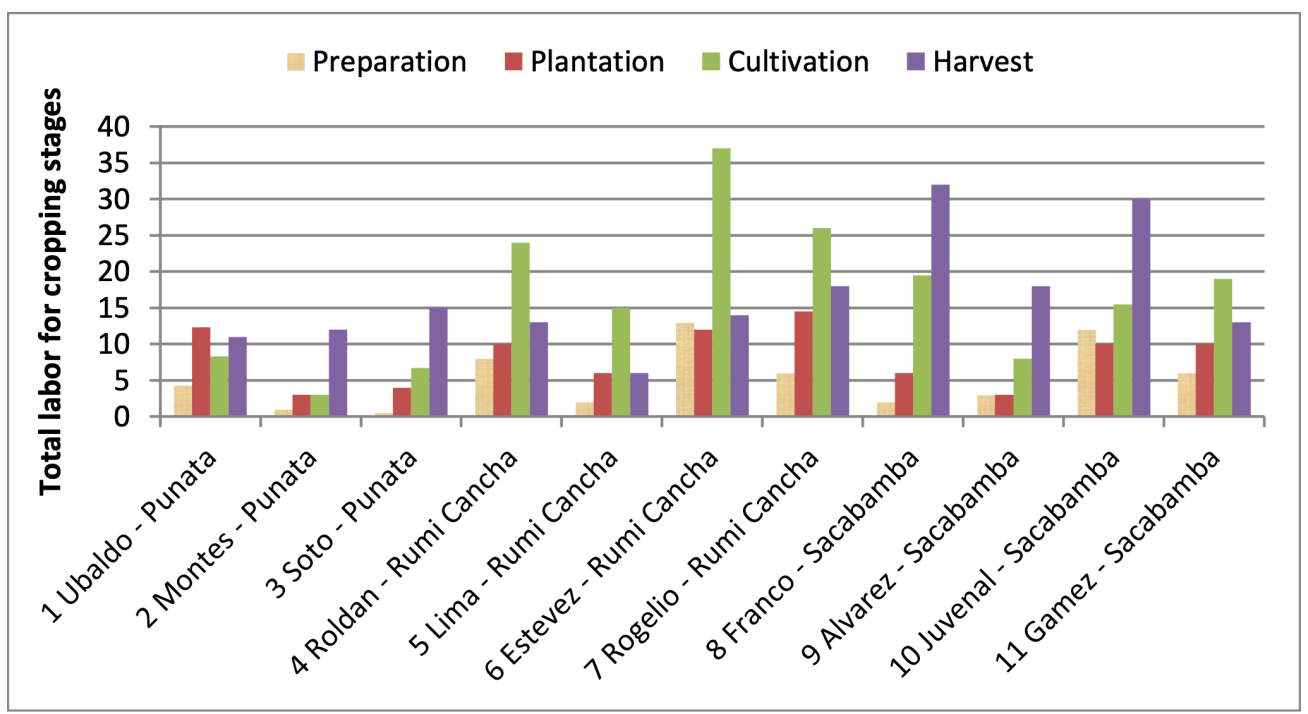

(Source: prepared by the author)

Maize production in Punata (See cases: 2-Montes and 3-Soto) has a similar pattern, although not with less labor than in potato production in Sacabamba. These Punata cases in general show that maize harvest is the most labor-demanding activity. The other stages of maize production are less labor-intensive because of an important technological change in the Upper Valley. Currently, land preparation and maize sowing is mostly done using machinery, considerably reducing the amount of labor and time devoted to this crop. During the cultivation stage, the only labor required for maize is the "aporque" (hilling soil around the base of the cornstalks to bolster them and prevent any tipping) and one or two irrigations. At the same time, machinery use has made it possible to expand the size of maize plots. In general, for Punata and other areas in the Cochabamba valleys, this progressive technological change has meant a trend to extend maize production, together with very labor- and land-intensive production of other crops.

Figures 5.4 to 5.6 show the amount of labor that the families studied devote for one plot and the main crop produced. However, the actual production intensity of labor can only be figured out if we consider all plots and all family members' productive and re-productive activities. For example: the Ubaldo family works around 2.4 Ha divided into 27 different small plots spread among 5 communities, cultivating 8 different types of crops, especially vegetables (onions, carrots, beets), potatoes, beans, maize and alfalfa. Besides the agronomic practices they execute in each plot, as explained in previous sections, they have to fulfill all the requirements for accessing water and other communal tasks. That is, conveying water from the intakes or tube wells towards their plots; attending different meetings for each system at least once a month; attending assemblies and collective works related to each system; and performing other communal duties. On the contrary, the Soto family in Punata grows extensively. They cultivate two main crops, maize and alfalfa, on plots relatively larger than the other cases. These crops do not have high labor requirements during the cultivation stage and their irrigation intensity is lower. All case studies show a direct relationship in production 
system intensification, in principle conditioned by water availability and then by labor availability or by the household's life cycle. This statement is based on the contrasting characteristics of water availability if we compare the Soto family with the other two in Punata.

In the case of the Montes family, they have more water available than the Soto family, however, they have adjusted their production system to their own priorities and capabilities. Previous research (Del Callejo, 1999; Vásquez, 2007) showed that the Montes family was moving from a system of intensive horticultural production to a more extensive system (fodder and dairy cattle) mainly because of the family's age (life cycle) so they can no longer work as intensively as before. Besides, the new production system they are adopting gives them a relatively steady monthly income, apparently more secure than vegetables' highly fluctuating prices.

Intensification, from the land-use point of view throughout the agricultural calendar (area cultivated per year), also offers the possibility of cultivating outside the rainy season. This involves selecting appropriate crops in response to precipitation and irrigation and peasant families' benefits if they can sell such products on the market when prices are favorable. Next, labor intensification in irrigated agriculture will also result from crops' increased technological (and agronomic) requirements. Rumi Cancha cases show high labor utilization during the growing season, similar to the cases of Sacabamba. The effect of irrigation on agricultural intensification is expressed, then, as an increase in labor requirements throughout the crop cycle and not only during the stages of planting and harvesting. This increased labor requirement for irrigated crops has significantly reduced, for families in Rumi Cancha, the number of times and length of periods they migrate to their plots in Chapare, their tropical forest lands.

An equally interesting aspect to highlight in farming and irrigation activities, is that further intensification in agriculture also requires peasant families to maintain cooperation and reciprocity relations at key stages of the growing cycle, such as planting / sowing and harvesting. In these periods, work is strongly based on social networks and family ties within or outside communities.

\subsubsection{Diversification and specialization}

In the study of peasant agriculture and economies, diversification has been documented extensively as a response or (livelihood) strategy adopted by peasant families to cope with uncertainty or risks imposed by the environment (natural hazards such as drought, frost, pests and diseases) and also by the market (access to inputs, price fluctuation), or access to production factors such as labor, water or land (e.g., Ellis, 2000; Le Grand, 2014; Mayer, 2002; Scoones, 1998). Some authors see diversification as "effective" risk management strategies (Valdivia et al., 1996), or a phenomenon recently (re-)"discovered" in discussions about the climate crisis, as mechanisms of "adaptation" to climate change (Howden et al., 2007). In another arena, regarding agricultural development and the feasibility of diverse types of farms and farming in Europe and the United States, diversification is also discussed in terms of agriculture's "multifunctionality": the "implications for the range of functions and farming 
activities considered relevant" (van der Ploeg et al., 2009; Renting et al., 2009:116). In short, diversification can be described as a characteristic feature of peasant families' livelihood strategies. As discussed in Chapter 2, they base their livelihoods on agriculture and on various other productive activities, trade, services, and other craft work, usually called "pluriactivity". Within these strategies, this section's analysis focuses only on agricultural diversification, to discuss its relationship with water control and the resulting expression in different farming styles.

Diversification and specialization of productive systems in peasant agriculture are often perceived as opposing processes. It is generally assumed that peasant agriculture tends toward diversification. However, irrigation - depending on water availability and the security it represents for the production system - may promote "conversion" toward more specialized patterns, which in general are assumed to be more profitable economically. The examples used in this section to illustrate specialization / diversification strategies are two cases in Punata and two in Rumi Cancha. The former are associated with longtime experience with water management and control supported by collective action, and the latter are relatively recent experiences, with many water access limitations under eminently individual (family-based) strategies realted to managing atajados.

The Soto family in Punata cultivates a small number of crops, especially fodder (alfalfa and maize) for milk production (see Figure 5.7). Maize also plays an important role as a staple of the family diet, and a small proportion is sold on the local market to produce chicha or through neighbors or middlemen for sale as processed food (cooked corn called "mote"). A relatively specialized cropping pattern based on fodder and grains is clear in this case, but if we look in more detail, the family produces at least four varieties of maize for different purposes ("mote", fresh consumption, dried and roasted and to make chicha).

In this case, the strategy to produce rainfed crops, or others with larger tolerance to water stress, is related to insecure water availability combined with the limited availability of family labor.

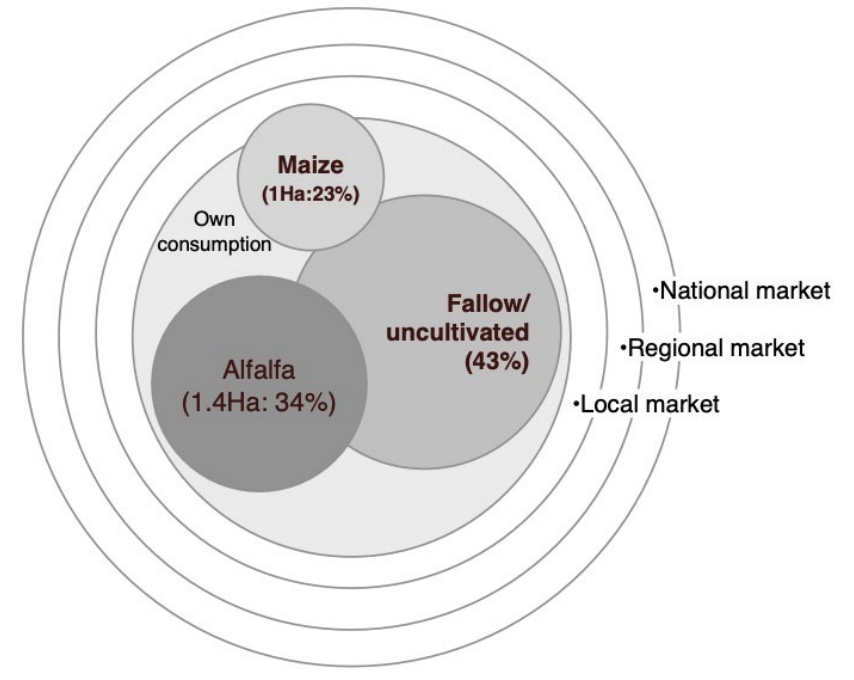

Figure 5-7. Cropping pattern and market orientation. Soto family strategy 
(Source: Prepared by the author)

The Ubaldo family presents a contrasting situation compared to the Soto family. Besides farming an intensive system, their crop diversification is also considerable. Diversification extends to crops that are produced either for market (onions, carrots, flowers and beets), for their own self-supply (maize), or for both purposes (beans, potatoes, some corn varieties). In terms of area, the most important crops are beans, onions and maize. In previous research (Del Callejo, 1999) this case was characterized as "intensive horticulturist and florist", representing a "farming style" specializing in those cash crops.

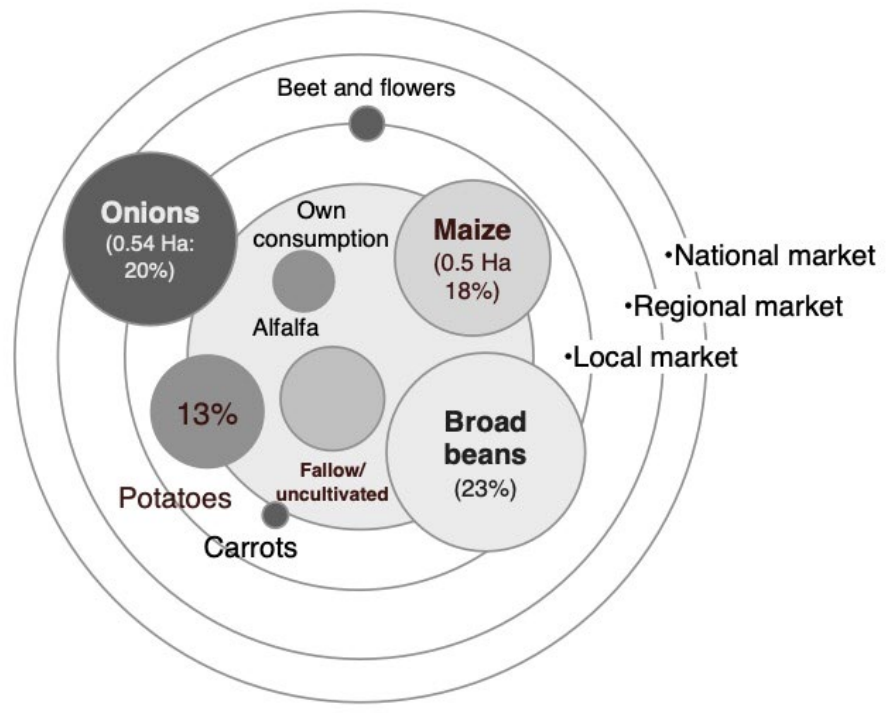

Figure 5-8. Cropping pattern and market orientation. Ubaldo family strategy

(Source: prepared by the author)

Currently and according to Mr. Ubaldo, they have gradually reduced their horticultural specialization. While still producing large areas of vegetables, they currently seem to be in a transition phase, firstly by diversifying with less labor-demanding crops (e.g. beans and maize), and gradually with the intention of also raising dairy cows on a small scale. This strategy seems to have been influenced primarily by the availability of family labor (two daughters living abroad and two sons helping them only on some weekends). According to the family, this strategy was also adopted due to high labor costs and less linkage to different markets than before (rising transport rates and fluctuating prices on these markets). Despite these difficulties, the family is still strongly linked to both the local and regional markets (Upper Valley and Cochabamba Valleys) and nationally (selling their products on markets in La Paz and Santa Cruz occasionally, though less frequently in the latter because of increasing production in Santa Cruz' Valleys). 


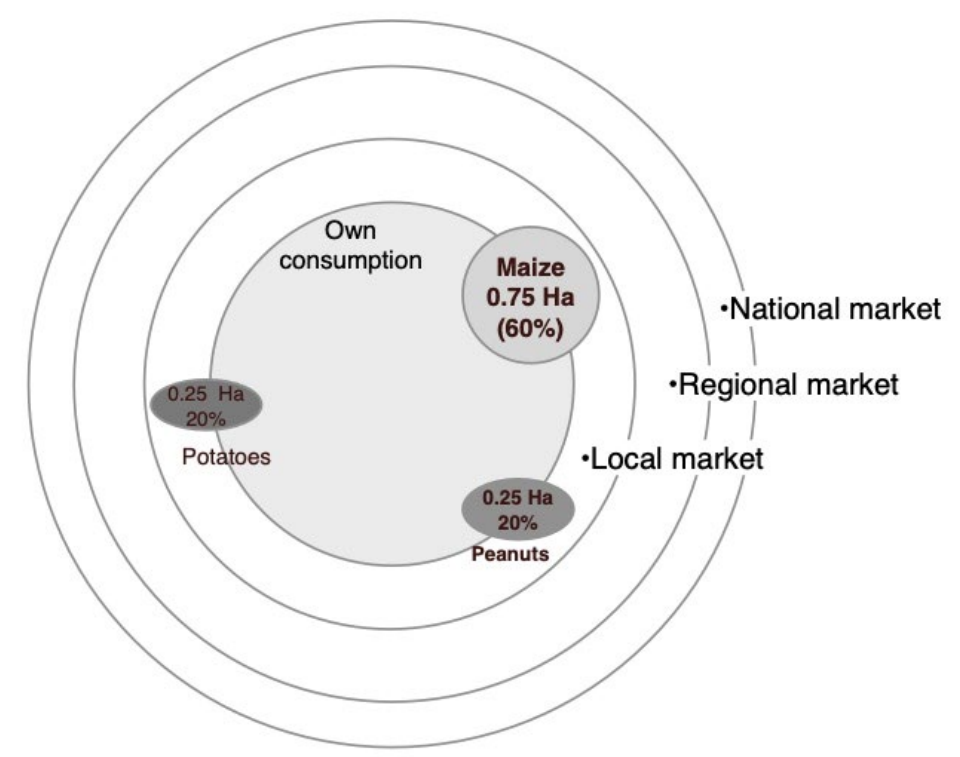

Figure 5-9. Cropping pattern and market orientation. Lima family strategy (Rumi Cancha)

(Source: prepared by the author)

Rumi Cancha cases (Lima and Roldán families) help to confirm that, as they develop experience and knowledge with irrigation, and greater water security, peasant families tend first to diversify their production and then may reduce their commitment to other off-farm activities. The Lima family changed relatively abruptly from an extensive system of rainfed agriculture and goat-raising towards a mixed system (under irrigation and rainfed), growing larger areas of maize and peanuts and experimenting with potatoes and onions in very small areas. However, the Roldán family, already had an atajado system. A second atajado significantly increased their water availability (quantity and security) enabling them to intensify and diversify their production even more, reducing extensive crops and significantly reducing migration to the Chapare. 


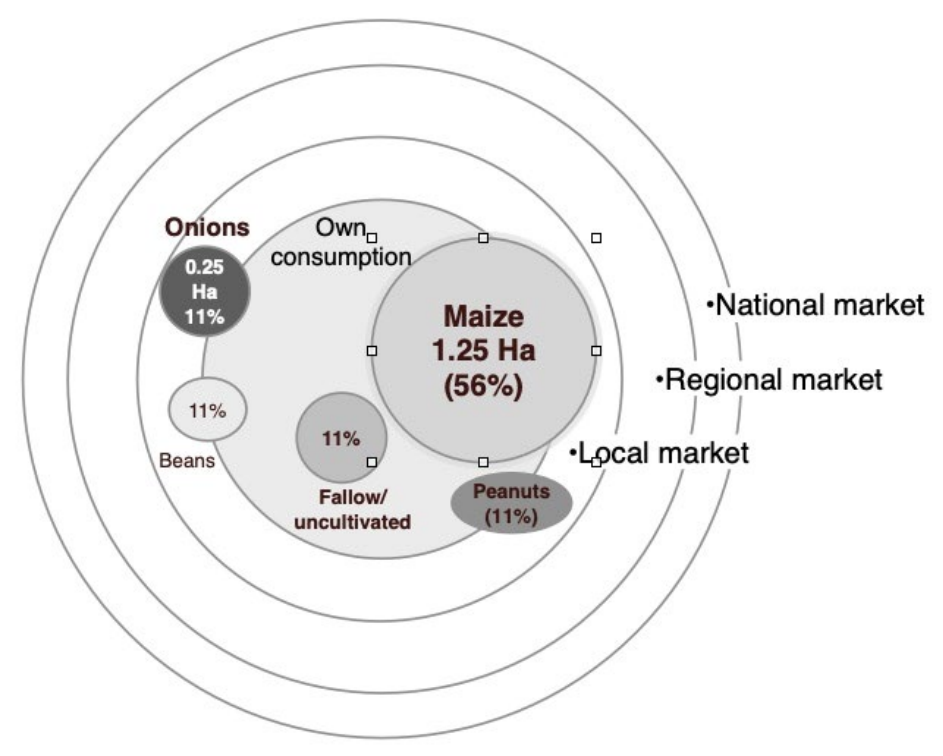

Figure 5-10. Cropping pattern and market orientation. Roldán family strategy (Rumi Cancha)

(Source: prepared by the author)

Migration to the tropical lands owned by these families, to grow coca and fruits, could be considered part of a strategy of "extensification". Nevertheless, it also means some degree of specialization, due to the particular characteristics of coca growing. From a broader familystrategy perspective, these activities are part of diversified livelihood strategies.

Diversification represents, then, a way to achieve higher use of internal resources, especially labor (including knowledge). That maximizes the use of family labor. This then implies that diversification cannot be seen as an opposite or an alternative strategy to intensification but, on the contrary, an important strategy to reach significant labor-intensity and greater use of other inputs and production factors.

In conclusion, diversification or specialization strategies depend on different factors. The case studies help identify the most relevant factors: availability of family labor, the family's life cycle, water availability, labor cost, and peasant families' access to information or level of experience regarding new crops. Water access and water control will play a decisive role. As in the case of Soto family in Punata, restrictions on access to water make the family engage in more extensive farming, combining rainfed and "semi-rainfed crops" (grown with complementary irrigation), a specialized strategy for dairy farming.

Combined factors, such as the family's life cycle and thus family labor availability also have their influence, as in the case of the Ubaldo family, who have decided to gradually change from a very intensive, diversified farming style towards a less-intensive, less-diversified one. This 
change is occurring despite their high, secure water availability and access. High labor costs and insecurity in getting workers when required by diversified, intensive vegetable production also appear to be influencing this transition.

Cases of Sacabamba (the Chiyara Khochi system) and Rumi Cancha reveal a key role for knowledge, skills and experience in irrigation and in certain crop types and also access to information and markets. These factors seem to be limiting diversification in these particular locations. In 10 years, the change has been gradual and, even today, they are still making adjustments in both system management and production systems, in an attempt to reconcile the requirements with both domains: collective water management and control, and family decisions about the production system.

\subsubsection{Interplay between commoditization and non-commoditization in production}

Peasant agriculture is not isolated from the market, either in relation to the flow of inputs to produce, or in the final products (agricultural, livestock or transformation products). Several authors emphasize the unfavorable conditions under which farmers are integrated with the market. This is mainly due to issues of scale, quality standards established in specific product markets, farmers' difficulties to access more productive technologies and because of trade barriers (intermediary traders) and unfair prices for peasant farm products (Ellis, 2000; Mayer, 2002; van der Ploeg, 2008).

This section discusses the degree of inter-relation between peasant families and the market, regarding their main crops. The different combinations of labor, inputs used in production, and traction (oxen or machinery) are analyzed as the main organized production factors/inputs. These three categories reveal the type of technology used and the balance between the use of factors acquired through market and non-market relations. In turn, this analysis is highly instructive to understand peasant strategies to reproduce their farm and production over time, identifying factors that favor or hinder such reproduction.

Analyzing the use of "domestic inputs" (produced by the family) and the use of family labor shows that cases in Rumi Cancha and Sacabamba use few inputs of their own, but employ a higher proportion of family labor (see Figure 5.11). 


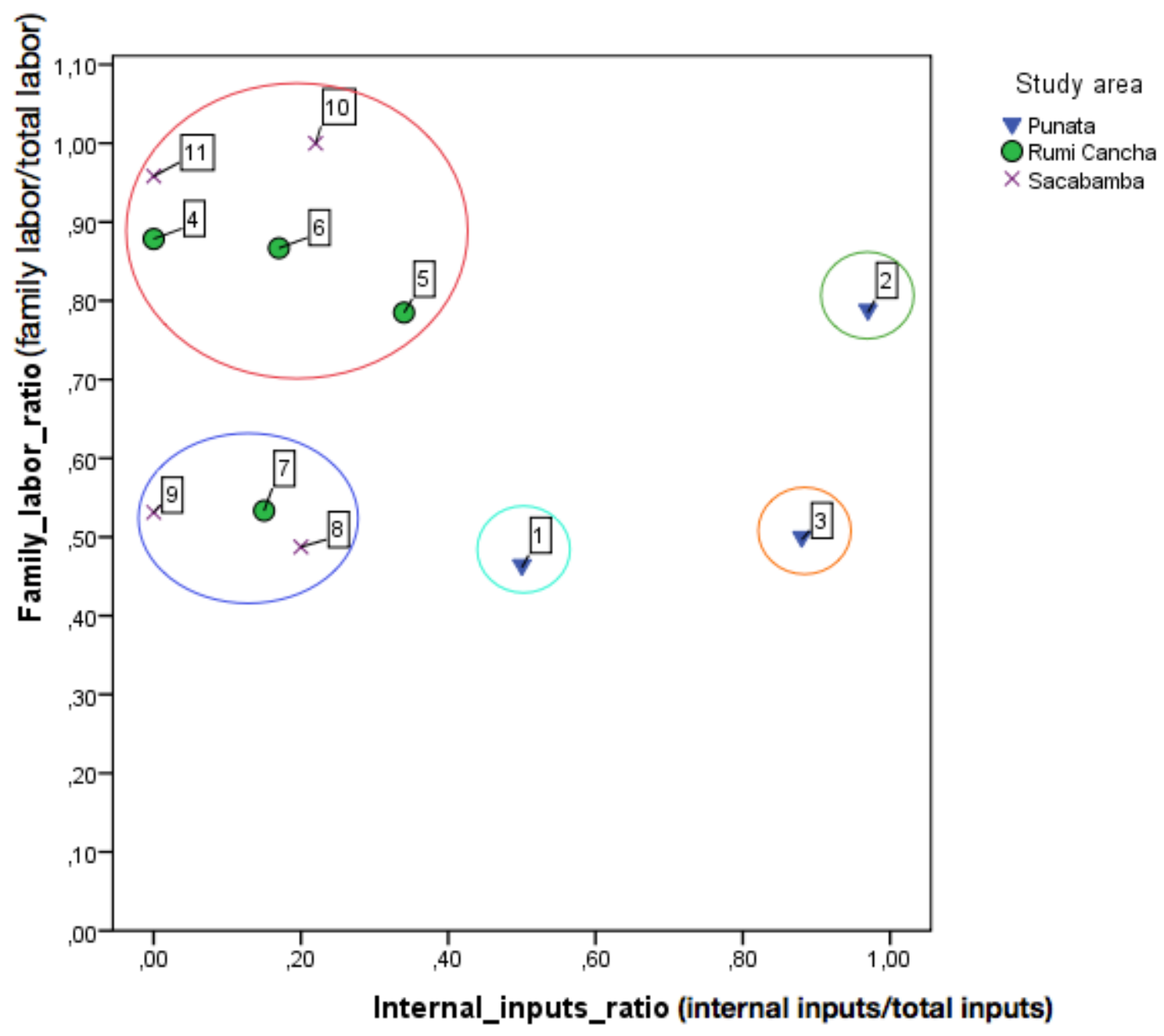

Figure 5-11. Use of family labor and imputs

(Source: Prepared by the author)

Reviewing the technical itinerary in detail shows that, in those cases, the low ratio internal input use results from the purchase of seeds or seedlings and fertilizers to grow potatoes and onions. These are just the areas with the least access to markets for inputs and products because of their remote location, far from the main centers of commerce, and besides they are communities with relatively recent experience in irrigated crops. By contrast, cases in Punata, with greater market participation and linked to one of the most important centers for agricultural trade in Cochabamba (Punata Fair) show less dependence on external inputs for both extensive production of maize or alfalfa (cases 2 and 3 respectively) or intensive production of vegetables (onions in case 1). They have less possibility to meet their manpower requirements with family labor (or are organized in that way).

Based on the above discussion, peasant families with greater experience in irrigated agriculture (for example, Punata's cases), despite close relationships with markets (for agricultural products and some inputs), tend to both use more family labor and depend less on key (external) 
inputs. This is an important feature of these cases, to attempt to depend less on markets and therefore reproduce their farming systems with more autonomy.

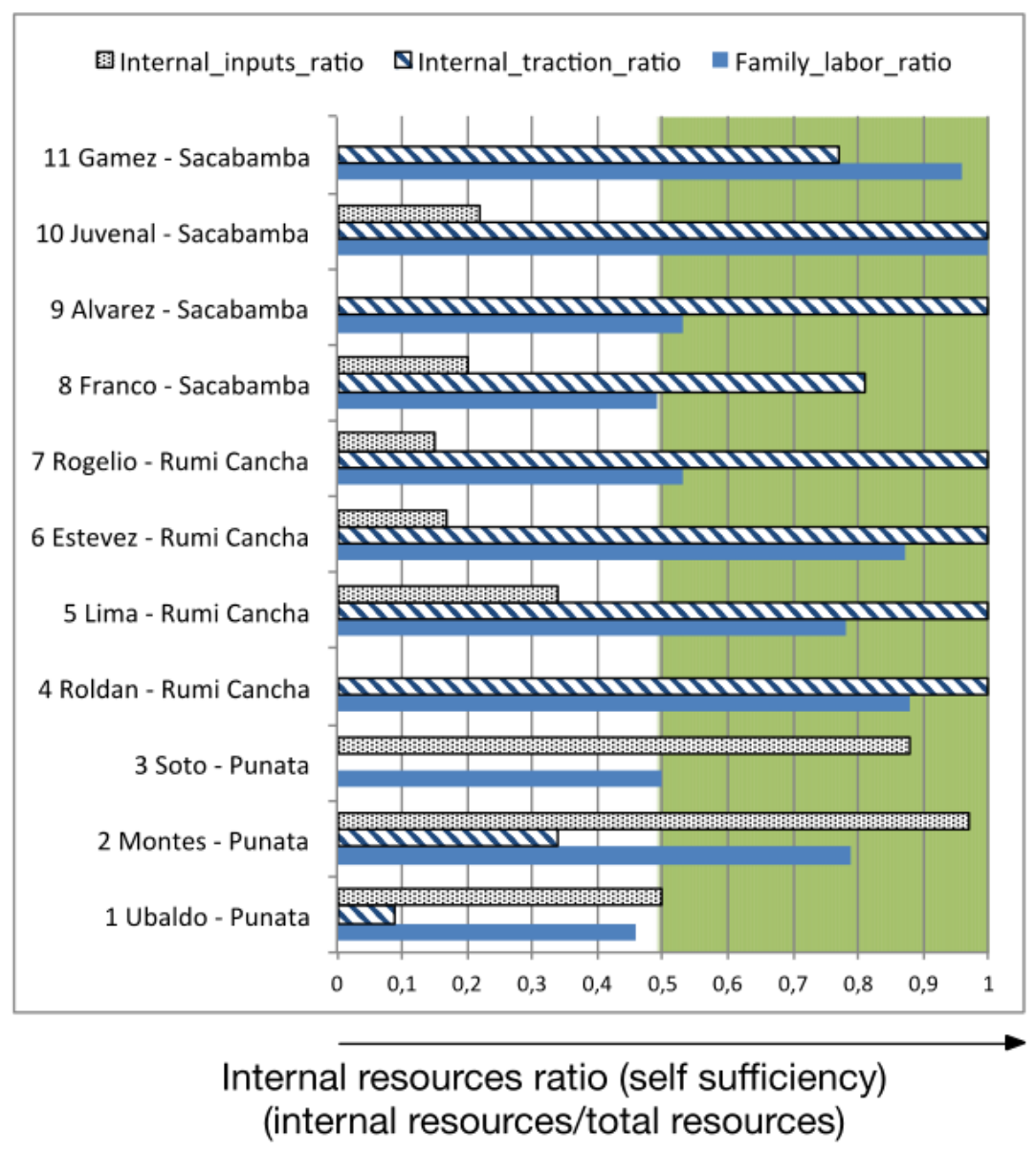

\section{Figure 5-12. Organization of production process for main crops. Use of families' own resources}

(Source: prepared by the author)

Analyzing the three main components of inputs or factors used in production, the following aspects can be highlighted (see Figure 5.12): In general, in all cases, family labor is important on their own fields, whether in crops mainly for market such as early plantings of potatoes (Sacabamba) or onions (Rumi Cancha) or crops for subsistence (maize and others). Family labor utilization, considering all cases, is between 50 and $100 \%$.

The figure shows that more domestic inputs are used in Punata. In these cases, the Soto and Montes families had a strategy to ensure production and use of their own maize seeds for each growing season. The Ubaldo family also began some years ago, producing their own onion seedlings, because of the high cost and low quality of seedlings. Mr. Ubaldo mentions that, by producing their own seedlings, they will have greater security and control for potential diseases 
and to control proper size and uniformity to use for their onion planting. In this case, the other $50 \%$ of inputs is chemical fertilizers purchased for this crop, something that they cannot avoid at this time. It is noteworthy that in Punata's cases, the draft technology used to grow the "main crop" primarily hires oxen or a tractor. This is the case of Soto family during land preparation and maize sowing, or to prepare the plot (land leveling and furrowing) and the Ubaldo family to plant onions. Mr. Montes highlights his vocation of "Yuntero" (oxen driver), recognized even outside his community. Currently, one of his main sources of income is to provide tilling services for others and also for their own plots.

The other cases, both Rumi Cancha and Sacabamba, show a high percentage using their own animal traction. What is not yet conclusive is whether this way of working the land is explained by soil characteristics (soil type and slope) and crop type (potato) or simply by preference and the intention to maximize the use of their own resources, as in the case of Sacabamba. In Rumi Cancha, this may be due to the transition to crops that are irrigated and the relatively low animal traction (oxen) requirements for more intensive vegetable production.

All cases reveal family strategies to control and reproduce, cycle after cycle, one or more of these production factors, in various combinations, for these crops (and others) for sustained reproduction over time. Water is one of these factors, as a direct production factor in peasant farming and as a "binding" (and mobilizing) factor for other resources, thanks to the different production relations it generates and as a source of social cohesion.

\subsection{Concluding remarks}

This chapter has presented and discussed different family strategies that link water control and production. This last section will conclude regarding the inter-relationships of these individual water management and farm-productive strategies, as essential elements in reproducing peasant farms. In general, agriculture in the Andean region and particularly in the areas studied depends on irrigation water supply. Rainfall irregularity, high seasonality, and low amount of water that falls every year would not allow reliable production or, in many cases, even allow peasant families to risk seasonal sowings as rainfed cultivation. In this context, they perform different activities or actions collectively to collect, convey and distribute water under certain rules. People perform other activities in the family domain, to handle water on their plots, prioritize use and application in different quantities for various crops, etc. In turn, water availability in the system and a family's possibilities to access water through different strategies or to exercise their water rights are the starting point for the family to decide what crops to grow, when, and in what quantities. Moreover, off-farm work is essential, as a way to diversify and assure the family's livelihood, and often as a means to invest in acquiring or creating new water rights, and to purchase of inputs or other production factors.

The previous section discussed how peasant families move between two domains that are often contradictory in their operating logic, but ultimately, as part of their livelihood strategies, are combined in different proportions at different times: the market domain and the community and social networks domain. These are governed by different mechanisms, the former by 
commoditized exchange relationships where money is the fundamental element of measurement. In the community and social networks domain, peasants' actions are based on family (kinship) relations, social identity, and belonging to a community, or on their mutual need for cooperation. This is complementary to exchanging different products, supplies or resources. This exchange is not measured by money but rather by the "use value" or other subjective values rooted in peasant culture. In both domains, it is also possible to identify power relations that influence various interactions. The way in which a peasant farm is reproduced year after year, cycle after cycle, means combining different production cycles according to crop diversity or specialization and other productivie and off-farm family activities (Figure 5.13).

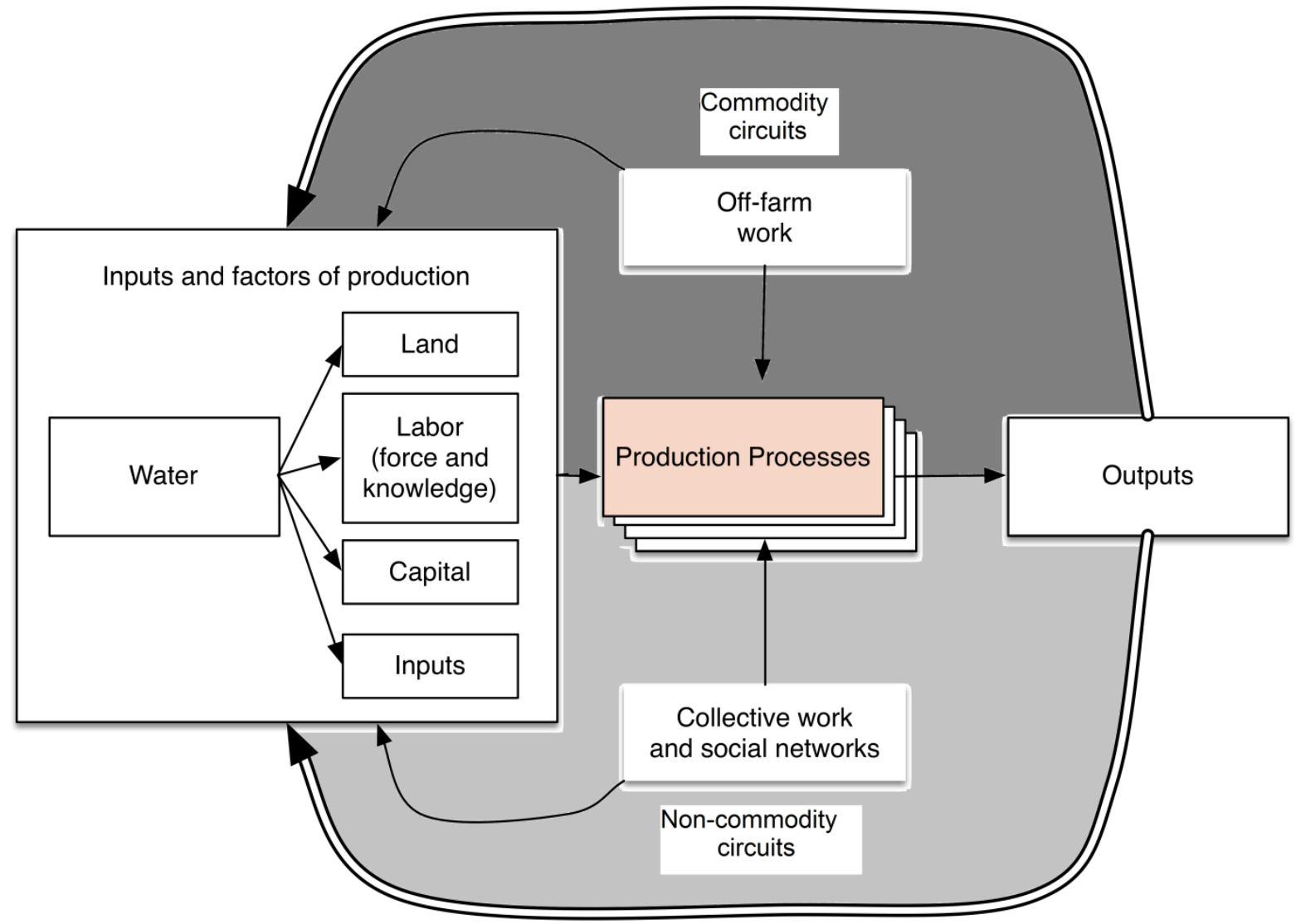

Figure 5-13. Commodity and non-commodity circuits in reproducing peasant farms

(Source: prepared by the author)

This research shows that peasant production is not isolated from but neatly entwined with markets, in highly diverse, sometimes strategic and at the same time subordinated ways. As illustrated in the different cases studied, the family domain features divergent degrees of market dependence, or rather different combinations of resource flows (agricultural production factors and inputs) through commoditized and non-commoditized circuits. This "degree of incorporation" (as proposed by van der Ploeg, 1990) differs for each factor or input. For 
example, in some cases, a certain crop is produced solely with family labor, while at the same all inputs (seeds, fertilizers) come from the market. In other cases, similar proportions of family labor and hired labor are used, while the seeds or seedlings (in the case of onions in Punata) are reproduced annually by the family, also using a combination of own animal traction and machinery hired for certain tasks. The same happens with the main products or subproducts derived from crops grown. In different proportions, the products are sold on the market, consumed by the family, or saved for a new production cycle.

This also shows the importance of other extra-agricultural tasks, in which the family organizes its work for different purposes. The figure includes off-farm work and collective work within the community or the irrigation organization. Both types of activities or labor have a dominant impact on peasant farm reproduction, whether for cash income from selling labor (in commoditized circuits) or communal work and using social and family networks to mobilize different types of resources. When families sell their labor, they can access (buy) production inputs, hire labor, rent or purchase equipment or transportation facilities, and cover other family needs. As in the case of Rumi Cancha's irrigation practices or the wells in Punata, these earnings have also been invested directly in creating new water rights. Mr. Roldán's testimony very clearly reflects these family strategies: "We grow food for my family's table and I work outside to bring money..."

Moreover, there is the collective work or other activities that family members perform within their family networks or broader social networks through non-monetary exchange relationships. These relationships of reciprocity, share cropping, or other mechanisms, also enable them to organize their production or access different key resources, such as land, water, labor, and others. Here, water is both an input, an important production factor, and a mobilizing factor for other resources, "bridging" between collective and individual peasant strategies. The result of this dynamic in organizing labor in peasant agriculture under irrigation is a high degree of heterogeneity, manifested as various production styles, with varying degrees of market incorporation and therefore varying contribution to food production and other services in different locations. 


\section{Chapter 6 . Conclusions: Local agrarian development patterns as a result of water and agroproductive control}

\subsection{Introduction}

The Andean region's diversity, beyond its physical characteristics or biodiversity, also extends to its people and culture. Andean diversity is also expressed through different ways of organizing, cultural expressions, and how people survive day-to-day. This intrinsic diversity and expression of social relations makes heterogeneity a characteristic of the region. This heterogeneity also enables different production styles, in which water is an essential element.

The dynamics within peasant life, its collective scopes, its individual expressions and the families comprising this collectivity have been the focus of this study. Thereby, the research shows how water is a history- and context-defined key component in peasants' life that requires collective action to manage it. Here, peasant families' actions and strategies are a response that has been shaped by their biophysical context and the complex socio-political environment. These different contexts or environments have changed over time and are mostly uncertain. Context shapes strategy development, all with the same main goal: controlling the water for agro-livelihood production. The main question to answer in this study has been: How do collective action and individual strategies entwine in peasant irrigation to foster diverse patterns of irrigation management and production organization in response to the quest for autonomous water control?

The cases studied, as a sample of the aforementioned heterogeneity, have made it possible to understand, from their different scales in size and complexity, how context- and historyparticular interaction between biophysical and sociocultural conditions shape collective and individual dynamics, and how they result in different responses in terms of water management and use practices.

The case of Punata, shows that the basis of the development of irrigated agriculture in the area has been grounded in collective action, the progressive development of organizational capacities, political alliances, mobilization of work force and generation of knowledge and own experiences around water control. This in turn has meant the creation of a diverse productive base, in response to the possibilities of accessing and controlling water, inputs and key factors in the production process.

Communities in Punata face new challenges. Despite having developed a great experience in irrigation, the socio-political context around the control of water in the basin, partly exacerbated by the recently installed irrigation law, poses new restrictions and risks to the irrigators. The uses and customs and the agreements to access water are now, in many cases, subject to new conditions imposed by the highland communities who have control over the water sources that are located in their territories. This is: territorial claims based on a growing notion of "ownership" over the water sources, generate new situations of uncertainty about access to water for Punata irrigators, as in other valleys in Bolivia. 
The case of Chiyara Khochi in Sacabamba, has served to illustrate the process of generating experience in water management, showing the organizational and operational adjustments that need to be implemented together with the (new) agricultural practices that are developed at the same time. That is, the co-evolution of collective and individual practices in the attempt to control water and the production process. This case also shows that productive changes can take a long time, because in addition to developing experience (practices) in water management, peasant families are testing new technologies and are inserted into new networks that allow or condition them to control and reproduce their productive system and therefore their sustenance. This also raises the need to progressively develop knowledge and new interactions with the market

Finally, the case of Rumi Cancha, with the "atajado" systems, shows the importance of water managment at the individual level. Despite having individual control over water, this control is subject to rules and agreements that the community makes to enable the capture of water from communal or inter-family lands. This case allows us to see the key role of irrigation in boosting the family productive system and thus to modify priorities or the composition of their livelihoods.

In this closing section, I summarize the findings that have been described and analyzed in the previous chapters. This chapter's goal is to answer the main question and the sub questions that have been investigated and discussed in each chapter.

This chapter organizes the discussion in concordance to the empirical chapters (chapters 3 to 5). I start by exploring the irrigation sector's institutional setup and development in Bolivia and its local manifestations. This is discussed starting from the notion of 'uses and customs' as the expressions of the local institutional arrangements. Then I explore the role that collective action plays in water control and its relationships with family-level organization.

Finally, family strategies, their relationships with water control and production to overcome restrictions, and their degree of dependence on markets, institutions and the state are analyzed. I conclude with institutional development, irrigation policies and agrarian transformation in Bolivia.

\subsection{Uses and customs. Local institutional arrangements and practices and the quest for autonomy}

This section focuses on the relationship between "usos y costumbres" and peasant irrigation practices and their different implications for irrigation and agricultural policies, to answer the question: How have irrigation institutions developed from local practices, how do they conflict with official views and policies concerning irrigated agriculture; and how these mismatches in turn influence water control? 
Diffrent from its neighboring countries, in Bolivia, the role, intervention and influence of the State in local water governance always has been extremely limited. Whenever the State did try to intervene and govern water affairs of the peasant and indigenous communities and territories, interventions have been directly related to programs and projects to invest in local irrigation infrastructure. But also here, the government's vision has mostly been distant from local farmer institutions' needs and practices. During recent years, the government's efforts to regulate water access and particularly irrigation were aiming to consolidate peasant organizational capacity. Partly, this capacity has enabled them to access new decision-making opportunities and to obtain power at different state levels (Perreault, 2008). Hand-in-hand with peasant mobilizations, all these factors played a role in the recognition of peasants' norms, rights, authorities and ways of life, in different spheres of society. It has also contributed to the rise of new leaders who can access power within their own organization as well as in the state apparatus.

In fact, rather than the State-supported facilitation of inclusion and participatory water governance, in recent years, institutional development of the water sector in Bolivia has been influenced by the strong organizational capacity, alliance-building and social mobilization of the irrigators themselves; as a basis for local water control autonomy (self-management of their systems) and to claim strengthening of their role in formal water policies and governance. During the Morales government, this peasant dynamic has been intermingled, via political alliances, with the government's strategies to regulate the sector. Among the mechanisms from the government to achieve this control have been: the recognition or formalization of the "uses and customs" in the official normative framework; and the incorporation (co-optation) of local leaders in government structures - which partly has created a contradiction in the achievement of autonomy for irrigators as explained below:

-An important consequence is that the mechanisms of representation have been weakened, not being accompanied by accountability mechanisms that relate these leaders to their bases.

- The political alliances of (water) peasant organizations with the (technicist and infrastructurebiased) government have resulted in a vicious circle, in which projects of poor quality or decontextualized design and intervention promote new cycles of demands towards the government -- demands that presumably can be addressed only with new intervention projects.

- While formally claiming to support local indigenous and peasants' norms and principles, the State's ignorance of the very functioning of such local norms, rights and arrangements has generated deep contradictions. A fundamental local principle, which is the users' creation of water rights and "hydraulic property" based on collective work investment for the construction of infrastructure, is a case in point. This peasant notion is the foundation for the construction of many of the uses and customs and local institutional arrangements that govern water management; the cornerstone for the self-management of the systems. In recent years, with the Morales government, irrigation investment policies have largely neglected this core water governance and rights principle, supplanting complex historical water-rights-building processes, rooted in the culture of each locality, by paternalistic interventions with a prominent 
role for expert knowledge and government investment. These have altered local principles based on collective work, weakening the management capabilities of irrigation organizations. This in turn has created confusion among users and non-water users with respect to the mechanisms for acquiring and consolidating water rights - at individual (family) and collective (community) levels.

Therefore, the new rise of peasants' institutional power, especially after local water leaders' inclusion in the state institutions and the formalization of local usos and costumbres, is ambiguous. In part, it has meant the distantiation of leaders from local reality and practices, clearly changing the dynamics of social interactions. Now for peasants, dealing with locally managed irrigation systems is not their only concern; they must deal with new structures such as bureaucracy, corruption, and formal laws. Thereby, the fact that usos y costumbres were officially recognized does not assure local water control autonomy; rather, it creates dependence on official laws and government.

Without doubt, paradoxically, the growing visibility of usos y costumbres has played a crucial role because of their symbolic value. This value represents a social affirmation of culture; with the possibility for autonomously managing natural resources, especially water, beyond formality. This research has highlighted and clarified this dynamic, intriguing paradox; it is crucial for comprehending Bolivian water governance, the more since most of these cultural resources have been forgotten by technical and legal experts, or were denied by the "people's government".

The cases studied in the paper have manifested how usos y costumbres operate at different levels, dimensions and within different time frames of peasant water management. Expressions of usos y costumbres have been explored within daily practices, actual social relationships, highlighting and scrutinizing peasant communities' relations with water and the environment. These relationships dynamically transform and adapt through different interactions with the market and governmental recognition, often resulting however in disputes over water territories, and conflicts of interest based on water and natural resource ownership. As many Bolivian cases show, once informal rights and norms get formal recognition and thereby, "invisible" norms and agreements become "visible", this triggers profound conflicts not just between the State and the water user collectives but also, and especially, among water user groups themselves.

The examples presented in chapter 3 about the recognition of the uses and customs or the construction (formalization) of laws and norms from the practice and the needs of organizations also show that, regardless of where the initiative to create (formalized) norms originates, the results are similar. These "recognition policies and politics", therefore, tend to create the opposite of the original goal, which was to support achieving local autonomy. Rather, they create conflicts that make it harder for local communities to control their own resources. In the cases of the national law on aggregates and the municipal ordinance that tried to regulate the use of groundwater in Punata, both initiatives started from the demands and problems that the communities faced daily. Under the assumption or image attributed to the state and its 
institutions as protective entities, especially in conflictive situations around resources of common use, local organizations promoted the enactment of these norms without considering the State's and their own limitations for enforcement.

For the State, this recognition of uses and customs and all the irrigation institutional setup, has not meant reaching a minimum level of regulation of access or water (re) allocation between or within water sectors. On the contrary, as the case of Punata shows, this recognition (in particular, legally providing 'eternal water rights' to those who already control the water) has imposed new barriers to the State itself in irrigation intervention processes (infrastructure projects) and very limited possibilities for the National or the Departmental Irrigation Services to help in conflicts resolution.

This new scenario, where peasant communities face territorial problems that go beyond their traditional working arenas, involves growing water disputes. As the research has made clear, increasingly, there are conflicts between those who have water flowing through their territories (claiming territorial ownership over water) versus those who actually use it (historic rights; hydraulic property rights; inheritance and purchase of water rights, etc.), adding also groups who had no water access at all but now claim for more equality and fairness. These issues force new organizations and social movements to form, to defend their territories or gain access to water. Water is the key factor creating movements and organizations.

\subsection{Seeking water control from collective action in water management}

Collective action within peasant communities in the Andes has different expressions, purposes and starting points; they change and adapt to new sociopolitical, economic and cultural environments. In this research, I have shown the collective strategies that peasant communities deploy to shape and secure their livelihoods. In Chapter 4, the main question to explore was: How do the various forms of collective action in peasant irrigation systems become manifest and how do they inter-relate with the different dimensions of water control?

The historical processes in which peasant communities have formed in the Cochabamaba Valleys show the importance of social cohesion cores or nuclei which enable collective action. A clear evidence of these "social cohesion cores" has been peasant families' control over their own work and their own land. These two factors drove a major social and political movement, which was used as the foundation for peasants to form agrarian unions and later to be recognized as peasant communities. After long struggles and historical change, water has proven to be the strongest social cohesion core; it continues building relationships and new forms of interactions in rural and peri-urban areas.

Water is a social cohesion core, a vital element enabling peasant communities' collective action and survival. It is also a central element in many economic, industrial activities and in ecosystem preservation. However, water is also a disputed element, which generates a lot of wealth and empowerment for some, while creating need and segregation for groups that have 
limited access to it. All these differences lead to long, ongoing negotiation and conflicts, with new collective action emerging to manage water as well as these same conflicts.

The case findings manifest how water access and control is one of the main factors building collective action. In peasant communities' irrigation systems, community-level water control is strictly related to family-level water control. All these relations are clearly based on and directed at adapting peasants' irrigation practices on their farms. Thereby, changes in irrigation practices can be seen in the crops produced, in organizational changes (such as the case of Sacabamba), in water distribution, in distribution rules, or in any other operational work.

Collective water management is then the umbrella under which peasant families develop multiple strategies to ensure the reproduction of their livelihoods. Since it is this collective management that generates conditions of water availability for each family, mediated by agreements and rules established in the user group, and by the infrastructure socio-technically constructed. As a counterpart, it are the peasant families who sustain social organization, collective work and the sense of collectivity based on relationships of interdependence, social identity and other sociocultural or family ties.

The interaction between these individual and collective areas, plus the multidimensionality of water management, shows that neither management nor irrigated agriculture in peasant systems can be fully pre-designed or detailed. Because of these changes, what is actually important is to identify the factors that jeopardize water control and family and organizational work. Therefore, the cases explored show the relevance of viewing irrigation technology as in constant change and adaptation. In this adaptation, one can see a close, reciprocal relationship between technologies used at plot levels and those in collective water practices; to cover plotlevel requirements, collective management and family-level water management practices will change continuously as mutually entwined.

The cases studied show the progressive development and incidence of collective work, initially as a basis for the construction of infrastructure linked to state interventions and then as a basis for the (self) management of irrigation systems and their sustainability. In the systems or organizations that have already developed these experiences (for example Punata and recently Sacabamba), important steps have been taken towards broader areas of influence, for example in the management of their own intervention and coping projects (irrigation and development interventions); in definitions of public investments or in political negotiations of how the state instances are to be related to their irrigation institutions.

Closely linked to the development and incidence of this collective action, is the organizational capacity of peasant families. The study of the different collective strategies that are developed in each locality, including the continuous adaptations that are implemented in the organizations, has allowed to identify certain "principles" of water organizational dynamics. These principles importantly relate to, for instance:

First, how the daily needs of families regarding water access and control, translate into the forceful need to cooperate between families and create firm bonds of collaboration. 
Second, how the flexibility in the structures and organizational mechanisms of water control collectives, are based on the progressive ability to identify internal needs and translate them into new tasks and innovative ways of organizing water(-related) livelihoods; organizational adaptations make that organizations are increasingly functional to the familes' needs. The cases studied show that internal, practical and everyday-needs and their visibility within organizations are more relevant than the degree of formalization or the apparent rigidity (robustness) with which these organizations (re)present themselves. This flexibility, and the possibilities of adapting organizations, appears to be related also to the legitimacy and authority that these organizations assume in front of their members and towards external entities.

Third, an important element, evident in amongst others the cases of Punata, is the constant scrutiny from actors within the organization, regarding differentiation and (un)balance in power relations. Members claim, and actively build, "checks and balances" to control, as much as possible, the workings of power within their collectives.

Fourth, water user colectives and families constantly balance the technical water control dimensions with the organizational, normative and the political control dimensions, to enlarge opportunities for self-management. That relates to their ways of designing each detail of the water access, distribution and governance system. For instance, in Punata communities have figured out how, to reduce water losses (after dam water releases that flow through the river to reach their communities and fields), they must send well-defined, carefully negotiated, large flows from the dam intake structures. In the irrigation area, they could subdivide and use more manageable flows but this would extend the run time of the water, increasing the opportunities for stealing, leakages and percolation, and requiring even more people to watch the canals and to irrigate. Reduced flows in the river and on the fields imply more need for control along the river, surveillance in the irrigation zone, and irrigation labour-time. By technically sub-dividing the delivery flow, the operating and distributive levels in the system will also increase; this has direct organizational implications for the irrigation system and for organizing family labor. In each component of their system's organization, the collective and the individual require a careful fine-tuning; just as there is a precise need to fine-tune the infrastructure, the organizational set-up, and the water norms and rights.

These organizing principles have demonstrated, in the cases studied, the wide possibilities of continuously adapting organizations to internal and external socio-political contexts; strategic inputs in the search for autonomy that peasant families pursue through their organizations, in order to "free themselves" from dependence on the state, the market, or other institutional actors. Collective strategies in the different case studies are broad, such as organizational adaptations, creating supra organizations, social mobilization strategies inside and outside irrigation systems, and territorial defence strategies during water conflicts. These strategies in Bolivia are the foundation for gradual but sustained social empowerment within peasant communities. By no means does this mean that these interactions are harmonious; they commonly are difficult and based on hard-fought battles and, in some cases, have fragmented peasant movements.

These strategies are also part of broader processes of scaling up organizational capacities and the participation of peasant organizations in decision-making and water policy spheres, within 
their own organizations as well as in the structures of local governments and even at the national level. As the research has shown, the socio-technical development of water user systems and collectives, in many cases, has exceeded the organizational limits posed by single communities or peasant unions - and also the hydrosocial territorial boundaries in which these systems were developed -, making that hydrosocial territories and networks constantly reorganize, reshape and reinvent.

\subsection{Water and agroproductive control on peasant farms}

In the Andes, water for peasant agriculture cannot be seen simply as any other production factor. Chapters 3 and 4 have shown the complexity of water management practices, its cultural, political and socio-economic embeddedness - besides technological and agro-physical challenges-, and the key role that collective work and shared action play. At the same time, in the family domain, important questions, such as what, how, how much and when to produce, must be answered. Indeed, all the answers to these questions depend on the individual family's access to and control over resources, a fundamental one being water. But even if those answers and decisions depend directly on water accessibility, they are also crucialy related to the collective scope. This section, related to Chapter 5, answers the question: How do different peasant farming strategies of families relate to water control and control over production?

The cases and findings show how the most important factor in agricultural production and livelihoods reproduction is family labor - the only factor that the family can actually control relatively well because they do the work. Agricultural practices and production are based on family labor and also assure water access, which, in its turn, connects to collective action within the community, as families necessarily must work together to guide water and realize all watersystem related operational actions. Therefore, family labor is the cornerstone in water control and agricultural production.

The cases have shown how water control at the family domain is highly related to organizing family work in agricultural and water governance based cycles, determined by factors such as water access, participation in collective work as part of creating and maintaining water rights, and by establishing reciprocity relations between families to access water. Family work is organized with different rhythms or intensity; and depends on the availability of inputs and other production factors that influence agronomic, migration and hydrological cycles, as well as on the changing of lifestyles in the countryside.

Sufficient and timely water access on plot level can only partly be secured by the individual families, even though they demand the water distribution and management system to operate in accordance with their particular needs. Therefore, smallholder farmers continuously balance between flexibilization of the water use system (to make it respond to their household production system's water needs) and, conversely, flexibilizing their family's production system (to make it respond to the technical and organizational possibilities and impossibilities given by the structures and contigencies of the water use system and the climate, ecology and 
market context. Smallholder farmers operating in collective water use systems show to be experts in this iterative fine-tuning and two-sided flexibilization endeavor.

One illustration is their staggered planting techniques, which is an important productive strategy for organizing work and scheduling production on peasant farms. While literature only or primarily explains this strategy as a response to marketing opportunities, the cases show that, in addition, staggered planting is deployed to balance and create complementarity between rainfal and irrigation. Next, it is strategized to somehow control weather factors such as frost and drought periods. Bolivian smallholders, forced by condition and history, are water security experts. In extremely harsh biophysical and climatological conditions, their aim is to have some control over uncertain water availability. Therefore, they sow or plant a crop on various plots, some weeks or months apart, and also are keen to develop multiple-cropping systems.

Such strategic practices are not isolated elements (as on mono-culture capitalist farms) but are embedded in integrated multi-crop, multi-altitude, multi-water source, multi-scale and multiactor production systems. Relationships of reciprocity, share cropping, and other exchange mechanisms, enable them to diversify their production and organize access to different key resources, such as land, water, seeds, labor, and financial means. Here, water is both an important production factor and a mobilizing and connecting factor for other resources. Water bridges between individual and collective peasant strategies. Here, connecting the family and colective domains is a finetuned calibration practice. For instance, many families have their plots scattered among different locations all with different water availability and growing conditions. The art of irrigation entwines different strategies, combining a number of water sources (that may range from river water, reservoris, waste water to groundwater) at different times and in different places.

Therefore, individual water rights, norms and control are deeply connected with collective work, responding to cultural norms that vary from place to place. Case-specific are also the contacts with different markets, institutions and the state; this contact with different agents changes dynamically and takes place in different moments and conditions. Creating or acquiring new water rights by "buying shares" in multiple systems such as dams and wells in Punata is one example of the different variations. Another example is community work to manage and keep water rights; sometimes families do not have enough workforce and they need to hire other workers. This happens more often during periods of state intervention to build or improve irrigation systems.

Family-domain water control is also deeply related to their site-particular water management knowledge, artifacts and on-farm irrigation practices. Aside from these components, the cases bear witness to how access to information, market contacts and adaptability of artifacts in socioeconomic conditions and irrigation system development are fundamental for livelihoods' technological innovations.

In "controlling agro-production" we can conclude that access to capital assets, workforce, inputs, water and land are not connected only through market relationships, nor exclusively by 
reciprocity relations. Even if the market plays a key role in access to these different factors and inputs, to avoid market dependence, peasants develop alternative production strategies that adapt to the diversity of water access and agro-production relations, combining market and non-market relations. The cases have shown how these relations find expression in crops and products that go to markets and equally, according to season-particular and family-specific strategies, also are grown for family self-supply. The studies performed in this research show all different types of combinations.

Balancing market and non-market relations is part of the "room for maneuver" or "degrees of freedom" in which peasants organize production systems and other activities that are crucial to their livelihoods. This "room for maneuver" reflects their quest for autonomy, control over resources and production, in which families act with different dynamics to achieve their goals. Interactions between market and non-market spheres, and activities that enable peasant families' livelihoods, again, are a result of the ways they manage to work under difficult highland conditions. If families would only depended on the market, unfavorable conditions easily arise beyond their control over their production. In summary, strategic balancing acts and interactions between market and non-market spheres enable these families' production and farm development. This development is closely entwined with other livelihood strategies that include labour migration within Bolivia and internationally. Permanent or seasonal labour migration (by one or a few members of an extended family) has become common in the area. The remittances from migration have come to play an important role in the sustenance and reorganization of peasant families and their related livelihoods in the area. Remittances enable new investments in peasant production systems while also forming a buffer for periods of low incomes from agriculture.

Peasant families' life cycle plays an important role in defining their livelihoods, especially in organizing their work, and their intensification and diversification strategies over different time spans. This also affects the way families relate to the market. Examples such as the Ubaldo and Montes families in Punata show that older and larger families tend to diversify more while decreasing family labor-intensity and moving to less demanding physical activities. These activities also tend to generate less income, but provide more stable economic income, such as selling milk. The less demanding physical labor in Punata and, to a lesser degree, in Sacabamba, is also related to increasing demand for dairy products in nearby cities. Meanwhile, young families tend to work with and strategize multiple different activities, crops and plots. For example, horticulturists are directly and indirectly related to the growing demand for food on local and regional markets such as in Cochabamba, La Paz and Santa Cruz.

The result of this dynamic in organizing water and labor in peasant agriculture is a high degree of heterogeneity, manifested as various production styles, with varying degrees of market incorporation and therefore varying contribution to food production 


\subsection{Conceptual contributions and considerations}

This study has focused on the peasant dynamics analyzed from the collective and individual domains and their interrelation with the biophysical, State- and NGO-institutional, and marketspheres. This approach has made it possible to identify the ways of interaction that are generated among these spaces and spheres of social action, and above all to understand the different responses or expressions of heterogeneity in the management of water and agroproductive resources.

The conceptual emphasis on collective water management in the thesis research, points at the core of Bolivian smallholder water control (Beccar et al., 2001; Boelens and Vos, 2014; Bustamante, 2010; Gerbrandy and Hoogendam, 1998). The conceptual framework has organized the multi-dimensional activities and tasks in which water organizations play different roles, which for analytical purposes were classified into technical, organizational and regulatory. In the analysis these dimensions were considered as intimately interrelated and therefore were treated simultaneously. The 'context' of these multi-dimensional water governance activities - provided by civil society institutions, the state, the market, culture and the agro-ecological and physical-technological environment - has been studied not as a given but as being continuously modified and readapted according to contextual changes and power relations (see also Gutiérrez, 2005; Hidalgo et al., 2017; Saldías et al., 2012). All cases investigated have made manifest how peasant irrigation systems in Bolivia are managed 'independently' by users' organizations (see also Rocha et al., 2015; Seemann, 2014, 2016). The basis for the creation and re-creation of these users'organizations that maintain peasant production is the mobilization and careful allocation of labour investments. At the collective level, this mobilization of labour is translated principally into an empowerment of peasant organizations and their ability to develop political leverage at broader scales (Hoogesteger and Verzij1, 2015; Perreault, 2008). Clear examples of these strategies are: the access to financing and support from the state and NGOs/funders for their projects (irrigation and others) via political alliances; the scaling up of their political leverage in broader socio-political domains; occupation of power spaces and legal and institutional shopping when defending their collective rights over water sources. At the same time it has offered these communities greater capacities to interact with their "peers" (other user organizations or peasant organizations) around disputes over water or other resources in a certain territory (Boelens et al., 2016; Seeman, 2016). In the process of organizational (re)creation, they develop and deploy their own rules and regulations; but these rules, rights and regulations change according to environmental changes, state interventions through infrastructural projects, changing relationships and agreements between irrigation systems that share the same source, new agreements within the system by modifying the water rights framework, or new water demands from internal or external parties. The thesis has examined how this, in turn, provokes changes in infrastructure operation, maintenance requirements, water flows, distribution rules, etcetara: a continuous calibration and adaptation of the irrigation system's technical, organizational and normative components or dimensions (cf. Boelens and Vos, 2014; Gerbrandy and Hoogendam, 1998; Gutiérrez, 2005; Hoogesteger, 2013b). In this way collective action through specific ties of dynamic cultural and place based identity provides the actual social, institutional and 
material possibilities to control, manipulate and distribute water flows over time; something that would be impossible at family or individual level (Boelens and Vos, 2014).

To understand this spatial-geographical, socio-economic, organizational-political and cultrural-symbolic configuration of water-based livelihoods, water use systems, and watershed organizations, the concept of hydrosocial territories (Boelens, 2016) has proven to be of strong conceptual importance. The cases show how family and community social networks are intermingled with water infrastructural networks, human-adapted hydrological cycles, and simultaneously, with economic structures, political strategies, cultural patterns and discursive frames, at different, interconnected scales - all being disputed and subject to continuous negotiation and power plays: they reveal the struggle over imagining and shaping hydro-social territories (Duarte-Abadía and Boelens, 2016; Hidalgo et al., 2018; Hommes and Boelens, 2017, 2018; Hommes et al., 2016, 2018; Linton and Budds, 2014; Seemann, 2016). Because of these dynamics, different from those portrayals that picture Bolivian peasant systems and indigenous smallholder water cultures as 'traditional', 'archaic' or 'centuries-old and static', the findings confirm how constituting elements, linkages and boundaries of these complex hydro-social territories are not fixed; not in physical-geographical terms, much less in politicaladministrative or socio-cultural terms. In time and socio-space, territorial contents, meanings, relationships and boundaries are re-defined continuously (cf. Harris, 2015; Hoogesteger and Verzij1, 2015; Mena-Vásconez et al., 2017).

The families and water user collectives in the case studies, when building, defending and redefining their irrigation systems, are permanently on the move, to establish and transcend new geographical, political-administrative and hydrological boundaries (Barnes and Alatout, 2012; Seemann, 2014; Swyngedouw, 2009). The hydro-territorial constructions, therefore, in many instances contest techno-political engineers' systems and, at the same time, are deeply transdiciplinary and endogenous - though not necessarilly 'equitable': they are products of inhouse and external struggles, negotiations and conflicts (Perreault, 2008, 2014; Zwarteveen and Boelens, 2014; Hoogesteger, 2013b, 2013c; Roa-García, 2014). This conceptual focus on hydro-social territoriality also has allowed to examine how, in Bolivian water control, territorial arguments are increasingly important in defining usos y costumbres, as a foundation for defining water access and water rights, and in general, to establish control over water (Hoogendam and Boelens, 2019; Saldias et al, 2012, 2013; Seemann, 2016). This, in turn, has enabled seeing and conceptualizing how different territorial notions and material configurations intertwine and "overlap", assuring that some have infrastructure and water access and others are excluded (see also Boelens, 2016; Hoogesteger et al., 2016).

The focus on water rights and water organizational forms from a legal pluralism perspective (Benda-Beckmann et al. 1998; Boelens, 2015; Bustamante, 2010) has allowed the study to see and examine how Bolivian water users not only create water rights, organizing principles and water governance forms, but also, the dynamic and sometimes subtle ways in which they recreate them, transform them to suit new eras and threats, or to generate new oportunities (cf Mayer 2002; Zoomers, 2013; Sanchis-Ibor, 2017). In this way, fundamental mistakes in litetrature, about traditional "usos y costumbres" as if fixed by history and culture, have been 
dismanteld by the case evidences (see also Roth et al., 2005, 2015). Hereby, the analytical perspective of ongoing development of uses and customs also shows the importance of legal shopping (Benda-Beckmann, 1981) and institutional bricolage (Cleaver and de Koning, 2015), both core elements in everyday Bolivian irrigation governance. In other words, water norms, rules, practices and organizations are continuously recomposing. Even the engineers- and government-directed water works, organizations and normative repertoires were continuously "localized" in the case studies (cf. Long and van der Ploeg, 1989; Stuiver et al., 2004); they regain meaning in local contexts, because the different localities give their own meaning to the official institutional framework and engineers'designs (Boelens, 2015).

Together, this makes that the thesis findings debunk the 'participatory water management' literature so common in Bolivia and around the world, and also challenge many of the 'empowerment approaches' very popular in Latin America. The cases manifest how, often despite of external 'participatory interventions, the local water user populations are often not only the drivers of water governance; they were already a 'participant' in struggles for irrigation water long before external intervention projects have come to the area to 'develop' irrigation systems (see also Gandarillas et al., 1993; Cleaver, 1999; Parfitt, 2004). In the eyes of many local water leaders, the claim by irrigation project engineers, government officials, or international development institutes, that their intervention projects actively aim to incorporate 'the locals' in participatory projects, seems bizarre: the world upside down. In fact, it are the external intervention projects that, for a short, specific phase of the hydro-territorial life cycle, 'participate' in the transformation of local water control realities (see also Gerbrandy and Hoogendam, 2002; Gelles, 2000; Boelens, 2014; Hoogesteger, 2013c).

\subsection{Conclusion: Heterogeneity and endogenous development patterns: collective action, family strategies and state interventions.}

This thesis shows how heterogeneity in irrigated peasant agriculture expresses through different types of work organization and in very diverse and dynamic production systems on farms and organizational diversity at different territorial scales. This heterogeneity is a result of many combinations of different social and agro-ecological features, complex interactions with the environment and cultures in each particular place. It also reflects interactions with markets and the state. Processes of technological and institutional intervention facilitated, promoted and sometimes even imposed by the state and other external agents such as NGOs usually disturb these peasant livelihoods and their forms of organization. In Bolivia, as in many other countries, irrigation policies and interventions have tended to focus on the modernization of infrastructure and technologies under the assumption of being the (only) central element that will guarantee greater (or better) availability and therefore access to water leading to higher incomes for peasant families by boosting agricultural production and through it the social and economic development. However, such interventions have by-and-large failed to recognize or have just taken for granted local institutions, their rules and coordination processes as well as the close relations these hold with peasant families and their production systems. In doing so most interventions have neglected: 
- The close interrelation between the physical / technical, organizational and normative dimensions in the control of water and the non-neutral nature of technology in the control of people's behavior, in its prescriptive and normative character on how "practice should be carried out" but also in its physical-territorial influence and generation of collective work mobilization requirements to guarantee its "adequate" operation and maintenance (Winner 1986, Pfaffenberger 1988, Boelens 2008, 2014, Meehan, 2013).

- The need to adjust (as the cases of Punata and Chiyara Khochi have shown) the forms and organizational structures according to practical operational requirements for the distribution of water or for use at the plot level and also in the oposite direction: the need to adapt the irrigation practices to the conditions of infrastructure and management of the systems.

However, the study also shows that despite these shortcomings water users and peasants are resilient, creative and adaptive in re-shaping their organizational arrangements, their collective and individual irrigation practices and their related production systems and livelihoods. Evaluating livelihoods and agriculture as a lifestyle as in this study, has opened important avenues to better understand the interactions and interrelatedness between these different elements that compose and sustain irrigated peasant agriculture in Bolivia. It shows for instance the imporatnce of recognizing the interplay peasant families have between the commoditized and non-comoditized spheres based on available labour and other productive resources. This allows rural families to reduce dependence on markets, and (external) institutions as a means to compensate for the lack or difficulties of mobilizing other factors of production. As such intensificatition/extensification, diversification/specialization or commodification/noncommodification, represent strategies and productive responses that respond to the availability of family labour and social networks that enable families to access different factors of production (particularly water and land). In this sence the social and the natural are closely interconnected highlighting the importance of considering the socio-economic cycles of peasant families and collectives and its relationships with other technical and hydrologic cycles which ultimately define irrigated peasant agriculture. This does not mean that once certain style is conformed, it is definitive. On the contrary, these are highly dynamic, being able to change in relatively short terms according to the prevalent conditions.

This thesis highlights the resilience and adaptiveness of the peasantry in Bolivia and shows that despite increased socio-economic pressures, increased and sometimes problematic state involvement and climatic variabilities this sector will find strategies to sustain itself. This will be done through the interplay between creative adaptation and use of organizations for collective action at different scales and the transformation of peasant/family strategies of agricultural (re)production. In this process, external interventions and relations with state and none state intervening actors will be inevitable especially when it concerns the construction of large hydraulic works. However peasant users are the ones that will make such interventions work through the mobilization and adaptation of their organizations and practices and through these guarantee the sustainability of a specific hydro-social territory that is sustained by the dynamic peasantry of the region. 


\section{References}

Achi, A. (2010) 'El Agua Como Bien Comunal: Síntesis de Las Investigaciones en Bolivia', in: Lo colectivo y el agua: entre los derechos y las prácticas, R. Bustamante (ed) pp75108, IEP, Lima.

Albó, X. (1987a) ‘¿Khitipxtansa? ¿Quiénes Somos?. Identidad Localista, Étnica y Clasista de los Aymaras de Hoy', in: Identidades andinas y lógicas del campesinado, pp147-59 Mosca azul editores. Institut Universitaire D'etudes du Développement, Geneva.

Albó, X. (1987b) ‘¿Por Qué El Campesino Qhochala Es Diferente?’ Cuarto Intermedio, 4359.

Albó, X. (2004) 'Muchos de Los Municipios Más Débiles Han Quedado Librados a Su Propia Suerte', in: Voces críticas de la descentralización. Una década de participación popular. 14 entrevistas a cargo de Diego Ayo, D. Ayo (ed.), pp39-64, La Paz, Bolivia: FES-ILDIS/ Plural editores.

Ampuero, R. (2007) Análisis de actores y marco institucional de la gestión de agua en Punata, Cochabamba, Bolivia. Centro AGUA

Andolina, R. (2012) 'The Values of Water: Development Cultures and Indigenous Cultures in Highland Ecuador', Latin American Research Review 47(2):3-26.

Assies, W. (2003) 'David versus Goliath in Cochabamba. Water Rights, Neoliberalism and the Revival of Social Protest in Bolivia', Latin American Perspectives 30(130 No. 3):14-36.

Barnes, K. and J. Torrico-Angulo (1971) 'Cambios Socio-Económicos En El Valle Alto de Cochabamba Desde 1952: Los Pueblos Provinciales de Cliza, Punata, Tiraque, Arani, Sacaba Y Tarata', Estudios Andinos II(I):141-71.

Barnes, J., \& Alatout, S. (2012) 'Water worlds: Introduction to the special issue of Social Studies of Science', Social Studies of Science, 42(4), 483-488.

Baud, M. (2010) 'Identity Politics and Indigenous Movements in Andean History', in: Out of the Mainstream. Water Rights, Politics and Identity, R. Boelens, D. Getches and A. Guevara-Gil (eds), pp99-118, London and Washington DC: Earthscan.

Bebbington, A. (1997) 'Social capital and rural intensification: Local organizations and islands of sustainability in the rural Andes'. Geogr. J. 163(2):189-197.

Bebbington, A. (1999) 'Capitals and Capabilities: A Framework for Analyzing Peasant Viability, Rural Livelihoods and Poverty', World Development 27(12):2021-2044.

Bebbington, A., Humphreys-Bebbington, D., \& Bury, J. (2010) 'Federating and defending: Water, territory and extraction in the Andes', In: R. Boelens, D. H. Getches, \& J. A. Guevara-Gil (Eds.), Out of the mainstream: Water rights, politics and identity (pp. 307328). London: Earthscan.

Beccar, L., R. Boelens \& P. Hoogendam (2001) 'Derechos de Agua y Acción Colectiva en el Riego Comunitario', in: Derechos de agua y acción colectiva, R. Boelens and P. Hoogendam (eds.), pp21-46, Lima: IEP.

Benda-Beckmann, K. von (1981) 'Forum shopping and shopping forums: Dispute processing in a Minangkabau village in West Sumatra', Journal of Legal Pluralism and Unofficial Law, 13, 117-159.

Benda-Beckmann, F.von, von Benda-Beckmann, K., Spiertz, J., (1998) 'Equity and legal pluralism: taking customary law into account in natural resource policies’ In: Searching 
for Equity, Boelens, R., Dávila, G. (Eds.). Pp57-69, Assen: Van Gorcum.

Benencia, R. and M. Geymonat (2005) 'Migración Transnacional y Redes Sociales en la Creación de Territorios Productivos en la Argentina. Río Cuarto, Córdoba', Cuadernos de desarrollo 55:9-28.

Boelens, R. (1998). 'Economía Campesina y Riego Andino', in: Buscando la Equidad, R. Boelens and G. Davila (eds.), pp247-58 Assen, the Netherlands: van Gorcum.

Boelens, R. (2008a) The Rules of the Game and the Game of the Rules. Normalization and Resistance in Andean Water Control, PhD Thesis, Wageningen University.

Boelens, R. (2008b) 'Water Rights Arenas in the Andes : Upscaling Networks to Strengthen Local Water Control', Water alternatives 1(1):48-65.

Boelens, R., (2011) 'Luchas y Defensas Escondidas. Pluralismo Legal y Cultural como una Práctica de Resistencia Activa y Creativa en la Gestión Local del Agua en los Andes', Anuario de Estudios Americanos, 68(2), 673-703.

Boelens, R. (2014) 'Cultural politics and the hydrosocial cycle: water, power and identity in the Andean highlands'. Geoforum 57, 234-247.

Boelens, R. (2015) 'Water, Power and Identity. The Cultural Politics of Water in the Andes', London and Washington DC: Routledge/Earthscan.

Boelens, R. and X. Albó (2007) 'Más allá de las formas formalizadas y las normas normalizadas', in: Derechos y Gestión del Agua en Ancoraimes, Bolivia, La Paz: Plural Editores and CIPCA.

Boelens, R. and J. Vos (2012) 'The danger of naturalizing water policy concepts: water productivity and efficiency discourses from field irrigation to virtual water trade', Agric. Water Management 108, 16-26.

Boelens, R. and J. Vos, (2014) 'Legal pluralism, hydraulic property creation and sustainability: the materialized nature of water rights in user-managed systems' Curr. Opin. Environ. Sustain. COSUST 11, 55-62.

Boelens, R., R. Bustamante \& T. Perreault (2010) 'Networking Strategies and Struggles for Water Control: From Water Wars to Mobilizations for Day-to-Day Water Rights Defence', in: Out of the mainstream: Water rights, politics and identity, R. Boelens, D. Getches \& A. Guevara-Gil (eds.), pp281-306, London, Washington, D.C.: Earthscan.

Boelens, R., David Getches, Armando Guevara (2010) Out of the Mainstream: Water Rights, Politics and Identity'. London, Washington D.C.: Earthscan.

Boelens, R., J. Hoogesteger, E. Swyngedouw, J. Vos, and P. Wester (2016) 'Hydrosocial Territories: A Political Ecology Perspective', Water International 41(1):1-14.

Boelens, R. \& J. Hoogesteger (2017) 'Collective Action, Community and the Peasant Economy in Andean Highland Water Control', In: Water Governance and Collective Action. Multiscale Challenges, D. Suhardiman, A. Nicol, E. Mapedza (eds.), pp96-107, London and New York: Routledge.

Boelens, R., T. Perreault, J. Vos (eds.) (2018) Water Justice, Cambridge: Cambridge University Press.

Borras, S. M. (2009) 'Agrarian Change and Peasant Studies: Changes, Continuities and Challenges - an Introduction', Journal of Peasant Studies 36(1):5-31.

Bos, M. G. and J. Nugteren (1990). 'On Irrigation Efficiencies', Fourth edition, Wageningen, The Netherlands: International Institute for Land Reclamation and Improvement/ILRI. 
Boserup, E. (1965) The Conditions of Agricultural Growth. The Economics of Agrarian Change under Population Pressure, London, UK: George Allen \& Unwin Ltd.

Bradby, B. (1982) 'Resistance to Capitalism' in the Peruvian Andes', in: Ecology and exchange in the Andes, D. Lehmann (ed.), pp97-122, Cambridge, UK: Cambridge University Press.

Bromley, D., D. Taylor and D. Parker (1980) 'Water Reform and Economic Development: Institutional Aspects of Water Management in Developing Countries', Economic development and cultural change, 28(2):365-87.

Brouwer, C., K. Prins, M. Kay, and M. Heibloem (1990) Irrigation Water Management: Irrigation Methods, Training Manual $n^{\circ} 5$. (5):140.

Bustamante, R. (1995) 'Normas de la Gestión y Gestión de las Normas en Sistemas de Riego Campesinos. Estudio de los Usos, Costumbres y Legislación en los Sistemas de Riego Tradicional de Tiquipaya', Cochabamba: Universidad Mayor de San Simón.

Bustamante, R. (ed.) (2010) Lo colectivo y el agua: entre los derechos y las prácticas, Lima: IEP.

Bustamante, R. and Z. Gutiérrez (1999) 'Usos y costumbres en la Gestión de Riego; Caos u Orden en la Gestión de Agua para Riego', in: Aguas y municipios, P. Hoogendam (ed). Pp163-88, Plural Editores, La Paz, Bolivia: PEIRAV, CID.

Cáceres, W. (2009) 'Evaluación de Efectos e Impactos de la Implementación de Atajados en la Comunidad de Rumi Cancha (Aiquile, Cochabamba)', Cochabamba: Universidad Mayor de San Simón.

Del Callejo, I. (1999) 'Agua, Proyectos de Riego y Estrategias Campesinas de Producción', MSc Thesis, Wageningen Agricultural University.

Del Callejo, I. (2010) 'El Riego Campesino: Dinámicas en la Seguridad Hídrica y Seguridad Alimentaria en Bolivia', in: Riego campesino en los Andes. Seguridad hídrica y seguridad alimentaria en Ecuador, Peru y Bolivia. J. Vos (ed), pp207-42, Lima: IEP.

Del Callejo, I., F. Quiroz, and V. Cossio (2012) 'Dinámicas Organizativas en Torno al Agua en la Cuenca Hidrosocial Pucara', in: Aguas arriba y aguas abajo. Investigación aplicada en gestión integral de recursos hídricos (GIRH) en la cuenca hidrosocial Pucara, O. Delgadillo, F. Quiroz, and A. Duran (eds.) p181-226, Cochabamba, Bolivia: Plural editores.

Del Callejo, I. and S. Vásquez (2007) Caracterización y Cambios en el Uso del Agua en Punata, Cochabamba, Bolivia: Centro AGUA

Calvo, L. M., C. Espinoza, T. Hosse, and P. Regalsky (1994) 'Raqaypampa. Los Complejos Caminos de Una Comunidad Andina. Estrategias Campesinas, Mercado, Revolución Verde', P. Regalsky (ed.), Cochabamba, Bolivia: Centro de Comunicación y Desarrollo Andino-CENDA.

Camacho, A. (2007) 'Uso de Aguas Residuales en el Riego de Cultivos de La Zona Suroeste de Punata', Cochabamba, Bolivia: Centro AGUA.

Centellas, R. (1998) 'Estudio de las prácticas de barbecho dentro y fuera del área de influencia de los sistemas de riego en Punata'. Cochabamba, Bolivia: Universidad Mayor de San Simón.

CERES (1983) 'De Los Valles Al Chapare. Estrategias Familiares en un Contexto de Cambio', CERES (eds.) - Centro de Estudios de la Realidad Económica y Social. Cochabamba, Bolivia: Talleres gráficos "El Buitre." 
Chila, G. and O. Delgadillo (2010) 'La Lucha Contra La Sequia: Desarrollo del Riego para la Seguridad Hídrica y Alimentaria en Sacabamba, Bolivia', in: Riego campesino en los Andes. Seguridad hídrica y seguridad alimentaria en Ecuador, Perú y Bolivia, J. Vos (ed.), p261-82, Lima: IEP.

Cleaver, F. (1999). 'Paradoxes of Participation: Questioning Participatory Approaches to Development', Journal of International Development 11:597-612.

Cleaver, F. (2000) 'Moral Ecological Rationality, Institutions and the Management of Common Property Resources', Development and Change 31:361-83.

Cleaver, F. (2018) 'Everyday water injustice and the politics of accommodation'. In: Water Justice, Boelens, R., Perreault, T., Vos, J., Zwarteveen, M. (Eds.), Cambridge: Cambridge University Press.

Cleaver, F. and T. Franks (2005) 'How Institutions Elude Design: River Basin Management and Sustainable Livelihoods, Bradford.

Cleaver, F., and de Koning, J. (2015) 'Furthering critical institutionalism', International journal of the Commons, 9(1), 1-18.

Colque, G., M. Urioste \& J. L. Eyzaguirre (2015) Marginalización de la Agricultura Campesina e Indígena: Dinámicas Locales, Seguridad y Soberanía Alimentaria, Fundación Tierra (Eds.), La Paz: Creativa Producciones.

Consejo de Ministros (2006). 'Decreto Supremo No 28818. Reglamento a La Ley No. 2878 Reconocimiento y Otorgación de Derechos de Uso y Aprovechamiento de Recursos Hídricos Para el Riego', La Paz, Bolivia.

CORACA (1993) Proyecto de Fortalecimiento de la Organización y Mejoramiento de la Producción en la Provincia Campero con Coraca-Aiquile, Cochabamba, Bolivia.

Cossio, V. (2004) 'Participation of Beneficiaries in Irrigation Intervention Projects. The Case of Challaqe Irrigation Project, Cochabamba-Bolivia', MSc. Thesis, Wageningen University.

Cossio, V. (2009) 'El Marco Institucional de la Gestión del Agua en Bolivia'. Cochabamba, Bolivia: Centro AGUA.

Cossio, V. (2011) 'Justicia hídrica en Bolivia: afectación en el acceso al agua y conflictos', in: Justicia Hídrica: Acumulación, Conflicto y Acción Social, R. Boelens, L. Cremers and M. Zwarteveen (eds.) pp297-316, Lima: IEP

Coward, E. W. (1986) 'State and Locality in Asian Irrigation Development: The Property Factor', in: Irrigation Management in Developing Countries: Current Issues and Approaches, K. C. Nobe and R. K. Sampath (eds.) pp491-508, London: Westview Press. Coward, E. W. (1990) 'Property-Rights and Network Order: The Case of Irrigation Works in the Western Himalayas', Human Organization 49:78-88.

Coward, W. (1980) 'Irrigation and Agricultural Development in Asia: Perspectives from the Social Sciences', Ithaca, NY: Cornell University Press.

Crespo, C. (2006) 'Hacia Una Política de Los Bienes Comunes del Agua en Bolivia. Los Desafíos y Contradicciones de la Agenda Post Guerra Del Agua', p20, in: Taller de Investigación en Agua y Gobernabilidad. Barcelona: Ingeniería Sin Fronteras.

Dandler, J. (1984) 'Desarrollo de la Agricultura, Políticas Estatales y el Proceso de Acumulación en Bolivia', Estudios Rurales Latinoamericanos 7(2):81-149.

Dandler, J. and C. Medeiros (1985) 'Migración Temporal de Cochabamba a Buenos Aires: 
Patrones e Impacto en las Áreas de Envío', Cochabamba, Bolivia.

Delgadillo, O. (2003a) 'Criterios de Adopción y Adaptación de Tecnologías de Riego Por Aspersión en Sistemas de Riego por Gravedad Manejado por Agricultores', MSc. Thesis, Wageningen University.

Delgadillo, O. (2003b) Prácticas Campesinas de Manejo de Agua y Suelo. Valle Alto y Valle Central de Cochabamba. Cochabamba, Bolivia: Centro AGUA.

Delgadillo, O. and A. Durán (2012) 'La Cuenca Hidrosocial: Una Aproximación Conceptual y Metodológica para la Gestión del Agua en Cuencas', in: Aguas Arriba, Aguas Abajo. Luces y Sombras de la Gestión Integral de los Recursos Hídricos: Reflexiones Desde la Investigación Aplicada, F. Quiroz, O. Delgadillo, and A. Durán (eds.), p81-134, La Paz, Bolivia: Plural editores.

Delgadillo, O. and N. Lazarte (2007a) Gestión de los Sistemas de Aprovechamiento de Agua en el Municipio de Punata', Cochabamba, Bolivia: Centro AGUA.

Delgadillo, O. and N. Lazarte (2007b) Inventario de Pozos Perforados en el Abanico de Punata, Cochabamba, Bolivia: Centro AGUA.

van den Dries, Adri L. J. (2002) The Art of Irrigation. The Development, Stagnation, and Redesign of Farmer-Managed Irrigation Systems in Northern Portugal, PhD Thesis, Wageningen University.

Duarte-Abadía, B., \& R.Boelens (2016) 'Disputes over territorial boundaries and diverging valuation languages: The Santurban hydrosocial highlands territory in Colombia'. Water International, 41(1), 15-36.

Eggink, J. W. \& J. Ubels (1984), 'Irrigation, Peasants and Development', MSc Thesis, Wageningen Agricultural University.

Ellis, F. (1998) 'Peasant Economics', Second Edi. Cambridge: Cambridge University Press.

Ellis, F. (2000) 'Rural Livelihoods and Diversity in Developing Countries'. New York: Oxford University Press.

Erickson, C. L. (2006) 'Intensification, Political Economy, and the Farming Community: In Defense of a Bottom-up Perspective of the Past', in: Agricultural Strategies, M. Joyce and S. Charles (eds.), p334-63, Los Angeles, California: Cotsen Institute of Archaeology.

Escobar, A. (1995) 'Imagining a Post-Development Era', In: Power of Development, J. Crush (ed.), p211-27, London; New York: Routledge.

Fernandez Gomez, E. (2004) 'Furrow Irrigation Erosion and Management', Irrigation Science 23(3):123-31.

Figueroa, A. (1981) 'La Economía Campesina en la Sierra del Perú', Lima, Peru: Pontificia Universidad Católica del Perú.

Gandarillas, H., L. Salazar, L. Sánchez, L. C. Sánchez and P. de Zutter (1993) 'Dios da el Agua, ¿Qué Hacen los Proyectos? Manejo de Agua y Organización Campesina', La Paz: HISBOL.

Gelles, P. (1986) 'Sociedad Hidráulica en los Andes: Algunas Perspectivas desde Huarochirí: IPA', pp99-147, Allpanchis.

Gelles, P. (1994) 'Channels of Power, Fields of Contention: The Politics of Irrigation and Land Recovery in an Andean Peasant Community', in: Irrigation at High Altitudes: The Social Organization of Water Control Systems in the Andes, W. P. Mitchell and D. W. Guillet (eds), pp233-74, The American Anthropological Association, Washington D.C. 
Gelles, P. (2000) 'Water and Power in Highland Peru. The Cultural Politics of Irrigation and Development', New Brunswick, N.J.: Rutgers University Press.

Gerbrandy, G. (1998a) 'River water distribution in a community of the Bolivian Altiplano. The case of Sullcayana', in: Searching for Equity, R. Boelens and G. Dávila (eds), pp315-21, Assen: Van Gorcum.

Gerbrandy, G. (1998b) 'Water distribution in the Inter-Andean Valleys: the case of Chilijchi, Bolivia’, in: Searching for Equity, R. Boelens and G. Dávila (eds), pp322-330, Assen: Van Gorcum.

Gerbrandy, G. and P. Hoogendam (1998) ‘Aguas y Acequias', Cochabamba, Bolivia: Plural editores.

Gerbrandy, G. and P. Hoogendam (2002) 'Materialising rights: hydraulic property in the extension and rehabilitation of two irrigation systems in Bolivia', in: Water Rights and Empowerment, R. Boelens and P. Hoogendam (eds), pp36-51, Assen: Van Gorcum.

Gobierno Municipal de Punata (2005) 'Ordenanza Municipal 13/2005 Sobre Aprovechamiento de Aguas Subterráneas en la Jurisdicción del Municipio de Punata'. Cochabamba, Bolivia.

Golte, J. (1980) 'La Racionalidad de la Organizacidn Andina', Lima: IEP.

Golte, J. and M. de la Cadena (1983), 'La Codeterminación de La Organización Social Andina', Alpanchis 22:7-34.

Gonzales de Olarte, E. (1990) ‘Agricultura Andina: Unidad y Sistemas de Producción', Lima, Peru: Editorial Horizonte.

Gow, D. and J. Vansant (1983) 'Beyond the Rhetoric of Rural Development Participation: How Can It Be Done?', World Development 11(5):427-46.

Grillo, E. (1993) 'La Cosmovisión Andina de Siempre y La Cosmología Occidental Moderna', in: ¿Desarrollo o descolonización en los Andes?, pp189-236, Lima: PRATEC.

Guevara-Gil, A., Boelens, R., Getches, D. (2010) 'Conclusions: Water rights, power and identity', in: Out of the Mainstream. Water Rights, Politics and Identity. R. Boelens, D. Getches, and A. Guevara-Gil (eds.), pp329-339, London and Washington, DC: Earthscan.

Guillet, D. W. (1995) 'Covering Ground. Communal Water Management and the State in the Peruvian Highlands', Michigan, USA: The University of Michigan Press.

Gutiérrez, Z. (2005) Appropiate Designs and Appropriating Irrigation Systems, PhD Thesis, Wageningen University.

Gutiérrez, Z. (2009) Política Nacional de Riego y Plan Nacional de Cuencas, Cochabamba, Bolivia: Centro AGUA.

Gutierrez, Z. (2010) 'Procesos de Resistencia: Acomodo y Cambio en las Concepciones y en el Ejercicio de los Derechos de Agua en Bolivia' in: Lo colectivo y el agua: entre los derechos y las prácticas, R. Bustamante (ed), pp131-52, Lima: IEP.

Gutiérrez, Z. and G. Gerbrandy (1998a) 'Multiple-source irrigation systems and transparency: the case of Punata, Bolivia', in: Searching for Equity, R. Boelens and G. Dávila (eds), pp331-343, Assen: Van Gorcum.

Gutiérrez, Z. and G. Gerbrandy (1998b) 'Water distribution, social organization and equity in the Andean vision', in: Searching for Equity, R. Boelens and G. Dávila (eds), pp242-249, Assen: Van Gorcum.

Gutiérrez, Z. \& W. Claure (1995) 'El Proceso Social en la Definición de la Distribución del Agua de La Represa Totora Khocha en la Zona de Riego de Punata', MSc. Thesis, 
Wageningen Agricultural University.

de Haan, L. and A. Zoomers (2005) 'Exploring the Frontier of Livelihoods Research', Development and Change 36(1):27-47.

Harris, L. (2015) 'Scalar Politics, Networks and Power in Water Governance', In:

Negotiating Water Governance: Why the Politics of Scale Matter, E. Norman, C.

Cook and A. Cohen (Eds), pp. 226-250. London: Ashgate.

Hendriks, J. (2002), 'Water rights and strengthening users' organizations: The art of negotiating. Challenges for institutions assisting community irrigation in the Andes'. In: Water rights and empowerment, R. Boelens and P. Hoogendam (eds.), pp52-73. Assen, The Netherlands: Van Gorcum.

Hendriks, J. (2006) 'Legislación de aguas y gestión de sistemas hídricos en países de la región Andina. In: Derechos colectivos y políticas hídricas en la región Andina, P. Urteaga and R. Boelens (eds.), pp47-111, Lima: IEP.

Hidalgo, J. P., R. Boelens and J. Vos (2017) 'De-colonizing water. Dispossession, water insecurity, and Indigenous claims for resources, authority, and territory', Water History 9: 67-85.

Hidalgo-Bastidas, J. P., R. Boelens., E. Isch, (2018) 'Hydroterritorial Configuration and Confrontation: The Daule-Peripa Multipurpose Hydraulic Scheme in Coastal Ecuador', Latin American Research Review 53(3), 517-534. doi: https://doi.org/10.25222/larr.362

Hommes, L., \& R. Boelens (2017). 'Urbanizing rural waters: Rural-urban water transfers and the reconfiguration of hydrosocial territories in Lima', Political Geography, 57, 71 80.

Hommes, L., \& R. Boelens (2018). 'From natural flow to 'working river': hydropower development, modernity and socio-territorial transformations in Lima's Rímac watershed, Journal of Historical Geography, 62, 85-95.

Hommes, L., Boelens, R., and H. Maat (2016). 'Contested hydrosocial territories and disputed water governance: struggles and competing claims over the Ilisu Dam development in southeastern Turkey'. Geoforum, 71, 9-20.

Hommes, L., R. Boelens, B. Duarte-Abadía, J.P. Hidalgo, J. Hoogesteger (2018). 'Reconfiguration of Hydrosocial Territories and Struggles for Water Justice', In: Water Justice, R. Boelens, T. Perreault, \& J. Vos (Eds.), pp151-68, Cambridge, UK: Cambridge University Press.

Hommes, L., and R. Boelens (2017) 'Urbanizing rural waters: Rural-urban water transfers and the reconfiguration of hydrosocial territories in Lima', Political Geography 57: 71-80.

Honorable Congreso Nacional (2004) 'Ley de Promoción y Apoyo al Sector Riego'. La Paz, Bolivia.

Hoogendam, P. and R. Boelens (2019) 'Dams and Damages. Conflicting epistemologies around "compensating" socio-environmental impacts of the Misicuni project, Cochabamba, Bolivia. Water, Spring, 2019.

Hoogesteger, J. (2012) 'Democratizing water governance from the grassroots: The development of Interjuntas-Chimborazo in the Ecuadorian Andes'. Human Organization, 71(1), 76-86.

Hoogesteger, J. (2013a) Movements against the Current: Scale and Social Capital in Peasants' Struggles for Water in the Ecuadorian Highlands', $\mathrm{PhD}$ Thesis, Wageningen University. Hoogesteger, J. (2013b) 'Trans-forming social capital around water: Water user organizations, 
water rights, and nongovernmental organizations in Cangahua, the Ecuadorian Andes'. Society and Natural Resources, 26(1), 60-74.

Hoogesteger, J. (2013c) 'Social capital in water user organizations of the Ecuadorian highlands'. Human Organization, 72(4), 347-357.

Hoogesteger, J., and A. Verzijl (2015) 'Grassroots scalar politics: Insights from peasant water struggles in the Ecuadorian and Peruvian Andes'. Geoforum, 62, 13-23.

Hoogesteger, J., R. Boelens. and M. Baud (2016) 'Territorial pluralism: water users' multi scalar struggles against state ordering in Ecuador's highlands', Water International 41(1): 91-106.

Howden, S. M. et al. (2007) 'Adapting Agriculture to Climate Change', PNAS 104(50):1969196.

Instituto Nacional de Estadística (2013) 'Principales Resultados del Censo Nacional de Población y Vivienda 2012’ La Paz, Bolivia.

Instituto Nacional de Estadística (2014) 'Un Pincelazo a las Estadísticas con Base a Datos de Censos. Censo Nacional Agropecuario 2013'. La Paz, Bolivia.

Jansen, K., Vellema, S. (2011) 'What is technography?', NJAS-Wageningen J. Life Sci. 57(3), $169-177$.

Kay, C. (2006) 'Rural Poverty and Development Strategies', Journal of Agrarian Change 6(4):455-508.

Kearney, M. (1996) Reconceptualizing the Peasantry. Anthropology in a Global Perspective, Boulder Co:Westview Press.

Kobbi, M. (1995) 'Proyecto de Riego Sacabamba. Informe Técnico de Ingeniería', La Paz, Bolivia: CIPCA

Kohl, J. V. (1978) 'Peasant and Revolution in Bolivia, April 9, 1952-August 2, 1953', The Hispanic American Historical Review 58(2):238-59.

Lagos, M. (1997) Autonomía y Poder, Dinámica de Clase y Cultura en Cochabamba, La Paz, Bolivia: Plural editores.

Lana, B. (2007) Ambient Impact of the Culture of the Common Feijoeiro, Brasilia: EMBRAPA

Larson, B. (1988) Colonialism and Agrarian Transformation in Bolivia. Cochabamba, 15501900, New Jersey: Princeton Univeristy Press

Larson, B. (2000). Cochabamba: [ Re ] Construcción de Una Historia, La Paz, Bolivia: Plural editores.

Laruta, H., and R. Bustamante (2007) Derechos y Gestión del Agua en Ancoraimes, Bolivia. La Paz: CIPCA, WALIR, Plural Editores

Latour, B. (1992) 'Where Are the Missing Masses? The Sociology of a Few Mundane Artifacts.' In: Shaping Technology/Building Society. Studies in sociotechnical change, W. E. Bijker and J. Law (eds.), p225-58, Cambridge Mass and London: MIT Press.

Latour, B. (1994) ‘On Technical Mediation’, Common Knowledge Vol.3, n`2 p.29-64.

Le Grand, J.W. (2014) Sustainable pathways or troubled development? Rural community dynamics in the Andean Valleys of Bolivia, PhD Thesis, ISS, The Hague.

Lehmann, D. (1980) 'Proletarizacion Campesina: de las Teorias de Ayer a las Prácticas de Mañana.', Nueva Antropología IV (13-14):65-86.

Lehmann, D. (1982a) ‘After Chayanov and Lenin. New Paths of Agrarian Capitalism.' Journal 
of Development Economics 11(2):133-61.

Lehmann, D. (1982b) Ecology and Exchange in the Andes, Cambridge, UK: Cambridge University Press.

Lehmann, D. (1982c) 'Introduction: Andean Societies and the Theory of Peasant Economy.' In: Ecology and exchange in the Andes, edited by D. Lehmann, pp1-26, Cambridge, UK: Cambridge University Press.

Linton, J., \& Budds, J. (2014) 'The hydro-social cycle: Defining and mobilizing a relationaldialectical approach to water'. Geoforum, 57, 170-180.

Long, A. and J. D. van der Ploeg (1994) 'Endogenous Development: Practices and Perspectives', in: Born from within: Practice and perspectives of Endogenous Rural Development, p1-7. Assen, The Netherlands: van Gorcum.

Long, N. (2001a) 'Demythologising Planned Intervention', in: Development Sociology. Actor perspectives, pp30-48, London; New York: Routledge.

Long, N. (2001b) 'Knowledge, Networks and Power', in: Development Sociology. Actor perspectives, pp169-88, London; New York: Routledge.

Long, N. and J. D. van der Ploeg (1989) 'Demythologizing Planned Intervention: An Actor Perspective’, Sociologia Ruralis XXIX (3/4):226-49.

Lukat, E. (2012) Scrutinising Atajados - an Investigation to Reassess Their Viability as a Measure for Bolivian National Policy towards IWRM, MSc. Thesis, Wageningen University.

Lynch B.D. (2012) 'Vulnerabilities, competition and rights in a context of climate change toward equitable water governance in Peru's Rio Santa Valley', Global Environmental Change 22(2):364-373.

Mabry, J. B. (1996) Canals and Communities: Small-Scale Irrigation Systems, Tucson: University of Arizona Press.

Maita, J. C. and M. Verweij (1996) Gestión de Riego del Sistema de Atajados Inter-Conectados de Oloy, Cochabamba, Bolivia: PEIRAV.

Mayer, E. (2002) The Articulated Peasant. Household Economies in the Andes, Oxford, UK: Westview Press. University of Arizona Press.

Mayta, A. (2012) Disponibilidad de Agua Subterránea en el Abanico de Punata. Cochabamba, Bolivia: Centro AGUA.

Meehan, K. (2013) 'Disciplining de facto development: water theft and hydrosocial order in Tijuana, Environment and Planning D 31:319-336

Mehta, L., M. Leach, and I. Scoones (2001) 'Editorial: Environmental Governance in an Uncertain World', IDS Bulletin 32(4).

Meinzen-dick, R. and K. V Raju (2002) 'What Affects Organization and Collective Action for Managing Resources? Evidence from Canal Irrigation Systems in India', World Development 30(4):649-66.

Meireles, B. C. M., E. M. De Andrade, and M. Cross (2003) 'The Evaluation of the Impact of the Fertirrigação in Cambissolos in the Chapada One of the Apodi, Ceará, Magazine Science Agronômica 34(2):207-12.

Mena-Vásconez, P., Boelens, R., Vos, J., (2016) 'Food or flowers? Contested transformations of community food security and water use priorities under new legal and market regimes in Ecuador's highlands'. Journal of Rural Studies. 44, 227-238. 
Mena-Vásconez, P., Vincent, L., Vos, J., Boelens, R. (2017) 'Fighting over water values: diverse framings of flower and food production with communal irrigation in the Ecuadorian Andes', Water International, 42(4), 443-461.

Mitchell, W. P. and D. Guillet (1994) 'Introduction: High Altitude Irrigation', in: Irrigation at High Altitudes: The Social Organization of Water Control Systems in the Andes, W. P. Mitchell and D. Guillet (eds), pp1-20, Washington DC: American Anthropological Association.

Molden, D. (1997) 'Accounting for Water Use and Productivity', Colombo, Sri Lanka: International Water Management Institute.

Molden, D. et al. (2007) 'Pathways for Increasing Agricultural Water Productivity' in: Water for food, water for life. A comprehensive assessment of water management in agriculture, D. Molden (ed.), p278-310 Colombo, Sri Lanka: International Water Management Institute.

Molle, F. et al. (2007) 'River Basin Development and Management', In: Water for food, water for life, D. Molden (ed.), p585-624, London: Earthscan, and Colombo: IWMI.

Molle, F. and P. Wester, (eds.) (2009) 'River Basin Trajectories: Societies, Environments and Development'. Wallingford, UK: Cabi.

Mollinga, P. (1998) On the Water Front. Water Distribution, Technology and Agrarian Change in South Indian Canal Irrigation System, PhD Thesis, Wageningen University.

Montaña, E. (2007) 'Identidad Regional y Construcción del Territorio en Mendoza (Argentina): Memorias y Olvidos', Bulletin de l'Institut Francais d'Études Andines- IFEA 36(2):277-97.

Montaño, H. (1995) Sostenibilidad de Gestion de Sistemas de Riego Manejado por Campesinos en la Asociación de Riego y Servicios Punata, Cochabamba, Bolivia: Universidad Mayor de San Simón.

Montes de Oca, I. (1992) Sistemas de Riego y Agricultura en Bolivia. Taller de Análisis del Riego, pp235, La Paz, Bolivia: Comité Interinstitucional del Riego, Ministerio de Asuntos Campesinos y Agropecuarios (MACA)

Montes de Oca, I. (1997) Geografía y Recursos Naturales de Bolivia, La Paz, Bolivia: Impresión Edobol.

De Morrée, D. (1998) 'El Rol de Organizaciones Económicas Campesinas en Procesos de Desarrollo y Estrategias Campesinas', p304-37 in: Estrategias campesinas en el sur andino de Bolivia, A. Zoomers (ed.), La Paz: Plural editores.

Mosse, D. (2006) 'Collective Action, Common Property, and Social Capital in South India: An Anthropological Commentary', Economic Development and Cultural Change 54(3):695724.

Muñoz, D. (2000) Public Policies and Processes in the Bolivian Andes, London: International Institute for Environment and Development.

Nijenhuis, G. (2002) Decentralisation and Popular Participation in Bolivia. The Link between Local Governance and Local Development. PhD Thesis, Utrecht University.

North, D. C. (1990) Institutions, Institutional Change and Economic Performance, Cambridge, UK: Cambridge University Press.

Ortiz, J (2015) Análisis de los Criterios de Diseño para Implementar Riego Tecnificado en Sistemas Colectivos con Pozos Perforados en el Abanico de Punata, MSc. Thesis, 
Cochabamba, Bolivia: Universidad Mayor de San Simón.

Ostrom, E. (1990) 'Reflections on the Commons and a Framework for Analysis of SelfOrganizing and Self-Governing CPRS', in: Governing the commons: The evolution of institutions for collective action, pp182-221 Cambridge, UK: Cambridge University Press.

Ostrom, E. (1992) Diseño de Instituciones para Sistemas de Riego Autogestionarios, San Francisco, California: ICS Press.

Ostrom, E. (2009) 'A general framework for analyzing sustainability of social-ecological systems', Science 325:419-22.

Ostrom, E. (2010) 'Polycentric systems for coping with collective action and global environmental change', Global Environmental Change 20:550-57.

Pannel, D. J. and M. A. Ewing (2006) 'Managing Secondary Dryland Salinity: Options and Challenges for Agricultural Water Management' 80(1-3):41-56.

Parfitt, T. (2004) 'The Ambiguity of Participation: A Qualified Defence of Participatory Development', Third World Quarterly 25(3):537-55.

Pellens, T. (2006) Composición del Ingreso Familiar y la Diversificación Agrícola. Una Aproximación a Seis Zonas Campesinas de Cochabamba y Norte de Potosí, Cochabamba, Bolivia: CIPCA.

Perreault, T (2005) 'State Restructuring and the Scale Politics of Rural Water Governance in Bolivia', Environment and Planning 37:263-84.

Perreault, T. (2006) 'From the Guerra del Agua to the Guerra del Gas: Resource Governance, Neoliberalism and Popular Protest in Bolivia', Antipode 38(1):150-72.

Perreault, T. (2008) 'Custom Governance and Contradiction: Rural Water Governance and the Politics of Usos y costumbres in Bolivia's Irrigators' Movement', Annals of the Association of American Geographers 98(4):834-54.

Perreault, T. (2014) 'What kind of governance for what kind of equity? Towards a theorization of justice in water governance’ Water International, 39 (2), 233-245.

Perreault, T., A. Bebbington, and T. Carroll (1998) 'Indigenous Irrigation Organizations and the Formation of Social Capital in Northern Highland Ecuador', Conference of Latin Americanist Geographers Yearbook 24(1):1-15.

Pfaffenberger, B. (1988) 'Fetishised objects and humanised nature: Towards an anthropology of technology', Man (N.S.) 23:236-252.

Pinch, T. J. and W. E. Bijker (1989) 'The Social Construction of Artifacts: Or How the Sociology of Science and Sociology of Technology Might Benefit Each Other', in: The social construction of technological systems: New directions in the sociology and history of technology, W. E. Bijker, T. P. Hughes, and T. Pinch (eds.), Cambridge, UK: Cambrige (MA): MIT Press.

van der Ploeg, J. D. (1985) 'Patterns of Farming Logic, Structuration of Labour and Impact of Externalization', Sociologia Ruralis XXV(1):5-25.

van der Ploeg, J. D. (1990) Labor, Markets, and Agricultural Production, Boulder, Colorado; Oxford: Westview Press.

van der Ploeg, J. D. (1994) 'Styles of Farming: An Introductory Note on Concepts and Methodology', in: Born from within: Practice and perspectives of Endogenous Rural Development, J. D. van der Ploeg and A. Long (eds.), pp7-30, Assen, The Netherlands: 


\section{Van Gorcum.}

van der Ploeg, J. D. (1998) 'Peasants and power', in: Searching for Equity. Conceptions of justice and equity in peasant irrigation. R. Boelens and G. Dávila (eds), pp39-45, Assen: Van Gorcum,

van der Ploeg, J. D. (2003) The Virtual farmer, Assen: Van Gorcum, van der Ploeg, J. D. (2006) El Futuro Robado. Tierra, Agua y Lucha Campesina, WALIR, Quito:AbyaYala, Lima: IEP

van der Ploeg, J. D. (2008) The New Peasantries. Struggles for Autonomy and Sustainability in an Era of Empire and Globalization, London; Sterling, VA: Earthscan.

van der Ploeg, J. D., C. Laurent, F. Blondeau, and P. Bonnafous (2009) 'Farm Diversity, Classification Schemes and Multifunctionality', Journal of Environmental Management 90:S124-31.

PRATEC (1996) 'La Crianza Andina de La Biodiversidad', L. Gomez (ed.), Lima: Talleres G y G Impresores.

Programa de Desarrollo Alternativo (1992) Evaluación de los Efectos de la Sequía en las Provincias Campero y Mizque del Departamento de Cochabamba, Cochabamba, Bolivia: PDAI.

Remmers, G. A. (1998) Con Cojones y Maestría. Un Estudio Sociológico Agronómico Acerca del Desarrollo Endógeno y Procesos de Localización en la Sierra de La Contraviesa (España), Amsterdam: Thela Publishers Amsterdam.

Renting, H. et al. (2009) 'Exploring Multifunctional Agriculture. A Review of Conceptual Approaches and Prospects for an Integrative Transitional Framework', Journal of Environmental Management 90:S112-23.

Richards, P. (1993) 'Cultivation: Knowledge or Performance?' in: An anthropological critique of Development. The growth of ignorance, M. Hobart (ed.), London, UK: E.I.D.O.S. Routledge.

Ríos, R. (1999) Problemática socio-técnica de la explotación de las Aguas Subterráneas en el abanico de Punata, Cochabamba, Bolivia: PEIRAV, UMSS.

Roa-García, M. C. (2014) 'Equity, efficiency and sustainability in water allocation in the Andes: Trade-offs in a full world'. Water Alternatives, 7(2), 298-319.

Rocha, R. and A. Mayta (2007) Dinámica del Cambio del Uso de Tierra en Punata (1983-19962005), Cochabamba, Bolivia: Centro AGUA.

Rocha, R., L. Vincent and E. Rap (2015) 'Re-Engineering Closing Watersheds: The Negotiated Expansion of a Dam-Based Irrigation System in Bolivia' International Journal of Water Resources Development 31(1):50-63.

Rocha, R., J. Vos y R. Boelens (2016) 'Territorios hidro-sociales y valoración del agua: Perspectivas divergentes sobre los derechos de agua en la Cuenca Pucara, Bolivia. In: Gobernanza del Agua. Una mirada desde la ecología política y la justicia hídrica, B. Duarte-Abadía, C. Yacoub \& J. Hoogesteger (eds), pp153-176. Quito, Abyayala.

Rodriguez, G. (1997) Historia Del Trópico Cochabambino (1768-1972), Cochabamba, Bolivia: Impresiones Poligraf.

Rodríguez, R. (2003) Estudio de los Principales Factores que Influyeron en la Innovación Tecnológica del Riego Parcelario en la Microcuenca de Mishka Mayu, Cochabamba, Bolivia: Universidad Mayor de San Simón. 
Romano, S. T. (2016) 'Democratising discourses: Conceptions of ownership, autonomy, and 'the state' in Nicaragua's rural water governance', Water International 41 (1):74-90.

Romano, S. T. (2017) 'Building Capacities for Sustainable Water Governance at the Grassroots: "Organic Empowerment" and Its Policy Implications in Nicaragua', Society \& Natural Resources Vol. 30, Iss. 4, 471-487.

Romero, R. (1998) Evaluación de Prácticas Campesinas Relacionadas con la Uniformidad de Aplicación en Riego Parcelario en Punata, Cochbamba, Bolivia: Universidad Mayor de San Simón.

Roseberry, W. (1995) 'Latin American peasant studies in a 'postcolonial' era', Journal of Latin American Anthropology 1(1):150-177

Roth, D., R. Boelens \& M. Zwarteveen (eds) (2005) Liquid Relations. Legal pluralism and contested water rights, New Brunswick,NJ / London: Rutgers University Press

Roth, D., R. Boelens, R. \& M. Zwarteveen (2015) 'Property, legal pluralism, and water rights: the critical analysis of water governance and the politics of recognizing "local" rights', Legal Pluralism Unofficial Law 47 (3), 456-475.

Ruttan, L. M. (2008) 'Economic Heterogeneity and the Commons: Effects on Collective Action and Collective Goods Provisioning', World Development 36(5):969-85.

Salazar, L., R. Saravia \& R. Rafael (2010) Sustentabilidad y Autogestión de Sistemas de Riego, Cochabamba, Bolivia: PROAGRO

Saldías, C. (2009) 'Revelando la distribución del agua. Abanico Punata, área de influencia de la cuenca Pucara, Bolivia, Wageningen University.

Saldías, C., R. Boelens, K. Wegerich and S. Speelman (2012) 'Losing the watershed focus: a look at complex community-managed irrigation systems in Bolivia', Water International 37(7): 744-759.

Saldías, C., S. Speelman, and G. Van Huylenbroeck (2013) 'Access to Irrigation Water and Distribution of Water Rights in the Abanico Punata, Bolivia', Society \& Natural Resources 26(9):1008-21.

Saleth, M. (2004) Strategic Analysis of Water Institutions in India. Application of a New Research Paradigm', Colombo, Sri Lanka: IWMI.

Saleth, M. and A. Dinar (1999) 'Water Challenge and Institutional Response: A Cross-Country Perspective', pp1-50, World Bank Policy Working Paper No. 2045.

Sanchez, R. (1982) 'The Andean Economic System and Capitalism', in: Ecology and exchange in the Andes, D. Lehmann (ed.), pp157-90, Cambridge, UK: Cambridge University Press.

Sanchis-Ibor, C., R. Boelens and M. García-Mollá (2017) Collective irrigation reloaded. Recollection and re-moralization of water management after privatization in Spain. Geoforum 87, 38-47.

Saravia, R. (1998) Gestión de Agua de las Diferentes Fuentes en la Comunidad de Pucara, Cochabamba, Bolivia: Universidad Mayor de San Simón.

Scoones, I. (1998) Sustainable Rural Livelihoods. A Framework for Analysis, Brighton: IDS Bulletin 72

Scoones, I and W. Wolmer (2003) Introduction: Livelihoods in Crisis: Challenges for Rural Development in Southern Africa, Ids Bulletin 34(3):1-14.

Seemann, M. (2014) Water security and the politics of water rights formalization in Peru and Bolivia. The struggle for water justice in Andean water user communities, $\mathrm{PhD}$ Thesis 
Hamburg University, Hamburg.

Seemann, M. (2016) 'Inclusive recognition politics and the struggle over hydrosocial territories in two Bolivian highland communities', Water International, 41(1), 157-172.

Servicio Nacional de Meteorología e Hidrología (2014) 'Sistema de Procesamiento de Datos

Meteorológicos. Base de datos', Retrieved December 1, 2014 (http://www.senamhi.gob.bo/sismet/index.php).

Sharma, B., D. Molden, \& S. Cook (2015) 'Water Use Efficiency in Agriculture: Measurement, Current Situation and Trends', in: Managing Water and Fertiliser for Sustainable Intensification', Drechsel, P, P. Heffer, H. Magan, R. Mikkelsen, and D. Wichlens (eds.), pp39-64, Paris: International Fertiliser Association.

Sherbondy, J. (1994) 'Water and Power: The Role of Irrigation Districts in the Transition from Inca to Spanish Cuzco', in: Irrigation at High Altitudes: The Social Organization of Water Control Systems in the Andes, W. P. Mitchell and D. Guillet (eds), pp69-97, Washington DC: American Anthropological Association.

Sherbondy, J. (1998) 'Andean irrigation in history', in: Searching for Equity, R. Boelens and G. Dávila (eds), pp210-215, Assen: Van Gorcum

Small, L. E. and M. Svendsen (1990) 'A Framework for Assessing Irrigation Performance', Irrigation and Drainage Systems 4(4):283-312.

SOS FAIM (2004) 'Las Organizaciones Económicas Campesinas En Bolivia: Una Estrategia del Pequeño Productor', pp1-8.

Soto, L. (1997) Estrategia de Manejo de Agua a Nivel Familiar según su Acceso. Estudios de Caso en la Comunidad de Chillcar Grande, Cochabamba, Bolivia: Universidad Mayor de San Simón.

Steins, N. A., N. G. Röling, and V. M. Edwards (2000) 'Re- 'Designing' the Principles: An Interactive Perspective to CPR Theory', in: 8th Conference of the International Association for the Study of Common Property, pp1-20, Bloomington, Indiana.

Ströbele-Gregor, J. (1999) 'Ley de Participación Popular y Movimiento Popular en Bolivia' in: Congreso de la Asociación Alemana de Investigación sobre América Latina ADLAF, P. Hengstenberg, K. Kohut, and G. Maihold (eds), pp133-46, Fundación FriedrichEbert, Caracas.

Stuiver, M., Leeuwis, C., and van der Ploeg, J. D. (2004) The power of experience: farmers' knowledge and sustainable innovations in agriculture. Seeds of Transitions, Wiskerke, H. and J.D. van der Ploeg., (Eds.), pp93-118, Assen: Royal Van Gorcum..

Suhardiman, D., A. Nicol, E. Mapedza (eds.) (2017) 'Water Governance and Collective Action. Multi-scale Challenges', pp96-107. London and New York: Routledge.

Swyngedouw, E. (2009) 'The political economy and political ecology of the hydrosocial cycle', Journal of Contemporary Water Research \& Education, 142, 56-60.

Tammes, B., W. Cáceres, and C. Durán (2001) El Nuevo Riego en los Valles de Cochabamba. La Rentabilidad de los Atajados', in: X Encuentro de Riego Andino - CORA 2001. "Rentabilidad de los sistemas de riego y políticas de inversión". Cochabamba, Bolivia: Centro AGUA - UMSS.

Toner, A. and T. Franks (2006) 'Putting Livelihoods Thinking into Practice: Implications for

Development Management', Public Administration and Development 26(1):81-92.

Trawick, P. (2001) 'Successfully Governing the Commons: Principles of Social Organization 
in an Andean Irrigation System', Human Ecology 29(1):25.

Urteaga, P. (2006) 'El Derecho Colectivo al Agua', in: Derechos colectivos y políticas hídricas en la región andina, P. Urteaga and R. Boelens (eds.), pp113-58, Lima: IEP.

Urteaga, P. and R. Boelens (eds.) (2006) 'Derechos Colectivos y Políticas Hídricas en la Región Andina', Lima: IEP.

Valdivia, C., E. G. Dunn, and C. Jetté (1996) 'Diversification as Risk Management Strategy in an Andean Agropastoral Community', American Journal of Agricultural Economics 78(5):1329-34.

Valldolid, J. (1994) 'Agricultura Campesina Andina: Crianza de la Diversidad de la Vida en la Chacra' in: Crianza Andina de la Chacra, E. Grillo, V. Quiso, G. Rengifo, and J. Valladolid (eds.). Lima: Proyecto Andino de Tecnologías Campesinas - PRATEC.

Vargas S.M. (1997) La Migración Temporal en la Dinámica de la Unidad Doméstica Campesina, Sucre, Bolivia: PIED-ANDINO.

Vásquez, S. (2007) Caracterización del Uso del Agua en el Abanico de Punata, Cochabamba, Bolivia: Universidad Mayor de San Simón.

Vega, D. (1996) Organización de la Producción Familiar y Acceso al Agua de Riego. Análisis Comparativo de Unidades Productivas en el Area de Influencia del Programa de Riegos Inter-Valles (Punata)', Cochabamba, Bolivia: Universidad Mayor de San Simón.

Vega, D. and J. Iriarte (2003) Análisis de la Distribución de Agua Sistema de Riego "Chiyara Qhochi” - Sacabamba. Diagnóstico y Recomendaciones, Cochabamba, Bolivia: Centro AGUA, CIPCA.

Veldwisch, G.J.A., Bolding, J.A., Wester, P. (2009) 'Sand in the engine: the travails of an irrigated rice scheme in Bwanje Valley, Malawi', Journal of Development Studies. 45 (2), 197-226.

Venot, J.P., Kuper, M., Zwarteveen, M. (Eds.) (2017) 'Drip Irrigation: Untold Stories of Efficiency, Innovation \& Development', Routledge, London: Earthscan.

Verzijl, A, J. Hoogesteger \& R. Boelens (2017) 'Grassroots Scalar Politics in the Peruvian Andes: Mobilising Allies to Defend Community Waters in the Upper Pampas Watershed', in: Water Governance and Collective Action. Multi-scale Challenges, D. Suhardiman, A. Nicol, E. Mapedza (eds.), pp34-45. London and New York: Routledge.

VRHyR (2013) 'Agenda del Riego 2025', Ministerio de Medio Ambiente y Agua - Vice Ministerio de Recursos Hídricos y Riego (VRHR), Cochabamba, Bolivia.

Viceministerio de Recursos Hídricos y Riego (2012) 'Inventario Nacional de Sistemas de Riego 2012'. La Paz, Bolivia.

Vos, H. de, R. Boelens, R. Bustamante (2006) 'Formal law and local water control in the Andean region: A fiercely contested field', International Journal of Water Resources Development, 22(1), 37-48.

Vos, J. (ed.) (2010) Riego campesino en los Andes. Seguridad hídrica y seguridad alimentaria en Ecuador, Perú y Bolivia. Lima: IEP.

Vos, J. and R. Boelens (2014) 'Sustainability standards and the water question' Development and Change, 45(2), 205-230.

Winner, L. (1978) Autonomous Technology: Technics-out-of-Control as a Theme in Political Thought, Massachusetts and London: The MIT Press.

Zeitoun, M., B. Lankford, T. Krueger, T. Forsyth, R. Carter, A. Hoekstra, R. Taylor, O. Varis, 
F. Cleaver, R. Boelens, L. Swatuk, D. Tickner, C. Scott, N. Mirumachi, N. Matthews (2016). 'Reductionist and integrative research approaches to complex water security policy challenges', Global Environmental Change, 39:143-154.

Zimmerer, K. S. (2000) 'Rescaling Irrigation in Latin America: The Cultural Images and Political Ecology of Water Resources', Cultural Geographies 7(2):150-75.

Zoomers, A. (1998) Estrategias campesinas en el surandino de Bolivia, La Paz, Bolivia: PLURAL.

Zoomers, A. (2001) 'Introduction: Linking Land to Livelihood', in: Land and sustainable livelihood in Latin America, A. Zoomers (ed.), Amsterdam: Royal Tropical Institute.

Zoomers, A. (2010) 'Land, Water and the Search for Sustainable Livelihood in the Andes', in: Out of the Mainstream. Water Rights, Politics and Identity. R. Boelens, D. Getches \& A. Guevara-Gil (eds), pp145-163, London and Washington DC: Earthscan.

Zoomers, A. (2013) 'Medios de vida en ámbitos rurales: reflexiones sobre sus alcances y limitaciones', in Agua e inequidad. Discursos, políticas y medios de vida en la región andina, J. Hoogester and P. Urteaga (eds), pp87-94, Lima: IEP.

Zuidema, T. (1986) 'Inca Dynasty and Irrigation: Another look at Andean concepts of history'. In: Anthropological History of Andean Polities, J.Murra, N. Wachtel and J. Revel (eds), pp177-200, Cambridge: Cambridge University Press.

Zwarteveen, M., D. Roth, and R. Boelens (2005) 'Water Rights and Legal Pluralism", in: Liquid relations. Contested water rights and legal complexity, D. Roth, R. Boelens, and M. Zwarteveen (eds.), pp254-91. New Jersey, USA: Rutgers University Press.

Zwarteveen M. and R. Boelens (2014) 'Defining, researching and struggling for water justice: some conceptual building blocks for research and action', Water International 39:2, 143158, DOI: $10.1080 / 02508060.2014 .891168$ 


\section{Summary}

Irrigation research in Bolivia, and particularly in the Andean region, has focused mainly on watershed or irrigation system management. Few studies have scrutinized how peasant families develop and sustain the everyday management of water as a fundamental, integrated component of their individual productive strategies while simultaneously embedding these individual water control schemes and irrigation practices in the broader norms, rules and organizational forms of peasant communities' collective work and subsistence endeavors.

This thesis fills this gap by posing the following central research question:

\section{How do collective action and individual strategies entwine in peasant irrigation to foster diverse patterns of irrigation management and production organization in response to the quest for autonomous water control?}

This research question has been responded through the study of three sub-questions. The first sub-question seeks to understand the institutional framework of the irrigation sector and the respective water use and control systems, which in the Bolivian case strongly grounds in collective action and customary norms and practices, even though in recent years the state has tried to formalize and regulate the sector. The second sub-question focuses on understanding collective action and its implications for water control in its different dimensions. Finally, the third sub-question focuses on family production strategies and scrutinizes the link between mercantile and non-mercantile spheres of production. The analysis shows how these interact with the collective domain of water control.

Chapter two presents the conceptual framework that was developed to analyze the interrelationships between the collective and the individual domains, as well as their link with the state, institutions and the market. The chapter identifies the object of study, which is defined as the peasant dynamics in irrigation systems. These are divided in two analytical categories. The first category constitutes collective action for irrigation management, which is analyzed based on the concept of socio-technical "water control". The second category corresponds to the concept of "peasant strategies" that, in the collective domain and especially in the individual (family) domain, serves as a lens to better understand the logic behind the decisions that peasant families make about what, when and how much to produce with the water they are able to access through individual and collective action.

Chapter three analyzes the institutional development of irrigation in Bolivia, highlighting the role of peasant organizations in this process. It starts with the description and discussion of the different expressions of the so-called "uses and customs" in the study cases, illustrating the form and dynamics of water management and governance in the sector. In turn, these uses and customs demonstrate the different dimensions in water control and show the need to analyze these dimensions simultaneously. The chapter explains the risks and difficulties that accompany state attempts to formalize these customary norms in official legal frameworks and shows the resilience and adaptation strategies of existing customary practices that shape the 
daily functioning of irrigation systems and peasant communities. "Usos y costumbres" include more than just rules, norms and agreements for the access to resources; they actively interrelate organizational practices, administrative arrangements and the mobilization of resources. In the irrigation systems' water management and governance domains, these shape very specific operational aspects, such as water distribution rules and infrastructure's operation and maintenance activities. I argue that the principles and practices that are framed as 'uses and customs' essentially constitute peasant strategies to achieve their autonomy from institutions and state norms, which seem to create greater uncertainty and lack of control in families and communities' efforts to manage their resources and direct their livelihoods.

Chapter four, first, analyzes the history of collective action in the region, showing how, gradually, after the struggles for land water became the binding factor within and among communities in the region. Then water control arrangements in different irrigation systems are examined, focusing on the interrelatedness of modes of individual and collective action, and their links to formal organizations, politics, infrastructure and water flows. This chapter shows that the changes and interactions in, and between these elements, constantly redefine "water control systems" in their different components and levels. This chapter highlights the importance and dynamism of collective action to both make these systems function internally and ensure that the small-farmer sector is visible vis-à-vis the State, donors and nongovernmental organizations. The latter have been important in financing the development of irrigation infrastructure and have commonly used this intervention to try to impose specific organizational forms and related norms. However, this chapter shows that "peasant principles" for managing their resources are deeply entrenched and resilient as they form the basis for the quest for autonomy in managing key resources and livelihoods.

Chapter five focuses on peasant households and their production systems. It starts with a discussion of the different strategies that peasant households implement for materializing water access, and how this is done through diverse interactions with their own community or third organizations in the collective domain. These take place through locally institutionalized practices and social networks; by means of monetary transactions; or through a very creative combination of commodity and non-commodity strategies. A second important element discussed in this chapter is how peasant families organize labor as the basis for controlling the production process. Family labor, analyzed here as the working force but also as the knowledge and skills involved and deployed in the labor process, constitutes a key factor for resource control, and for the production and reproduction of the family farm. The chapter also demonstrates how peasant families strategically interact in and entwine very diverse spheres of operation: that of the market through commoditized interactions and with their own nonmonetarized rural activities and organizations - this takes place at different levels in both community based organizations and water-use based organizations. The chapter shows how families sustain their livelihoods through this interplay of market and non-market based exchanges that enable families to obtain sufficient control over their own production and thereby over the reproduction of their livelihoods. 
The thesis findings question the 'participatory water management' literature that finds much resonance in Bolivia and around the world and they challenge many of the popular 'empowerment approaches'. The cases show that local water users are the most important actors in shaping local irrigation development, water governance and local production practices. Users, since long, have actively involved themselves as 'participants' in struggles for irrigation, long before external 'participatory' intervention projects have come to 'develop' irrigation systems. These peasant strategies and practices show that the common claim that is made by intervening external actors -- that their intervention projects aim to incorporate 'the locals' through participatory projects - is to be considered as the world upside down. From a local perspective, it is the external intervention projects that 'participate' for a short specific phase in the transformation of local water control realities and (re)production practices.

The results highlight the dynamism and adaptive capacity of the peasantry in Bolivia. They show that, despite changing socio-economic pressures, increased and sometimes problematic state and third party external involvement, this sector actively shapes and deploys strategies to sustain itself. This is done through the interplay between creative adaptation at individual and family level as well as through collective action at community and supra-community level. These adaptations go hand in hand with the transformation of peasant family strategies regarding their agricultural (re)production. In this process, external interventions and relations with state and none state actors are not only inevitable but often also keenly strategized, especially when it concerns the construction of large hydraulic works. But also in cases where external interventions and support are mobilized, peasant water users commonly are the ones who make such interventions work for themselves, shaping their own projects whereby their organizations, principles and practices are tactically adapted, inserted and mobilized. Despite deeply adverse contexts, these strategic and rooted modes of operation and practice-based governance seek to guarantee the sustainability of the peasantry's mode of life in the region, with families in charge of their own irrigation systems dynamically shaping their livelihood strategies. 


\section{Resumen}

La investigación de riego en Bolivia, y particularmente en la región andina, se ha centrado principalmente en la gestión de cuencas hidrográficas o de los sistemas de riego. Pocos estudios han analizado cómo las familias campesinas desarrollan y mantienen la gestión diaria del agua como un componente fundamental e integrado de sus estrategias productivas individuales al tiempo que incorporan estos esquemas individuales de control de agua y de las prácticas de riego en las normas, reglas y formas organizativas más amplias de trabajo colectivo y de los esfuerzos de subsistencia de las comunidades campesinas.

Esta tesis llena este vacío al plantear la siguiente pregunta de investigación central:
¿Cómo se unen la acción colectiva y las estrategias individuales en el riego campesino para fomentar diversos patrones de gestión del riego y organización de producción en respuesta a la búsqueda del control autónomo del agua?

Esta pregunta de investigación ha sido respondida a través del estudio de tres subpreguntas. La primera subpregunta busca comprender el marco institucional del sector de riego y los respectivos sistemas de control y uso del agua, que en el caso boliviano se basan en la acción colectiva y en las normas y prácticas consuetudinarias, aunque en los últimos años el estado ha intentado formalizar y regular el sector. La segunda subpregunta se centra en comprender la acción colectiva y sus implicaciones para el control del agua en sus diferentes dimensiones. Finalmente, la tercera subpregunta se centra en las estrategias de producción familiar y examina el vínculo entre las esferas de producción mercantiles y no mercantiles. El análisis muestra cómo estos interactúan con el ámbito colectivo del control del agua.

El capítulo dos presenta el marco conceptual que se desarrolló para analizar las interrelaciones entre los ámbitos colectivo e individual, así como su vínculo con el estado, las instituciones y el mercado. El capítulo identifica el objeto de estudio, que se define como la dinámica campesina en los sistemas de riego. Tratar esta dinámica ha llevado a utilizar dos categorías analíticas. La primera categoría constituye la acción colectiva para la gestión del riego, que se analiza en función del concepto de "control hídrico" desde una perspectiva socio-técnica. La segunda categoría corresponde al concepto de "estrategias campesinas" que, en el ámbito colectivo y especialmente en el ámbito individual (familiar), sirve como una lente para entender mejor la lógica detrás de las decisiones que toman las familias campesinas sobre qué, cuándo y cuánto producir con el agua que son capaces de acceder a través de la acción individual y colectiva.

El capítulo tres analiza el desarrollo institucional del riego en Bolivia, destacando el papel de las organizaciones campesinas en este proceso. Comienza con la descripción y discusión de las diferentes expresiones de los llamados "usos y costumbres" en los casos de estudio, que ilustran la forma y dinámica de la gestión y la gobernanza del agua en el sector. A su vez, estos usos y costumbres demuestran las diferentes dimensiones en el control del agua y muestran la necesidad de analizar estas dimensiones simultáneamente. El capítulo explica los riesgos y dificultades que acompañan a los intentos estatales de formalizar estas normas consuetudinarias 
en los marcos legales oficiales y muestra la reisiliencia y las estrategias de adaptación de las prácticas consuetudinarias existentes que dan forma al funcionamiento diario de los sistemas de riego y de las comunidades campesinas. Los "usos y costumbres" incluyen más que solo reglas, normas y acuerdos para el acceso a los recursos; interrelacionan activamente las prácticas organizativas, los arreglos administrativos y la movilización de recursos. En los ámbitos de la gestión y de la gobernanza del agua en los sistemas de riego, estos usos y costumbres dan forma a aspectos operativos muy específicos, como las reglas de distribución del agua y las actividades de operación y mantenimiento de la infraestructura. En este capitulo sostengo que los principios y las prácticas que se enmarcan como 'usos y costumbres' constituyen esencialmente estrategias campesinas para lograr su autonomía frente a las instituciones y las normas estatales, que parecen crear mayor incertidumbre y falta de control en los esfuerzos de las familias y las comunidades para administrar sus recursos y dirigir sus medios de vida.

El capítulo cuatro, primero, analiza la historia de la acción colectiva en la región, mostrando cómo, gradualmente, después de las luchas por la tierra, el agua se convirtió en un factor vinculante dentro y entre las comunidades de la región. Luego se examinan los arreglos necesarios para el control hídrico en diferentes sistemas de riego, centrándose en la interrelación de los modos de acción individual y colectiva, y sus vínculos con organizaciones formales, la política, la infraestructura y los flujos de agua. Este capítulo muestra que los cambios e interacciones en, y entre estos elementos, redefinen constantemente los "sistemas de control de agua" en sus diferentes componentes y niveles. Este capítulo destaca la importancia y el dinamismo de la acción colectiva para que estos sistemas funcionen internamente y para que el sector de pequeños agricultores sea visible frente al Estado, a los donantes y a las organizaciones no gubernamentales. Estos últimos han sido importantes para financiar el desarrollo de la infraestructura de riego y comúnmente han utilizado estas intervenciones para tratar de imponer formas organizativas específicas y normas relacionadas. Sin embargo, este capítulo muestra que los "principios campesinos" para administrar sus recursos están profundamente arraigados y son resilientes, ya que forman la base para la búsqueda de autonomía en la gestión de recursos clave y de sus medios de vida.

El capítulo cinco se centra en las familias campesinos y sus sistemas de producción. Comienza con una discusión de las diferentes estrategias que implementan los hogares campesinos para materializar el acceso al agua, y cómo esto se hace a través de diversas interacciones con su propia comunidad o con otras organizaciones en el ámbito colectivo. Estos se realizan a través de prácticas institucionalizadas localmente y redes sociales; por medio de transacciones monetarias; o a través de una combinación muy creativa de estrategias mercantilizadas y no mercantilizadas. Un segundo elemento importante discutido en este capítulo es cómo las familias campesinas organizan el trabajo como la base para controlar el proceso de producción. El trabajo familiar, analizado aquí como la fuerza laboral, pero también como el conocimiento y las habilidades involucradas y desplegadas en el proceso laboral, constituye un factor clave para el control de recursos, y para la producción y reproducción del predio camepsino. El capítulo también demuestra cómo las familias campesinas interactúan de manera estratégica y se entrelazan en esferas muy diversas de operaciones: la del mercado a través de interacciones 
mercantilizadas y con sus propias actividades y organizaciones rurales no monetarizadas; esto ocurre en diferentes niveles tanto en organizaciones comunitarias como en organizaciones alrededor del agua. El capítulo muestra cómo las familias mantienen sus medios de vida a través de esta interacción de intercambios mercantiles y no mercantiles que les permiten a las familias obtener un control suficiente sobre su propia producción $y$, por lo tanto, sobre la reproducción de sus medios de vida.

Los hallazgos de la tesis cuestionan la literatura sobre "gestión participativa del agua" que encuentra mucha resonancia en Bolivia y en todo el mundo y cuestionan muchos de los "enfoques de empoderamiento" populares. Los casos muestran que los usuarios locales del agua son los actores más importantes en la configuración del desarrollo del riego local, la gobernanza del agua y las prácticas de producción locales. Los usuarios, desde hace mucho tiempo, se han involucrado activamente como "participantes" en las luchas por el riego, mucho antes de que los proyectos de intervención "participativa" externa hayan venido a "desarrollar" los sistemas de riego. Estas estrategias y prácticas campesinas muestran que el reclamo común que hacen los actores externos intervinientes, que sus proyectos de intervención apuntan a incorporar a los "locales" a través de proyectos participativos, debe considerarse como el mundo al revés. Desde una perspectiva local, son los proyectos de intervención externa los que 'participan' en una breve fase específica en la transformación de las realidades locales de control del agua y de las prácticas de (re) producción.

Los resultados resaltan el dinamismo y la capacidad de adaptación del campesinado en Bolivia. Muestran que, a pesar de las presiones socioeconómicas cambiantes y el involucramiento creciente y muchas veces problemático del estado o de otros agentes externos, este sector moldea y despliega activamente estrategias para sostenerse. Esto se hace a través de la interacción entre la adaptación creativa a nivel individual y familiar, así como a través de la acción colectiva a nivel comunitario y supra-comunitario. Estas adaptaciones van de la mano con la transformación de las estrategias de las familias campesinas con respecto a la (re) producción agrícola. En este proceso, las intervenciones externas y las relaciones con el estado y con actores no estatales no solo son inevitables sino que a menudo también representan estrategias precisas, especialmente cuando se trata de la construcción de grandes obras hidráulicas. Pero también en los casos en que se movilizan las intervenciones y el apoyo externos, los usuarios de agua campesinos son los que comúnmente hacen que dichas intervenciones funcionen por sí mismas, configurando sus propios proyectos según los cuales sus organizaciones, principios y prácticas se adaptan, insertan y movilizan tácticamente. A pesar de los contextos profundamente adversos, estos modos de operación estratégicos y arraigados y la gobernanza basada en la práctica, buscan garantizar la sostenibilidad del modo de vida del campesinado en la región, con familias a cargo de sus propios sistemas de riego dando formas dinámicas a sus estrategias de subsistencia. 


\section{Curriculum Vitae}

Ivan G. del Callejo Veracc was born in Cochabamba, Bolivia on November 2, 1969. He studied agronomy for his professional career at Universidad Mayor de San Simón (UMSS, Cochabamba), following a specialization on irrigation and drainage during the last year of his study and working as a lecturer assistant on Hydraulics for some years. He got his BSc. in 1994. After his graduation, he started working as reseach assistant at PEIRAV, a research and teaching co-operation program funded by NUFFIC and executed between UMSS (Agronomy Faculty) and Wageningen University (former Irrigation and Water Engineering group). He started working as researcher and lecturer at PEIRAV (Department of agricultural engineering) since 1995. He was invited to lecture in various undergraduate courses: Hydraulics, Drainage of agricultural lands, Irrigated agriculture and Irrigation and drainage and in 2006 he got the position of permanent teacher in the subject of Agro-climatology.

Between 1997 and 1999 he followed a MSc program at Wageningen University on Soil and Water (specializaton Irrigation). Until that moment his academic and scientific interest experienced a transition path, starting from very technical (technocratic) topics toward more "sociotechnical" perspectives. This transition was influenced by his fieldwork and close interaction with peasant irrigators during BSc and MSc theses.

In 2000, after the globally known "Water War" in Cochabamba, and a transition (closure) phase of PEIRAV Program at UMSS, he was part of the team of researchers that organized the Andean Center for Water Management and Wate Use (Centro AGUA) at the same university, continuing thus the academic cooperation between Wageningen University and UMSS. From that year on, he got engaded with the development and consolidation of Centro AGUA through different tasks in different periods: As main or associate researcher on several national and international projects; as responsible of Centro AGUA's research program on "water uses"; co-ordinator of a postgraduate program on Integrated Water Resources Management and as Centro AGUA's general co-ordinator (this between 2014 to 2017). The topics researched during this time were: irrigated agriculture, irrigation interventions' impacts, irrigation technology, peasant strategies, water and climate risks and local responses, water security. Part of this research was executed in the frame of his $\mathrm{PhD}$ thesis at Wageningen University in collaboration between Water Resources Management (former Irrrigtion and Water Engineering) and Rural Sociology groups. He published several articles, book chapters and research reports on these topics. 
Ivan Gonzalo del Callejo Veracc

Wageningen School of Social Sciences (WASS)

Completed Training and Supervision Plan

Wageningen School

of Social Sciences

Name of the learning activity

A) Project related competences

$\begin{array}{ll}\text { Research proposal } & \text { IWE-RSO } \\ \text { Governance } & \text { CERES/MGS } \\ \text { Scientific Writing } & \text { WGS } \\ \text { B) General research related competences }\end{array}$

Workshop Bridging the gaps: a learning workshop on practical methods for local water management

"Management and Sustainability of
Irrigation in Arid and Semi-Arid regions"

Seminar on Transdisciplinary approaches to integrating policy and science for sustainability

Coordination of a national study on peasant irrigation and water security
CapNet-CEDARE, Cairo, Egypt

2005

1

Universidad Federal de Recóncavo

2008

1

de Bahía, Salvador, Brazil

InterAmerican Institute for Global

2017

1

Change Research (IAI)

University of Calgary, Canada

IWE-WUR - Concertación Project

$2008-2010$

2

\section{C) Career related competences/personal development}

Teaching,

- Peasant irrigated agriculture

Teaching,

- Water Management and Water Use

- Agro-Hydrology

- Design and evaluation of field irrigation

MSc student supervision

Prior research experience in the field of irrigation
Universidad Mayor de San Simón (UMSS)

Universidad Mayor de San Simón (UMSS)

Universidad Mayor de San Simón
(UMSS)
Universidad Mayor de San Simón
(UMSS): Andean Center for Water
Management and Water Use (Centro
AGUA)

6

3

1.8

1

1

2005

2017

2018

2018

2003, $2018 \quad 1$

2000-2018 10.2

Total

${ }^{*}$ One credit according to ECTS is on average equivalent to 28 hours of study load 
The research described in this thesis was financially supported by NUFFIC.

Financial support from Wageningen University for printing this thesis is greatfully acknowledged.

Cover design: Ivan del Callejo-Veracc and Sophia Alvarado

Photographs on the cover: Raul Ampuero and Ivan del Callejo-Veracc

Lay-out, maps and graphs: Ivan del Callejo-Veracc

Printed by: GVO drukkers \& vormgevers B.V. 


\section{Propositions}

1. "Uses and customs" are localized expressions of water control that challenge the relationship of dependency and uncertainty created by state institutions in peasant irrigation systems.

(this thesis)

2. The capacity to construct collective and individual water access rights constitutes the starting point for peasant families to decide on their agro-productive systems.

(this thesis)

3. Transdisciplinary research requires creating collaborative spaces for knowledge generation that transcend barriers imposed by disciplinary boundaries, institutional powers and personal "egos".

4. The growing, uncritical policy attention to territorial claims based on "ownership notions" generates new uncertainties and conflicts among natural resources' user groups.

5. A "sandwich PhD" involves the increased risk of being trapped between the demands of one's daily work and those of the $\mathrm{PhD}$ research.

6. Combining the identities of a scholar and a peasant requires investigating the peasant way of life and skills as a researcher, and tapping into the researchers' world and skills as a farmer.

Propositions belonging to the thesis, entitled

Water Control and Autonomy. Peasant Irrigation Strategies in the Bolivian Andes

Ivan G. del Callejo-Veracc

Wageningen, September 3, 2019 